Wilson Hideki Hirota

\title{
AVALIAÇÃO DE TÉCNICAS CALORIMÉTRICAS APLICADAS AO MONITORAMENTO DE PROCESSOS QUÍMICOS
}


Wilson Hideki Hirota

\section{AVALIAÇÃO DE TÉCNICAS CALORIMÉTRICAS APLICADAS AO MONITORAMENTO DE PROCESSOS QUÍMICOS}

Tese apresentada à Escola Politécnica da Universidade de São Paulo para obtenção do título de Doutor em Engenharia 
Wilson Hideki Hirota

\section{AVALIAÇÃO DE TÉCNICAS CALORIMÉTRICAS APLICADAS AO MONITORAMENTO DE PROCESSOS QUÍMICOS}

Tese apresentada à Escola Politécnica da Universidade de São Paulo para obtenção do título de Doutor em Engenharia

Área de Concentração:

Engenharia Química

Orientador: Prof. Dr. Reinaldo Giudici Coorientador: Prof. a Dra. Cláudia Sayer 
Este exemplar foi revisado e alterado em relação à versão original, sob responsabilidade única do autor e com a anuência de seu orientador.

São Paulo, 30 de setembro de 2009.

Assinatura do autor

Assinatura do orientador

\section{FICHA CATALOGRÁFICA}

Hirota, Wilson Hideki

Avaliação de técnicas calorimétricas aplicadas ao monitoramento de processos químicos / W.H. Hirota. -- ed.rev. -- São Paulo, 2009.

$285 \mathrm{p}$.

Tese (Doutorado) - Escola Politécnica da Universidade de São Paulo. Departamento de Engenharia Química.

1. Reatores químicos 2. Geração de calor 3 . Hidrólise 4. Polimerização I. Universidade de São Paulo. Escola Politécnica. Departamento de Engenharia Química II. t. 


\section{AGRADECIMENTOS}

Agradeço ao Prof. Reinaldo Giudici pela oportunidade, apoio, paciência e pela valiosa orientação durante esses três anos de trabalho em conjunto.

Agradeço a Prof. Cláudia Sayer pela co-orientação e pela sua participação em mais esta etapa da minha formação.

Agradeço aos professores Darci Odloak e Galo A. Carrillo Le Roux pela participação em minha qualificação e pelas sugestões e devidas correções.

Agradeço ao Departamento de Engenharia Química da Escola Politécnica da Universidade de São Paulo pelo apoio e pelas oportunidades proporcionadas.

Agradeço à Fundação de Amparo à Pesquisa do Estado de São Paulo (FAPESP) pela concessão da bolsa e pelo suporte financeiro a este projeto.

A BASF pelo fornecimento dos monômeros. 


\section{RESUMO}

A crescente demanda por produtos poliméricos com propriedades cada vez mais estritas tem forçado o desenvolvimento de técnicas de monitoramento em linha cada vez mais precisas e robustas.

Infelizmente, grande parte das principais propriedades poliméricas não são quantificáveis em linha a partir das metodologias analíticas atualmente disponíveis e, portanto, na prática, as propriedades finais dos látices poliméricos são obtidas através da caracterização off line de amostras discretas coletadas do processo, resultando em um tempo de análise longo e indesejado para qualquer algoritmo de controle em tempo real. Por outro lado, como as reações de polimerização são altamente exotérmicas é possível quantificar continuamente a taxa de calor gerado pela reação a partir das medidas de temperatura e do balanço de energia que, por sua vez, pode ser usada para obter importantes informações acerca do estado do processo. Entretanto, esta técnica requer a atualização contínua do coeficiente global de troca térmica ao longo da reação, uma vez que este parâmetro está sujeito a variações temporais significativas.

Portanto, o presente trabalho tem por objetivo analisar a viabilidade da aplicação conjunta dos conceitos da calorimetria e dos observadores não-lineares para a estimação dos estados de um processo químico. Para isso, serão analisadas duas reações químicas distintas: a) uma reação de hidrólise de anidrido acético, b) uma reação copolimerização em emulsão.

Os resultados obtidos mostraram que essa metodologia é extremamente dependente dos parâmetros de sintonia do observador de estado, inviabilizando o seu uso para o monitoramento em linha de um processo químico. Por outro lado, a aplicação direta do balanço de energia para estimação do calor gerado pela reação, mostrou-se uma forma alternativa simples e viável para a estimação em tempo real dos estados de uma reação de polimerização.

Palavras-chave: observador de estado não linear, calorimetria, hidrólise do anidrido acético, polimerização em emulsão. 


\section{ABSTRACT}

The increasing demand for the production of polymers with more tight properties has placed great emphasis on the development of accurate and robust online monitoring techniques of polymerization reactions.

Unfortunately, most of the main characteristics are not measurable online from analytical methodologies currently available and, therefore, in practice, the final properties of polymer latexes are obtained through off line characterization of discrete samples collected from the process, resulting in measurement delay which is undesirable for real-time control. On the other hand, since most of the polymerization reactions are highly exothermic, it is possible to quantify continuously the heat release rate based on temperature measurements and energy balance equations that, in turn, can be used to infer valuable information about the state of process. However, this approach requires up-dating the value of the global heat exchange coefficient through reaction, once this parameter is subject to significant time variations.

Therefore, this work aims to examine the feasibility of joint implementation of the concepts of reaction calorimetry and nonlinear state observers for estimation of the states of a chemical process. In order to do that, two distinct chemical reactions will be considered: a) a hydrolysis of acetic anhydride reaction, b) an emulsion copolymerization reaction.

The results showed that this approach shows a strong dependence of the tuning parameters, preventing its use for online monitoring of a chemical process. On the other hand, applying the heat balance it is possible to infer continuously the heat release rate and the states of polymerization reactions.

Keywords: nonlinear state observer, reaction calorimetry, hydrolysis of acetic anhydride, emulsion polymerization. 


\section{LISTA DE ILUSTRAÇÕES}

Figura 2.1 - Etapas da polimerização em emulsão (Teoria de Harkins) a) antes da adição de iniciador, b) estágio I, c) estágio II, d) estágio III. 34

Figura 4.1 - Reator tipo tanque agitado: fluxos térmicos. 101

Figura 4.2 - Perfis de temperatura pela aproximação de fluxo de calor estacionário. 105

Figura 4.3 - Perfis de $T_{r}$ e $T_{j}$ - calorimetria adiabática 120

Figura 4.4 - Perfis de $T_{r}$ e $T_{j}$ - calorimetria isoperibólica. 121

Figura 4.5 - Perfis de $\mathrm{T}_{\mathrm{r}}$ e $\mathrm{T}_{\mathrm{j}}$ - calorimetria isotérmica..... 121

Figura 5.1 - Representação simplificada da unidade experimental. 149

Figura 5.2 - Curvas de calibração: a) acetato de vinila e b) acrilato de butila. 152

Figura 5.3 - Difração dinâmica de luz: diagrama funcional. 153

Figura 5.4 - Procedimento computacional dos observadores de estado em cascata e do balanço de massa no instante $t_{k}$. 170

Figura 6.1 - Estimação gráfica do coeficiente UA do: a) sistema 1, b) sistema 2, c) sistema 3.

Figura 6.2 - Copo de poliestireno: comparação entre a) $T_{r}$ experimental e temperaturas ajustadas por IP e FSG, b) resíduos, c) derivadas de temperatura, e d) taxas de reação.

Figura 6.3 - Balão volumétrico: comparação entre a) $T_{r}$ experimental e temperaturas ajustadas por IP e FSG, b) resíduos, c) derivadas de temperatura, e d) taxas de reação

Figura 6.4 - Garrafa térmica: comparação entre a) $T_{r}$ experimental e temperaturas ajustadas por IP e FSG, b) resíduos, c) derivadas de temperatura, e d) taxas de reação.

Figura 6.5 - Gráfico de Arrhenius para o sistema 1 usando o a) método 1 (DPI), b) método 2 (FSG), c) método 3 (DFC).

Figura 6.6 - Gráfico de Arrhenius para o sistema 2 usando o a) método 1 (DPI), b) método 2 (FSG), c) método 3 (DFC).

Figura 6.7 - Gráfico de Arrhenius para o sistema 3 usando o a) método 1 (DPI), b) método 2 (FSG), c) método 3 (DFC). 
Figura 6.8 - Comparação entre os gráficos de Arrhenius para o a) sistema 1, b) sistema 2, e c) sistema 3, usando os valores de $\mathrm{k}_{0}$ e E obtidos por DPI, FSG e DFC e aqueles reportados na literatura .183

Figura 6.9 - Substituição nucleofílica acílica. 184

Figura 6.10 - Substituição nucleofílica acílica catalisada por ácido 184

Figura 6.11 - Hidrólise alcalina .185

Figura 6.12 - Hidrólise ácida 185

Figura 6.13 - Valores experimentais e preditos de: a) temperatura e b) conversão para o sistema 1, c) temperatura e d) conversão para o sistema 2, e) temperatura e f) conversão para o sistema 3 .

Figura 6.14 - Sistema 1: sensibilidade de a) $\mathrm{X}_{\mathrm{AA}}$ e b) $\mathrm{T}_{\mathrm{r}}$ em relação ao coeficiente UA, c) $X_{A A}$ e d) $T_{r}$ em relação ao parâmetro $k_{0}$, e) $X_{A A}$ e f) $T_{r}$ em relação ao parâmetro $\mathrm{E}$

Figura 6.15 - Sistema 2: sensibilidade de a) $\mathrm{X}_{\mathrm{AA}}$ e b) $\mathrm{T}_{\mathrm{r}}$ em relação ao coeficiente UA, c) $X_{A A}$ e d) $T_{r}$ em relação ao parâmetro $k_{0}$, e) $X_{A A}$ e f) $T_{r}$ em relação ao parâmetro $\mathrm{E}$

Figura 6.16 - Sistema 3: sensibilidade de a) $X_{A A}$ e b) $T_{r}$ em relação ao coeficiente UA, c) $X_{A A}$ e d) $T_{r}$ em relação ao parâmetro $k_{0}$, e) $X_{A A}$ e f) $T_{r}$ em relação ao parâmetro $\mathrm{E}$ .191

Figura 6.17 - Coeficiente global de troca térmica experimental de predito pelo observador de estado para a) copo de poliestireno, b) balão volumétrico, c) garrafa térmica.

Figura 6.18 - Valores experimentais e preditos de a) temperatura e b) conversão para o sistema $1, \mathrm{c}$ ) temperatura e d) conversão para o sistema 2, e) temperatura e conversão para o sistema 3.

Figura 7.1 - Efeito do número de pontos passados sobre a filtragem das medidas de temperatura a) $n_{L}=10$ pontos, b) $n_{L}=20$ pontos, c) $n_{L}=30$ pontos, d) $n_{L}$ $=40$ pontos 203

Figura 7.2 - Efeito do grau do polinômio sobre a filtragem das medidas de temperatura a) $r=1$, b) $r=2$, c) $r=3$, d) $r=5$.

Figura 7.3 - Reações em batelada: remoção de ruídos das medidas de a) $T_{r}$ e b) $T_{j}$ do ensaio $R C 01 A, c) T_{r}$ e d) $T_{j}$ do ensaio $\left.R C 01 B, e\right) T_{r}$ e $T_{j}$ do ensaio RC01C 
Figura 7.4 - Reações intermitente e semi-contínuas: remoção de ruídos das medidas de a) $T_{r}$ e b) $T_{j}$ do ensaio RC01F, c) $T_{r}$ e $T_{j}$ do ensaio RC01D, e) $T_{r}$ e $T_{j}$ do ensaio RC01E. 206

Figura 7.5 - Temperaturas de entrada $\left(T_{j, \text { in }}\right)$ e saída $\left(T_{j, \text { out }}\right)$ da camisa medidos pelos sensores PT100 e K para os ensaios RC01B a) $T_{j, \text { in }}$ e b) $T_{j, \text { out }}$, RC01F c)

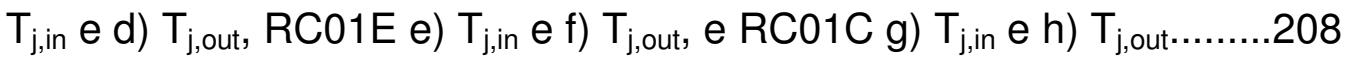

Figura 7.6 - Determinação gráfica de $\left(\mathrm{mC}_{\mathrm{p}}\right)_{\mathrm{r}}$ da a) carga inicial e b) látex da reação $\mathrm{RC01D}, \mathrm{c})$ carga inicial e d) látex da reação $\mathrm{RC01E}$, e) carga inicial e f) látex da reação $\mathrm{RC} 01 \mathrm{C}$

Figura 7.7 - Rampas de temperatura experimental e predita para a) carga inicial e b) látex (reação RC01D), c) carga inicial e d) látex (reação RC01E), e) carga inicial e f) látex (reação RC01C). .212

Figura 7.8 - Rampas de temperatura experimental e predita (corrigida) para a) carga inicial e b) látex (reação RC01D), c) carga inicial e d) látex (reação $\mathrm{RC01E)}$ 215

Figura 7.9 - Evolução de $T_{r}$ e $T_{j}$ durante as reações a) RC01A (batelada), b) RC01B (batelada), c) RC01C (batelada), d) RC01F (intermitente), e) RC01D (semi-contínuo), f) RC01E (semi-contínuo). 218

Figura 7.10 - Comparação entre os valores preditos e experimentais de $Q_{r}$ das reações a) RC01A (batelada), b) RC01B (batelada), c) RC01C (batelada), d) RC01F (intermitente), e) RC01D (semi-contínuo), f) RC01E (semi-contínuo) 220

Figura 7.11 - Evolução do número de partículas por grama de látex durante as reações a) RC01A (batelada), b) RC01B (batelada), c) RC01C (batelada), d) RC01F (intermitente), e) RC01D (semi-contínuo), f) RC01E (semi-contínuo). .221

Figura 7.12 - Evolução dos perfis preditos do coeficiente UA durante as reações a) RC01A (batelada), b) RC01B (batelada), c) RC01C (batelada), d) RC01F (intermitente), e) RC01D (semi-contínuo), f) RC01E (semicontínuo).

Figura 7.13 - Evolução das conversões preditas, gravimétricas e cromatográficas durante as reações a) RC01A (batelada), b) RC01B (batelada), c) RC01C (batelada), d) RC01F (intermitente), e) RC01D (semi-contínuo), f) RC01E (semi-contínuo). 
Figura 7.14 - Evolução da composição experimental e predita durante as reações a) RC01A (batelada), b) RC01B (batelada), c) RC01C (batelada), d) RC01F (intermitente), e) RC01D (semi-contínuo), f) RC01E (semicontínuo).

Figura 7.15 - Perfil dinâmico proposto para o coeficiente UA..............................228

Figura 7.16 - Reação RC01D: evolução da a) temperatura, b) calor de reação, c) conversões, e d) composição mássica experimentais e preditas usando um perfil de UA imposto

Figura 7.17 - Reação RC01E: evolução da a) temperatura, b) calor de reação, c) conversões, e d) composição mássica experimentais e preditas usando um perfil de UA imposto .230

Figura 7.18 - Reação RC01A (batelada): efeito das incertezas de UA sobre as estimativas de a) temperatura, b) calor de reação, c) coeficiente UA (caso A1), d) coeficiente UA (caso A2), e) conversão, f) composição. 233

Figura 7.19 - Reação RC01E (semi-contínuo): efeito das incertezas de UA sobre as estimativas de a) temperatura, b) calor de reação, c) coeficiente UA (caso A1), d) coeficiente UA (caso A2), e) conversão, f) composição. .234

Figura 7.20 - Reação RC01A (batelada): efeito das incertezas de $\left(\mathrm{mC}_{\mathrm{p}}\right)_{\mathrm{r}}$ sobre as estimativas de a) temperatura, b) calor de reação, c) coeficiente global de troca térmica, d) conversão, e) composição. .236

Figura 7.21 - Reação RC01E (semi-contínuo): efeito das incertezas de $\left(\mathrm{mC}_{\mathrm{p}}\right)_{\mathrm{r}}$ sobre as estimativas de a) temperatura, b) calor de reação, c) coeficiente global de troca térmica, d) conversão, e) composição. .237

Figura 7.22 - Reação RC01A (batelada): sensibilidade das estimativas de a) temperatura, b) calor de reação, c) coeficiente global de troca térmica, d) conversão, e e) composição com relação aos parâmetros de sintonia. .239

Figura 7.23 - Reação RC01E (semi-contínuo): sensibilidade das estimativas de a) temperatura, b) calor de reação, c) coeficiente global de troca térmica, d) conversão global, e) conversão instantânea, e f) composição com relação aos parâmetros de sintonia. 240

Figura 7.24 - Evolução do coeficiente U em função do teor de sólidos .242 
Figura 7.25 - Evolução a) do calor gerado pela reação, b) do coeficiente global de troca térmica, c) da conversão, e d) da composição ao longo da reação RC01A

Figura 7.26 - Evolução a) do calor gerado pela reação, b) do coeficiente global de troca térmica, c) da conversão, e d) da composição ao longo da reação $\mathrm{RC} 01 \mathrm{C}$ 245

Figura 7.27 - Evolução a) do calor gerado pela reação, b) do coeficiente global de troca térmica, c) das conversões, e d) da composição ao longo da reação RC01D

Figura 7.28 - Evolução a) do calor gerado pela reação, b) do coeficiente global de troca térmica, c) das conversões, e d) da composição ao longo da reação RC01E.

Figura 7.29 - Programa principal para monitoramento em linha .251

Figura 7.30 - Comparação entre as temperaturas do a) reator e b) camisa da reação $\mathrm{RC} 01 \mathrm{~A}$, e c) reator e d) camisa da reação RC01E filtradas em linha e e por simulações off line.

Figura 7.31 - Reação RC01A: a) calor de reação, b) coeficiente global de troca térmica, c) conversão e d) composição experimentais e preditos em linha e através de simulações off line.

Figura 7.32 - Reação RC01E (semi-contínuo): a) calor de reação, b) coeficiente global de troca térmica, c) conversão e d) composição experimentais e preditos em linha e através de simulações off line .254 


\section{LISTA DE TABELAS}

Tabela 4.1 - Comparação dos métodos calorimétricos........................................122

Tabela 5.1 - Calibração dos termômetros........................................................134

Tabela 5.2 - Cromatografia / condições operacionais (método VABA094A.MET)..151

Tabela 6.1 - Reagentes e reatores: volumes e massas.......................................173

Tabela 6.2 - Capacidade calorífica total......................................................173

Tabela 6.3 - Coeficientes globais de troca térmica experimentais.........................174

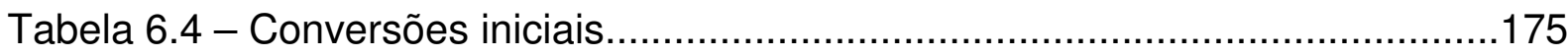

Tabela 6.5 - Parâmetros cinéticos experimentais..................................................181

Tabela 6.6 - Parâmetros da equação de Arrhenius reportados na literatura..........182

Tabela 7.1 - Formulação: reações em batelada................................................200

Tabela 7.2 - Formulação: ensaio RC01D (semi-contínuo)......................................200

Tabela 7.3 - Formulação: ensaio RC01E (semi-contínuo).....................................200

Tabela 7.4 - Formulação: ensaio RC01F (intermitente)......................................201

Tabela 7.5 - Calibração para estimação de UA e $\left(\mathrm{mC}_{\mathrm{p}}\right)_{\mathrm{r}}$ : potências dissipadas.....209

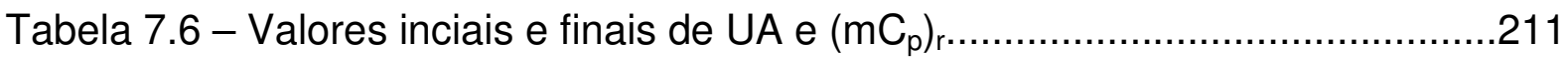

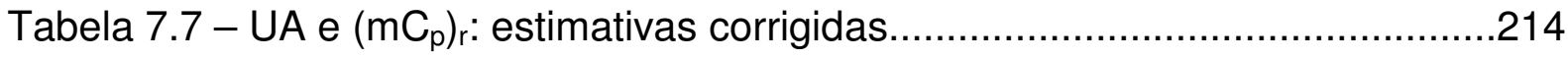

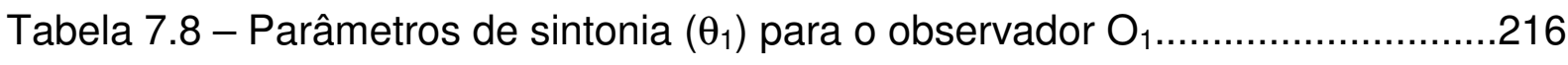

Tabela 7.9 - Parâmetros de sintonia $\left(\theta_{2}\right)$ para o observador $\mathrm{O}_{2} \ldots \ldots \ldots \ldots \ldots \ldots \ldots \ldots \ldots \ldots . . .216$

Tabela 7.10 - Parâmetros de sintonia $\left(\theta_{2}\right)$ para o observador $\mathrm{O}_{2} \ldots \ldots \ldots \ldots \ldots \ldots \ldots \ldots \ldots . . .217$

Tabela 7.11 - Parâmetros de sintonia $\theta_{1}$ / perfil polinomial de UA.........................228

Tabela 7.12 - Filtro Savitzky-Golay: parâmetros de suavização............................242 


\section{LISTA DE ABREVIATURAS E SIGLAS}

AA Anidrido acético

ARC Calorimetria acelerada

BA Acrilato de butila

CFD Fluido dinâmica computacional

CHDF Fracionador hidrodinâmico capilar

CMC Concentração micelar crítica

CRP Polimerização radicalar controlada mediante nitróxido

CSTR Reator tipo tanque agitado

CTA Agente de transferência de cadeia

DFC Diferenças Finitas Centradas

DGEBA Diglicidil éter de bisfenol-A

DISPO Polinômio de suavização digital

DLS Difração dinâmica de luz

DSC Calorimetria diferencial de varredura

DTA Calorimetria de análise térmica diferencial

DPI Diferenciação do polinômio interpolador

EDA Equação algébrico-diferencial

EKF Filtro de Kalman estendido

FID Detector de ionização de chamas

FSG Filtro Savitzky-Golay

GC Cromatografia em fase gasosa

GMC Modelo de controle genérico

GPC Cromatografia de permeação em gel

HID Massa de hidroquinona adicionada na amostra para análise gravimétrica

ICP-AES Espectroscopia de emissão atômica por plasma induzido

IDP Programação iterativa dinâmica

IP Interpolação polinomial

IR Infravermelho

LA Massa de látex da amostra gravimétrica 


$\begin{array}{ll}\text { MIMO } & \text { Múltiplas entradas - múltiplas saídas } \\ \text { MPC } & \text { Modelo de controle preditivo } \\ \text { MWD } & \text { Distribuição de pesos moleculares } \\ \text { NIR } & \text { Infravermelho próximo } \\ \text { NMR } & \text { Espectroscopia de ressonância magnética nuclear } \\ \text { PI } & \text { Controlador proporcional-integral } \\ \text { PLS } & \text { Mínimos quadrados parciais } \\ \text { PSD } & \text { Distribuição de tamanho de partículas } \\ \text { RS } & \text { Massa de resíduo seco (análise gravimétrica) } \\ \text { SISO } & \text { Única entrada - única saída } \\ \text { SLS } & \text { Lauril sulfato de sódio } \\ \text { TOC } & \text { Calorimetria de temperatura oscilatória } \\ \text { UV } & \text { Ultravioleta } \\ \text { VA } & \text { Acetato de vinila } \\ \text { W } & \text { Água }\end{array}$




\section{LISTA DE SÍMBOLOS}

\section{OBSERVADORES DE ESTADO}
A
Matriz das relações entre as variáveis de estado
b
Vetor de relações entre as variáveis de estado e a entrada
C
Vetor de relações entre as variáveis de estado e a saída
e
Erro na observação da variável de estado
f
Vetor de funções não-lineares das relações entre as variáveis de estado
g
Vetor de funções não-lineares das relações entre as variáveis de estado e as medidas de entrada
$\mathbf{h}$
Vetor de funções não-lineares das relações entre as variáveis de estado e as medidas de saída
K Vetor de ganho do observador de estado
$L_{f}$
Operador diferencial parcial linear de primeira ordem (derivada de Lie)
$\mathrm{n}$
Dimensão de um sistema dinâmico
$\mathbf{Q}$
Matriz observabilidade do sistema
$r$
Ordem relativa
$\mathbf{S}_{\theta} \quad$ Matriz simétrica positiva
t tempo
$\mathbf{u} \quad$ Vetor das medidas de entrada
U Vetor das derivadas no tempo da entrada de um sistema dinâmico
$\mathbf{x} \quad$ Vetor das variáveis de estado de um sistema dinâmico
y Vetor das medidas de saída
z Vetor das variáveis de estado transformadas

\section{Letras gregas}

Constante finita (constante de Lipschitz)

$\Phi$

Matriz de transformação de coordenadas 


\section{CALORIMETRIA}

A

Área efetiva de troca térmica

$m^{2}$

C

Fator geométrico dependente do tipo de agitador

$\mathrm{C}_{\mathrm{p}}$

Capacidade calorífica específica do meio reacional

$\mathrm{J} / \mathrm{K} \cdot \mathrm{g}$

$\mathrm{C}_{\mathrm{pi}}$

Capacidade calorífica específica do componente i

$\mathrm{J} / \mathrm{K} . \mathrm{g}$

$d_{r}$

Diâmetro interno do reator

$\mathrm{m}$

$d_{s}$

Diâmetro do agitador

$\mathrm{m}$

$E_{i}$

Energia específica mássica do componente i

$\mathrm{J} / \mathrm{g}$

$E_{\text {sis }}$

Energia total

$\mathrm{J}$

$\mathrm{F}$

Vazão instantânea de alimentação do componente i

$\mathrm{g} / \mathrm{s}$

g

Aceleração da gravidade

$\mathrm{m} / \mathrm{s}^{2}$

$h_{r}$

Coeficiente de transferência térmica do meio reacional

$\mathrm{W} / \mathrm{m}^{2} . \mathrm{K}$

$h_{j}$

Coeficiente de transferência térmica do fluido da camisa

$\mathrm{W} / \mathrm{m}^{2} . \mathrm{K}$

$\mathrm{H}_{\mathrm{i}}$

Entalpia específica

$\mathrm{J} / \mathrm{g}$

$\mathrm{H}_{\mathrm{i}}^{\circ}$

Entalpia de formação

$\mathrm{J} / \mathrm{g}$

L

Espessura da parede do reator

$\mathrm{m}$

$\mathrm{m}_{\mathrm{i}}$

Massa do componente $\mathrm{i}$

g

$\left(\mathrm{mC}_{\mathrm{p}}\right)_{\mathrm{r}}$

Capacidade calorífica total do reator

$\mathrm{J} / \mathrm{K}$

$\mathrm{N}$

Número de rotações por segundo do agitador

$\mathrm{s}^{-1}$

$\mathrm{Ne} \quad$ Número de Newton

$\mathrm{Nu} \quad$ Número de Nusselt

P Pressão absoluta

$\mathrm{Pa}$

$\mathrm{Pr} \quad$ Número de Prandtl

$Q_{\text {acum }}$

Taxa de acúmulo de calor

$\mathrm{J} / \mathrm{s}$

$Q_{c}$

Taxa de calor introduzido no sistema por uma fonte externa $\mathrm{J} / \mathrm{s}$

$Q_{\text {cond }}$

$Q_{\text {feed }}$

Taxa de calor perdida pelo condensador

$\mathrm{J} / \mathrm{s}$

Calor sensível de alimentação

$\mathrm{J} / \mathrm{s}$

$Q_{j}$

Taxa de calor transferido do reator para camisa

$\mathrm{J} / \mathrm{s}$

Qloss

Taxa de calor perdido para o ambiente

$\mathrm{J} / \mathrm{s}$

$Q_{r}$

Taxa de calor gerado pela reação

$\mathrm{J} / \mathrm{s}$

$Q_{s}$

Taxa de calor introduzido devido à agitação

$\mathrm{J} / \mathrm{s}$ 


$\begin{array}{lll}Q_{w} & \text { Fluxo de calor através da parede } & \mathrm{J} / \mathrm{s} \\ R_{\text {cond }} & \text { Resistência térmica condutiva } & \mathrm{K} / \mathrm{W} \\ \mathrm{R}_{\text {conv }} & \text { Resistência térmica convectiva } & \mathrm{K} / \mathrm{W} \\ \mathrm{R}_{\mathrm{pi}} & \text { Taxa de polimerização do monômero i } & \mathrm{mol} / \mathrm{s} \\ \mathrm{R}_{\mathrm{tot}} & \text { Resistência térmica total } & \mathrm{K} / \mathrm{W} \\ \mathrm{Re} & \text { Número de Reynolds } & \\ \mathrm{t} & \text { Tempo } & \mathrm{s} \\ \mathrm{T} & \text { Temperatura } & \mathrm{K} \\ \mathrm{T}_{\mathrm{amb}} & \text { Temperatura ambiente } & \mathrm{K} \\ \mathrm{T}_{\text {feed }} & \text { Temperatura da corrente de alimentação } & \mathrm{K} \\ \mathrm{T}_{\mathrm{j}} & \text { Temperatura da camisa } & \mathrm{K} \\ \mathrm{T}_{\mathrm{r}} & \text { Temperatura do reator } & \mathrm{K} \\ \mathrm{T}_{\text {ref }} & \text { Temperatura de referência } & \mathrm{K} \\ \mathrm{T}_{\mathrm{w}} & \text { Temperatura da parede do reator } & \mathrm{K} \\ \mathrm{U} & \text { Coeficiente total de troca térmica } & \mathrm{W} / \mathrm{m}^{2} . \mathrm{K} \\ \mathrm{U}_{\mathrm{i}} & \text { Energia interna específica } & \mathrm{J} / \mathrm{g} \\ \mathrm{UA} & \text { Coeficiente global de troca térmica } & \mathrm{W} / \mathrm{K} \\ \mathrm{V}_{\mathrm{i}} & \text { Volume específico do componente i } & \mathrm{L} / \mathrm{g} \\ z & \text { Constante do equipamento para transferência de calor em função } \\ & \text { da geometria do reator } & \end{array}$

\section{Letras Gregas}

$\begin{array}{lll}\gamma & \text { Constante física para transferência de calor } & \mathrm{W} / \mathrm{m}^{2} . \mathrm{K} \\ \varphi & \text { Coeficiente específico de troca térmica } & \mathrm{W} / \mathrm{m}^{2} . \mathrm{K} \\ \eta & \text { Viscosidade dinâmica do meio reacional } & \mathrm{Pa} . \mathrm{s} \\ \lambda & \text { Condutividade térmica do meio reacional } & \mathrm{W} / \mathrm{m} . \mathrm{K} \\ \lambda_{r} & \text { Condutividade térmica da parede do reator } & \mathrm{W} / \mathrm{m} . \mathrm{K} \\ \rho & \text { Densidade do meio reacional } & \mathrm{g} / \mathrm{m}^{3}\end{array}$




\section{MATERIAIS E MÉTODOS}

A Matriz das relações entre as variáveis de estado

$\mathrm{A}_{\mathrm{i}} \quad$ Área do pico cromatográfico do monômero $\mathrm{i}$

C Vetor de relações entre as variáveis de estado e as medidas de saída

$\mathrm{C}_{\mathrm{AA}} \quad$ Concentração molar de anidrido acético $\mathrm{mol} / \mathrm{L}$

$\mathrm{C}_{\mathrm{pi}} \quad$ Capacidade calorífica específica do reagente alimentado i $\mathrm{J} / \mathrm{K} . \mathrm{g}$

$\mathrm{C}_{\mathrm{W}} \quad$ Concentração molar de água $\mathrm{mol} / \mathrm{L}$

$d_{p} \quad$ Diâmetro hidrodinâmico equivalente $\quad \mathrm{cm}$

$\bar{d}_{p} \quad$ Diâmetro médio das partículas $\quad \mathrm{cm}$

D Coeficiente de difusão de uma partícula $\mathrm{cm} / \mathrm{s}$

E Energia de ativação $\mathrm{J} / \mathrm{mol}$

$\mathrm{f}_{\mathrm{CA}}{ }^{i} \quad$ Fração mássica de monômero i na corrente de alimentação

$\mathrm{f}_{\mathrm{m}} \quad$ Fração mássica de monômero

$\mathrm{f}_{\mathrm{p}} \quad$ Fração mássica de polímero

fres Fração mássica total de monômero residual

$f_{\text {snp }}$

Fração mássica de sólidos não poliméricos

$f_{G C}^{i}$

Fração mássica de monômero i não reagido

$f_{G C}^{L A}$

Fração mássica de látex

$\mathrm{F}_{\mathrm{i}}$

Vazão instantânea de alimentação do componente i $\quad \mathrm{g} / \mathrm{s}$

G Função de autocorrelação

$\mathrm{i}_{\mathrm{e}} \quad$ Corrente elétrica fornecida à termorresistência

A

I Intensidade das flutuações

k Taxa de reação específica da hidrólise do anidrido acético

$\mathrm{k}_{0} \quad$ Fator pré-exponencial ou fator de freqüência

L/mol.s

$k_{B}$

Constante de Boltzman

L/mol.s

$\left(m_{\mathrm{p}}\right)_{\mathrm{r}}$

Capacidade calorífica total do reator

$\mathrm{erg} / \mathrm{K}$

$\mathrm{m}_{\llcorner\mathrm{A}}$

Massa de látex

$\mathrm{J} / \mathrm{K}$

$m_{W}$

Massa de água

g

Índice de refração do diluente

$\mathrm{N}_{\mathrm{AA}} \quad$ Número de mols de anidrido acético

mol

$\mathrm{N}_{\mathrm{p}} \quad$ Número de partículas por grama de látex 


\begin{tabular}{|c|c|c|}
\hline $\mathrm{N}_{\mathrm{W}}$ & Número de mols de água & $\mathrm{mol}$ \\
\hline $\mathbf{Q}$ & \multicolumn{2}{|l|}{ Matriz de observabilidade } \\
\hline$Q_{r}$ & Taxa de calor gerado pela reação & $\mathrm{J} / \mathrm{s}$ \\
\hline Qloss & Taxa de calor perdido para o ambiente & $\mathrm{J} / \mathrm{s}$ \\
\hline$r_{\mathrm{AA}}$ & Taxa de consumo de anidrido acético & $\mathrm{mol} / \mathrm{s}$ \\
\hline$r_{i}$ & \multicolumn{2}{|l|}{ razão de reatividade do monômero i } \\
\hline $\mathrm{R}$ & Constante universal dos gases & $\mathrm{J} / \mathrm{mol} . \mathrm{K}$ \\
\hline $\mathbf{S}_{\theta}$ & \multicolumn{2}{|l|}{ Matriz simétrica positiva } \\
\hline $\mathrm{t}$ & tempo & s \\
\hline$t_{a}$ & tempo de atraso & s \\
\hline $\mathrm{T}$ & Temperatura & $\mathrm{K}$ \\
\hline $\mathrm{T}_{\mathrm{amb}}$ & Temperatura ambiente & $\mathrm{K}$ \\
\hline $\mathrm{T}_{\text {feed }}$ & Temperatura da corrente de alimentação & $\mathrm{K}$ \\
\hline $\mathrm{T}_{\mathrm{j}}$ & Temperatura da camisa & $\mathrm{K}$ \\
\hline$T_{r}$ & Temperatura do reator & $\mathrm{K}$ \\
\hline $\mathbf{u}$ & \multicolumn{2}{|l|}{ Vetor de medida de entrada } \\
\hline UA & Coeficiente global de troca térmica & $\mathrm{W} / \mathrm{K}$ \\
\hline$v_{p}$ & \multicolumn{2}{|c|}{ Volume médio das partículas não inchadas com monômero $\mathrm{cm}^{3}$} \\
\hline V & Volume total de reagentes & $\mathrm{L}$ \\
\hline$V_{e}$ & Voltagem fornecida à termorresistência & $\mathrm{V}$ \\
\hline $\mathbf{x}$ & \multicolumn{2}{|l|}{ Vetor de variáveis de estado } \\
\hline$x_{\text {inst }}$ & \multicolumn{2}{|l|}{ Conversão instantânea } \\
\hline$x_{g}$ & \multicolumn{2}{|l|}{ Conversão global } \\
\hline $\mathrm{X}_{\mathrm{AA}}$ & \multicolumn{2}{|l|}{ Conversão global de anidrido acético } \\
\hline y & \multicolumn{2}{|c|}{ Medida de saída de um sistema dinâmico tipo SISO } \\
\hline $\mathrm{y}_{\mathrm{A}}$ & \multicolumn{2}{|c|}{ Composição mássica acumulada de acetato de vinila no copolímero } \\
\hline $\mathrm{y}_{\mathrm{A}, \mathrm{inst}}$ & \multicolumn{2}{|c|}{ Composição instantânea de acetato de vinila no copolímero } \\
\hline $\mathbf{z}$ & \multicolumn{2}{|l|}{ Vetor das variáveis de estado transformadas } \\
\hline
\end{tabular}

\section{Letras Gregas}

$\varepsilon \quad$ Constante infinitesimal

$\phi_{i} \quad$ Coeficiente angular da curva de calibração do monômero i 
$\Phi$

$\Gamma$

$\eta$

$\lambda$

v

$\theta$

$\theta_{\mathrm{i}}$

$\rho_{\text {pol }}$

Matriz de transformação de coordenadas

Constante de decaimento

$s^{-1}$

P

Comprimento de onda do laser no vácuo

Medida de entrada de um sistema dinâmico

Ângulo de espalhamento do lase incidente

Parâmetro de sintonia do observador i

densidade do copolímero $\mathrm{g} / \mathrm{cm}^{3}$ 


\section{SUMÁRIO}

1 INTRODUÇÃO

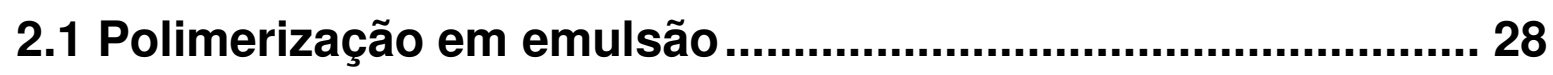

2.1.1 Teoria qualitativa de Harkins $(1945,1947)$..........................................33

2.1.2 Teoria quantitativa de Smith-Ewart (1948) .........................................35

2.1.3 Teoria qualitativa de Priest (1952) …....................................................37

2.2 Monitoramento em linha de reatores de polimerização.......... 38

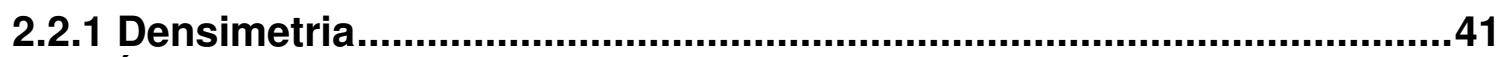

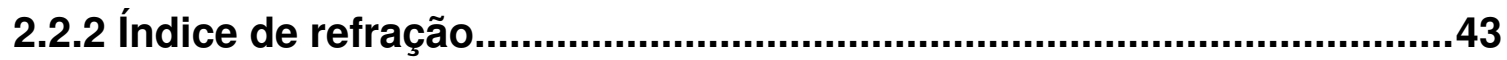

2.2.3 Cromatografia em fase gasosa ...........................................................4



2.2.5 Técnicas espectroscópicas.................................................................48

2.2.5.1 Técnicas espectroscópicas: Aplicações .......................................50

2.3 Conclusões Parciais............................................................... 54

3 OBSERVADORES DE ESTADO ................................................ 57

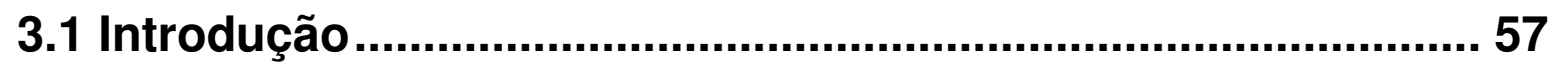

3.2 Filtro de Kalman estendido: aplicações ..................................60

3.3 Observador não-linear tipo Luenberger e de alto ganho......... 66

3.3.1 Representação em Espaço de Estados................................................67

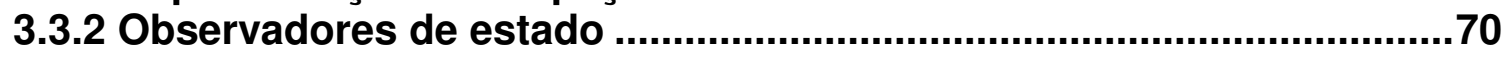

3.3.3 Derivadas de Lie......................................................................................

3.3.4 Medida da distância no espaço de estados...........................................73

3.3.5 Observabilidade de sistemas não-lineares.............................................73

3.3.5.1 Condições geométricas de observabilidade ....................................74

3.3.5.2 Condições analíticas de observabilidade........................................78





3.3.8 Observador não-linear tipo Luenberger - Projeto..................................83

3.3.9 Observador não-linear de alto ganho - Projeto ..................................86

3.3.10 Observador tipo Luenberger e de alto ganho: Aplicações..................91

3.4 Conclusões Parciais................................................................. 95

4 CALORIMETRIA ........................................................................... 96 


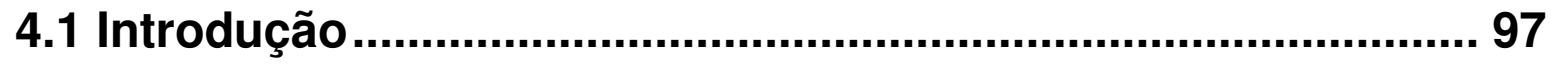

4.2 Calorimetria - Balanço de energia e equações..................... 100

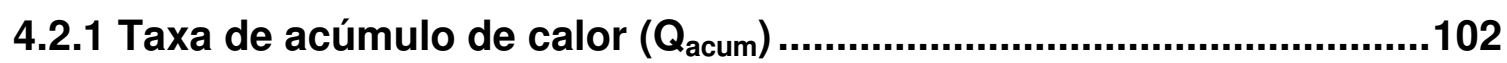

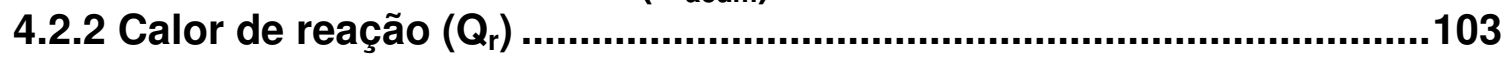

4.2.3 Calor sensível de alimentação $\left(Q_{\text {feed }}\right)$................................................104

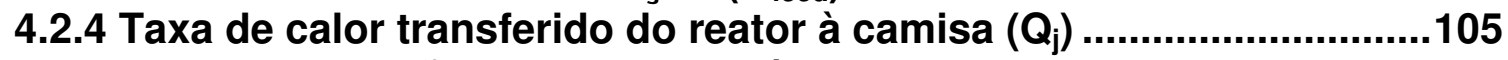

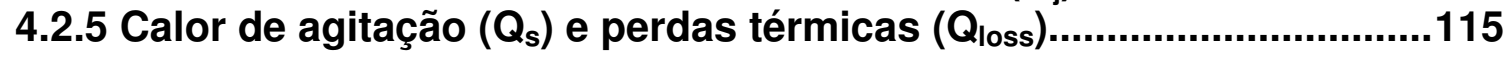

4.3 Calorimetria - Tipos e classificações ..................................... 117

4.3.1 Classificação quanto aos fluxos térmicos.........................................117

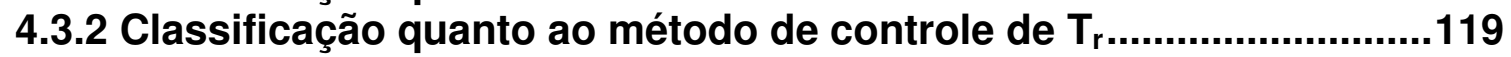

4.4 Calorimetria - Aplicações..................................................... 123

4.5 Conclusões Parciais.............................................................. 130

5 MATERIAIS E MÉTODOS ......................................................... 131

5.1 Hidrólise do anidrido acético.............................................. 132

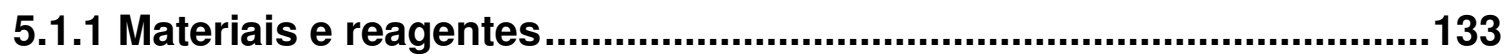

5.1.2 Técnicas analíticas......................................................................134

5.1.2.1 Método 1-Diferenciação do Polinômio Interpolador (DPI)...............139

5.1.2.2 Método 2 - Filtro Savitzky-Golay (FSG) ...................................... 140

5.1.2.3 Método 3 - Diferenças Finitas Centradas (DFC) .............................143

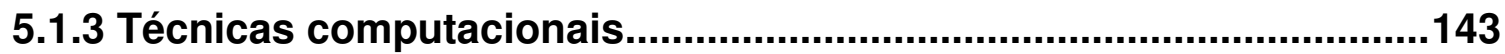

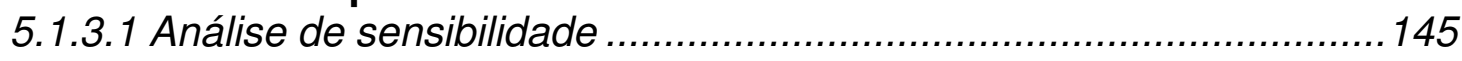

5.2 Polimerização em emulsão....................................................... 148

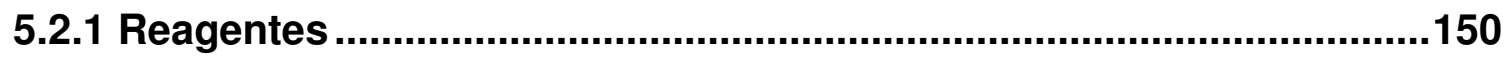

5.2.2 Técnicas analíticas e caracterização do látex .....................................150

5.2.2.1 Cromatografia em fase gasosa................................................... 151

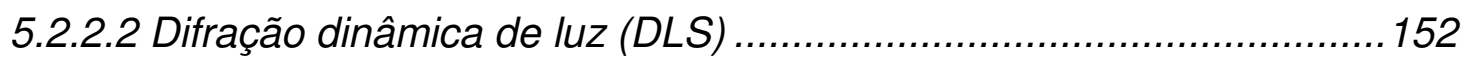

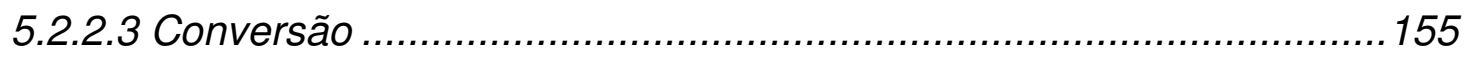

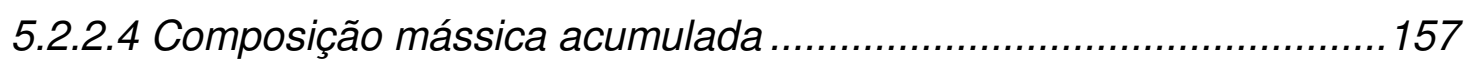

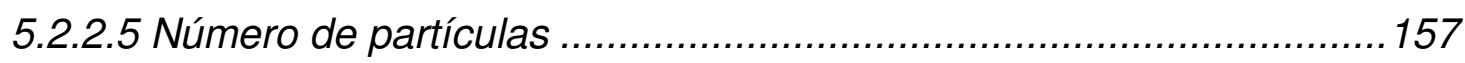

5.2.2.6 Coeficiente de troca térmica e capacidade calorífica total.................158

5.2.3 Técnicas computacionais................................................................160

5.2.3.1 Observador de estado para o calor de reação $\left(Q_{r}\right) \ldots \ldots \ldots \ldots \ldots \ldots \ldots \ldots \ldots . . . . . . . .162$

5.2.3.2 Observador de estado para o coeficiente de troca térmica (UA) ...... 165

5.2.3.3 Estimativas da conversão e da composição...................................... 168

6 RESULTADOS E DISCUSSÕES: HIDRÓLISE DO ANIDRIDO

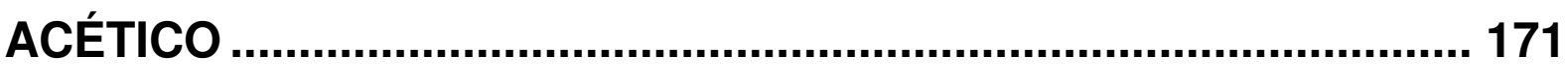


6.1 Dados experimentais............................................................ 172

6.2 Coeficientes de troca térmica e conversões iniciais ............. 173

6.3 Parâmetros da equação de Arrhenius .................................... 176

6.4 Análise de sensibilidade e observador de estado ................ 188

6.5 Conclusões Parciais................................................................. 197

7 RESULTADOS E DISCUSSÕES: POLIMERIZAÇÃO EM EMULSÃO

7.1 Formulações e condições experimentais ............................. 200

7.2 Temperaturas: remoção de distúrbios e perdas térmicas.... 201

7.3 Coeficiente de troca térmica e capacidade calorífica total... 209

7.4 Calorimetria em cascata ...................................................... 216

7.5 Calorimetria em cascata - Análise do efeito das incertezas 232

7.6 Estimação de $Q_{r}$ via balanço de energia............................... 241

7.7 Remoção de distúrbios e predição em linha dos estados ... 247

7.8 Conclusões Parciais.............................................................. 255

8 CONCLUSÕES E SUGESTÕES.............................................. 257

8.1 Conclusões ...................................................................... 257

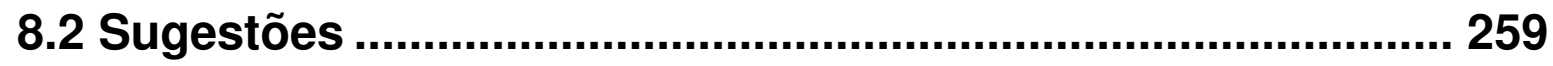

REFERÊNCIAS BIBLIOGRÁFICAS ............................................. 261

APÊNDICE A - BANCO DE DADOS.......................................... 280

APÊNDICE B - EQUACIONAMENTO GERAL DO BALANÇO DE ENERGIA. 


\section{INTRODUÇÃO}

A adequada implementação de estratégias para o monitoramento e o controle das propriedades moleculares e morfológicas podem ter um impacto significativo sobre a qualidade final dos produtos poliméricos, permitindo a produção de materiais com especificações cada vez mais estritas e assegurando, ao mesmo tempo, as condições de segurança e operabilidade do processo, uma vez que tais estratégias permitem identificar com antecedência sinais de mudanças ou distúrbios no processo, minimizando as ações corretivas necessárias para restabelecer a ordem operacional além de evitar que esses distúrbios possam afetar a qualidade final do produto, diminuindo, conseqüentemente, os custos operacionais decorrentes do descarte ou do reprocessamento do material fora de especificação.

Em geral, a qualidade final dos látices poliméricos é determinada por variáveis características que definem o estado de um processo em um dado instante como, por exemplo, a distribuição de pesos moleculares (MWD), distribuição de tamanhos de partículas (PSD), morfologia, temperatura de transição vítrea $\left(T_{g}\right)$ e composição e que, direta ou indiretamente, ditam a qualidade final do produto. Entretanto, devido a arquitetura molecular das cadeias poliméricas, estas propriedades são fortemente influenciadas pelas condições operacionais do reator, pelos perfis de alimentação dos reagentes, pela agitação e tipo de agitador, temperatura do reator, quantidade e tipo de aditivos e, portanto, o monitoramento e o controle de um processo de polimerização em emulsão são caracterizados por um grande número de variáveis manipuladas aumentando a complexidade dos modelos utilizados para sua descrição. Adicionalmente, Ray (1986) observa que, além destas dificuldades, grande parte das especificações exigidas pelo usuário final estão relacionadas a parâmetros não-moleculares como, por exemplo, cor, plasticidade e resistência.

Tradicionalmente a quantificação dessas variáveis de estado é obtida através da caracterização off line de amostras retiradas do processo como, por exemplo, gravimetria e cromatografia em fase gasosa (GC) para determinação da conversão; espectroscopia de ressonância magnética nuclear (NMR) para a determinação da composição acumulada ou outras informações estruturais das 
cadeias poliméricas obtidas em uma polimerização multicomponente; e a cromatografia de permeação em gel (GPC) para a determinação da MWD (HUA; DUBÉ, 2001).

Entretanto, essas técnicas requerem a retirada de amostras além de demandarem longos tempos de análises dificultando, ou mesmo inviabilizando, a implementação de estratégias voltadas ao controle em linha dessas propriedades. Consequentemente, nas últimas décadas, vários incentivos e trabalhos relacionados ao monitoramento e controle de reatores de polimerização têm sido reportados na literatura, principalmente, trabalhos baseados em técnicas não invasivas. Em contrapartida, Saenz de Buruaga et al. (1996) observa que o desenvolvimento de estratégias de monitoramento e controle de reatores de polimerização em emulsão tem sido sempre menor do que a de outros processos de polimerização em meio homogêneo devido, principalmente, a três fatores listados por Asua (2004):

a) látices são sistemas multifásicos termodinamicamente instáveis passíveis de sofrer coagulação;

b) polímeros em emulsão são materiais complexos com múltiplas características (composição, MWD, ramificações, gel, PSD e morfologia), cujas quantificações requerem o uso de várias técnicas analíticas;

c) grande parte das análises demandam longos tempos (muitas vezes maiores do que o próprio tempo de polimerização), os equipamentos, em geral, são caros e não adaptados para medições em linha.

Uma vez que as reações de polimerização são altamente exotérmicas é possível quantificar continuamente a taxa de calor gerado pela reação a partir das medidas de temperatura e do balanço de energia do reator. Essa informação, por sua vez, pode ser utilizada para estimar outras variáveis de estado como, por exemplo, a concentração de monômeros, conversão global, conversão instantânea e a composição do copolímero.

Nas últimas décadas vários trabalhos relacionados a calorimetria têm sido reportados na literatura (REGENASS, 1985; SCHULER; SCHMIDT, 1992; GUGLIOTTA et al., 1995a, GUGLIOTTA et al., 1995b; FEVOTTE et al., 1996; VICENTE et al, 2001; BENAMOR et al., 2002; FREIRE et al, 2004) devido, principalmente, a boa instrumentação dos reatores atualmente comercializados facilitando a aquisição das temperaturas da camisa e do reator e das vazões de alimentação. Além disso, a simplicidade, a natureza não invasiva e o baixo custo 
dessa tecnologia, torna a calorimetria bastante atrativa para implementação em um ambiente industrial.

Entretanto, apesar da calorimetria ter sido empregada com sucesso no monitoramento e controle de reatores de polimerização em escala laboratorial, esta técnica requer a predição contínua do coeficiente global de troca térmica, uma vez que este parâmetro está sujeito a variações temporais significativas devido a sua dependência em relação a conversão e a viscosidade do meio reacional.

$\mathrm{Na}$ prática, não há uma técnica única e simples para estimar simultaneamente o calor gerado pela reação e o coeficiente global de troca térmica para diferentes tipos e tamanhos de reatores. Para contornar este problema, diferentes métodos têm sido reportados na literatura incluindo os observadores de estado (BENAMOR et al., 2002; FREIRE et al., 2004) e a calorimetria oscilatória (CARLOFF et al., 1994; TIETZE et al., 1996).

Observadores de estado são modelos dinâmicos que fornecem, em um dado instante, uma estimativa das variáveis de estado do processo a partir das medidas de saída coletadas diretamente do sistema e, portanto, sujeitas à presença de distúrbios ou ruídos. A principal questão relacionada a estimativa em linha pelos observadores de estado é ponderar adequadamente as contribuições do modelo do processo e os resíduos das medidas e, portanto, sintonizar um observador é sempre um compromisso entre a sensibilidade ao ruído e o tempo dispendido na estimativa das variáveis de estado.

\section{OBJETIVOS}

O objetivo principal do presente trabalho é implementar técnicas nãolineares para estimar em linha as composições de copolímeros obtidas durante reações semi-contínuas em emulsão de acetato de vinila / acrilato de butila. As informações sobre a evolução do processo serão obtidas em linha estimando-se conjuntamente a taxa de geração de calor $\left(Q_{r}\right)$ e o coeficiente global de troca térmica (UA) a partir de medidas de temperatura e da equação do balanço de energia do reator. Estas variáveis de estado, por sua vez, serão estimadas através de 
observadores não-lineares conforme modelo proposto por BenAmor et al. (2002) e Freire et al. (2004).

As propriedades poliméricas experimentais serão obtidas a partir da:

a) cromatografia gasosa e gravimetria para determinação das conversões globais e instantâneas;

b) cromatografia em fase gasosa para a quantificação da composição do copolímero;

c) difração dinâmica de luz para a determinação do tamanho médio das partículas.

As predições off line e em linha das variáveis de estado e das propriedades dos látices poliméricos serão obtidas pela implementação de um programa computacional escrito em Fortran 90.

Para tanto, os observadores de estado não-lineares, em conjunto com os conceitos de calorimetria, foram inicialmente aplicados a uma reação de hidrólise de anidrido acético. Este estudo de caso inicial foi escolhido devido a sua simplicidade, pois grande parte das limitações encontradas em um processo de polimerização não estão presentes ou apresentam pouca influência nas estimativas das variáveis de estado calorimétrica.

\section{ESTRUTURA DA TESE}

Quanto à apresentação, o trabalho está dividido em 8 seções, contando com esta introdução.

Na seção 2 é apresentada uma breve revisão bibliográfica sobre os dois principais temas abordados nesta tese. Inicialmente é apresentada uma descrição resumida dos principais reagentes utilizados em uma formulação típica de polimerização em emulsão, as teorias clássicas e as principais vantagens e desvantagens desta técnica de polimerização. A seção é finalizada com a apresentação e a descrição das principais técnicas atualmente disponíveis para o monitoramento em linha de reatores de polimerização. 
Nas seções 3 e 4 são apresentados os principais fundamentos teóricos relacionados aos observadores de estado (seção 3) e à calorimetria (seção 4), bem como uma revisão da literatura na qual são descritas a utilização de ambas as técnicas para o monitoramento e controle em tempo real das variáveis de estado de um processo de polimerização em emulsão.

Na seção 5 são apresentados os reagentes, materiais, métodos analíticos e computacionais utilizados nos processos estudados neste trabalho (hidrólise do anidrido acético e reação de copolimerização em emulsão de acetato de vinila / acrilato de butila). As comparações entre os resultados experimentais e preditos são apresentadas nas seções 6 (hidrólise do anidrido acético) e 7 (reação de polimerização).

Na seção 8 são apresentadas as conclusões mais relevantes deste trabalho e sugestões para trabalhos futuros e, em seguida, as referências bibliográficas utilizadas para a elaboração do texto da tese e fundamentação dos resultados obtidos.

Para finalizar, no apêndice A são apresentados todos os parâmetros e constantes cinéticas utilizados durante as simulações, enquanto no Apêndice $B$ é apresentado o equacionamento geral do balanço de energia para um reator do tipo tanque agitado. 


\section{REVISÃO BIBLIOGRÁFICA}

O objetivo desta seção é apresentar um resumo sobre os sistemas em emulsão, descrevendo as suas principais características, formulação, vantagens e desvantagens, e as primeiras teorias propostas para explicar seus mecanismos e particularidades e que fornecem as bases para a formulação das teorias atuais. Em seguida é apresentada uma revisão sobre os principais sensores atualmente conhecidos e utilizados para o monitoramento de reatores de polimerização, acompanhada com o resumo de alguns trabalhos da literatura nos quais são demonstradas as aplicações práticas dessas técnicas.

\subsection{Polimerização em emulsão}

Polimerização em emulsão é uma técnica de polimerização heterogênea via radicais livres, na qual o monômero encontra-se distribuído através de todo o sistema como gotículas estabilizadas em emulsão, dissolvidos parcialmente na fase aquosa, ou ainda, solubilizados em micelas e partículas poliméricas; e desenvolvido com o principal objetivo de obter látices sintéticos com propriedades semelhantes ao látex natural.

As primeiras tentativas de produção de látex sintético foram realizadas durante a Primeira Guerra Mundial, na Alemanha, para a obtenção de matériasprimas voltadas à fabricação de materiais bélicos, atingindo seu auge durante a Segunda Guerra Mundial, quando essa técnica foi utilizada em larga escala, nos Estados Unidos, para a produção de copolímeros de estireno-butadieno com o objetivo de compensar o bloqueio no fornecimento de látex natural.

No entanto, a diversificação de produtos obtidos por emulsão, assim como o aumento no número de pesquisas voltadas à melhoria na qualidade destes produtos, foram observados apenas entre os anos de 1950 e 1980 quando grande parte dos principais conceitos, desenvolvidos principalmente por Fitch, Gardon, Vanderhoff, 
Hansen e Ugelstad, e dos produtos atualmente conhecidos e produzidos por essa técnica tiveram a sua origem.

Gilbert (1995) observa que, apesar da boa qualidade dos produtos obtidos nesse período, devido às limitações teóricas e instrumentais, as formulações e as condições operacionais foram obtidas por tentativa e erro e baseadas em suposições empíricas que, em sua maioria, foram derrubadas ou corrigidas posteriormente.

Em geral, uma formulação típica de uma reação de polimerização em emulsão é composta por monômeros, água, tensoativos, e um iniciador solúvel na fase aquosa. Além destes componentes, é comum encontrar ainda uma série de outros aditivos acrescentados ao meio reacional como, por exemplo, agentes tamponantes, agentes de transferência de cadeia; agentes redutores, colóides protetores, biocidas entre outros.

Uma das principais vantagens dessa técnica, em relação ao demais processos de polimerização, é a utilização de água como fase contínua, minimizando a toxicidade do produto final, além de manter a viscosidade do meio reacional baixa e de permitir uma remoção mais eficiente do calor gerado pela reação

Monômeros são substâncias orgânicas insaturadas provenientes, em grande parte, do gás natural ou da destilação fracionada do petróleo. Alguns destes compostos isolados do petróleo são utilizados diretamente como monômeros, enquanto outros, atuam como precursores para a síntese de monômeros com estruturas mais complexas como, por exemplo, o etileno utilizado na produção de outros três monômeros: cloreto de vinila, acetato de vinila e estireno. A escolha do monômero ou do sistema de monômeros dependerá do tipo de polímero e das propriedades mecânicas desejadas.

Emulsificantes, ou surfactantes, são moléculas híbridas formadas por uma extremidade hidrofóbica, composta por radicais graxos com elevado número de carbonos, e por uma porção hidrofílica, capazes de alterar as propriedades superficiais e interfaciais de um líquido garantindo a estabilidade termodinâmica das partículas poliméricas e a dispersão dos monômeros pela fase contínua. Outra propriedade fundamental dos tensoativos é a tendência de formar agregados chamados micelas que, geralmente, formam-se a baixas concentrações em água e são responsáveis pela formação das primeiras partículas poliméricas por nucleação 
micelar. A concentração mínima na qual se inicia a formação desses agregados é denominada concentração micelar crítica $(\mathrm{CMC})$. O aumento da concentração de tensoativos após este ponto tem pouco efeito na tensão superficial da solução na qual o emulsificante / surfactante está presente. Estas propriedades tornam os tensoativos o composto chave em muitos processos de polimerização em emulsão, visto que, o produto obtido em tais sistemas é uma dispersão coloidal composta por uma larga população de partículas submicrométricas hidrofóbicas e instáveis termodinamicamente, devido à natural incompatibilidade entre o polímero e a água. Consequentemente, a dosagem insuficiente desse composto pode terminar, inevitavelmente, na coagulação das partículas poliméricas ao longo do processo tornando a descrição matemática da nucleação de partículas e dos mecanismos de crescimento mais complexas. Ao mesmo tempo, a perda da estabilidade coloidal do látex pode acarretar no depósito e acúmulo de material sólido sobre a parede do reator e sobre o agitador aumentando os custos de produção e dificultando 0 controle de qualidade do produto.

De acordo com Odian (1981) os emulsificantes são classificados em nãoiônicos e iônicos. Neste último caso, os emulsificantes são ainda agrupados em emulsificantes aniônicos, catiônicos e anfóteros. Os surfactantes comumente utilizados são os aniônicos que incluem os sabões de ácidos graxos como, por exemplo, o estearato de sódio e potássio, laurato, palmitato; e os sulfonatos e sulfatos como, por exemplo, o lauril sulfato de sódio e o dodecilbenzeno sulfonato de sódio. Os sulfonatos e sulfatos são úteis para reações de polimerização em meio ácido, onde os sabões de ácido graxo são instáveis, ou quando o produto polimérico final deve ser estabilizado em meio ácido ou ter íons metálicos.

Surfactantes não-iônicos são compostos orgânicos com grupos hidroxilas, éter ou oxigênio, cuja principal característica é a capacidade de inversão da solubilidade em fase aquosa devido a quebra das pontes de hidrogênio entre a água e o tensoativo com 0 aumento da temperatura. Nesta categoria estão as alcalonamidas de ácidos graxos, derivados etoxilados de alquil fenois, alcoóis graxos, ácidos graxos, aminas e mercaptanas graxas, polióxi propileno glicois, ésteres graxos de sacarose, polisiloxanas e os fluorcarbonos. Raramente os surfactantes não-iônicos são utilizados de forma isolada devido à baixa eficiência desses compostos para formar emulsões estáveis quando comparados aos surfactantes aniônicos. 
Os tensoativos catiônicos raramente são utilizados em reações de polimerização em emulsão devido à baixa eficiência de emulsificação e aos efeitos adversos sobre a decomposição do iniciador. A utilização destes emulsificantes é recomendada apenas quando se deseja a produção de partículas carregadas positivamente (ODIAN, 1981).

Iniciadores são compostos inorgânicos, ou orgânicos, responsáveis pela formação de radicais livres que irão iniciar a reação de polimerização propriamente dita. A ação destes compostos é às vezes confundida (inapropriadamente) com a de um catalisador, o que não é correto pois os iniciadores são consumidos durante a reação. A geração de radicais livres pode ocorrer tanto pela decomposição térmica quanto pela ação de agentes oxidantes ou pela incidência de radiação. A fase preferencial (aquosa ou orgânica) na qual estes radicais serão gerados dependerá do tipo de iniciador utilizado.

Normalmente, os iniciadores usados nas reações de polimerização em emulsão são solúveis na fase aquosa como, por exemplo, os persulfatos de sódio, potássio ou amônia. Peróxidos parcialmente solúveis na fase aquosa como os peróxidos de ácido succínico ou hidroperóxidos de t-butila também têm sido empregados (ODIAN, 1981). Iniciadores organo-solúveis são empregados apenas em reações extremamente específicas como, por exemplo, para a produção de partículas de poliestireno monodispersas e com elevados diâmetros.

A ampla utilização industrial dos sistemas de polimerização em emulsão advém das numerosas vantagens desta técnica quando comparadas aos demais processos de polimerização. Porém, ela apresenta ainda uma série de desvantagens que podem eventualmente afetar a qualidade final do produto ou mesmo encarecer o custo final de produção. Gilbert (1995) sintetiza as principais vantagens e desvantagens dessa técnica e são citadas a seguir:

\section{VANTAGENS}

a) o calor gerado pela exotermia da reação pode ser rapidamente absorvido e dissipado pela fase aquosa, exigindo precauções menos rigorosas quanto a prevenção de sobretemperatura do reator;

b) a taxa de polimerização é, geralmente, maior do que a obtida em outros tipos de polimerização minimizando o tempo total de reação; 
c) possibilita a produção de polímeros com pesos moleculares extremamente elevados e com diferentes MWDs;

d) o polímero encontra-se em estado coloidal facilitando o manuseio e o transporte do produto

e) o processo utiliza água como fase contínua aumentando a segurança de operação e minimizando os efeitos tóxicos do produto final;

f) como os pesos moleculares são altos, estes podem ser controlados através da adição de agentes de transferência de cadeia;

g) na polimerização em emulsão são obtidas altas conversões, minimizando os problemas causados pelo acúmulo de monômero residual e, ao mesmo tempo, maximizando a eficiência do processo;

h) possibilidade de produção de partículas estruturadas tipo núcleo-casca (core shell) com diferentes características morfológicas aumentando, consequentemente, as possibilidades de aplicação do produto.

\section{DESVANTAGENS}

a) o produto obtido pode apresentar uma grande quantidade de aditivos de difícil remoção que podem afetar as propriedades do látex, além de encarecer o preço final do produto;

b) dependendo da aplicação final do produto, pode ser necessário separar o polímero da fase aquosa, elevando os custos do processo;

c) possibilidade de formação de coágulos devido a perda parcial da estabilidade, causando problemas com incrustações;

d) processo que envolve, no mínimo, a presença de duas fases, aumentando a complexidade dos mecanismos cinéticos.

Devido a sua natureza compartimentalizada e heterogênea, a polimerização em emulsão torna-se um processo extremamente complexo envolvendo uma gama enorme de variáveis e parâmetros, principalmente, no que diz respeito aos mecanismos de nucleação, à estabilidade das partículas e aos efeitos difusionais dos reagentes e de outras espécies presentes no meio reacional. Devido a esta complexidade, várias teorias foram propostas com o objetivo de descrever matematicamente as propriedades do polímero em função das condições 
operacionais e das propriedades difusionais. A seguir é apresentado um resumo das principais teorias existentes.

\subsubsection{Teoria qualitativa de Harkins $(1945,1947)$}

Elaborada em 1945 a partir de uma série de estudos quantitativos de reações em emulsão de estireno e isopreno, ambos na presença e na ausência de micelas, a teoria de Harkins foi a primeira teoria qualitativa proposta para descrever sistemas em emulsão. Apesar de bastante simplificada, constitui-se como uma das principais bases teóricas para a formulação das teorias quantitativas posteriores.

A partir dos resultados obtidos, Harkins $(1945,1947)$ observou que a taxa de polimerização era muito maior quando as micelas estavam presentes e, portanto, baseado nesta evidência, propôs que o locus de polimerização e o responsável pela formação das primeiras populações de partículas eram as próprias micelas. Para explicar esta hipótese e o prosseguimento das reações de polimerização, Harkins (1945, 1947) propôs os seguintes postulados:

P1) os radicais livres são produzidos na fase aquosa e são capturados pelas micelas, iniciando a formação das primeiras partículas poliméricas (nucleação micelar);

P2) o principal locus para formação dos polímeros são as próprias partículas inchadas com monômero;

P3) as gotas funcionam como reservatórios de monômeros, repondo aqueles consumidos na fase polimérica e mantendo constante a relação monômero/polímero, uma vez que a difusão dos monômeros das gotas para as partículas é mais rápida do que o consumo de monômero pela reação de propagação. Como a área superficial total das gotas de monômeros é, aproximadamente, duas ordens de grandeza menor do que a área superficial total das micelas e partículas, poucos radicais ingressam dentro das gotas de monômeros e, portanto, pouco ou nenhum polímero será formado nessa fase. 
Como conseqüência dos postulados propostos por Harkins, a polimerização em emulsão pode ser didaticamente dividida em três intervalos bem definidos: um intervalo de formação (intervalo I) e dois de crescimento de partículas (intervalos II e III). Um resumo com as principais características de cada intervalo é apresentada a seguir.

\section{A) INTERVALO I}

Intervalo caracterizado pelo aumento da velocidade de reação e pela formação de novas populações de partículas por nucleação. Durante este estágio, uma parte do emulsificante adicionado encontra-se na forma de agregados (micelas) responsáveis pela formação de novas partículas, enquanto uma outra parte encontra-se disperso no meio aquoso fornecendo, junto com as micelas, o emulsificante necessário para a estabilização das partículas em crescimento (Figuras 1.1a e 1.1b). O consumo de todas as micelas caracteriza o fim desse intervalo, cessando a formação de novas populações de partículas.

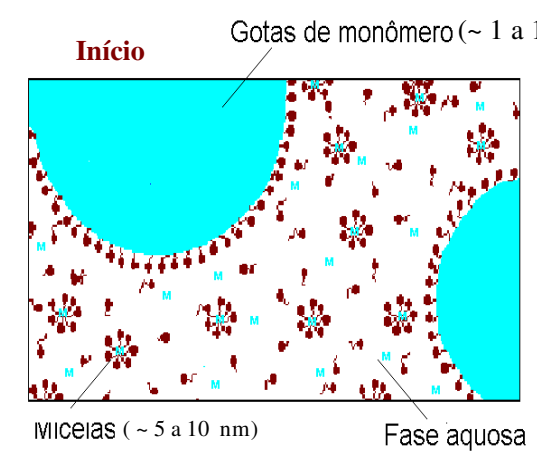

(a)

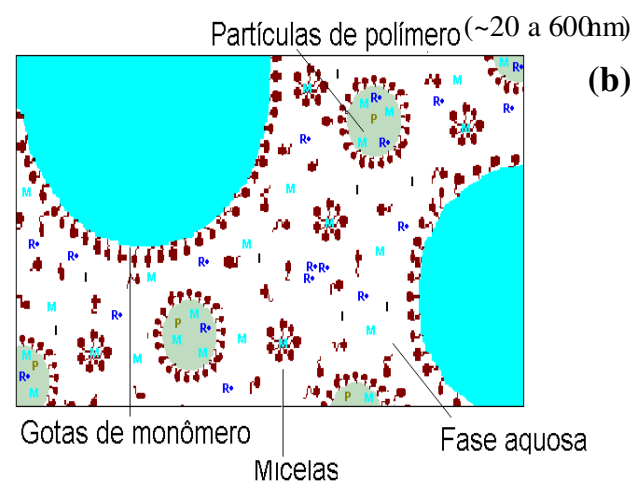

(c)
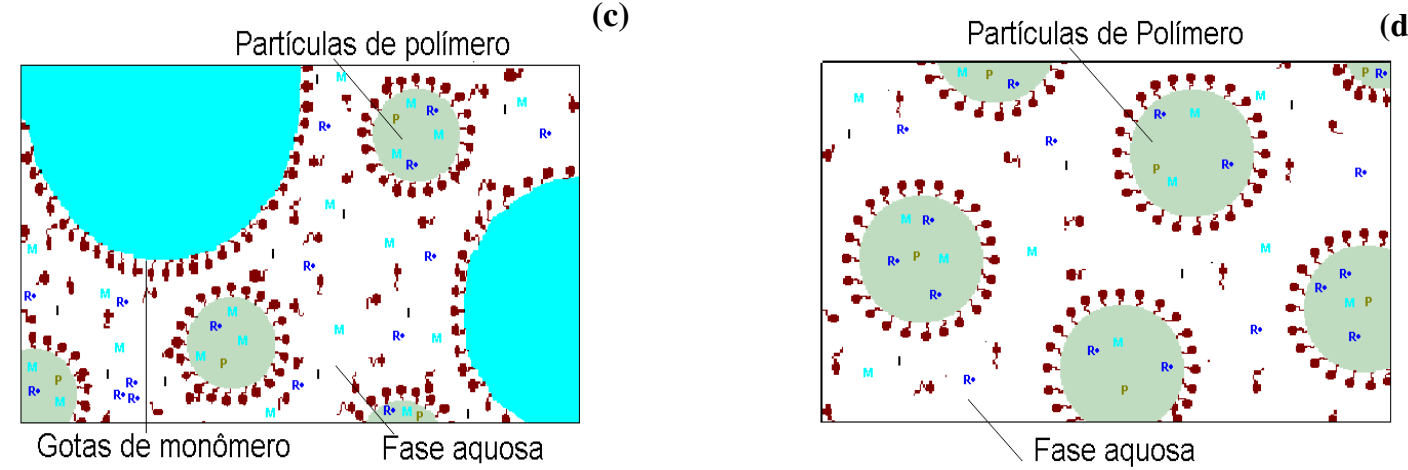

(d)

Figura 2.1 - Etapas da polimerização em emulsão (Teoria de Harkins) a) antes da adição de iniciador, b) estágio I, c) estágio II, d) estágio III (SAYER, 1999) 


\section{B) INTERVALO II}

Intervalo caracterizado pelo número de partículas e concentração de monômeros na fase polimérica constantes, diminuição do tamanho e do número de gotas de monômeros e pelo crescimento do diâmetro das partículas (Figura 1.1c). Como a concentração de monômeros na fase polimérica é constante e o número de partículas não é alterado, a taxa global de polimerização também permanece constante. $O$ consumo completo de todas as gotas caracteriza o fim desse intervalo.

\section{C) INTERVALO III}

Neste intervalo a dispersão é composta apenas por duas fases: a fase aquosa (fase contínua), e uma fase dispersa (orgânica) formada pelas partículas poliméricas inchadas com monômero (Figura 1.1d). Nessa etapa, o monômero restante é totalmente ou parcialmente convertido em polímero, diminuindo drasticamente a taxa de polimerização e aumentando ligeiramente o diâmetro médio das partículas.

\subsubsection{Teoria quantitativa de Smith-Ewart (1948)}

A teoria proposta no final dos anos 40 por Smith e Ewart descreve quantitativamente a formação de partículas e a distribuição de radicais na fase polimérica para os intervalos I e II da teoria de Harkins (1945, 1947).

Baseado nos postulados propostos por Harkins e em observações empíricas, Smith e Ewart (1948) dividiram o intervalo I em dois casos limites:

i) limite superior: todos os radicais formados na fase aquosa entram nas micelas gerando novas partículas poliméricas, ou seja, a formação de partículas é proporcional à velocidade de formação de radicais livres de iniciador na fase aquosa;

ii) limite inferior: os radicais podem entrar tanto nas micelas quanto nas partículas poliméricas, dependendo da área superficial total de cada uma destas estruturas. 
Para o intervalo II, Smith e Ewart (1948) consideraram a existência de três casos limites para a distribuição de radicais nas partículas poliméricas:

A) CASO I: a taxa de saída de radicais das partículas poliméricas é muito maior do que a taxa de entrada. Portanto, o número médio de radicais por partícula é muito menor do que um.

B) CASO II: a taxa de saída de radicais das partículas poliméricas é desprezível e a taxa de entrada é muito menor que a taxa de terminação. Logo, o número médio de radicais por partícula é aproximadamente igual a 0,5 e a taxa de reação independe do tamanho das partículas poliméricas.

C) CASO III: a taxa de entrada de radicais nas partículas poliméricas é muito maior do que a taxa de terminação. Portanto, o número médio de radicais por partícula é muito maior do que um.

Uma suposição chave no modelo proposto por Smith e Ewart (1948) é que todas as partículas são do mesmo tamanho e que crescem, em volume, a uma taxa constante. Originalmente esta teoria foi baseada, em grande parte, em resultados obtidos durante reações de polimerização em emulsão de estireno nas quais a formação de partículas, durante o intervalo I, estará completa após conversões entre $2-10 \%$, garantindo um crescimento uniforme e uma distribuição de tamanho de partículas estreita. Entretanto, essa teoria não consegue descrever sistemas nos quais são utilizados monômeros com relativa solubilidade na fase aquosa. Os principais motivos dessa limitação são listados abaixo conforme apresentados por Gao e Penlidis (2002):

i) monômeros com relativa solubilidade na fase aquosa como acrilonitrila, acetato de vinila, metacrilato de metila entre outros, podem polimerizar na fase aquosa;

ii) se a saída de radicais for significativa, o número médio de radicais por partícula será menor do que 0,5 (Caso II). Sempre que o número de radicais por partícula polimérica for menor que 0,5 , a variação da taxa de polimerização em resposta à variação na concentração de emulsificantes, não será como aquela predita pela teoria de Smith e Ewart (1948). Vários monômeros utilizados em sistemas de polimerização industrial estão 
incluídos neste grupo como, por exemplo, o cloreto de vinila, acrilato de metila e o acetato de vinila;

iii) o modelo proposto por Smith e Ewart (1948) é válido apenas para os intervalos I e II. Para região de altas conversões haverá um grande número de radicais coexistindo nas partículas e, portanto, o número de radicais por partícula polimérica será maior que 0,5. Cada partícula funciona como um mini-reator e as cinéticas de polimerização em massa podem ser aplicadas. A taxa de polimerização é maior no estágio III que no estágio II. Exemplos deste desvio podem ser observados em reações em emulsão de metacrilato de metila e acrilato de butila.

Araújo (1999) menciona que originalmente o intervalo III não foi incluído na teoria de Smith e Ewart (1948), sendo este intervalo tratado posteriormente por Alexander e Napper (1971) que propuseram a divisão do intervalo III em três subintervalos. O primeiro subintervalo corresponde ao período de consumo do monômero presente na fase aquosa e na fase polimérica. $O$ segundo subintervalo corresponde ao período caracterizado pelo aumento da viscosidade, tornando a difusão do monômero para o centro ativo das cadeias poliméricas a etapa limitante da reação. E por fim, o terceiro subintervalo correspondente ao período no qual a fase polimérica aproxima-se do ponto de transição vítrea.

\subsubsection{Teoria qualitativa de Priest (1952)}

Teoria de Priest foi proposta em 1952 com o objetivo de descrever qualitativamente o mecanismo de nucleação de partículas para reações com monômeros parcialmente solúveis na fase aquosa ou com concentração de emulsificante abaixo da CMC (nucleação homogênea).

De acordo com Araujo (1997), a teoria proposta por Priest estabelece que os radicais livres formados na fase aquosa iniciam a reação de polimerização com as moléculas de monômeros dissolvidos na água. Quando o oligômero atinge um determinado peso molecular, este se precipita e é, ao mesmo tempo, estabilizado pelas moléculas de emulsificante, dispersos pela fase aquosa, ou por radicais sulfato 
do iniciador, formando uma nova partícula polimérica. O número de partículas cresce até um ponto máximo e depois pode ocorrer uma redução devido a perda da estabilidade coloidal.

\subsection{Monitoramento em linha de reatores de polimerização}

Nas últimas décadas, o aumento na demanda por materiais poliméricos com especificações cada vez mais estritas tem forçado as indústrias produtoras de látex a buscar novas alternativas de monitoramento mais robustas voltadas à identificação das principais variáveis de estado controladas de um processo de polimerização. Estas informações, quando obtidas em linha, e associadas ao conhecimento das principais variáveis manipuladas, permitem ao engenheiro de processos exercer uma influência significativa sobre a qualidade final do produto e assegurar, ao mesmo tempo, as condições de segurança e operabilidade da planta.

Entretanto, devido à estrutura molecular das cadeias poliméricas e à inerente natureza complexa e viscosa do sistemas em emulsão, a instrumentação em linha tem sido o elo mais fraco nos esquemas de controle de reatores de polimerização, impedindo o adequado monitoramento e controle em malha fechada da qualidade do polímero. Estas dificuldades advêm, principalmente, da natureza físico-química dos processos em emulsão e da dificuldade para estabelecer uma relação quantitativa entre as propriedades físicas, térmicas, mecânicas, reológicas e químicas, com as propriedades moleculares e morfológicas do polímero formado.

Tradicionalmente, o controle e a quantificação das propriedades finais dos látices poliméricos são feitas através da caracterização off line de amostras retiradas durante o processo. Esta prática persiste até os dias atuais, visto que a quantificação off line de grande parte destas propriedades, além de ser complicada, requer $\mathrm{o}$ uso de sofisticadas e demoradas técnicas analíticas. Adicionalmente, $\mathrm{o}$ desenvolvimento de sensores para o monitoramento em linha exigem esforços multidisciplinares conjuntos de áreas como modelagem matemática $\mathrm{e}$ processamento de dados, projeto de processos, controle e instrumentação avançada. 
Inicialmente, grande parte dos esforços voltados ao desenvolvimento de sensores para o monitoramento em linha de reatores de polimerização foram focados na utilização das técnicas de caracterização off line já existentes incluindo a cromatografia gasosa, a difração dinâmica de luz e a ressonância magnética nuclear. Por outro lado, estas técnicas requerem a preparação prévia das amostras antes de serem analisadas e, portanto, para realizar essas análises em linha, o processo deve ser equipado com mecanismos de amostragem, ou mesmo com a inserção de loops, que podem ser custosos em termos de tempo e instalação e problemáticos quando implementados em um ambiente industrial. Desta forma, atualmente, grande parte dos incentivos destinados à área são voltados ao desenvolvimento de sensores in situ, uma vez que a instalação destas sondas demandam modificações mais simples e menos caras no processo, além de permitir a aquisição de dados em ambiente insalubres ou de difícil acesso.

Recentes avanços têm sido alcançados no desenvolvimento de técnicas e sensores para o monitoramento em linha das propriedades do polímero formado e foram revistos e publicados por Chien e Penlidis (1990) e, mais recentemente, por Kammona; Chatzi e Kiparissides (1999). Em ambas as revisões é mencionado que o surgimento de sensores baseados em fibras ópticas, principalmente NIR e Raman, têm contribuído fortemente para o desenvolvimento de técnicas de monitoramento mais robustas e in situ. No entanto, os autores observam que grande parte destas técnicas requerem ainda o pré-tratamento das amostras e/ou dos dados, dificultando o uso desses sensores para o monitoramento e controle em tempo real de reatores em escala laboratorial e, portanto, apresentando baixa aplicabilidade em reatores industriais.

Uma revisão mais compacta acerca desse assunto também pode ser encontrada em Dimitratos; Eliçabe e Georgakis (1994) e Richards e Congalidis (2006). Além disso, Dimitratos; Eliçabe e Georgakis (1994) apresentam também uma revisão bastante abrangente sobre as principais técnicas de controle da distribuição de tamanhos de partículas e pesos moleculares, da composição do copolímero e das variáveis operacionais.

$\mathrm{Na}$ revisão publicada por Kammona; Chatzi e Kiparissides (1999), os sensores em linha para reatores de polimerização foram divididos em três grupos de acordo com a propriedade que se deseja medir e são apresentados na Tabela 2.1. 
Tabela 2.1 - Classificação dos sensores em linha para reatores de polimerização

Propriedades do polímero

Conversão e composição do copolímero
Técnicas de monitoramento

Densimetria

Índice refratométrico

Cromatografia gasosa

Calorimetria / balanço de energia

Ultra-som

Espectroscopia de fluorescência

Espectroscopia de reflexão de UV

Espectroscopia de infravermelho próximo

Espectroscopia de infravermelho médio

Espectroscopia Raman

Cromatografia de permeação em gel

Difração dinâmica de luz

Turbidimetria

Distribuição de tamanho de partículas

Cromatografia de coluna empacotada

Cromatografia hidrodinâmica capilar

Espectroscopia de ultra-som

A aquisição de dados através dos sensores apresentados na Tabela 2.1 processa-se através de um sinal pneumático ou, em sua maioria, por um sinal elétrico que devem ser necessariamente transformado de modo a permitir o registro das grandezas medidas em um arquivo de dados. Devido à natureza elétrica destes sinais, grande parte dessas medidas podem sofrer a interferência de ruídos sendo necessário a aplicação prévia de um filtro sobre os dados obtidos a fim de minimizar a interferência de tais ruídos sobre as estimativas das propriedades de interesse. Adicionalmente, vale lembrar que as estimativas das propriedades poliméricas (conversão, composição, distribuição de pesos moleculares e distribuição de tamanho de partículas) não são diretas e, portanto, requerem sempre a utilização conjunta de um modelo matemático, de um observador de estado ou de um modelo de calibração multivariada obtido através de técnicas quimiométricas.

A seguir é apresentado um breve resumo das principais técnicas apresentadas na Tabela 2.1. O objetivo desta revisão é apontar algumas das dificuldades encontradas durante a implementação dessas metodologias para o monitoramento em linha de um reator de polimerização e, descrever brevemente, como elas podem ser utilizados para estimar a conversão e a composição. Mais informações em relação ao monitoramento das demais propriedades podem ser encontradas em Chien e Penlidis (1990) e Kammona; Chatzi e Kiparissides (1999). 
Os fundamentos teóricos e as aplicações dos observadores de estado não-lineares e da calorimetria serão apresentados nas seções 3 e 4, respectivamente. Estes dois tópicos serão abordados em seções à parte por serem as técnicas utilizadas neste projeto.

\subsubsection{Densimetria}

Nesta técnica as medidas de densidade das diferentes espécies presentes no reator em conjunto com um balanço de massa, apropriado ao tipo de operação e formulação do processo, são utilizados para acompanhar a evolução da conversão, estimada através da regra de aditividade dos volumes.

Este método é relativamente simples para reações de homopolimerização na ausência de gradientes de temperatura. Por outro lado, para reações multicomponentes e com deriva de composição, a densidade do polímero formado dependerá da composição acumulada. Neste caso, torna-se necessário o uso de um outro sensor capaz de medir em linha a evolução da composição do polímero, ou então de um modelo matemático que correlacione a composição com as medidas de densidade do látex.

As medidas em linha da densidade, tanto para reatores em escala laboratorial quanto em escala industrial são, em sua maioria, obtidas por um densímetro externo em $U$ com volume constante através do qual a amostra é bombeada. O tubo é então excitado eletronicamente para oscilar com uma determinada freqüência (geralmente 40 vezes por minuto).

As principais vantagens dessa técnica é que ela não requer a destruição do látex e nem calibrações frequentes, o sistema de amostragem é independente do tamanho do reator, e a aquisição de dados é rápida.

No entanto, para sistemas em emulsão, podem ocorrer problemas com o sistema de amostragem devido o ataque da bomba pelos monômeros, à floculação das partículas poliméricas no loop de circulação, e à possibilidade de separação de fases no densímetro. Além disso, a presença de bolhas de nitrogênio e a coalescência das gotas de monômeros no circuito de amostragem podem, eventualmente, causar erros nas medidas de densidade. Adicionalmente, foi 
verificado que a adição de um circuito externo pode causar a inibição da reação (OTHMAN, 2000).

Noël et al. (1995) utilizaram a densimetria e cromatografia gasosa para obter em linha as concentrações globais de estireno e de acetato de vinila durante reações de homopolimerização em emulsão, e as concentrações de acrilato de metila e acetato de vinila durante reações de copolimerização em emulsão. As medidas de densidade foram obtidas através de um densímetro em $U$ instalado na parte externa do reator. A injeção ao cromatógrafo foi realizada através de uma válvula de amostragem em disco que permitisse tanto a injeção automática quanto a injeção manual da amostra.

Févotte, Barudio e McKenna (1996) e Févotte, Barudio e Guillot (1996) combinaram a calorimetria e a densimetria para estimar em linha a evolução da conversão e de outras propriedades macromoleculares de copolímeros de estireno/acrilato de butila produzidos durante reações em emulsão e em solução.

Barudio; Févotte e McKenna (1999) utilizaram a densimetria para obter correlações empíricas da densidade do polímero em função da temperatura, para reações de homopolimerização em solução, e em função da composição acumulada, para reações de copolimerização em emulsão. O objetivo final do trabalho foi obter correlações precisas para o cálculo das densidades das diversas espécies presentes no reator para serem utilizados em modelos voltados à simulação de processos que envolvam o sistema de monômeros utilizados, ou para aplicações práticas que envolvam a exploração de sensores em linha, principalmente, a densimetria que requer medidas precisas de densidade para a estimação correta da conversão.

Park; Hur e Rhee (2002) utilizaram a densimetria e a viscosimetria para obter em linha as medidas de densidade e viscosidade de copolímeros de metacrilato de metila / acrilato de butila produzidos durante reações de polimerização em solução. As medidas obtidas foram utilizadas como entradas de um filtro de Kalman estendido responsável pela predição da composição e do peso molecular médio mássico do polímero formado. As saídas do estimador de estado foram então utilizadas como entradas de um modelo de controle preditivo (MPC), responsável pelo ajuste da vazão de alimentação dos monômeros e da temperatura do reator, para a obtenção de polímeros com composição uniforme e com peso molecular médio mássico pré-especificado. 
Immanuel et al. (2003) estimaram a conversão e a composição de copolímeros de acetato de vinila / acrilato de butila utilizando as informações obtidas pela densimetria. As medidas de densidade do látex foram obtidas a partir da vibração de um tubo em $U$ durante a passagem do látex pelo densímetro. Uma parte da corrente de amostragem foi utilizada para medir a distribuição de tamanho de partículas através de um fracionador hidrodinâmico capilar (CHDF). O objetivo final do trabalho era estudar os mecanismos de evolução da distribuição de tamanho de partículas e demostrar a evolução das distribuições multimodais durante reações conduzidos em regime semicontínuo.

\subsection{2 Índice de refração}

Devido ao aumento do índice de refração do meio reacional durante uma reação de polimerização, as medidas desta variável podem ser utilizadas para estimar a evolução da conversão.

Mignard et al. (2004) estimaram em linha o peso molecular médio mássico, a viscosidade intrínseca média mássica, as composições acumuladas e instantâneas, e as concentrações individuais de estireno e n-acrilato de butila durante reações de copolimerização radicalar controlada mediante nitróxido (CRP), utilizando os sinais obtidos por espalhamento dinâmico de luz, índice de refração e espectroscopia de UV.

$\mathrm{Li}$ et al. (2006) monitoraram a evolução do índice de refração, da condutividade e da intensidade de luz espalhada durante reações de polimerização em microemulsão inversa de metacrilato de metila / ácido acrílico. Os resultados mostraram um aumento acentuado no índice de refração ao longo da reação. Por outro lado, apesar dos autores concluírem que estas técnicas podem ser empregadas para monitorar reações em microemulsão inversa, não apresentaram nenhum resultado adicional acerca da viabilidade de utilizar essas medidas para estimar outras propriedades como, por exemplo, a conversão. 


\subsubsection{Cromatografia em fase gasosa}

Apesar de ser uma técnica predominantemente utilizada para análises off line, a cromatografia em fase gasosa também pode ser empregada para inferir em linha a composição e as conversões globais e individuais a partir das concentrações de monômero residual e do balanço de massa.

Nos últimos anos, vários dispositivos voltados à utilização da cromatografia gasosa para o controle em linha das propriedades poliméricas foram desenvolvidos, fornecendo estimativas bastante precisas e confiáveis. Por outro lado, esta técnica apresenta ainda uma série de desvantagens, descritas a seguir, que podem dificultar a sua implementação:

i) necessidade de instalação de sistemas de amostragem e diluição de amostras que podem ser custosos em termos de tempo e instalação;

ii) as análises fornecem apenas medidas discretas e, portanto, algoritmos avançados de controle, tolerantes à presença de tempo morto, devem ser implementados;

iii) possibilidade de entupimentos das bombas e dos circuitos utilizados no sistema de amostragem, devido à formação de coágulos, requerendo, portanto, sua limpeza periódica para remoção de eventuais depósitos de polímero;

iv) mudanças na formulação como, por exemplo, aumento acentuado do teor de sólidos ou troca dos monômeros, requerem novas condições de operação do cromatógrafo e, consequentemente, novas curvas de calibração devem ser obtidas.

Para contornar os problemas relacionados à possibilidade de entupimentos do circuito de amostragem e, ao mesmo tempo, aumentar a freqüência das análises, Othman(2000) observa que alguns trabalhos da literatura têm proposto o uso das análises cromatográficas da fase gasosa do reator para estimar a concentração residual dos monômeros presentes na fase líquida. Entretanto, a autora observa que este enfoque requer um modelo de equilíbrio termodinâmico líquido-vapor adequado 
e o conhecimento preciso dos coeficientes de partição dos monômeros entre as diferentes fases.

Dimitratos et al. (1991) utilizaram a cromatografia em fase gasosa para estimar em linha as concentrações residuais de monômeros presentes no reator durante reações de copolimerização em emulsão de acetato de vinila / acrilato de butila, conduzidos em regime semi-contínuo, e com diferentes taxas de alimentação de reagentes. As concentrações residuais dos comonômeros obtidas por esta técnica, por sua vez, foram usadas em um filtro de Kalman estendido adaptativo para estimar a concentração destes compostos nas partículas poliméricas e a composição do copolímero.

Leiza et al. (1993a) desenvolveram um sistema automático à vácuo para a diluição de amostras antes destas serem analisadas em linha por um cromatógrafo em fase gasosa. Posteriormente, Leiza et al. (1993b) utilizaram este mesmo sistema para o controle em malha fechada da composição de copolímeros formados durante reações semicontínuas em emulsão de acrilato de etila / metacrilato de metila. A estratégia de controle foi baseada na aplicação conjunta de um controlador adaptativo não-linear e de um controlador proporcional-integral (PI). A composição foi estimada através de um filtro de Kalman estendido em função das concentrações residuais de monômeros obtidas em linha pela cromatografia.

Urretabizkaia; Leiza e Asua (1994) utilizaram o sistema de amostragem desenvolvido por Leiza et al. (1993a) para implementar estratégias de controle em malha fechada e em linha da composição de terpolímeros obtidos durante reações semicontínuas em emulsão de acetato de vinila / metacrilato de metila / acrilato de butila com altos teores de sólidos (55\%). As estimativas das concentrações residuais de monômeros foram obtidas a partir de um algoritmo de otimização não-linear. Estas estimativas, por sua vez, são utilizadas em um controlador adaptativo nãolinear acoplado a um controlador proporcional-integral para estimar a vazão ótima do monômero mais reativo que permita a obtenção de terpolímeros com uma composição pré-determinada. 


\subsubsection{Ultrassom}

O interesse pela interação entre ondas acústicas e sistemas particulados remontam desde o século 19 a partir dos primeiros trabalhos realizados por Rayleigh. Este interesse tem se intensificado nas últimas cinco décadas devido, principalmente, aos avanços da eletrônica e da instrumentação, o que tem possibilitado a utilização intensiva do ultrassom na caracterização de misturas coloidais tanto em processos de escala laboratorial quanto de escala industrial.

Essa técnica é baseada nas medidas da velocidade e da atenuação de ondas sonoras de alta frequência ao passar através da amostra. Portanto, a caracterização de misturas coloidais a partir das medidas de velocidade de propagação ultrassônica requer uma base teórica formal que correlacione as propriedades da mistura, particularmente a distribuição de tamanhos de partículas, e complexas equações de número de ondas que governam a propagação destas pelo meio coloidal.

Recentemente, Dukhin et al. (2000) e Challis et al. (2005) publicaram uma revisão bastante detalhada sobre os principais conceitos teóricos e modelos envolvidos na caracterização das dispersões coloidais e as principais perspectivas e tendências futuras da aplicação dessa técnica. Basicamente, o enfoque principal destas revisões foi voltado à utilização das medidas de velocidade ultrassônica para a estimação da distribuição de tamanhos de partículas em meios coloidais, e em demonstrar como os efeitos dinâmicos do sistema como, por exemplo, floculação e cristalização, podem ser observados e modelados a partir dessa técnica.

Para sistemas em emulsão, as medidas da velocidade ultrassônica são obtidas através da técnica do pulso viajante, que consiste em medir o tempo necessário para que um pulso acústico viaje entre dois cristais piezoelétricos (transdutores) posicionados a uma distância fixa. Como em sistemas homogêneos, a velocidade de propagação depende do inverso da raiz quadrada do produto entre a densidade e a compressibilidade, e como ambas variam ao longo da reação de polimerização, é possível correlacionar a velocidade de propagação da onda com a conversão dos monômeros.

Segundo Othman (2000) as medidas de velocidade de propagação ultrassônica foram inicialmente utilizadas para estimar determinadas propriedades 
dos látices como, por exemplo, a solubilidade dos monômeros nas partículas poliméricas e a concentração micelar crítica, sendo apenas recentemente utilizadas para monitorar a evolução da conversão.

Bond et al. (2003) agruparam as técnicas ultrassônicas em quatro grupos principais de acordo com a configuração dos transdutores. Estas configurações podem ser implementadas em diversos sistemas, utilizando-se um ou dois transdutores, para os casos mais simples, ou vários transdutores simultaneamente, para os casos mais complexos. De acordo com essa classificação, as reações de polimerização, em suspensão ou emulsão, podem ser monitoradas pela técnica de transmissão ultrassônica, na qual é possível estimar as concentrações dos diferentes compostos presentes em um sistema multicomponente, assim como a distribuição de tamanho de partículas.

Zeilmann; Lavanchy e Meyer (2001) utilizaram as medidas da velocidade de propagação ultrassônica para monitorar em linha a conversão de homopolímeros de metacrilato de metila obtidos durante reações de polimerização com elevado teor de sólidos e conduzidos em um reator tubular operando em regime contínuo.

Além das aplicações usuais (monitoramento da conversão e da distribuição de tamanho de partículas), ultrassons de alta frequência também têm sido utilizados em alguns trabalhos para iniciar reações de polimerização a baixas temperaturas. Esta técnica foi utilizada por Price; Norris e West (1992) para iniciar reações de polimerização de metacrilato de metila e obter polímeros com propriedades prédeterminadas como, por exemplo, peso molecular, polidispersividade e taticidade. Embora polímeros com elevados pesos moleculares tenham sido obtidos, os autores verificaram que a principal limitação dessa técnica são as baixas conversões obtidas. Além disso, a incidência de ultrassom de alta frequência pode, eventualmente, causar a degradação das cadeias poliméricas.

Quando comparada à densimetria, as principais vantagens dessa técnica são a rapidez na aquisição de dados, as medidas são pouco afetadas pelas condições operacionais, e não é necessária a retirada de amostras e a instalação de loops, pois as medidas são coletadas in situ. No entanto, essa técnica requer extensivas calibrações a cada mudança na composição do copolímero. 


\subsubsection{Técnicas espectroscópicas}

Nas últimas décadas, o desenvolvimento de sondas capazes de coletar dados espectroscópicos remotamente através do uso de fibras ópticas, tem contribuído para o aumento das possibilidades de utilização de técnicas de monitoramento in situ mais robustas, mesmo em ambientes insalubres ou de difícil acesso, e a coleta simultânea de dados em diferentes pontos do processo, uma vez que a instalação destas sondas não demanda muito tempo e nem modificações caras no processo.

O fundamento básico da espectroscopia consiste em excitar a substância analisada, através da incidência de uma fonte de radiação, com o objetivo de provocar uma alteração do estado energético dos seus átomos ou moléculas. Como cada átomo, ou molécula, absorve, ou emite, uma radiação característica, os espectros resultantes tornam-se verdadeiras impressões digitais do material analisado e, portanto, as análises de tais espectros permitem identificar e quantificar importantes informações acerca do estado e da natureza das amostras analisadas.

Didaticamente, a espectroscopia pode ser dividida em três grupos: a) espectroscopia molecular, na qual se destacam a espectroscopia de ultravioleta visível (UV/Vis), infravermelho (IR), ressonância magnética nuclear (NMR) e Raman; b) espectroscopia atômica composta pela espectroscopia de fluorescência, espectroscopia de absorção atômica e espectroscopia de emissão atômica por plasma induzido (ICP-AES); e c) espectroscopia de massas, na qual são obtidos espectros não no sentido estrito da palavra, ou seja, espectros resultantes da interação entre a matéria e uma fonte de radiação, mas os espectros da massa de um analito obtidos após a amostra analisada passar pelas etapas de ionização, aceleração, separação e detecção.

A seguir é apresentado um breve resumo das principais técnicas espectroscópicas (fluorescência, UV, IR e Raman) utilizadas para a caracterização dos materiais poliméricos, ou para o monitoramento de reatores de polimerização, e, em seguida, são apresentados alguns trabalhos da literatura nos quais estas técnicas foram implementadas.

A) ESPECTROSCOPIA DE FLUORESCÊNCIA: esta técnica é baseada na análise do espectro de radiação emitido (fluorescência) durante o retorno de uma 
espécie excitada eletronicamente ao seu estado fundamental. Quando o estado excitado é um singleto, ou seja, o spin do elétron no orbital excitado mantém a orientação original, a luminescência molecular é denominada fluorescência. Entretanto, se a orientação do spin do elétron no orbital excitado é invertida, tem-se um estado excitado tipo tripleto e, neste caso, a luminescência molecular é chamada fosforescência. Em consequência da regra da conservação do spin, as transições radioativas de um elétron que se encontra em estado excitado singleto para o estado fundamental são transições permitidas e, portanto, estas transições ocorrem em curtos intervalos de tempo (da ordem de ns). Em contrapartida, os decaimentos radioativos de um estado excitado tripleto para o estado fundamental são proibidos pela regra da conservação do spin, tornando a fluorescência um fenômeno luminescente mais comum que a fosforescência. Três importantes parâmetros intrinsecamente relacionados tanto à fluorescência quanto à fosforescência são: o comprimento de onda de excitação; o comprimento de onda de emissão máximo (sensível à polaridade do meio); e a intensidade da emissão. A detecção dos espectros de fluorescência é feita através de um espectrofluorímetro com sondas que não sejam potencialmente reativas ,ou seja, que não reajam com os radicais vivos produzindo produtos fluorescentes.

B) ESPECTROSCOPIA DE ULTRAVIOLETA: a espectroscopia de reflexão do ultravioleta tem sido explorada como um método alternativo para o monitoramento de sistemas poliméricos com baixo rendimento quântico e, portanto, apresenta aplicabilidade limitada. Nesta técnica, os espectros são obtidos a partir da quantificação de luz absorvida pela amostra. A absorção, ou transmitância, de uma amostra é obtida quando um feixe de luz ultravioleta, com um determinado comprimento de onda, atravessa a amostra provocando a transição de elétrons entre os orbitais moleculares.

C) ESPECTROSCOPIA DE INFRAVERMELHO: a espectroscopia de infravermelho (IR) é uma das técnicas mais conhecidas e comumente utilizadas para obter, em tempo real, informações estruturais ou cinéticas de composto orgânicos e inorgânicos, sem a necessidade de técnicas de amostragem complicadas, já que a aquisição dos espectros processa-se pela simples inserção de uma sonda no meio reacional. Esta técnica é baseada na interação entre uma radiação eletromagnética da região do infravermelho (número de onda entre $13000 \mathrm{~cm}^{-1}$ à $10 \mathrm{~cm}^{-1}$ ) com espécies que apresentem momento dipolar permanente, ou induzido, e diferentes 
tipos vibracionais quando em estado excitado. Quando a vibração molecular resulta em uma mudança do momento dipolar da molécula, a radiação infravermelha é absorvida, provocando a transição da molécula do seu estado fundamental para um nível energético maior.

D) ESPECTROSCOPIA RAMAN: a espectroscopia Raman é baseada na análise do espalhamento inelástico de luz quando um fóton, com um comprimento de onda bem definido, atinge uma molécula. Após a colisão, grande parte da radiação é espalhada elasticamente (espalhamento Rayleigh), ou seja, não há mudança no nível vibracional da molécula e, portanto, a frequência da radiação espalhada é a mesma da radiação incidente. Por outro lado, uma pequena fração dos fótons é espalhada inelasticamente devido à transição vibracional da molécula e, portanto, a frequência da radiação espalhada é diferente daquela incidente. Neste último caso, se há uma perda global de energia devido a transição vibracional da molécula para um nível vibracional maior, o espalhamento é chamado espalhamento Stokes-Raman. Em contrapartida, se a colisão resultar em um ganho global de energia devido à vibração molecular, o estado vibracional resultante é menor do que o estado vibracional inicial e, portanto, tem-se um espalhamento inelástico antiStokes-Raman. Embora o efeito Raman seja conhecido desde o começo do século passado, o seu uso efetivo como técnica analítica tem sido explorado apenas nas últimas décadas. A principal razão deste atraso é atribuída à baixa quantidade de fótons espalhados inelasticamente, especialmente à baixas concentrações, e, portanto, a sua detecção requer sensores extremamente sensíveis e uma sofisticada instrumentação, que só foram desenvolvidos recentemente.

\subsubsection{Técnicas espectroscópicas: Aplicações}

Pekcan; Yilmaz e Okay (1997) usaram a espectroscopia de fluorescência para monitorar, em tempo real, as taxas de polimerização de metacrilato de metila usando o pireno como sonda de fluorescência. $O$ objetivo das análises foi verificar o início do efeito gel, à diferentes temperaturas, durante uma reação de polimerização em massa. De acordo com os autores, o início do efeito gel é caracterizado por um súbito aumento da intensidade de fluorescência normalizada do pireno. Este 
aumento é justificado pela baixa concentração de monômeros e pelo aumento da rigidez do meio reacional, causando, consequentemente, a diminuição da mobilidade do pireno e minimizando possíveis interações entre esta molécula com outros compostos, ou ainda o esmaecimento dos espectros da sonda de fluorescência frente aos espectros das demais moléculas presentes no meio reacional. Apesar dos resultados obtidos pelos autores terem demostrado a viabilidade da aplicação da espectroscopia de fluorescência para o monitoramento das taxas de polimerização e para a predição do início do efeito gel, a lista de monômeros vinílicos que apresentam absorção ultravioleta e/ou características fluorescentes não é extensa, limitando o uso dessa técnica a um grupo restrito de compostos.

Rudschunk; Adams e Fuhrmann (1998) aplicaram a espectroscopia de fluorescência para analisar os fenômenos dinâmicos que ocorrem dentro de partículas poliméricas obtidas durante reações de polimerização em emulsão na ausência de emulsificantes, e se, e como, o efeito gel pode ser analisado em linha por esta técnica durante reações de polimerização em massa.

Miguel et al. (2001) usaram diferentes sondas de fluorescência para analisar a formação de micelas, a formação de zonas hidrofóbicas, tamanho e forma dos agregados de surfactantes, e a associação, intra e intermolecular, entre as moléculas de surfactantes e as cadeias poliméricas. De acordo com os autores, uma das grandes vantagens da fluorescência é a possibilidade de deteç̧ão de microregiões hidrofóbicas e a observação da formação de diferentes agregados. Desta forma, através do uso de uma sonda apropriada e da análise das variáveis espectroscópicas obtidas como, por exemplo, o rendimento quântico de emissão ou o tempo de vida, torna-se possível identificar a concentração na qual as micelas começam a se formar.

Mikes et al. (2002) propuseram um novo método para monitorar in situ e em linha reações de cura de uma mistura de diglicidil éter de bisfenol-A (DGEBA) com nbutil amina, N-metil-etileno-diamina e etilenodiamina. Este método é baseado no cálculo do momento de primeira ordem das bandas de fluorescência, na presença de pireno, para acompanhar a evolução da conversão dos grupos funcionais presentes nestas reações de polimerização.

Baldi e Atvars (2005) utilizaram a espectroscopia foto-estacionária e de decaimento da fluorescência, usando a escala do pireno, para avaliar a polaridade superficial de diversos tipos de náilons obtidos durante reações de policondensação. 
Os autores observaram que tanto os espectros de fluorescência quanto o tempo de meia vida do pireno são propriedades fotofísicas dependentes da polaridade do náilon, permitindo a classificação destes materiais a partir da análise da razão entre a intensidade das bandas vibrônicas e o tempo de meia vida.

Santos; Lima e Pinto (1998) avaliaram a influência do tamanho médio das partículas de poliestireno sobre os espectros do infravermelho próximo coletados durante reações de polimerização em suspensão. Como resultado, os autores verificaram que os espectros NIR são sensíveis às variações do tamanho médio das partículas, permitindo o monitoramento e controle in line desta variável.

Vieira et al. (2002a) usaram a espectroscopia de infravermelho próximo para estimar, em linha e in situ, a concentração residual de monômeros e a concentração de polímeros durante reações semicontínuas de copolimerização em emulsão de metacrilato de metila / acrilato de butila. As predições de ambas as variáveis foram obtidas a partir de modelos de calibração independentes, confeccionados a partir dos espectros de doze reações agrupadas em três conjuntos de acordo com critérios heurísticos. Todas as formulações foram elaboradas para resultar em um teor de sólidos final de $30 \%$ a fim de evitar a formação de filme sobre a sonda. Posteriormente, Vieira et al. (2002b) utilizaram estes modelos para implementar estratégias de controle, em malha fechada e baseadas em um algoritmo de programação iterativa dinâmica (IDP), para controlar a composição e o peso molecular médio mássico. Além disso, para verificar a capacidade preditiva e a aplicabilidade desta técnica em uma situação real, distúrbios no processo foram introduzidos durante as reações. Nestas condições, os autores verificaram que estes distúrbios não causaram maiores problemas sobre as predições, comprovando a viabilidade de implementação da espectroscopia de infravermelho próximo em um processo industrial.

Reis et al. (2004a) utilizaram a espectroscopia do infravermelho próximo para monitorar simultaneamente a concentração residual de monômeros, a conversão, a composição, e o diâmetro médio de partículas de copolímeros obtidos durante reações semicontínuas em emulsão de estireno / acrilato de butila. O modelo de calibração foi obtido a partir dos espectros de um conjunto de nove reações, envolvendo o mesmo par de monômeros. Cinco destas reações foram usadas para a obtenção do modelo de calibração multivariada, enquanto os espectros das quatro reações restantes foram utilizados para validar o modelo 
obtido. Os resultados mostraram que, apesar da predição do tamanho médio das partículas estar mais sujeita a falhas devido a possíveis distúrbios ou coalescência de partículas, é possível monitorar simultaneamente diferentes variáveis de estado do processo a partir dos espectros do infravermelho próximo.

Reis et al. (2003) avaliaram a influência do tamanho médio das partículas de poliestireno, obtidos em emulsão, sobre os espectros Raman coletados em um curto intervalo de tempo para minimizar os efeitos de eventuais ruídos. Para assegurar que o modelo de calibração fosse capaz de estimar o diâmetro médio das partículas poliméricas independentemente do teor de sólidos, foram utilizados espectros de um conjunto de amostras diluídas e com o mesmo teor de sólidos (aproximadamente $7,2 \%$ ), e espectros de um conjunto de amostras obtidas durante uma reação usual de polimerização em emulsão. Os resultados mostraram que é possível correlacionar o espalhamento Raman com a evolução do diâmetro das partículas, abrindo a possibilidade de implementação de estratégias de controle em malha fechada desta variável. Uma descrição detalhada com relação ao tratamento estatístico utilizado nos dois trabalhos citados anteriormente, é apresentada por Reis et al. (2007).

Reis et al. (2004b) compararam diferentes modelos de calibração para a predição em linha das concentrações de acetato de vinila e acrilato de butila presentes no meio reacional durante reações semicontínuas de copolimerização em emulsão. Os modelos de calibração foram obtidos a partir dos espectros Raman coletados de amostras sintéticas que fossem capazes de mimetizar as diversas variabilidades presentes em um processo usual de polimerização em emulsão. As limitações dos modelos são discutidas em termos das complexidades do processo, principalmente, aquelas decorrentes da sobreposição dos espectros Raman de ambos os monômeros. Os autores observaram que as predições obtidas apresentaram resultados bastante satisfatórios, mesmo à baixas concentrações de acrilato de butila. Segundo Reis et al. (2004b), a boa capacidade preditiva desses modelos é atribuída ao número de scans usado durante a coleta dos espectros das amostras sintéticas, maior do que aquele normalmente usado em um processo real.

Elizalde; Asua e Leiza (2005a) utilizaram a espectroscopia Raman para monitorar em linha a conversão e a composição acumulada de copolímeros obtidos durante reações semicontínuas em emulsão de acrilato de butila / metacrilato de metila, com alto teor de sólidos e conduzidas sob condições de avidez de 
monômeros. O modelo de calibração foi elaborado a partir dos espectros obtidos de amostras coletadas ao longo do processo, sobre os quais são aplicadas técnicas quimiométricas, uma vez que há uma sobreposição de espectros de ambos os monômeros devido a similaridade das estruturas químicas.. A curva de calibração obtida apresentou boa capacidade preditiva, mesmo sob condições de avidez de monômeros.

Elizalde et al. (2005b) compararam o desempenho da calorimetria e da espectroscopia Raman para o monitoramento em linha da conversão e da concentração residual de monômeros de reações de copolimerização em emulsão, com alto teor de sólidos e sob condição de avidez e não-avidez de monômeros. Os resultados gravimétricos e cromatográficos foram utilizados como referências externas para a obtenção de um modelo de calibração que permitisse a predição das variáveis analisadas em função dos espectros coletados. Sob condições de nãoavidez, os autores observaram que, devido à presença de gotas de monômeros durante as análises cromatográficas, as concentrações residuais de monômeros, experimental e predita por ambas as técnicas, apresentaram um ligeiro desvio durante os instantes iniciais de reação. Adicionalmente, os resultados obtidos para este sistema mostraram que os espectros Raman são fortemente afetados pela coalescência das partículas. Sob condições de avidez de monômeros, os autores concluíram que a calorimetria fornece predições bastante pobres, principalmente, com relação à concentração residual de monômeros. Segundo os autores, esta imprecisão é inerente da calorimetria e tende a se acentuar em reações com conversões instantâneas elevadas, uma vez que não é possível quantificar de forma direta a concentração de monômeros por esta técnica.

\subsection{Conclusões Parciais}

Apesar de grande parte dos produtos poliméricos atualmente conhecidos serem considerados commodities, as necessidades do mercado e a adoção de regulamentações ambientais cada vez mais restritivas têm contribuído continuamente para o desenvolvimento de novas técnicas analíticas que, além de 
permitirem a melhoria dos processos já existentes e uma melhor compreensão de como a estrutura molecular dos polímeros influencia as propriedades finais, permitiram a implementação de técnicas de monitoramento e controle em tempo real cada vez mais robustas.

Entretanto, apesar das inúmeras vantagens proporcionadas pelas metodologias analíticas voltadas ao monitoramento e controle em linha dos reatores de polimerização, em uma revisão publicada por Embiruçu; Lima e Pinto (1996) foi demonstrado que existe uma enorme lacuna entre a pesquisa acadêmica e a prática industrial e, que de acordo com Richards e Congalidis (2006), pode ser atribuída aos seguintes fatores:

i) Grande parte das técnicas de monitoramento off line e em linha são voltadas à caracterização das propriedades dos materiais poliméricos comumente encontradas no mercado, enquanto poucas são voltadas à caracterização de materiais poliméricos mais especializados, que são cada vez mais importantes em aplicações de alto valor agregado como a indústria eletrônica. É quase certo que a implementação de técnicas de monitoramento mais robustas irá aumentar o desempenho dos sistemas de controle. Embiruçu; Lima e Pinto (1996) observaram que a implementação de estratégias avançadas de controle, para a área de engenharia de reações de polimerização, requer inicialmente a melhoria das técnicas de monitoramento e de estimação de estados.

ii) O desenvolvimento de modelos matemáticos adequados aos propósitos de controle é um desafio, devido à complexidade das cinéticas das reações de polimerização e do meio reacional, que pode ser homogêneo ou heterogêneo, ou caracterizado por zonas de estagnação devido à má agitação. Essas caracteristícas dos processos em emulsão fazem com que nem sempre seja óbvio que a complexidade apropriada do modelo, ou a melhor forma de identificar os parâmetros do modelo, ou a forma como as medidas disponíveis são integradas aos modelos serão suficientes para estimar os estados desconhecidos do processo.

iii) O aumento na demanda por produtos poliméricos com propriedades cada vez mais estritas é um poderoso incentivo econômico para a implementação de técnicas de monitoramento e controle em tempo real, 
especialmente se ambas as técnicas forem também utilizadas para a melhoria das condições de segurança e operabilidade da planta e para a minimização das perdas materiais durante as mudanças de grades ou decorrentes da necessidade de reprocessamento do material fora de especificação.

iv) Adicionalmente, espera-se que as técnicas de monitoramento e controle em linha permita não apenas o controle das propriedades médias dos materiais poliméricos mas também o controle da distribuição completa como, por exemplo, o controle da distribuição do tamanho de partículas e da distribuição das ramificações.

Diante do exposto anteriormente, fica claro que a implementação de metodologias voltadas ao monitoramento e controle das propriedades poliméricas, necessárias para atender as principais necessidades dos fabricantes, ainda é uma área aberta e com diversos desafios tanto para investigação acadêmica quanto para as indústrias. 


\section{OBSERVADORES DE ESTADO}

Esta seção é dedicada exclusivamente a apresentar uma revisão de trabalhos da literatura relacionados à aplicação de observadores de estado para a obtenção das variáveis-chave de um processo químico, mais especificamente de reações de polimerização. Inicialmente é apresentada uma breve introdução com uma visão geral dos principais tipos de observadores e os requisitos básicos para o projeto e aplicação desta metodologia de estimativa. Em seguida, a discussão estará centrada no uso e nas limitações do observador mais utilizado para estimar o estado de um processo químico (Filtro de Kalman estendido). Para finalizar, serão apresentados o desenvolvimento de um observador de estado não-linear de alto ganho, e os principais conceitos e definições necessários para a formalização matemática do projeto deste tipo de observador.

\subsection{Introdução}

A ausência de uma instrumentação robusta e de baixo custo capaz de medir em linha as variáveis de estado chave de muitos processos químicos, tem sido o principal obstáculo para 0 desenvolvimento de estratégias de controle retroalimentado (feedback contro). Esta dificuldade decorre, principalmente, da nãolinearidade da maioria destes processos e a natureza altamente acoplada das variáveis de estado. Além disso, atualmente muitos processos químicos têm se tornado cada vez maiores e mais complexos como, por exemplo, os processos de polimerização onde a qualidade do produto formado é extremamente dependente das condições operacionais e obtida em um curto espaço de tempo, necessitando, portanto, de sensores em linha suficientemente rápidos para monitorar, detectar possíveis falhas e implementar as ações de controle adequadas.

Uma alternativa viável e amplamente utilizada para contornar estes problemas e que explora, simultaneamente, o uso de modelos em conjunto com um número limitado de medidas, são os software sensors (ou sensores virtuais) que 
podem ser definidos como uma associação entre um sensor (hardware) e um observador ou um estimador de estado (software).

Observadores de estado são, basicamente, sistemas dinâmicos compostos pelo modelo do processo e um termo corretivo proporcional à diferença, ponderada pelo ganho do observador, entre as variáveis de saída e suas estimativas, desenvolvidos para estimar, sequencialmente e assintoticamente, o estado de um processo, utilizando apenas as informações das medidas de entrada e de saída. Adicionalmente, quando as condições de observabilidade são satisfeitas e quando os vetores de ganho são ajustados adequadamente, os observadores convergem rapidamente ao estado real do processo, diminuindo o tempo computacional necessário para a integração das equações diferenciais do sistema dinâmico.

De acordo com Dochain (2003) os observadores de estado comumente aplicados em processos químicos e bioquímicos podem ser agrupados, basicamente, em duas classes principais. A primeira classe é composta pelos chamados observadores exponenciais, na qual estão incluídos os clássicos observadores tipo Kalman e Luenberger aplicados tanto para sistemas lineares quanto para sistemas não-lineares. Neste último caso, os observadores são obtidos a partir da linearização do sistema em torno de uma trajetória de referência e, portanto, a estabilidade e a convergência são válidas apenas localmente em torno de um ponto de equilíbrio (KAZANTZIS; KRAVARIS; WRIGHT, 2000). A principal desvantagem desse grupo é que eles são desenvolvidos partindo-se do princípio que o modelo do processo é exato e, portanto, são pouco tolerantes à presença de incertezas nos parâmetros do modelo que, caso estejam presentes, podem resultar na presença de bias durante a estimativa das variáveis desconhecidas. O segundo grupo é composto pelos chamados observadores assintóticos que, assim como os observadores do grupo anterior, são obtidos a partir do balanço de massa e energia do sistema analisado, porém estes, diferentemente daqueles, são mais tolerantes à presença de incertezas no modelo cinético do processo. Uma potencial desvantagem dos observadores assintóticos está relacionada à forte dependência da velocidade de convergência em relação às condições operacionais. As limitações e potenciais dos principais observadores e estimadores de estado foram revistos e discutidos por Soroush (1998).

Portanto, a aplicação de observadores de estado, principalmente os observadores exponenciais, e a qualidade das estimativas das variáveis 
desconhecidas dependem da disponibilidade de modelos matemáticos suficientemente representativos e precisos, da disponibilidade de medidas pouco corrompidas pela presença de ruídos e da disponibilidade dos parâmetros, físicos ou cinéticos, do fenômeno modelado. Adicionalmente, a aplicação desta metodologia para a predição das variáveis de estado de um reator químico requer que três pontos importantes sejam levados em conta, conforme enumerados por Kozub e MacGregor (1992a):

i) a não-linearidade e as contínuas mudanças das condições do reator não podem ser ignoradas;

ii) os estimadores de estado devem ser formulados de tal modo que as variáveis de estado possam ser estimadas sem a presença de bias e com a presença de distúrbios inesperados no processo que possam eventualmente ocorrer durante a sua implementação;

iii) para reações de curta duração, a velocidade de convergência do estimador de estado na presença, ou ausência, de erros de inicialização do observador é um ponto crítico.

Embora um número considerável de modelos tenham sido testados e validados, modelar um processo de polimerização em emulsão apresenta ainda uma série de dificuldades, principalmente, quando os modelos envolvem propriedades de interesse industrial como, por exemplo, composição, distribuição de pesos moleculares e distribuição de tamanho de partículas, dificultando, ou até mesmo inviabilizando, a predição em malha aberta destas variáveis. Estas dificuldades advêm, em grande parte, da complexidade das leis físicas que governam o transporte das espécies reagentes da fase aquosa para a fase orgânica; da dificuldade em obter uma relação quantitativa entre a taxa de polimerização, o coeficiente de partição dos monômeros e os fenômenos de entrada e de saída de radicais; da influência dos emulsificantes e das forças iônicas da fase contínua sobre a estabilidade das partículas; e da dificuldade em obter determinados parâmetros do processo.

Grande parte dos modelos e correlações propostos para a estimação dos parâmetros cinéticos de um processo de polimerização, incluindo Adams et al. (1988), Brandrup e Immergut (1989), Casey; Morrison e Gilbert (1993), Gilbert 
(1995), Dubé et al. (1997), Gao e Penlidis (2002), Russell (2002) e Fan et al. (2003), envolvem diversos parâmetros não estacionários e incertos. Ao mesmo tempo, uma boa parte das variáveis utilizadas nestes modelos são bastante sensíveis às condições iniciais, que nem sempre são conhecidas a priori, e à presença de distúrbios aleatórios como, por exemplo, a presença de traços de inibidores. Dessa forma, a implementação de observadores de estado em um processo de polimerização requer cuidados adicionais de modo a assegurar a qualidade das estimativas das propriedades poliméricas.

\subsection{Filtro de Kalman estendido: aplicações}

Entre os diversos métodos disponíveis para a estimação de estados, o filtro de Kalman estendido (EKF) tem sido um dos métodos mais utilizados em reatores de polimerização. Uma das razões para a popularidade do EKF é atribuída à facilidade de implementação deste método, uma vez que o algoritmo pode ser obtido diretamente dos modelos de espaço de estados.

O filtro de Kalman estendido pode ser definido como um filtro recursivo, baseado na solução dinâmica da equação de Riccatti, usado para estimar as variáveis de estado de um sistema dinâmico não-linear governado por equações estocásticas e com presença de ruídos gaussianos nas variáveis de entrada. Este método é uma extensão direta do filtro de Kalman, na qual a estimativa de um estado, em um instante imediatamente posterior, é obtida pela linearização das funções do processo e das medidas de saída em torno dos valores da média e da covariância do estado atual.

Kozub e MacGregor (1992a) observam que apesar da base teórica do filtro de Kalman estendido ser bem compreendida atualmente, a sua aplicação em casos concretos gera ainda uma série de dúvidas. De acordo com os autores, um erro recorrente é negligenciar a incorporação de distúrbios não-estacionários, e/ou parâmetros de estado adequados, e que são necessários para eliminar a presença de bias nas variáveis estimadas de estado quando há a presença de erros de modelagem ou distúrbios desconhecidos no processo. Como resultado, fazendo 
uma analogia com a teoria de controle, obtém-se um tipo de estimador de estado "proporcional" sem nenhuma ação "integral" que elimine a presença de tais bias.

Como o filtro de Kalman estendido não é utilizado neste trabalho, a revisão bibliográfica se limita a apresentar apenas alguns trabalhos da literatura, nos quais este filtro e suas variações são aplicados para o monitoramento em linha de diversas propriedades poliméricas. Detalhes adicionais quanto ao formalismo matemático e limitações, podem ser encontrados na literatura especializada.

Schuler e Suzhen (1985) utilizaram o filtro de Kalman estendido para obter, em tempo real, a distribuição do tamanho de cadeias poliméricas de poliestireno produzidas durante reações em solução. A temperatura do processo e o índice de refração do meio reacional foram usados como medidas de entrada do filtro. A estimativa a priori da variável de estado foi obtida a partir de um modelo detalhado do processo, enquanto um modelo mais simples foi utilizado para obter as estimativas a posteriori. Os autores observaram que determinados termos do modelo podem ser omitidos sem afetar de forma significativa o desempenho e a capacidade preditiva do filtro.

Dimitratos et al. (1988) utilizaram um filtro de Kalman estendido adaptativo para estimar, simultaneamente e em linha, as variáveis de estado e o vetor de covariância do ruído de um processo semicontínuo de copolimerização em emulsão de acetato de vinila / n-acrilato de butila. A estimativa da concentração de cada comonômero na fase polimérica, obtida através do filtro, foi usada como entrada de um controlador feedforward / feedback responsável em manter a composição do copolímero constante ao longo da reação.

Adebekun e Schork (1989) aplicaram o filtro de Kalman estendido para estimar os momentos da distribuição de pesos moleculares de polímeros de metacrilato de metila obtidos em solução, e analisaram, para vários casos, a viabilidade de implementar estratégias de controle baseadas nas estimativas fornecidas pelo filtro.

Dimitratos et al. (1991) aplicaram o modelo dinâmico e o filtro de Kalman estendido adaptativo desenvolvidos por Dimitratos et al. (1989) para obter as estimativas ótimas das variáveis de estado de um processo de copolimerização em emulsão de acetato de vinila / acrilato de butila, conduzido em regime semicontínuo, com presença de erros de modelagem, distúrbios de processo e um número limitado de medidas. A estimação ótima consiste em obter estimativas aceitáveis das 
variáveis de estado em situações nas quais determinados estados não possam ser quantificados diretamente, ou estejam sujeitos a erros aleatórios de medidas ou a distúrbios de processo. Além das concentrações globais dos monômeros no meio reacional e nas partículas, o filtro adaptativo proposto também foi capaz de estimar a evolução do número médio de radicais por partícula polimérica.

Kozub e MacGregor (1992a) investigaram, através de simulações, o desempenho de três estimadores não-lineares aplicados em reações de copolimerização em emulsão de estireno / butadieno, e com introdução de estados estocásticos para representar a possível presença de impurezas no meio reacional. O primeiro estimador analisado foi um filtro de Kalman estendido que, apesar da simplicidade de implementação, apresentou como principal desvantagem a baixa velocidade de convergência devido à natureza recursiva do algoritmo e aos desvios introduzidos nas estimativas iniciais dos parâmetros. Para melhorar a convergência, o filtro de Kalman original foi acoplado a um outro filtro de Kalman estendido responsável pela predição dos estados iniciais desconhecidos. Reiterando o primeiro filtro com as estimativas atualizadas dos estados iniciais fornecidas pelo segundo filtro, melhores taxas de convergência foram obtidas. O terceiro estimador analisado foi um algoritmo de otimização não-linear baseado na minimização de uma função objetivo obtida ao longo de um horizonte finito. A principal vantagem deste algoritmo de otimização, em relação ao filtro de Kalman estendido, é a menor quantidade de parâmetros de sintonia. Por outro lado, este enfoque supõe que o processo é isento de distúrbios e que os estados desconhecidos são estacionários no horizonte de otimização analisado, hipóteses nem sempre verificadas em um caso real. Dentre os três estimadores testados, o filtro de Kalman estendido reiterativo foi o que melhor se adaptou ao problema de polimerização estudado.

Posteriormente, Kozub e MacGregor (1992b) utilizaram o filtro de Kalman estendido reiterativo para estimar, através de simulações, diversas propriedades de copolímeros de estireno / butadieno produzidos durante reações semicontínuas em emulsão. As estimativas obtidas foram usadas como medidas de entrada de um algoritmo de controle responsável pela determinação dos perfis ótimos das variáveis manipuladas, pelo controle das propriedades instantâneas do copolímero, e pela correção de eventuais desvios nas trajetórias ótimas causados por condições operacionais não-ideais. 
Eliçabe et al. (1995) estimaram em linha as taxas de reação de três sistemas de copolimerização em emulsão, em função das concentrações residuais de monômeros e aplicando um filtro de Kalman estendido sobre um modelo simplificado do processo, contornando, desta forma, os problemas relacionados à ausência de modelos que correlacionem a taxa de polimerização com as concentrações de monômeros nas diferentes fases e com as taxas de entrada e saída de radicais. Os parâmetros de ajuste, gerados pela aplicação do filtro de Kalman, foram obtidos utilizando conceitos da teoria de controle e da teoria de sistemas.

Mutha; Cluett e Penlidis (1997) propuseram um novo estimador de estado para sistemas nos quais as informações e as medidas utilizadas pelo estimador apresentam diferentes tempos de amostragem. O algoritmo proposto é baseado em um filtro de Kalman estendido com suavização fixa da defasagem (fixed-lag smoothing). Como este algoritmo trabalha com diferentes tempos mortos, nenhuma informação é descartada e, portanto, o estimador pode ser implementado a qualquer instante, incluindo a etapa de partida. Uma reação de copolimerização em emulsão de acrilonitrila / butadieno foi utilizada como um estudo de caso para ilustrar o uso e o desempenho do estimador proposto.

Crowley e Choi (1998) utilizaram dois filtros de Kalman estendidos independentes para realizar estudos experimentais de controle ótimo das distribuições de pesos moleculares de homopolímeros de metacrilato de metila obtidas durante reações de polimerização em solução. O primeiro filtro foi implementado para estimar as variáveis de estado do processo a partir das medidas de temperatura e conversão obtidas a cada intervalo de 1 minuto. No segundo filtro, as medidas discretas dos pesos moleculares obtidas a partir de análises off line por cromatografia de permeação em gel (GPC), foram incorporadas para a predição dos momentos de ordem zero, um e dois. As principais vantagens do desacoplamento do filtro de Kalman em dois filtros independentes, quando medidas com longos e curtos tempos de aquisição estão presentes, são a redução da quantidade de cálculos das covariâncias e a simplificação da etapa de atualização do filtro, uma vez que a predição das variáveis de estado do processo é independente da disponibilidade das medidas com longo tempo de análise.

Shahrokhi e Fanaei (2001) aplicaram um filtro de Kalman estendido para a predição da conversão e dos pesos moleculares médio, mássico e numérico, de 
homopolímeros de metacrilato de metila obtidos durante reações de polimerização em suspensão. O desempenho do filtro foi analisado comparando-se os resultados, simulados e experimentais, obtidos na presença de diferentes graus de incertezas nos parâmetros do modelo e do processo.

Kiparissides et al. (2002) propuseram uma estratégia para o controle do peso molecular médio e para o controle da distribuição de pesos moleculares de polímeros produzidos durante um processo de polimerização via radicais livres, e sob a influência de parâmetros não-estacionários e condições iniciais desconhecidas. A estratégia de controle proposta combina um estimador de estado e de parâmetro com uma etapa de otimização que calcula, periodicamente, a temperatura ótima do processo a partir das informações obtidas em linha. A etapa de estimação inclui um filtro de Kalman estendido, responsável pela estimação das variáveis de estado e das constantes cinéticas de terminação, e um estimador baseado em um algoritmo de otimização não-linear, responsável pelo cálculo da concentração de impurezas presentes no começo da reação. A temperatura ótima de polimerização, responsável pela produção do polímero com a propriedade final desejada, foi determinada aplicando-se o método de colocação ortogonal sobre elementos finitos para a discretização das equações algébrico-diferenciais do processo em um sistema de equações algébricas.

Fontoura et al. (2003) utilizaram a espectroscopia de infravermelho próximo em conjunto com um filtro de Kalman estendido para monitorar e controlar, simultaneamente, a conversão e o peso molecular médio mássico de poliestireno obtidos durante reações semicontínuas de polimerização em solução. A estratégia de controle foi baseada na teoria de controle ótimo e consiste, basicamente, em dividir o tempo de reação em curtos intervalos de tempo e determinar a quantidade de iniciador que deve ser adicionada no início de cada intervalo, a temperatura neste intervalo e a duração de cada intervalo que minimiza o tempo total da reação e, ao mesmo tempo, assegure a obtenção das propriedades finais desejadas. A conversão e a concentração residual dos monômeros foram estimadas a partir dos espectros do infravermelho próximo e foram utilizadas como vetor de medidas de entrada do filtro de Kalman estendido.

Krämer et al. (2003) e Krämer e Gesthuisen (2005) propuseram a aplicação de um filtro de Kalman estendido para estimar, simultaneamente, o coeficiente de troca térmica e o calor gerado por uma reação semibatelada de polimerização, na 
qual a troca térmica, entre o reator e a camisa, seja dependente da viscosidade do meio reacional. A validação da estratégia proposta foi feita a partir dos resultados obtidos pela simulação de um modelo detalhado do processo e das equações tradicionalmente aplicadas em estudos calorimétricos. Segundo os autores, como ambas as variáveis desconhecidas são estimadas simultaneamente, a observabilidade global do sistema dinâmico e a estabilidade local do EKF são asseguradas.

Embora o filtro de Kalman estendido tenha sido aplicado com sucesso para vários casos, este enfoque apresenta ainda uma série de desvantagens que dificultam a sua implementação e são enumeradas por Astorga et al. (2002):

i) a convergência e a estabilidade do observador não são comprovadas teoricamente;

ii) a possibilidade da presença de bias imprevisíveis nas variáveis estimadas é o principal fator que tem impedido um uso mais intenso do EKF em muitos sistemas de monitoramento. A presença de eventuais bias não preditas ocorre, pois o filtro de Kalman supõe que o modelo do processo é exato e, portanto, o EKF não é capaz de contornar os problemas relacionados a erros na modelagem;

iii) presença de vários parâmetros de sintonia, relacionados com a matriz de covariância, cujos ajustes nem sempre é uma tarefa simples;

iv) a solução das equações do observador podem demandar um tempo computacional razoável, uma vez que a cada passo são integradas as matrizes de estado e de ganho do observador.

Além disso, Rawlings e Bakshi (2006) observam que o filtro de Kalman estendido é, na melhor da hipóteses, uma solução ad hoc para resolver um problema complicado e, portanto, a aplicação desta técnica em casos comumente encontrados em unidades industriais na área de processos químicos pode esconder diversas armadilhas e implicações como àquelas apontadas por Wilson; Agarwal e Rippin (1998).

Devido às limitações do filtro de Kalman estendido, recentemente outros observadores de estado têm sido propostos como, por exemplo, observadores de alto ganho para sistemas não-lineares com saída única, proposto por Bornad e 
Hammouri (1991) e Gauthier; Hammouri e Othman (1992). Esta abordagem supõe que o processo é observável para cada medida de entrada e que a mudança de coordenadas das variáveis de estado transforma o sistema original em um sistema canônico observável. Uma extensão dos observadores de alto ganho para sistemas não-lineares, com matriz dinâmica de estados e com múltiplas entradas e múltiplas saídas, foi proposta por Farza et al. (1997).

A estabilidade desse tipo de observador é teoricamente comprovada e sua robustez tem sido demonstrada através da sua aplicação em biorreatores por Gauthier; Hammouri e Othman (1992), em reatores químicos por Gibon-Fargeot; Hammouri e Celle (1994) e em reatores de polimerização por Févotte et al (1998).

$\mathrm{Na}$ subseção seguinte serão apresentados o desenvolvimento de um observador de estado não-linear tipo Luenberger e de um observador de estado não-linear de alto ganho, utilizados neste trabalho, e os principais conceitos e definições necessários para o projeto desses tipos de observadores.

\subsection{Observador não-linear tipo Luenberger e de alto ganho}

O observador de estado não-linear tipo Luenberger utiliza o modelo linear do processo obtido a partir de uma mudança nas coordenadas das variáveis de estado de tal forma que o sistema modificado torna-se linear na relação entre as variáveis de estado mantendo, porém, uma relação não-linear entre a entrada e a saída. Os conceitos básicos envolvidos na determinação dessa mudança de coordenadas são oriundos da Geometria Diferencial, um dos ramos da Teoria de Sistemas Não-Lineares.

Antes de iniciar o desenvolvimento dos observadores não-lineares de estado, tipo Luenberger e de alto ganho, e estabelecer as condições necessárias para o decaimento assintótico do erro na observação, é essencial apresentar os seguintes conceitos e definições da teoria de sistemas dinâmicos de interesse específico para o projeto de observadores de estado. 


\subsubsection{Representação em Espaço de Estados}

A primeira etapa para a implementação de estratégias efetivas de controle é a aquisição de informações confiáveis acerca do estado de um processo a fim de identificar as variáveis controladas e correlacionar as entradas e saídas do sistema. Dessa forma, na ausência de técnicas analíticas, a quantificação das variáveis de estado de um determinado processo deve necessariamente ser obtida através de modelos matemáticos.

Modelos de um processo são representações matemáticas obtidos a partir da aplicação de leis físicas, equações constitutivas, regras estatísticas, e relações empíricas ou semiempíricas dos elementos que compõem o sistema e que, em geral, conduz a um sistema de equações algébrico-diferenciais que correlacionam as variáveis de entrada, as medidas de saída e os estados internos do processo. Tal sistema de equações pode ser representado de três maneiras distintas: a) representação em Espaço de Estados; b) representação por equação I/O (entrada/saída); e c) representação por matriz de transferência.

A representação por Espaço de Estados é um enfoque mais moderno, que repousa sobre o conceito de variáveis de estado. Nesta representação, as variáveis de estado são expressas como vetores e as equações diferenciais e algébricas expressas na forma matricial. A representação por Espaço de Estados é uma forma conveniente e compacta para analisar sistemas com múltiplas entradas e múltiplas saídas e é particularmente útil na análise e no projeto de sistemas de controle. As principais características dessa classe de representação são:

i) são representados no domínio do tempo;

ii) podem ser usadas quaisquer condições iniciais;

iii) aplicabilidade mais ampla. Podem ser usados para descrever sistemas lineares e não-lineares; sistemas invariantes e variantes no tempo; e sistemas SISO (entrada única - saída única) e MIMO (múltiplas entradas múltiplas saídas);

iv) interpretação física mais abstrata. 
A representação de sistemas por equações dinâmicas, também chamada de descrição através de variáveis de estado ou espaço de estados, é a seguinte:

$$
\begin{aligned}
& \frac{d \mathbf{x}(t)}{d t}=\mathbf{f}(\mathbf{x}(t), \mathbf{u}(t)) \\
& \mathbf{y}(t)=\mathbf{h}(\mathbf{x}(t))
\end{aligned}
$$

sendo o $\mathbf{x}(t)=\left[\begin{array}{lll}x_{1}(t) \ldots & x_{n}(t)\end{array}\right]^{T}$ vetor de variáveis de estado, $\mathbf{u}(t)=\left[\begin{array}{llll}u_{1}(t) \ldots & u_{n}(t)\end{array}\right]^{T} \mathrm{o}$ vetor das medidas de entrada, $\mathbf{y}(t)=\left[y_{1}(t) \ldots y_{n}(t)\right]^{T}$ o vetor das medidas de saída, e $\mathbf{f}(\mathbf{x}(t), \mathbf{u}(t))$ e $\mathbf{h}(\mathbf{x}(t))$ vetores compostos por funções não-lineares $C^{\infty}$ (classe de funções diferenciáveis com derivadas parciais contínuas).

Em sua forma mais geral, o sistema dinâmico descrito pela eq.(3.01) pode também ser expresso como sendo explicitamente dependente do tempo (sistemas dinâmicos variantes no tempo) através do vetor de funções $\mathbf{f}(\mathbf{x}(t), \mathbf{u}(t), t)$ e $\mathbf{h}(\mathbf{x}(t), \mathbf{u}(t), t)$, ou seja:

$$
\begin{gathered}
\frac{d \mathbf{x}(t)}{d t}=\mathbf{f}(\mathbf{x}(t), \mathbf{u}(t), t) \\
\mathbf{y}(t)=\mathbf{h}(\mathbf{x}(t), \mathbf{u}(t), t)
\end{gathered}
$$

Entretanto, a aplicação dos observadores de estado requer a utilização de representações em espaço de estados mais específicas, entre as quais podem ser citadas as seguintes (BESANÇON, 2007):

i) Sistemas de controle afins (Control-affine systems)

$$
\mathbf{f}(x, u)=\mathbf{f}_{0}(x)+\mathbf{g}(x) \mathbf{u}
$$

ii) Sistemas de estado afins (State-affine systems)

$$
\begin{aligned}
& \mathbf{f}(x, u)=\mathbf{A}(u) x+\mathbf{B}(u) \\
& \mathbf{h}(x)=\mathbf{C x}(\text { ou } \mathbf{C}(u) \mathbf{x}+\mathbf{D}(u))
\end{aligned}
$$


iii) Sistemas lineares variantes no tempo

$\mathbf{f}(x, u, t)=\mathbf{A}(t) \mathbf{x}+\mathbf{B}(t) \mathbf{u}$

$\mathbf{h}(x, u, t)=\mathbf{C}(t) \mathbf{x}+\mathbf{D}(t) \mathbf{u}$

iv) Sistemas lineares invariantes no tempo

$$
\begin{aligned}
& \mathbf{f}(x, u)=\mathbf{A} \mathbf{x}+\mathbf{B u} \\
& \mathbf{h}(x, u)=\mathbf{C} \mathbf{x}+\mathbf{D u}
\end{aligned}
$$

Neste trabalho, seguindo a notação proposta por Freire (2003), são considerados os sistemas dinâmicos não-lineares e variantes no tempo expressos da seguinte forma:

$$
\begin{aligned}
& \frac{d \mathbf{x}(t)}{d t}=\mathbf{f}(\mathbf{x}(t))+\mathbf{g}(\mathbf{x}(t)) u \\
& y(t)=h(\mathbf{x}(t))
\end{aligned}
$$

onde

$$
\begin{array}{ll}
\mathbf{x}(t)=\left[\begin{array}{llll}
x_{1}(t) & x_{2}(t) \ldots & \ldots & x_{n}(t)
\end{array}\right]^{T} & \text { o vetor de variáveis de estado } \\
\mathbf{f}(x)=\left[\begin{array}{llll}
f_{1}(x) & f_{2}(x) \ldots & \ldots & f_{n}(x)
\end{array}\right]^{T} & \text { o vetor composto por funções não-lineares das } \\
& \text { relações entre as variáveis de estado } \\
\mathbf{g}(x)=\left[\begin{array}{lllll}
g_{1}(x) & g_{2}(x) \ldots g_{n}(x)
\end{array}\right]^{T} & \text { o vetor composto por funções não-lineares das } \\
& \text { relações entre as variáveis de estado e a entrada } \\
& \text { do sistema dinâmico } \\
& \text { a medida de entrada do sistema dinâmico } \\
u(t) & \text { a medida de saída do sistema dinâmico } \\
h(x) & \text { função não-linear que correlaciona as variáveis de } \\
& \text { estado e a saída do sistema dinâmico }
\end{array}
$$




\subsubsection{Observadores de estado}

Um observador de estado pode ser definido como uma representação matemática de um dado sistema, composto pelo modelo do processo e um termo corretivo proporcional à diferença entre as medidas reais e estimadas da saída, desenvolvido com o principal objetivo de quantificar os estados internos de um processo dispondo-se apenas das medidas de entrada e saída do sistema.

Conhecer o estado de um processo pode ser motivado por diversas razões: modelagem (identificação), monitoramento (detecção de falhas), e controle. Entretanto, na maioria dos casos práticos, o estado físico de um dado sistema não pode ser determinado pela simples observação direta, pois grande parte dos processos possuem diversas variáveis de estado não mensuráveis, ou mesmo que mensuráveis, o custo para se obter tais informações pode ser demasiadamente alto a ponto de inviabilizar economicamente as suas medições. Dessa forma, as variações do estado interno de um processo são quantificadas indiretamente pela observação dos efeitos que estas variações causam sobre as saídas do sistema, ou seja, o problema de observação pode ser sintetizado pela seguinte frase:

"Dado um processo, descrito pelo sistema (3.01), encontrar uma estimativa $\hat{\mathbf{x}}(t)$ para $\mathbf{x}(t)$ a partir das informações de $u(\tau)$ e $y(\tau)$ com $0 \leq \tau \leq t$." (BESANÇON, 2007)

Uma possível solução para este problema seria obter a melhor estimativa $\hat{\mathbf{x}}(0)$ de $\mathbf{x}(0)$, via técnicas de otimização, que possa predizer o perfil de $\mathbf{y}(\tau)$ no intervalo $[0, t]$ e, a partir desse valor inicial, obter a estimativa $\hat{\mathbf{x}}(t)$ integrando o sistema (3.01). As principais desvantagens dessa metodologia são aquelas tradicionalmente encontradas em otimização não-linear como, por exemplo, tempo computacional e mínimo local.

Alternativamente, as estimativas do vetor de estados podem também ser obtidas usando os conceitos de controle retroalimentado (feedback control). A idéia central deste método é que se $\mathbf{x}(0)$ é desconhecido, ou seja, o vetor $\hat{\mathbf{x}}(0)$ é composto por valores incertos, ou mesmo errados, as estimativas $\hat{\mathbf{x}}(t)$ podem ser corrigidas em linha a partir do erro $\mathbf{h}(\hat{\mathbf{x}}(t))-\mathbf{y}(t)$, isto é, a estimativa $\hat{\mathbf{x}}(t)$ é obtida pela solução da seguinte equação diferencial: 


$$
\dot{\hat{\mathbf{x}}}(t)=\mathbf{f}(\hat{\mathbf{x}}(t), \mathbf{u}(t))+\mathbf{K}(t, \mathbf{h}(\hat{\mathbf{x}}(t))-\mathbf{y}(t)), \operatorname{com} \mathbf{K}(t, 0)=0
$$

A eq.(3.08) é uma equação auxiliar denominada observador de estado.

O conceito de observador de estado é apresentado de maneira formal pela seguinte definição:

Definição 3.1 (Observador de estado) Seja o sistema dinâmico dado pela eq.(3.01), o observador de estado deste sistema será dado pelo seguinte sistema de equações auxiliares (BESANÇON, 2007):

$$
\begin{aligned}
& \dot{\mathbf{X}}(t)=\mathbf{F}(\mathbf{X}(t), \mathbf{u}(t), \mathbf{y}(t), t) \\
& \hat{\mathbf{x}}(t)=\mathbf{H}(\mathbf{X}(t), \mathbf{u}(t), \mathbf{y}(t), t)
\end{aligned}
$$

tal que:

$$
\begin{aligned}
\text { i) } & \hat{\mathbf{x}}(0)=\mathbf{x}(0) \Rightarrow \hat{\mathbf{x}}(t)=\mathbf{x}(t), \quad \forall t \geq 0 ; \\
\text { ii) } & \|\hat{\mathbf{x}}(t)-\mathbf{x}(t)\| \rightarrow 0 \text { conforme } t \rightarrow \infty
\end{aligned}
$$

Se ii) vale para qualquer $\mathbf{x}(0), \hat{\mathbf{x}}(0)$, o observador é global.

Se ii) vale com convergência exponencial, o observador é exponencial.

Se ii) vale para uma taxa de convergência que pode ser ajustado, o observador é sintonizável.

\subsubsection{Derivadas de Lie}

A derivada de Lie pode ser definida como a derivada direcional de uma função escalar $h(x)$ na direção do vetor de funções $f(x)\left(L_{f} h\right)$, e é dada pela seguinte relação: 
$L_{f} h(x)=\langle\nabla h(x), \mathbf{f}(x)\rangle=\sum_{i=1}^{n} f_{i}(x) \frac{\partial h(x)}{\partial x_{i}}$

onde $\nabla$ representa o operador gradiente.

Para ordem maior que 1, as derivadas de Lie podem ser obtidas através da seguinte relação recursiva (VALLURI; SOROUSH, 1996):

$$
\left\{\begin{array}{l}
L_{f}^{k} h(x)=L_{f}\left(L_{f}^{k-1} h(x)\right) \\
L_{g} L_{f}^{k-1} h(x)=L_{g}\left(L_{f}^{k-1} h(x)\right) \quad k=1,2, \ldots \\
L_{f}^{0} h(x)=h(x)
\end{array}\right.
$$

sendo $L_{g} L_{f}^{k-1} h(x)$ a composição dos operadores derivada de Lie $\left(\mathrm{L}_{\mathrm{g}}\right.$ e $\left.\mathrm{L}_{\mathrm{f}}\right)$ onde a função escalar $h(x)$ é derivado primeiro na direção de $f(x)$ e depois na direção $g(x)$. Portanto, $L_{g} L_{f}^{k-1} h(x)$ será dado pelo seguinte operador diferencial parcial:

$$
L_{g} L_{f}^{k-1} h(x)=\sum_{j=1}^{n} \sum_{i=1}^{n}\left[g_{j}(x) f_{i}(x) \frac{\partial^{k} h(x)}{\partial x_{j} \partial x_{i}}+g_{j}(x) \frac{\partial^{k-1} f(x)}{\partial x_{j}} \frac{\partial h(x)}{\partial x_{i}}\right]
$$

\section{Propriedades da derivada de Lie (FREIRE, 2003)}

Sendo $f(x)$ e $\mathbf{g}(x)$ campos vetoriais e $h(x)$ e $t(x)$ campos escalares de $C^{\infty}$, então:

P1) $\quad L_{f}(h+t)=L_{f} h+L_{f} t$

P2) $\quad L_{f}(h t)=h L_{f} t+t L_{f} h$

P3) $L_{f+g}=L_{f}+L_{g}$

P4) $\quad L_{h f}=h_{f}$

As duas primeiras regras representam propriedades de qualquer operador diferencial linear; o segundo par de regras estabelece a linearidade de $L_{f}$ com respeito ao seu vetor argumento. Essas regras são relativamente simples de serem utilizadas em aplicações de controle. 


\subsubsection{Medida da distância no espaço de estados}

A distância euclidiana entre dois pontos quaisquer, $x_{1}$ e $x_{2}$, no espaço de estados é dada na forma:

$$
\left\|x_{1}-x_{2}\right\|=\sqrt{\sum_{i=1}^{n}\left(x_{1 i}-x_{2 i}\right)^{2}}
$$

sendo $x_{j}=\left[\begin{array}{llll}x_{j 1} & x_{j 2} & \ldots & x_{j n}\end{array}\right]^{T}, \mathrm{j}=1,2$ vetores pertencentes ao $\Re^{n}$

\subsubsection{Observabilidade de sistemas não-lineares}

Em termos práticos, um dado sistema dinâmico é dito observável caso seja possível reconstruir, ou estimar, o seu estado a partir das medidas de entrada (u) e de saída (y) durante um intervalo de tempo t. À primeira vista, isso é possível apenas se 0 vetor $\mathbf{y}$ carregar informações suficientes a respeito de todas as variáveis de estado do sistema.

No entanto, restringindo o conceito de observador estritamente aos itens i) e ii) da definição 3.1, é possível obter estimativas de um observador mesmo quando y não contenha informações suficientes à respeito das variáveis de estado. Por exemplo, considere o seguinte sistema:

$$
\begin{aligned}
& \dot{\mathbf{x}}=-\mathbf{x}+\mathbf{u} \\
& \mathbf{y}=0
\end{aligned}
$$

Nesse sistema, é evidente que não é possível obter qualquer informação sobre $\mathbf{x}$ de $\mathbf{y}$, e mesmo assim o sistema:

$$
\dot{\hat{\mathbf{x}}}=-\hat{\mathbf{x}}+\mathbf{u}
$$


satisfaz as condições i) - ii) e ainda fornece uma estimativa de $\mathbf{x}$.

Isto corresponde à noção de detectabilidade. Note, no entanto, que nesses casos a taxa de convergência não pode ser ajustada (BESANÇON, 2007).

Entretanto, se nos limitarmos aos observadores sintonizáveis, então a observabilidade torna-se uma condição necessária para que os estados de um processo possam ser estimados a partir das medidas de entrada e de saída do sistema.

A condição conceitual de observabilidade é apresentada de maneira formal por um conjunto de definições agrupadas em duas categorias: a) condições geométricas de observabilidade, e b) condições analíticas de observabilidade.

\subsubsection{Condições geométricas de observabilidade}

Recuperar a informação sobre o vetor de estados a partir das medidas de saída implica em dizer que o observador, baseado nas informações contidas em y, deve ser capaz de distinguir, entre os vários estados iniciais possíveis, o estado real do processo, o que equivale a afirmar que não é admitida a indistinguibilidade dos estados, cuja definição é apresentada a seguir.

Definição 3.2 (Indistinguibilidade) $O$ par de estados $\left(x_{0}, x_{0}^{\prime}\right) \in \mathbf{R}^{n} \times \mathbf{R}^{n}$ do sistema (3.01) é indistinguível se (BESANÇON, 2007):

$\forall u \in U, \forall t \geq 0, y\left(x_{0}, u, t\right)=y\left(x_{0}^{\prime}, u, t\right)$

O estado $x$ é indistinguível de $x_{0}$ se o par $\left(x_{0}, x_{0}^{\prime}\right)$ é indistinguível.

A observabilidade pode então ser estabelecida com base nesta definição da forma como segue.

Definição 3.3 (Observabilidade) Dado um estado $x_{0}$, o sistema (3.01) é observável se ele não admite nenhum par indistinguível (BESANÇON, 2007). 
A definição 3.3 é bastante geral e pouco aplicável em casos práticos, uma vez que determinados sistemas podem não ser globalmente observáveis, mas podem apresentar uma vizinhança que contenha um estado $x_{0}^{\prime}$ tal que o par $\left(x_{0}, x_{0}^{\prime}\right)$ seja distinguível. Assim, faz-se necessário definir uma condição de observabilidade menos restritiva.

Definição 3.4 (Observabilidade fraca) O sistema (3.01) é fracamente observável, com respeito a um dado estado $x_{0}$, se existir uma vizinhança $U$ que não contenha nenhum estado $x_{0}^{\prime}$, tal que o par $\left(x_{0}, x_{0}^{\prime}\right)$ seja indistinguível (BESANÇON, 2007).

A definição 3.4 é válida para o estado $x_{0}$, mas não localmente para a sua vizinhança. Assim, mais uma definição de observabilidade pode ser dada:

Definição 3.5 (Observabilidade local fraca) O sistema (3.01) é localmente fracamente observável, com relação a um estado $x_{0}$, se existir uma vizinhança $U$, tal que para todo $x \in U$, não exista uma vizinhança $V \subset U$, tal que para todo $x^{\prime} \in V, o$ par $\left(x, x^{\prime}\right)$ seja indistinguível (BESANÇON, 2007).

Esta condição garante que, dado um estado $x_{0}$, não existam estados indistinguíveis em sua vizinhança, criando um subespaço $U$ onde o sistema é observável, ou seja, é possível distinguir cada estado a partir de seus vizinhos sem precisar "ir longe demais". Esta idéia é mais aplicável em casos práticos, e também apresenta a vantagem de remeter ao conceito de "condição de posto" para observabilidade. Essa condição fornece uma ferramenta prática para a verificação do conceito de observabilidade e apresenta grande relevância na área de controle geométrico. A formalização dessa condição invoca o conceito de espaço de observação que, a grosso modo, corresponde ao espaço de todos os estados observáveis: 
Definição 3.6 (Espaço de observação) $O$ espaço de observação do sistema (3.01) é definido como o menor espaço vetorial (denotado por $\boldsymbol{O}(h)$ ) gerado pelos componentes $C^{\infty}$ da função $h$, tal que para $\forall \varphi \in \boldsymbol{O}(h), \quad L_{f_{u}} \varphi \in \boldsymbol{O}(h)$ (BESANÇON, 2007).

Definição 3.7 (Condição de posto para observabilidade) $O$ sistema (3.01) satisfaz a condição de posto para observabilidade se a seguinte condição for verdadeira (BESANÇON, 2007):

$\forall x,\left.\quad \operatorname{dim}(d \boldsymbol{O}(h))\right|_{x}=n$

Onde $\left.d \boldsymbol{O}(h)\right|_{x}$ é o conjunto de $d \varphi(x) \operatorname{com} \varphi \in \boldsymbol{O}(h)$.

Para um dado estado $x_{0}$ :

$\left.\operatorname{dim}(d \boldsymbol{O}(h))\right|_{x 0}=n$

A partir da Definição 3.7, tem-se:

Teorema 3.1 Se o sistema (3.01) satisfaz a condição de posto para observabilidade, então o sistema (3.01) será localmente fracamente observável.

Reciprocamente, se o sistema (3.01) é localmente fracamente observável, então o sistema (3.01) satisfaz a condição de posto para observabilidade em um subconjunto aberto denso de $X$ (BESANÇON, 2007).

Este teorema decorre do fato que: 
i) A condição de posto para observabilidade, para um dado estado $x_{0}$, significa que exitem $n$ elementos do espaço de observação gerando um difeomorfismo ${ }^{1}$ em torno de $x_{0}$;

ii) Para qualquer par indistinguível $\left(x_{0}, x_{0}^{\prime}\right)$ e para qualquer elemento $\varphi \in \boldsymbol{O}(h), \varphi\left(x_{0}\right)=\varphi\left(x_{0}^{\prime}\right)$

Para sistemas lineares do tipo:

$\dot{\mathbf{x}}=\mathbf{A x}$

$\mathbf{y}=\mathbf{C x}$

a seguinte condição, formalizada no teorema a seguir, é uma condição suficiente para garantir a observabilidade do sistema.

Teorema 3.2 Para o sistema linear (3.18) (BESANÇON, 2007) :

i) A condição de posto para observabilidade é equivalente à

$\operatorname{posto}(\mathbf{Q})=\left(\begin{array}{c}\mathbf{C} \\ \mathbf{C A} \\ \mathbf{C A}^{2} \\ \vdots \\ \mathbf{C A}^{n-1}\end{array}\right)=n$

onde $\boldsymbol{Q}$ é a chamada matriz de observabilidade

ii) A condição de posto para observabilidade é equivalente à observabilidade do sistema

\footnotetext{
${ }^{1}$ Difeomorfismo é um conceito de igualdade da topologia diferencial. Duas variedades diferenciáveis (differential manifolds) dizem-se difeomeomorfas se existir uma aplicação entre estas variedades que seja diferencial, invertível e sua inversa seja diferenciável. Mais formalmente: seja uma $\mathrm{f}: \mathrm{M} \rightarrow \mathrm{N}$ uma aplicação (mapeamento) de uma variedade diferenciável $\mathrm{M}$ para uma variedade diferenciável $\mathrm{N}$ na qual a aplicação inversa também é continuamente diferenciável. Se $\mathrm{f}(\mathrm{M})=\mathrm{N}$, diz-se que $\mathrm{M}$ e $\mathrm{N}$ são difeomeomorfas (ANOSOV, D. V. Encyclopaedia of Mathemathics - ISBN 1402006098)
} 
Observação 3.1: Se o sistema (3.18) satisfaz a condição de posto para observabilidade, o par (A,C) é geralmente chamado observável (BESANÇON, 2007).

Observação 3.2: O Teorema 3.2 vale também para sistemas controlados do tipo $\dot{\mathbf{x}}=\mathbf{A x}+\mathbf{B u}$ (BESANÇON, 2007).

Observação 3.3: A condição de posto para observabilidade é também uma condição suficiente para o projeto de um observador para o sistema (3.18) (ou mesmo, uma condição necessária e suficiente para o projeto de um observador sintonizável) (BESANÇON, 2007).

No entanto, para sistemas não-lineares, a condição de posto para observabilidade não é uma condição suficiente para o projeto de um observador. Isto ocorre, pois, mesmo que seja assegurada a observabilidade para algumas entradas, pode existir uma entrada $u \in U$, tal que exista um par $\left(x_{0}, x_{0}^{\prime}\right)$ indistinguível. Dessa forma, a observabilidade de sistemas não-lineares pode se tornar dependente das entradas e, portanto, torna-se necessário definir condições adicionais relacionadas às entradas. Mais precisamente, as definições de entrada universal e observabilidade uniforme para um sistema dinâmico não-linear do tipo dado pela eq.(3.01), e as noções de persistência e regularidade. Todos estes conceitos são agrupados como condições analíticas de observabilidade.

\subsubsection{Condições analíticas de observabilidade}

Definição 3.8 (Entrada universal) Uma entrada u do sistema (3.01) é dita universal se atendida a seguinte condição (BESANÇON, 2007):

$$
\forall x_{0} \neq x_{0}^{\prime}, \forall t \in T \quad y\left(x_{0}, u, t\right) \neq y\left(x_{0}^{\prime}, u, t\right)
$$

A entrada u será considerada uma entrada singular sempre que esta não for uma entrada universal. 
Com base nesta definição, a observabilidade uniforme pode ser definida como segue:

Definição 3.9 (Observabilidade uniforme) Um sistema é considerado uniformemente observável, se toda entrada u for uma entrada universal (BESANÇON, 2007).

A Definição 3.9 remove a dependência da observabilidade em relação à entrada, permitindo a construção de observadores para sistemas não-lineares de forma independente da entrada $u$. O conceito de observabilidade uniforme será particularmente útil para a construção dos observadores de alto ganho.

Para sistemas não uniformemente observáveis, essa construção ainda é possível, entretanto, o observador resultante estará restrito às entradas $u$ uniformemente observáveis, ou seja, nem todas as entradas serão admissíveis. Nesses casos, restringir as entradas a um grupo que seja uniformemente observável não é suficiente, pois caso o sistema sofra um distúrbio, o vetor de estados não poderá ser reconstruído corretamente. Isto significa que a universalidade deve ser garantida ao longo do tempo, isto é, ela deve ser persistente. Essa afirmação expressa o conceito de entrada persistente o qual é apresentado de maneira formal pela seguinte proposição e definição:

Proposição 3.1 Uma entrada u do sistema (3.01) é uma entrada universal se e somente se (BESANÇON, 2007):

$$
\int_{0}^{t}\left\|y\left(x_{0}, u, \tau\right)-y\left(x_{0}^{\prime}, u, \tau\right)\right\|^{2} d \tau>0 \quad \forall x_{0} \neq x_{0}^{\prime}
$$

Esta proposição pode ser checada a partir da Definição 3.8.

Com base nesta proposição, o conceito de entrada persistente pode ser definido como segue:

Definição 3.10 (Entrada persistente) Uma entrada u do sistema (3.01) é dita persistente se atendida a seguinte condição (BESANÇON, 2007): 
$\exists t_{0}, T: \forall t \geq t_{0}, \forall x_{t} \neq x_{t}^{\prime}, \quad \int_{t}^{t+T}\left\|y\left(x_{t}, u, \tau\right)-y\left(x_{t}^{\prime}, u, \tau\right)\right\|^{2} d \tau>0$

Equivalentemente, a condição apresentada na Definição 3.10 pode ser expressa em função das medidas passadas, ou seja:

$$
\int_{t-T}^{t}\left\|y\left(x_{t-T}, u, \tau\right)-y\left(x_{t-T}^{\prime}, u, \tau\right)\right\|^{2} d \tau>0, \quad \forall x_{t-T} \neq x_{t-T}^{\prime}
$$

A Definição 3.10 garante, basicamente, a observabilidade ao longo de um dado intervalo de tempo. Contudo, esta definição não garante a observabilidade do sistema caso $t \rightarrow \infty$. Caso isto ocorra, o observador deve ser compensado por um termo de correção (ganho) e, portanto, as variáveis de estado serão agora reconstruídas por uma equação auxiliar semelhante à eq.(3.08). Entretanto, dependendo do caso, este recurso pode assegurar a convergência do observador, ou seja, $\|\hat{\mathbf{x}}(t)-\mathbf{x}(t)\| \rightarrow 0$ conforme $t \rightarrow \infty$, mas a custa de $\mathbf{K} \rightarrow \infty$. Assim, para evitar isto, faz-se necessário definir o conceito de entrada regularmente persistente:

Definição 3.11 (Entrada regularmente persistente) Uma entrada $u$ do sistema (3.01) é dita regularmente persistente se (BESANÇON, 2007):

$$
\exists t_{0}, T: \forall x_{t-T}, x_{t-T}^{\prime}, \forall t \geq t_{0}, \int_{t-T}^{t}\left\|y\left(x_{t-T}, u, \tau\right)-y\left(x_{t-T}^{\prime}, u, \tau\right)\right\|^{2} d \tau \geq \beta\left(\left\|x_{t-T}-x_{t-T}^{\prime}\right\|\right)
$$

Apesar das condições analíticas de observabilidade serem definidas em função da entrada e para sistemas não-lineares controlados, similares ao sistema (3.01), estas condições são válidas também para outros tipos de sistemas como, por exemplo, sistemas não-lineares variantes no tempo. 


\subsubsection{Matriz de observabilidade}

Para o sistema dinâmico não-linear representado pela eq.(3.01), a matriz $\mathrm{nXn}$ :

$$
\mathbf{Q}=\frac{\partial}{\partial \mathbf{x}}\left[\begin{array}{c}
y \\
\frac{d y}{d t} \\
\vdots \\
\frac{d^{n-1} y}{d t^{n-1}}
\end{array}\right]
$$

é chamada de matriz de observabilidade

Observação 3.4: Sendo r a ordem relativa do sistema (3.01) (menor ordem de derivadas no tempo de y que depende explicitamente da entrada $u$, ou seja, é o menor inteiro para o qual $L_{g} L_{f}^{r-1} h(x) \neq 0$ ), a matriz de observabilidade $Q$ será dada por (VALLURI; SOROUSH, 1996):

$\mathbf{Q}(x, U)=\frac{\partial \Phi(x, U)}{\partial x}$

sendo $\Phi$ e $U$, respectivamente, a matriz de transformação de coordenadas e o vetor das derivadas no tempo da entrada manipulada do sistema dinâmico, dados por:

$$
\boldsymbol{\Phi}(x, U)=\left[\begin{array}{l}
y \\
d y / d t \\
\vdots \\
d^{r-1} y / d t^{r-1} \\
d^{r} y / d t^{r} \\
d^{r+1} y / d t^{r+1} \\
\vdots \\
d^{n-1} y / d t^{n-1}
\end{array}\right]=\left[\begin{array}{l}
h(x) \\
L_{f} h(x) \\
\vdots \\
L_{f}^{r-1} h(x) \\
L_{f}^{r} h(x)+L_{g} L_{f}^{r-1} h(x) u \\
\psi_{r+1}(x, U) \\
\vdots \\
\psi_{r-1}(x, U)
\end{array}\right]
$$


$U(t)=\left[u^{(0)}(t) u^{(1)}(t) \ldots u^{(n-r-1)}(t)\right]^{T}=\left[u(t) \frac{d u(t)}{d t} \ldots \frac{d^{n-r-1} u(t)}{d t^{n-r-1}}\right]^{T}$

$\psi_{l}(x, U)=L_{f+g u} \psi_{l-1}(x, U)+\sum_{k=0}^{m(l)} u^{(k+1)} \frac{\partial \psi_{l-1}[x, U]}{\partial u^{(k)}} \quad l=r+1, \ldots, n-1$

onde $\mathrm{n}$ é a dimensão do sistema dinâmico, $\psi_{r}(x, U)=L_{f}^{r} h(x)+L_{g} L_{f}^{r-1} h(x) u$ e $m(l)=\min (l-3, r-1)$.

Observação 3.5: Para sistemas dinâmicos lineares, isto é, $h(x)=\mathbf{C x}$ e $\mathbf{f}(\mathrm{x})=\mathbf{A} \mathbf{x}$, a matriz de observabilidade $\mathbf{Q}(\mathrm{x}, \boldsymbol{U})=\left[\begin{array}{ll}\mathbf{C} & \mathbf{C A}^{2} \ldots \mathbf{C A}^{\mathrm{n}-1}\end{array}\right]^{\top}$ é independente de $\mathbf{x} \mathrm{e}$ $u$. Isso implica que, em sistemas lineares, a observabilidade é uma propriedade global, ou seja, se um sistema dinâmico linear é observável, ele será sempre observável (VALLURI; SOROUSH, 1996).

Observação 3.6: As variáveis de estado de um processo podem ser reconstruídas por um observador de estado se o processo é observável. Como mencionado anteriormente, no caso de um sistema linear, a observabilidade é uma propriedade global e, portanto, pode ser verificada simplesmente calculando-se a matriz de observabilidade. Entretanto, para sistemas não-lineares, a observabilidade pode não ser uma propriedade global e, portanto nesses casos, se a matriz de observabilidade não for singular para um determinado conjunto, diz-se que o processo não-linear é localmente observável (VALLURI; SOROUSH, 1996).

\subsubsection{Definições adicionais}

Definição 3.12 Uma função $\mathbf{f}(x)$ é dita Lipschitz em $\mathbf{X} \subset \mathbf{R}^{n}$ se, e somente se, para todo $x_{1}, x_{2} \in \mathbf{X}$, existir uma constante finita $\gamma$, conhecida como constante de Lipschitz, tal que (VALLURI; SOROUSH, 1996):

$\left\|\mathbf{f}\left(x_{1}\right)-\mathbf{f}\left(x_{2}\right)\right\| \leq \gamma\left\|x_{1}-x_{2}\right\|$ 
Definição 3.13 Uma função $f(x)$ é globalmente Lipschitz se, e somente se, ela for Lipschitz em $\mathbf{X}=\mathbf{R}^{n}$ (VALLURI; SOROUSH, 1996).

\subsubsection{Observador não-linear tipo Luenberger - Projeto}

O método para o projeto de observadores de estado apresentado por Ciccarella; Dalla Mora e Germani (1993) propõe a seguinte mudança de coordenadas de estado:

$$
\mathbf{z}=\boldsymbol{\Phi}(x, U)
$$

Nessas novas coordenadas, o sistema dinâmico não-linear representado pela eq. (3.07) assume a seguinte forma canônica de Brunowsky:

$$
\begin{aligned}
& \dot{\mathbf{z}}=\tilde{\mathbf{A}} \mathbf{z}+\tilde{\mathbf{b}} \psi_{n}\left[\boldsymbol{\Phi}^{-1}(z, U), U, u^{(n-r)}\right] \\
& y=\widetilde{\mathbf{C}} \mathbf{z}
\end{aligned}
$$

sendo:

$$
\psi_{n}\left[x, U, u^{(n-r)}\right]=L_{f+g u} \psi_{n-1}[x, U]+\sum_{k=0}^{m(n)} u^{(k+1)} \frac{d \psi_{n-1}(x, U)}{d u^{(k)}}
$$

$$
\widetilde{\mathbf{A}}=\left[\begin{array}{ccccc}
0 & 1 & 0 & \ldots & 0 \\
0 & 0 & 1 & \ldots & 0 \\
\vdots & \vdots & \vdots & & \vdots \\
0 & 0 & 0 & \ldots & 1 \\
0 & 0 & 0 & \ldots & 0
\end{array}\right] \in \mathbf{R}^{n x n}
$$




$$
\begin{aligned}
\widetilde{\mathbf{b}} & =\left[\begin{array}{c}
0 \\
0 \\
\vdots \\
0 \\
1
\end{array}\right] \in \mathbf{R}^{n x 1} \\
\widetilde{\mathbf{C}} & =\left[\begin{array}{llll}
1 & 0 & \ldots & 0
\end{array}\right] \in \mathbf{R}^{1 x n}
\end{aligned}
$$

No momento, assume-se que as primeiras (n-r-1) derivadas no tempo da medida de entrada u estão disponíveis. Então, para o sistema transformado (3.32) utiliza-se o observador de Luenberger linear, obtendo-se:

$$
\begin{aligned}
& \dot{\hat{\mathbf{z}}}=\tilde{\mathbf{A}} \hat{\mathbf{z}}+\tilde{\mathbf{b}} \psi_{n}\left[\Phi^{-1}(\hat{z}, U), U, u^{(n-r)}\right]+\mathbf{K}(y-\widetilde{\mathbf{C}} \hat{\mathbf{z}}) \\
& \hat{\mathbf{z}}(0)=\boldsymbol{\Phi}\left(\hat{x}_{0}, U_{0}\right)
\end{aligned}
$$

onde $\hat{\mathbf{z}}$ é o valor estimado do vetor $\mathbf{z}$, e $\mathbf{K} \in \mathbf{R}^{n}$ o ganho do observador. Nesse caso, o erro na observação $\tilde{\mathbf{e}}=\hat{\mathbf{z}}-\mathbf{z}$ será governado pela seguinte equação:

$$
\begin{aligned}
& \dot{\tilde{\mathbf{e}}}=(\tilde{\mathbf{A}}-\mathbf{K} \widetilde{\mathbf{C}}) \widetilde{\mathbf{e}}+\widetilde{\mathbf{b}}\left\{\psi_{\mathrm{n}}\left[\Phi^{-1}(\hat{z}, U), U, u^{(n-r)}\right]-\psi_{n}\left[\boldsymbol{\Phi}^{-1}(z, U), U, u^{(n-r)}\right]\right\} \\
& \widetilde{\mathbf{e}}(0)=\widetilde{\mathbf{e}}_{0}
\end{aligned}
$$

A solução da eq.(3.38) é dada por:

$$
\begin{array}{r}
\widetilde{\mathbf{e}}(t)=\exp [(\tilde{\mathbf{A}}-\mathbf{K} \widetilde{\mathbf{C}})] \widetilde{\mathbf{e}}_{0}+ \\
\int_{0}^{t} \exp [(\tilde{\mathbf{A}}-\mathbf{K} \tilde{\mathbf{C}})(t-\tau)] \widetilde{\mathbf{b}}\left\{\psi_{n}\left[\Phi^{-1}(\hat{z}(\tau), U(\tau)), U(\tau), u^{(n-r)}(\tau)\right]-\right. \\
\left.\psi_{n}\left[\Phi^{-1}(z(\tau), U(\tau)), U(\tau), u^{(n-r)}(\tau)\right]\right\} d \tau
\end{array}
$$

Ciccarella; Dalla Mora e Germani (1993) demonstraram que o observador (3.37) apresenta decaimento globalmente assintótico do erro na observação, ou seja: 
$\lim _{t \rightarrow \infty}\|\widetilde{\mathbf{e}}(t)\|=0, \quad \forall \hat{\mathbf{z}}(0) \in \mathbf{R}^{n}$

se:

i) a matriz de ganho do observador $\mathbf{K}$ for escolhida de tal forma que todos os autovalores da matriz $(\tilde{\mathbf{A}}-\mathbf{K} \widetilde{\mathbf{C}})$ estejam no semiplano complexo esquerdo;

ii) a matriz de observabilidade $\mathbf{Q}(x, \bigcup)$ tiver posto completo (posto igual à ordem do sistema) para todo $(\mathrm{x}, U) \in \mathbf{R}^{n} \times \mathbf{R}^{n-r}$;

iii) $\quad \psi_{n}\left[\boldsymbol{\Phi}^{-1}(z, U), U, \xi\right]$ for globalmente Lipschitz em $(z, U, \xi)$.

O observador dado pela eq.(3.37), re-escrito em função das variáveis de estado originais do sistema, será expresso da seguinte forma:

$$
\begin{aligned}
& \dot{\hat{\mathbf{x}}}=\mathbf{f}(\hat{x})+\mathbf{g}(\hat{x}) u+\left[\frac{\partial \boldsymbol{\Phi}(\hat{x}, U)}{\partial \hat{x}}\right]^{-1} \mathbf{K}[y-h(\hat{x})] \\
& \hat{\mathbf{x}}(0)=\hat{\mathbf{x}}_{0}
\end{aligned}
$$

sendo $\hat{\mathbf{x}}$ o valor estimado do vetor de estado $\mathbf{x}$, que sob as três condições mencionadas acima apresenta a seguinte propriedade:

$\lim _{t \rightarrow \infty}\|\hat{\mathbf{x}}(t)-\mathbf{x}(t)\|=0, \quad \forall \hat{\mathbf{x}}(0) \in \mathbf{R}^{n}$

A implementação do observador de estado não-linear (3.41) requer que as (n-r-1) derivadas no tempo da medida de entrada sejam conhecidas. No caso de uma entrada que varie no tempo, Valluri e Soroush (1996) apresentaram as formas para a obtenção das derivadas das medidas de entrada no domínio do tempo. Entretanto, no presente trabalho a entrada é invariante e, portanto, para um processo descrito pela eq.(3.07) e com uma entrada constante $u(t)=u_{0}, \quad 0$ observador de estado não-linear pode ser escrito da seguinte forma: 


$$
\begin{aligned}
& \dot{\hat{\mathbf{x}}}=\mathbf{f}(\hat{x})+\mathbf{g}(\hat{x}) u_{0}+\left[\frac{\partial \boldsymbol{\Phi}(\hat{x})}{\partial \hat{x}}\right]^{-1} \mathbf{K}[y-h(\hat{x})] \\
& \hat{\mathbf{x}}(0)=\hat{\mathbf{x}}_{0}
\end{aligned}
$$

O erro do observador (3.43) converge exponencialmente a zero, se as seguintes condições forem satisfeitas (CICCARELLA; DALLA MORA; GERMANI, 1993):

i) há um conjunto limitado, conectado $\Omega_{\mathrm{x}}$, tal que $\mathbf{x}(\mathrm{t}) \in \Omega_{\mathrm{x}}$, para todo $\mathrm{t} \geq 0$;

ii) $\mathbf{Q}(\mathbf{x})$ tem posto completo (posto igual a ordem do sistema) para todo $\mathbf{x} \in$ $\Omega_{\mathrm{X}}$;

iii) $\quad\|\hat{\mathbf{x}}(0)-\mathbf{x}(0)\| \leq \beta$, para $\beta>0$;

iv) as raízes do polinômio $\lambda^{n}+K_{1} \lambda^{n-1}+\ldots+K_{n-1} \lambda+K_{n}=0$ devem estar no semiplano complexo esquerdo;

v) $\quad L_{f+g u_{0}}^{n} h\left[\boldsymbol{\Phi}^{-1}(\xi)\right]$ é Lipschitz em $\Omega_{\mathrm{x}}$.

\subsubsection{Observador não-linear de alto ganho - Projeto}

Em geral, a observabilidade de sistemas não-lineares são dependentes das entradas. Entretanto, existe um classe de sistemas que é observável qualquer que seja a entrada. Esta classe é conhecida como sistemas uniformemente observáveis. Gauthier e Bornard (1981) demonstraram que sistemas de controle afins, com saída única, e uniformemente observáveis podem, na maioria dos casos, ser transformados localmente para uma forma canônica observável, composta por um termo linear observável e por um termo não-linear controlado, através de uma mudança de coordenadas de estado apropriada. Posteriormente, Gauthier; Hammouri e Othman (1992) propuseram um observador não-linear (observador de alto ganho) para essa classe de sistemas com saída única. Mais precisamente, o observador foi proposto para a seguinte classe de sistemas de controle afins: 
$\Gamma:\left\{\begin{array}{l}\dot{\mathbf{x}}=\mathbf{f}(x)+\mathbf{g}(x) \mathbf{u} \\ \mathbf{y}=\mathbf{h}(x)\end{array}\right.$

sendo $\mathbf{x}(t) \in \mathbf{R}^{n}$ o vetor de estados, $\mathbf{u} \in \mathbf{R}^{m}$ o vetor das medidas de entrada e $\mathbf{y}(t) \in \mathbf{R}$ o vetor de medidas de saída. As funções $\mathbf{f}(\mathrm{x})$ e $\mathbf{g}(\mathrm{x})$ são vetores compostos por funções pertencentes à classe $C^{\infty}$.

Sendo $\Phi$ a matriz de transformação de coordenadas definida por:

$\mathbf{z}=\boldsymbol{\Phi}(x)=\left[\begin{array}{c}\Phi_{1}(x) \\ \vdots \\ \Phi_{n}(x)\end{array}\right], \quad \Phi_{k}(x)=L_{f}^{k-1} h(x) k=1, \ldots, n$

então o seguinte teorema pode ser proposto:

Teorema 3.3 Se o sistema (3.44) é uniformemente observável, então existe um subconjunto aberto denso $\mathcal{M}$ de $\boldsymbol{R}^{n}$ tal que para $\forall x_{0} \in \mathcal{M}$, existe um subconjunto vizinho $V$, tal que o mapa (map) $\Phi$ torna-se um difeomeomorfo de $V$ (HAMMOURI,2007).

A partir do Teorema 3.3, o sistema (3.44) assume a seguinte forma canônica:

$\left\{\begin{array}{l}\dot{\mathbf{z}}(t)=\mathbf{F}(\mathbf{s}(t), \mathbf{y}(t)) \mathbf{z}(t)+\mathbf{G}(\mathbf{u}(t), \mathbf{s}(t), \mathbf{z}(t)) \\ \mathbf{y}(t)=\mathbf{C z}(t)\end{array}\right.$

onde $\mathbf{z} \in \mathbf{R}^{n}, \quad \mathbf{u} \in \mathbf{R}^{m}, \mathbf{y} \in \mathbf{R}$, s é um sinal de entrada (ou saída) diferenciável conhecido, e:

$$
\mathbf{F}(s, y)=\left[\begin{array}{cccc}
0 & f_{1}(s, y) & & 0 \\
\vdots & & \ddots & \\
& & & f_{n-1}(s, y) \\
0 & \ldots & \ldots & 0
\end{array}\right]
$$




$$
\begin{gathered}
\mathbf{G}(u, z)=\left[\begin{array}{c}
g_{1}\left(u, s, z_{1}\right) \\
g_{2}\left(u, s, z_{1}, z_{2}\right) \\
\vdots \\
g_{n}(u, s, z)
\end{array}\right] \\
\mathbf{C}=\left[\begin{array}{llll}
1 & 0 & \ldots & 0
\end{array}\right]^{T}
\end{gathered}
$$

Antes de iniciar o projeto do observador de alto ganho, é necessário apresentar as seguintes hipóteses:

Hipótese 3.1 Existe uma classe $\mathcal{U}$ limitada, um conjunto compacto $K \subset \mathbf{R}^{n}$ e duas constantes positivas $\alpha$ e $\beta$, tal que para $\forall u \in \mathcal{u}$ e para todo $y(t)$ relacionado a u e ao estado inicial $z(0) \in K$ é válida a seguinte relação (BUSAWON; FARZA; HAMMOURI, 1998):

$0<\alpha \leq\left|f_{i}(s, y)\right| \leq \beta, \quad i=1, \ldots, n-1$

Hipótese $3.2 O$ sinal $s(t)$ e a sua derivada temporal são limitados (BUSAWON; FARZA; HAMMOURI, 1998).

Hipótese 3.3 As funções $f_{i}, i=1, \ldots, n-1$ são da classe $c^{r}, r \geq 1$, com relação aos seus argumentos (BUSAWON; FARZA; HAMMOURI, 1998).

Hipótese 3.4 As funções $g_{i}(u, s, z) \quad i=1, \ldots, n$ são globalmente Lipschitz. Esta hipótese é sempre verdadeira se os estados são limitados (BUSAWON; FARZA; HAMMOURI, 1998).

Observação 3.7: Se as trajetórias de interesse do sistema situam-se em um subconjunto limitado $\Omega \in \mathbf{R}^{n}$, então o termo não-linear $\mathbf{G}(\mathbf{u}(t), \mathbf{s}(t), \mathbf{z}(t))$ pode ser estendido para uma função globalmente Lipschitz $(\widetilde{\mathbf{G}}(\mathbf{u}(t), \mathbf{s}(t), \mathbf{z}(t)))$ em um 
subconjunto externo $B$, de modo que as trajetórias do novo sistema coincidam com aquelas do sistema inicial (HAMMOURI, 2007).

Sendo a matriz $\mathbf{S}_{\theta}$ a solução única da equação algébrica de Lyapunov:

$\theta \mathbf{S}_{\theta}+\mathbf{A}^{T} \mathbf{S}_{\theta}+\mathbf{S}_{\theta} \mathbf{A}-\mathbf{C}^{T} \mathbf{C}=0$

onde:

$$
\begin{aligned}
& \mathbf{A}=\left[\begin{array}{cccc}
0 & 1 & & 0 \\
\vdots & & \ddots & \\
& & & 1 \\
0 & \ldots & \ldots & 0
\end{array}\right] \\
& \mathbf{C}=\left[\begin{array}{llll}
1 & 0 & \ldots & 0
\end{array}\right]
\end{aligned}
$$

e $\Lambda(s, y)$ uma matriz diagonal definida por:

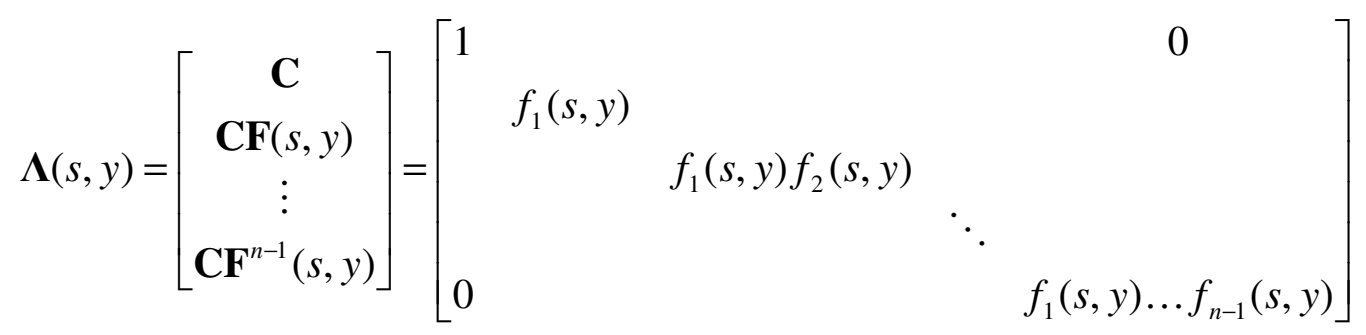

então o seguinte teorema pode ser enunciado:

Teorema 3.4 Se o sistema (3.46) satisfaz as hipóteses 3.1-3.4, então existe um $\theta_{0}>0$, tal que $\forall \theta \geq \theta_{0}, \forall u \in \mathcal{U}, \forall z(0) \in K, \forall \hat{z}(0) \in \mathbf{R}^{n}$, o seguinte sistema:

$$
\hat{\mathbf{z}}=\mathbf{F}(s, y) \hat{\mathbf{z}}+\mathbf{G}(u, s, \hat{z})-\boldsymbol{\Lambda}^{-1}(s, y) \mathbf{S}_{\theta}^{-1} \mathbf{C}^{T}(\mathbf{C} \hat{\mathbf{z}}-\mathbf{y})
$$


quando $\boldsymbol{S}_{\theta}$ satisfaz a eq.(3.51), é um observador exponencial do sistema (3.46) (BUSAWON; FARZA; HAMMOURI, 1998).

A natureza exponencial do observador (3.55) é assegurada pela Hipótese 3.4, conforme o seguinte teorema:

Teorema 3.5 Usando a Hipótese 3.4, o sistema (3.55) torna-se um observador exponencial para o sistema (3.46). Mais precisamente, tem-se:

Sendo $U$ um subconjunto compacto de $\mathbf{R}^{m}$, então existe uma constante $\theta_{0}>0$, tal que $\forall \theta>\theta_{0} ; \quad \exists \alpha>0 ; \quad \exists \beta>0 ; \quad \forall \hat{\mathbf{z}}(0)$ de modo que $\|\hat{\mathbf{z}}(t)-\mathbf{z}(t)\| \leq \alpha \exp (-\beta t)\|\hat{\mathbf{z}}(0)-\mathbf{z}(0)\|$, onde $\mathbf{z}(t)$ é a trajetória desconhecida a ser estimada (HAMMOURI, 2007).

Caso todas as funções $f_{i}$ sejam identicamente iguais a 1 , e caso $\theta>0$ seja suficientemente grande, o observador (3.55) é equivalente ao observador obtido por Gauthier; Hammouri e Othman (1992) (sistemas SISO), ou seja:

$\hat{\mathbf{z}}=\mathbf{F}(s, y) \hat{\mathbf{z}}+\mathbf{G}(u, s, \hat{z})-\mathbf{S}_{\theta}^{-1} \mathbf{C}^{T}(\mathbf{C} \hat{\mathbf{z}}-\mathbf{y})$

que re-escrito em função das variáveis de estado originais, será expresso da seguinte forma:

$$
\dot{\hat{\mathbf{x}}}(t)=\mathbf{f}(\hat{\mathbf{x}}(t), \mathbf{u})-\left(\left.\frac{\partial \Phi}{\partial \mathbf{x}}\right|_{\hat{\mathbf{x}}(t)}\right)^{-1} \mathbf{S}_{\theta}^{-1} \mathbf{C}^{T}[\mathbf{C} \hat{\mathbf{x}}(t)-\mathbf{y}(t)]
$$

Além disso, pode ser demonstrado que a solução explícita da eq.(3.51) é dada por:

$$
S_{\theta}(i, j)=\frac{(-1)^{i+j} C_{i+j-2}^{j-1}}{\theta^{i+j-1}}, \quad 1 \leq i, j \leq n
$$

onde: 


$$
C_{n}^{p}=\frac{n !}{(n-p) ! p !}
$$

Portanto, para um sistema $2 \times 2$ tem-se:

$$
\mathbf{S}_{\theta}=\left[\begin{array}{cc}
\frac{1}{\theta} & -\frac{1}{\theta^{2}} \\
-\frac{1}{\theta^{2}} & \frac{2}{\theta^{3}}
\end{array}\right]
$$

Uma extensão deste observador para sistemas MIMO foi proposta por Bornard e Hammouri (1991), Farza et al. (1997) e Hammouri e Farza (2003).

\subsubsection{Observador tipo Luenberger e de alto ganho: Aplicações}

Farza et al. (1997), Farza; Busawon e Hammouri (1998) e Farza et al. (1999) propuseram um método teórico, baseado em observadores de estado nãolineares de alto ganho, para a estimação sistemática e robusta das velocidades de reação de um processo bioquímico sem a necessidade de um conhecimento mais detalhado dos modelos que regem estas variáveis. Esses observadores foram projetados para trabalhar com medidas contínuas e discretas. A discretização do observador foi obtida através do método de Euler, reduzindo a calibração dos observadores ao ajuste de um único parâmetro de sintonia, independentemente do número de componentes ou reações usadas no modelo. Apesar da boa concordância entre os resultados estimados e as medidas experimentais, os autores verificaram que este método ainda apresenta algumas limitações, principalmente no que diz respeito ao fato de que o observador assume que determinadas medidas estão disponíveis em linha o que, na prática, nem sempre é possível.

Févotte; Barudio e Guillot (1996) propuseram uma estratégia de calorimetria adaptativa baseada no emprego das medidas discretas de conversão gravimétrica e de um algorítimo de otimização, para estimação do coeficiente $U$ e $Q_{\text {loss, }}$ e na utilização dos observadores de estado de Luenberger estendido para a predição do 
calor de reação e das conversões. Apesar das dificuldades em modelar detalhadamente um processo de polimerização em emulsão, a estratégia adaptativa e o observador de estado apresentaram boa velocidade de convergência e resultados preditos bastante próximos daqueles obtidos experimentalmente por gravimetria e cromatografia gasosa. Posteriormente, esta técnica foi utilizada por Févotte et al. (1998) para estimar e controlar a temperatura de transição vítrea de copolímeros de estireno / acrilato de butila produzidos em emulsão.

Valluri e Soroush (1996) analisaram, através de simulações, diversos aspectos relacionados à aplicação de três observadores de Luenberger (ordem plena, estendido e tipo Luenberger) para estimar os estados de um sistema químico composto por três reações paralelas e conduzido em um reator CSTR contínuo e com múltiplos estados estacionários. Neste trabalho, os autores demonstraram, analiticamente e através de simulações, que os observadores de Luenberger de ordem plena e estendido, com ganho constante, são inadequados para estimar as variáveis de estado de um processo determinístico não-linear, e que a diferença entre os estados "reais" e os estados estimados pelo observador não-linear tipo Luenberger convergirá sempre assintoticamente para zero. Porém, os autores destacaram que o observador tipo Luenberger, proposto por Ciccarella; Dalla Mora e Germani (1993), apresenta ainda algumas limitações, dentre as quais a impossibilidade de verificar analiticamente se uma função é globalmente lipschitziana, exceto em casos muito simples; e a impossibilidade de provar analiticamente a convergência global do observador e, portanto, esta convergência é demonstrada apenas através de simulações numéricas.

Hammouri; McKenna e Othman (1999) utilizaram dados calorimétricos como medidas de entrada de um observador não-linear de alto ganho para estimar, em tempo real, a evolução de parâmetros-chave de uma reação de copolimerização em solução. Estes parâmetros incluíam as composições instantâneas e acumuladas, a conversões globais e individuais de cada monômero, e a constante cinética de terminação. As informações obtidas, por sua vez, foram utilizadas para controlar a composição acumulada do copolímero mantendo, ao mesmo tempo, a produtividade em um patamar o mais alto possível.

Freire e Côrrea (2000) compararam, através de simulações, o desempenho de três observadores não-lineares de Luenberger aplicados a dois diferentes processos: uma reação de primeira ordem irreversível conduzida em um reator 
CSTR, e uma reação de fermentação conduzida em um fermentador contínuo. O primeiro observador testado foi um observador de Luenberger de ordem plena, cujas estimativas ficaram muito aquém dos resultados esperados teoricamente, uma vez que o projeto deste tipo de observador é baseado em um modelo não-linear com linearização local. O segundo observador foi um observador de Luenberger estendido que, apesar de estimar adequadamente os estados da maioria dos casos estudados, apresentou como principal desvantagem a lenta convergência para o fermentador contínuo. O terceiro foi um observador não-linear tipo Luenberger que, dentre os três métodos analisados, foi o que melhor se adaptou aos casos analisados.

Kaboré et al. (2000) investigaram o problema de detecção e isolamento de falhas (FDI), utilizando como estudo de caso uma reação de copolimerização em solução de acrilato de butila / acetato de vinila. O método de detecção e isolamento de falhas proposto pelos autores é baseado na técnica da dissociação (decoupling techniques) da geometria diferencial, e em observadores de alto ganho. As falhas consideradas pelos autores foram o mau funcionamento das bombas de alimentação dos monômeros e do iniciador, e a presença de inibidores. O uso de observadores de alto ganho para a detecção de falhas também pode ser encontrado em MartínezGuerra; Garrido e Osorio-Miron (2005).

Guo et al. (2001) desenvolveram uma estratégia de controle adaptativo nãolinear, combinando um observador de estado de alto ganho, usado para a estimação em tempo real dos parâmetros desconhecidos do processo, e um algoritmo de controle genérico (GMC). A estratégia proposta foi aplicada a dois casos: a) a um sistema químico composto por duas reações em paralelo e conduzido em um reator operando em batelada, b) a um tanque pressurizado. O ajuste dos parâmetros de sintonia foi obtido por tentativa e erro, e o observador não-linear foi capaz de fornecer estimativas bastante precisas dos parâmetros dinâmicos do processo. Posteriormente, essa estratégia de controle adaptativo não-linear foi utilizada por Hua; Rohani e Jutan (2004) para a implementação de estratégias de controle e otimização em malha fechada e em cascata, voltadas a sistemas com lacunas de informações.

Astorga et al. (2002) utilizaram observadores de alto ganho para acompanhar a evolução da concentração molar de monômeros e a evolução da composição das cadeias poliméricas durante reações semicontínuas e em emulsão 
de estireno / acrilato de butila e metacrilato de metila / acrilato de butila. Apesar da boa capacidade preditiva do método proposto, os autores observaram que os observadores de alto ganho tornam-se muito sensíveis ao ruído quando o parâmetro de sintonia é fixado em valores muito alto. Dessa forma, os autores chamam a atenção para a necessidade do uso de valores moderados para estes parâmetros, a fim de assegurar a rápida convergência do observador de estado e, ao mesmo tempo, diminuir a interferência dos ruídos sobre os estados estimados.

Besançon; Zhang e Hammouri (2004) propuseram uma estratégia adaptativa, baseada em observadores de alto ganho, para a estimação das variáveis de estado e dos parâmetros de um sistema dinâmico não-linear.

Edouard; Othman e Hammouri (2005) desenvolveram um novo modelo matemático para monitorar a distribuição de tamanho de partículas (PSD) de sistemas em emulsão. Baseado neste modelo, um observador de estado de alto ganho foi utilizado para estimar, simultaneamente, a PSD e o número médio de radicais por partícula polimérica. De acordo com os autores, a metodologia proposta foi capaz de detectar a etapa de nucleação e reconstruir a PSD, mesmo na presença de erros nas taxas de entrada e saída de radicais.

Othman e Othman (2006) utilizaram um método de controle geométrico nãolinear multivariado para maximizar a velocidade de reação $\left(R_{p}\right)$ de um processo semicontínuo de polimerização em emulsão. As estimativas da velocidade de reação foram obtidas a partir de um sistema dinâmico composto pelo balanço de energia e pela dinâmica desconhecida de $\mathrm{R}_{\mathrm{p}}$ e sobre o qual é aplicado os conceitos de observadores de alto ganho. Os termos desconhecidos do balanço de energia $\left(\mathrm{Q}_{\text {loss }}\right.$ e UA) foram obtidos a partir das medidas discretas de teor de sólidos.

Bachir et al (2008a) propuseram a utilização de observadores de alto ganho interconectados para a estimação de todas as variáveis de estado de um processo de polimerização via radicais livres. A idéia básica do observador interconectado é separar os modelos dinâmicos do processo em diversos subsistemas, sob os quais são aplicados os observadores de alto ganho, e assumindo a hipótese que os estados estimados por um subsistema estejam disponíveis para os demais.

Bachir et al. (2008b) aplicaram um observador de estado de alto ganho para estimar, em tempo real, as concentrações dos reagentes e subprodutos de uma reação em série conduzida em um reator CSTR contínuo, usando a temperatura e a concentração do produto como o vetor de medidas de entrada do sistema dinâmico. 
A estabilidade do observador é tratada analiticamente através da teoria de Lyapunov, a fim de obter as condições nas quais a convergência exponencial é obtida. O desempenho deste observador com múltiplas entradas - múltiplas saídas (MIMO) é comparado com o desempenho de um observador de alto ganho com entrada única, ou seja, quando apenas a temperatura do reator é a medida de entrada do sistema dinâmico.

\subsection{Conclusões Parciais}

Uma vez que um dos principais obstáculos para a implementação de técnicas de controle é a falta de sensores capazes de fornecer em linha as propriedades dos materiais poliméricos, diversas metodologias voltadas à identificação das principais variáveis de estado têm sido publicadas na literatura, dentre as quais os observadores de estado.

Observador de estado é uma alternativa simples e amplamente utilizada para contornar a falta de uma instrumentação robusta e de baixo custo capaz de medir em linha as variáveis de estado chave de muitos processos químicos.

Vários fatores devem ser levados em conta durante a aplicação de um observador não-linear de estado tais como: a representação do modelo do processo na forma de espaço de estados, a observabilidade dos estados de interesse, e as sensibilidades das medidas de saída frente às mudanças dos estados internos.

Entretanto, esta técnica por si só não é capaz de fornecer diretamente as variáveis desconhecidas do processo sendo necessária a utilização de outras metodologias como, por exemplo, a calorimetria apresentada na seção seguinte. 


\section{CALORIMETRIA}

Uma das principais características das reações químicas é a produção de variações da energia livre de Gibbs do sistema, que frequentemente se manifestam na forma de variações de calor. Como a taxa de calor gerado ou consumido é uma característica particular de cada reação química, o conhecimento desta grandeza permite inferir importantes informações acerca do estado e da evolução do processo.

Em geral, a taxa de calor liberado ou absorvido por um sistema, ao sofrer uma reação química, é quantificada através de equipamentos chamados calorímetros, desenvolvidos com base nos conceitos e métodos da calorimetria. Sendo assim, a calorimetria pode ser definida como uma ferramenta analítica usada para medir as perdas, ou ganhos térmicos, a partir das alterações de temperatura decorrentes das transformações, físicas ou químicas, das espécies reagentes.

Por ser uma técnica não invasiva e de baixo custo, ao longo dos anos, diversos métodos e dispositivos baseados na calorimetria foram desenvolvidos e utilizados para a caracterização da cinética e para a determinação das propriedades termodinâmicas de diversos compostos químicos, ou ainda para a observação de fenômenos que normalmente não poderiam ser investigados por outras técnicas convencionais. Dentre os tipos mais comuns de calorímetros destacam-se: a calorimetria diferencial de varredura (DSC); a calorimetria de análise térmica diferencial (DTA); bombas calorimétricas; calorimetria de solução; calorimetria de reação; calorimetria acelerada (ARC); calorimetria de pressão constante; calorimetria de titulação isotérmica; microcalorímetros de raio $X$; calorimetria de perdas térmicas; calorimetria de combustão; e calorimetria foto-acústica (LANDAU, 1996; RANDZIO, 2002).

Devido a grande diversidade de calorímetros atualmente disponíveis, esta seção tem por objetivo apresentar uma revisão da literatura relacionada aos princípios teóricos e à aplicação da calorimetria como ferramenta analítica, implementável em um reator de bancada, e na qual os dados possam ser obtidos e tratados de maneira simples e direta. Portanto, esta revisão restringe-se a apresentar apenas os principais conceitos e equações da calorimetria de reação 
usadas para a estimação indireta das variáveis de estado de um reator de polimerização, excluindo os demais calorímetros utilizados em análises específicas ou com configurações mais complexas.

Para descrever a importância e as principais dificuldades da calorimetria de reação e justificar a sua escolha como técnica de monitoramento, esta seção será subdividida em 4 subseções. Inicialmente é apresentada uma breve introdução na qual são apresentadas as principais áreas de aplicação, enfatizando a sua importância no desenvolvimento de processos químicos seguros. Na subseção seguinte os termos do balanço de energia são apresentados e discutidos separadamente com o objetivo de apontar aqueles mais relevantes e críticos em um estudo calorimétrico. Em seguida são apresentadas as principais formas de classificação dessa técnica. Para finalizar, serão apresentados alguns trabalhos da literatura nos quais são demonstrados a aplicação prática, limitações e tendências da calorimetria na engenharia de reações de polimerização.

\subsection{Introdução}

A produção de polímeros com especificações cada vez mais estritas e a necessidade de redução dos riscos inerentes a sua produção, requer um profundo conhecimento da natureza cinética e termodinâmica das reações de polimerização e o contínuo monitoramento e controle do processo, a fim de assegurar que as propriedades dos materiais poliméricos e as condições operacionais não se desviem daquelas previamente especificadas. Consequentemente, o processo deve ser equipado com sensores em linha capazes de lidar com a natureza multifásica e viscosa do látex e, ao mesmo tempo, serem suficientemente rápidos e sensíveis para permitir a observação, em tempo real, das variações das propriedades de interesse.

Dentre os diversos métodos e sensores atualmente conhecidos e disponíveis, a calorimetria de reação tem sido uma das mais utilizadas não apenas para o monitoramento e controle de reatores de polimerização mas também para o desenvolvimento e projeto de processos químicos seguros, uma vez que os dados 
térmicos obtidos através desta técnica permitem antecipar a ocorrência de autoaceleração da reação e verificar se a reação será controlável em condições normais de operação.

Como o calor gerado é uma característica específica de uma determinada reação química e como cada reação processa-se a diferentes velocidades, as medidas de temperatura combinadas com as medidas das vazões, com as leis de conservação de massa e energia e com as leis de transferência de calor, permitem inferir, indiretamente e em tempo real, diversas propriedades de interesse incluindo a conversão e a composição.

Ao longo dos anos, numerosas revisões e publicações abordando as principais aplicações, classificações, comparação entre os diversos calorímetros comerciais disponíveis, princípios teóricos, modelagem, e a utilização de dados calorimétricos para o diagnóstico e controle de reatores têm sido reportados na literatura incluindo Marti (1977), Regenass (1985, 1997), Rouquerol e Zielenkiewicz (1986), Karlsen e Villadsen (1987a, 1987b), Jacobsen (1990), Schuler e Schmidt (1992), Landau (1996), Zaldívar; Hernández e Barcons (1996), Stoessel (1997), Lebedev (1997), Ferguson et al (2000), Hansen (2001), Stoessel e Ubrich (2001), Randzio (1998, 2002), Zogg et al. (2004), Hansen e Hart (2004), Gesthuisen et al. (2005), Westerterp e Molga (2006) e Zielenkiewicz (2008).

Segundo Landau (1996), a maioria das aplicações da calorimetria estão centradas basicamente em três principais áreas:

i) análise de segurança do processo: uma vez que a calorimetria visa determinar a taxa de calor gerado, ela encontra vasto uso em processos químicos e, em especial, em reações de polimerização que são essencialmente exotérmicas. Desta forma, um dos usos mais recentes da calorimetria diz respeito à sua aplicação para a solução de problemas relacionados à segurança de processos, principalmente, para sistemas que possam apresentar um abrupto aumento da taxa de reação, causando a perda de controle da mesma. Reações com estas características podem levar à liberação de substâncias nocivas ou mesmo causar sérios danos físicos no reator. Apesar de, estatisticamente, o risco de acidentes químicos ser menor quando comparado a outras atividades industriais, estes acidentes, quando ocorrem, são frequentemente graves e mal vistos 
pela opinião pública. Desta forma, Westerterp e Molga (2006) observa que três pontos importantes devem ser considerados durante o projeto e a operação de um reator para garantir uma operação segura:

a) escolha das condições operacionais adequadas: velocidade de agitação do meio reacional, velocidade de alimentação dos reagentes, temperatura do fluido de resfriamento, e capacidade de resfriamento do reator sempre maior do que a máxima quantidade de calor produzido pela reação;

b) possibilidade de detecção precoce de eventuais falhas decorrentes de erros humanos, ou decorrentes de motivos de força maior como, por exemplo, quebra do agitador ou problemas com a circulação do fluido de resfriamento;

c) implementação de sistemas que possam conter ou minimizar os efeitos decorrentes da auto-aceleração da reação quanto esta não puder ser evitada.

De acordo com os autores em torno de $60 \%$ dos incidentes envolvendo reatores químicos poderiam ser evitados caso esses três pontos fossem observados durante o projeto ou a operação do reator. Além disso, os autores observam que, apesar de mais de $80 \%$ das reações executadas diariamente não apresentarem energia suficiente para sofrer autoaceleração, este fenômeno não é uma situação hipotética e, portanto, o terceiro ponto também deve ser considerado como um aspecto relevante e levado em conta durante o projeto.

ii) calorimetria para o desenvolvimento e otimização de processos: apesar de grande parte dos trabalhos relacionados à calorimetria não serem voltados ou não citarem explicitamente o projeto de processos como objetivo, as informações obtidas por esta técnica combinadas com ferramentas de simulação podem fornecer importantes contribuições durante o scale-up do processo. Adicionalmente, estas informações podem ser utilizadas ainda para a otimização e o controle do reator. Controlando a taxa de polimerização, a temperatura do reator pode ser mantida em um patamar inferior àquela na qual iniciar-se-ia a auto-aceleração da reação, permitindo, portanto, manter as condições de segurança e, 
simultaneamente, melhorar a produtividade e a qualidade do produto, além de reduzir o custo global do processo.

iii) pesquisas básicas em processos químicos: as aplicações definidas como pesquisas básicas incluem as áreas nas quais a calorimetria tradicionalmente não era empregada como ferramenta analítica como, por exemplo, estudo de reações catalisadas; estudo de reações enantioseletivas (reações nas quais os isômeros ópticos são formados seletivamente, não ocorrendo misturas); desenvolvimento de microcalorímetros termoanalíticos, análise térmica diferencial e calorímetro diferencial de varredura utilizados para obtenção de parâmetros térmicos (calor específico e entalpia) e cinéticos (energia de ativação, ordem da reação e constante de taxa de reação). Outros avanços recentes incluem: a aplicação da calorimetria para o estudo de diversos aspectos das reações de polimerização, a aplicação da calorimetria combinada com outras ferramentas analíticas (e.g. potenciometria, densimetria e gravimetria) e a investigação da distribuição de tamanho de partículas durante reações em miniemulsão.

\subsection{Calorimetria - Balanço de energia e equações}

Um dos principais objetivos da calorimetria é estimar a quantidade de calor produzido pela reação. Essa variável é obtida tomando o reator como volume de controle e aplicando um balanço macroscópico de fluxos térmicos (Figura 4.1) no qual são consideradas as contribuições dos termos cinéticos e termodinâmicos para a variação de temperatura do sistema.

Considerando um reator perfeitamente agitado, semicontínuo e encamisado, o balanço global de fluxos térmicos clássico será dado por:

$\left(\begin{array}{c}\text { Acúmulo de } \\ \text { calor no sistema }\end{array}\right)=\left(\begin{array}{c}\text { Entrada de } \\ \text { calor no sistema }\end{array}\right)-\left(\begin{array}{c}\text { Saída de } \\ \text { calor do sistema }\end{array}\right)$ 
Expandindo a eq.(4.01) obtém-se:

$Q_{\text {acum }}=\left(Q_{\mathrm{r}}+Q_{\mathrm{c}}+Q_{\mathrm{s}}\right)-\left(Q_{\mathrm{j}}+Q_{\text {feed }}+Q_{\text {loss }}\right)$

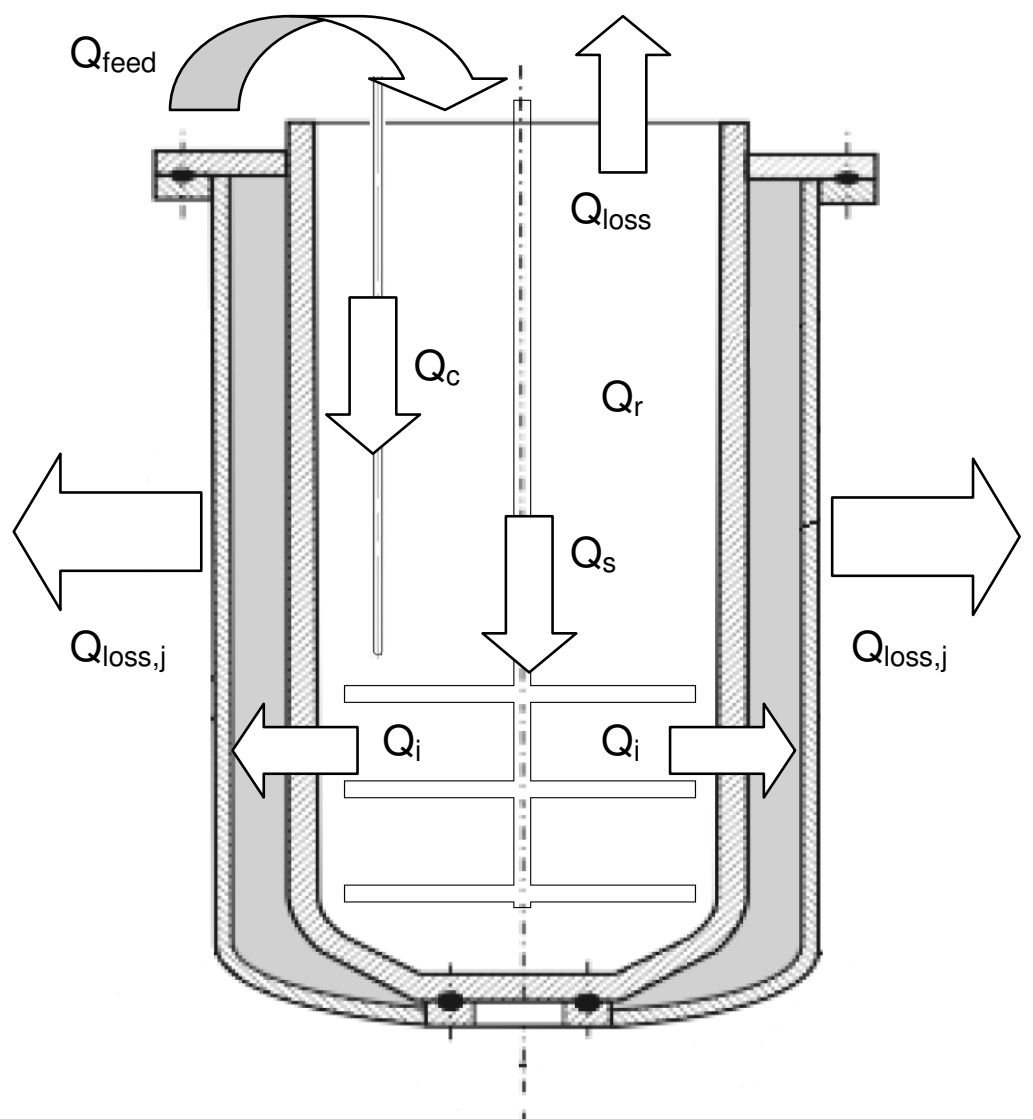

Figura 4.1 - Reator tipo tanque agitado: fluxos térmicos

sendo:

$Q_{\text {acum }}: \quad$ taxa de acúmulo de calor no sistema

$Q_{r}: \quad$ taxa de calor gerado pela reação

$Q_{\mathrm{c}}$ : $\quad$ taxa de calor introduzido no meio reacional por um fonte externa de energia durante a etapa de calibração

$Q_{\mathrm{s}}$ : $\quad$ taxa de calor introduzido no sistema devido à agitação

$Q_{\mathrm{j}}: \quad$ taxa de calor transferido do reator à camisa de refrigeração

$Q_{\text {teed }}$ : taxa de calor retirado do meio reacional devido a alimentação de reagentes à temperatura ambiente

$Q_{\text {loss }}$ : $\quad$ taxa de calor perdido para o ambiente 
A eq.(4.02) é a forma geral, em termos de fluxos térmicos, da lei da conservação de energia e constitui o instrumento teórico básico para a análise e a classificação das diversas técnicas calorimétricas. Desta forma, é necessário o entendimento claro do significado físico de cada parcela que aparece no balanço e, portanto, as equações e as hipóteses simplificadoras adotadas para o cálculo dos principais termos da eq.(4.02) são apresentadas e discutidas a seguir.

$O$ equacionamento formal do balanço de energia para reatores do tipo tanque agitado, no qual são demonstradas as deduções dos termos $Q_{a c u m}, Q_{r}$ e $Q_{\text {feed, }}$ é apresentado no Apêndice B.

\subsubsection{Taxa de acúmulo de calor ( $\left.Q_{\text {acum }}\right)$}

A quantidade de energia acumulada no reator $\left(Q_{\text {acum }}\right)$ é uma função da variação de temperatura e das capacidades caloríficas dos reagentes e dos componentes do reator, quantificada através da seguinte equação:

$$
Q_{\text {acum }}=\sum_{i} m_{i} C_{p i} \frac{d T_{r}}{d t}=\left(m C_{p}\right)_{r} \frac{d T_{r}}{d t}
$$

sendo $\left(\mathrm{mC}_{\mathrm{p}}\right)_{\mathrm{r}}$ a capacidade calorífica total do sistema.

É importante ressaltar que, a capacidade calorífica total é uma variável que engloba tanto as variações da capacidade calorífica dos reagentes quanto as variações da capacidade calorífica dos componentes não-reativos (parede, agitadores, sensores de temperatura, termorresistência...). De acordo com Tietze (1998 ${ }^{2}$ apud de LUCA e SCALI, 2002), as variações de $\left(\mathrm{mC}_{\mathrm{p}}\right)_{\mathrm{r}}$ ao longo da reação ocorrem, principalmente, devido à influência da parede do reator, uma vez que parte do calor introduzido no, ou retirado do, sistema é utilizada para aquecer ou arrefecer esta parede. Adicionalmente, Bou-Diab et al. (2001) observam que grande parte dos fatores que afetam o coeficiente global de troca térmica (UA) também afetam a

\footnotetext{
${ }^{2}$ TIETZE, A. (1998). Möglichkeiten und Grenzer der Temperaturschwingungskalorimetrie. Ph.D. Thesis, Technical University of Berlin. ISBN 3-89685-462-3.
} 
distribuição de temperaturas na parede. Consequentemente, os valores de $\left(m C_{p}\right)_{r}$ obtidos antes de cada reação por calibrações estáticas serão diferentes daqueles obtidos ao final da reação e, portanto, estes valores são válidos apenas nos pontos nos quais este parâmetro foi estimado.

Em face do exposto acima, fica claro que a utilização da calorimetria isotérmica apresenta algumas vantagens adicionais em relação aos demais tipos de calorimetria, pois neste caso as variáveis desconhecidas do processo podem ser obtidas sem a necessidade de se conhecer a capacidade calorífica dos componentes "secos" do reator $\left(Q_{a c u m}=0\right)$, e os efeitos das variações de temperatura sobre os parâmetros físicos, químicos e termodinâmicos dos componentes presentes no sistema. Entretanto, devido às não idealidades do sistema de controle da temperatura e a necessidade de elevadas taxas de troca térmica, condições estritamente isotérmicas dificilmente são obtidas na prática e, portanto, se a variação de temperatura for significativa, o termo de acúmulo deve ser levado em conta no balanço térmico. Devido às dificuldades de estimar individualmente as capacidades caloríficas dos reagentes e dos componentes nãoreativos, em geral, ambos os termos são estimados conjuntamente através de calibrações realizadas antes e depois de cada reação, ou através da utilização da calorimetria de temperatura oscilatória (TOC).

\subsubsection{Calor de reação $\left(Q_{r}\right)$}

A taxa de geração de calor pela reação $\left(Q_{r}\right)$ pode ser quantificada através das taxas individuais de conversão dos monômeros e assumindo que o calor gerado pela propagação cruzada seja igual ao calor gerado pela reação de homopolimerização. Portanto, para reações conduzidas à pressão constante, o calor gerado durante uma reação de polimerização será quantificado através da relação:

$Q_{\mathrm{r}}=\sum_{i=1}^{k}\left(-\Delta H_{i}\right) R_{p i}$ 
sendo $\left(-\Delta \mathrm{H}_{\mathrm{i}}\right)$ a entalpia de homopolimerização do monômero i, k o número total de monômeros usados na formulação e $R_{p i}$ a taxa de polimerização do monômero i.

Desta forma, a estimação de $Q_{r}$ requer que as concentrações individuais de cada monômero sejam conhecidas ao longo da reação, dificultando, ou mesmo inviabilizando, a utilização da eq.(4.04) para a estimação em linha desta variável. Por outro lado, caso as capacidades caloríficas de todos os componentes presentes no sistema e o coeficiente de troca térmica sejam conhecidos, a quantidade de calor liberado pela reação pode ser rapidamente estimada a partir do balanço térmico sem a necessidade de técnicas analíticas adicionais para a estimação das concentrações individuais dos monômeros. Entretanto, é importante ressaltar que a estimativa de $Q_{r}$ fornecida pela calorimetria de reação é um valor global e, portanto, o seu uso em sistemas químicos que apresentem reações paralelas com formação de produtos indesejados podem causar erros caso os valores de $Q_{r}$ sejam usados para inferir a conversão ou a composição do produto formado.

\subsubsection{Calor sensível de alimentação $\left(Q_{\text {feed }}\right)$}

Para reações conduzidas em regime semicontínuo, diversos componentes podem ser adicionados à uma temperatura maior, ou menor, que a do reator. O calor introduzido, ou retirado, pela alimentação dos reagentes (calor sensível de alimentação) será dado por:

$Q_{\text {feed }}=\sum_{i} F_{\mathrm{i}} C_{\mathrm{pi}}\left(T_{\text {feed }}-T_{\mathrm{r}}\right)$

sendo $F_{\mathrm{i}}$ e $\mathrm{C}_{\mathrm{pi}}$, respectivamente, a vazão instantânea de alimentação e a capacidade calorífica específica do reagente i, e $T_{\text {feed }}$ a temperatura da corrente de alimentação. 


\subsubsection{Taxa de calor transferido do reator à camisa $\left(Q_{j}\right)$}

O fluxo de calor entre o meio reacional e a camisa $\left(Q_{\mathrm{j}}\right)$ é obtido considerando um fluxo térmico unidimensional e estacionário sobre uma parede plana (Figura 4.2). Na Figura 4.2, uma parede plana (reator) separa dois fluidos à temperaturas diferentes, $T_{r}$ e $T_{j}$, que, em geral, são consideradas homogêneas, exceto no filme formado próximo à parede do reator no qual são observados gradientes de temperatura. Portanto, a transferência térmica pode ser separada em três diferentes etapas: 1) a transferência de calor ocorre por convecção do meio reacional, a uma temperatura $T_{r}$, para uma face da parede a uma temperatura $\left.T_{w}(L, t) ; 2\right)$ por condução através da parede; 3 ) e novamente por convecção da outra face da parede, a uma temperatura $T_{w}(0, t)$, para a camisa a uma temperatura $T_{j}$.

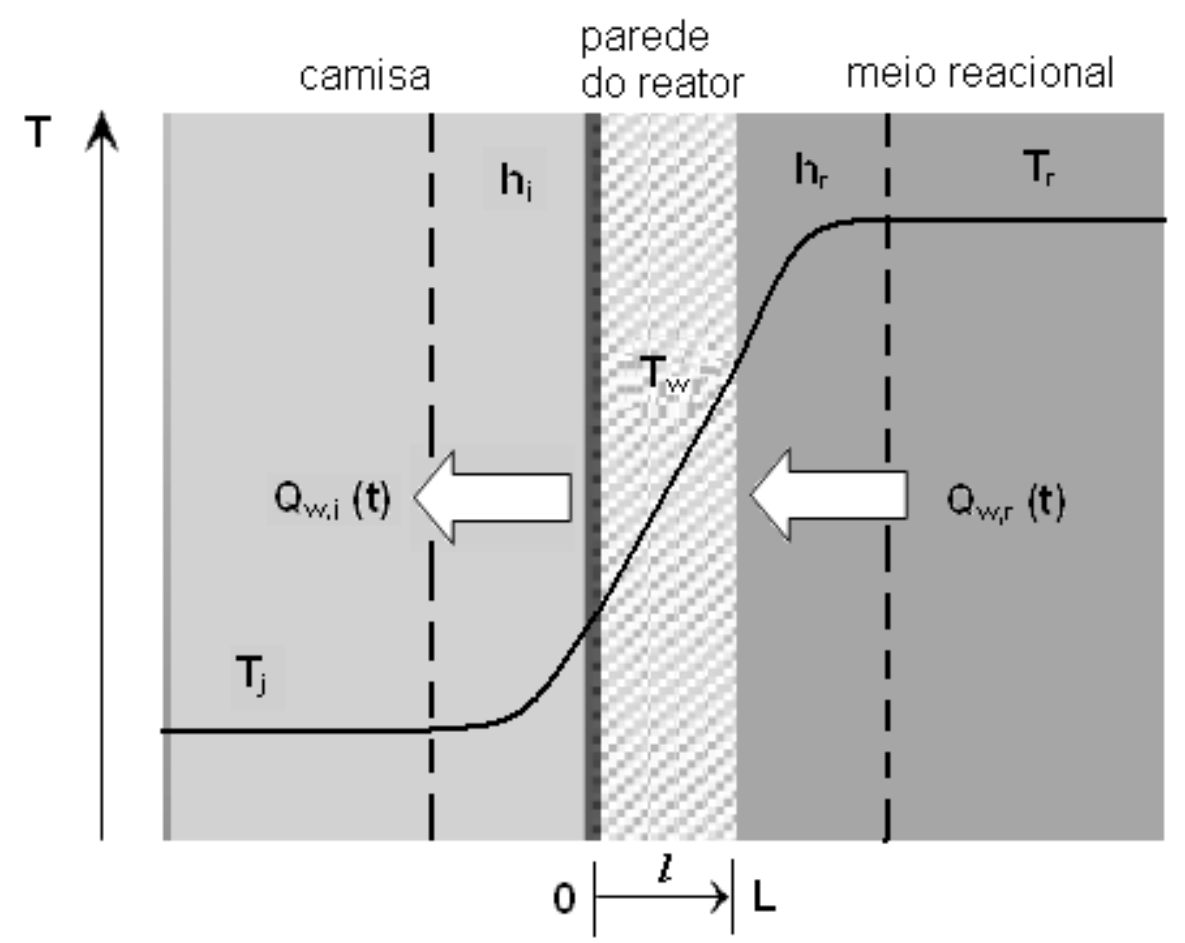

Figura 4.2 - Perfis de temperatura pela aproximação de fluxo de calor estacionário

Como na camada limite térmica, próxima à superfície da parede do reator, não há movimento do fluido, a transferência de energia ocorre exclusivamente por condução e, portanto, o fluxo local de calor pode ser obtido mediante a lei de Fourier aplicada ao fluido em $l=0$ e $l=\mathrm{L}$, ou seja: 


$$
\begin{aligned}
& l=L \quad Q_{w, r}(t)=\left.A \lambda_{r} \frac{\partial T_{w}}{\partial l}\right|_{L} \\
& l=0 \quad Q_{w, j}(t)=\left.A \lambda_{r} \frac{\partial T_{w}}{\partial l}\right|_{0}
\end{aligned}
$$

sendo $\lambda_{r}$ a condutividade térmica da parede do reator $(\mathrm{W} / \mathrm{mK})$ e $A$ a área da parede normal à direção da transferência de calor (área efetiva de troca térmica) $\left(\mathrm{m}^{2}\right)$.

Combinando as eqs.(4.06) e (4.07) com a lei de Newton do resfriamento, obtêm-se as seguintes condições de contorno:

$$
\begin{aligned}
& l=L \quad Q_{w, r}(t)=\left.A \lambda_{r} \frac{\partial T_{w}}{\partial l}\right|_{L}=A h_{r}\left[T_{r}(t)-T_{w}(L, t)\right] \\
& l=0 \quad Q_{w, j}(t)=\left.A \lambda_{r} \frac{\partial T_{w}}{\partial l}\right|_{0}=-A h_{j}\left[T_{j}(t)-T_{w}(0, t)\right]
\end{aligned}
$$

sendo $h_{r}$ o coeficiente de transferência térmica do meio reacional $\left(W / m^{2} K\right)$ e $h_{j}$ o coeficiente de transferência térmica do fluido da camisa $\left(\mathrm{W} / \mathrm{m}^{2} \mathrm{~K}\right)$

A distribuição de temperatura na parede do reator pode ser determinada pela resolução da equação de condução de calor, com as condições de contorno apropriadas. Sob condições estacionárias, sem fontes nem sorvedouros de energia distribuídos dentro da parede, o balanço de energia, supondo transferência de calor unidirecional, será dado por:

$$
\frac{\partial}{\partial l}\left(\lambda_{r} \frac{\partial T_{w}}{\partial l}\right)=0
$$

Caso a condutividade térmica $\lambda_{r}$ seja constante, a eq.(4.10) pode ser integrada duas vezes para se ter a solução geral:

$$
T_{w}=C_{1} l+C_{2}
$$


As constantes $\mathrm{C}_{1}$ e $\mathrm{C}_{2}$ podem ser obtidas a partir das condições de contorno de primeira espécie em $l=0$ e $l=\mathrm{L}$ :

$l=0 \quad T_{w}=T_{w}(0, t)$

$l=L \quad T_{w}=T_{w}(L, t)$

Fazendo as substituições na solução geral, a distribuição de temperaturas na parede do reator será dada por:

$T_{w}=\left[T_{w}(L, t)-T_{w}(0, t)\right] \frac{l}{L}+T_{w}(0, t)$

Portanto, a taxa de transferência térmica através da parede pode ser definida como:

$Q_{w}=-A \lambda_{r} \frac{\partial T_{w}}{\partial l}=\frac{A \lambda_{r}}{L}\left[T_{w}(0, t)-T_{w}(L, t)\right]$

Neste ponto, observa-se um conceito importante sugerido pelas eqs.(4.08), (4.09) e (4.15). Em particular, o que mostra uma analogia entre a difusão de calor e a condução de carga elétrica. Da mesma forma que uma resistência elétrica está associada à condução de eletricidade, pode-se associar uma resistência térmica à condução de calor. Definindo a resistência como a razão entre a força motriz e a taxa de transferência que provoca, segue-se, pela eq.(4.15), que a resistência térmica na condução $\left(R_{\text {cond }}\right)$ será dada por:

$R_{\text {cond }}=\frac{T_{w}(0, t)-T_{w}(L, t)}{Q_{w}}=\frac{L}{\lambda_{r} A}$

Uma resistência térmica também pode ser associada à transferência convectiva de calor em uma superfície e, portanto, as resistências térmicas na convecção, aplicada ao fluido em $l=0$ e $l=\mathrm{L}$, serão dadas por: 


$$
\begin{aligned}
& l=\left.L \quad R_{\text {conv }}\right|_{l=L}=\frac{T_{r}(t)-T_{w}(L, t)}{Q_{w, r}}=\frac{1}{h_{r} A} \\
& l=\left.0 \quad R_{\text {conv }}\right|_{l=0}=\frac{T_{w}(0, t)-T_{j}(t)}{Q_{w, j}}=\frac{1}{h_{j} A}
\end{aligned}
$$

Desta forma, a taxa global de transferência de calor pode ser determinada a partir da consideração isolada de cada elemento do circuito, isto é:

$$
Q_{j}=\frac{T_{r}-T_{w}(L)}{\frac{1}{h_{r} A}}=\frac{T_{w}(0)-T_{w}(L)}{\frac{L}{\lambda_{r} A}}=\frac{T_{w}(0)-T_{j}}{\frac{1}{h_{j} A}}
$$

Em termos de diferença global de temperatura, $T_{r}-T_{j}$, e da resistência térmica total, $\mathrm{R}_{\mathrm{tot}}$, a taxa global de transferência de calor pode também ser expressa como:

$$
Q_{j}=\frac{T_{r}-T_{j}}{R_{\text {tot }}}
$$

Em virtude das resistências condutiva e convectiva estarem em série e, portanto, poderem ser somadas, segue-se que:

$$
R_{t o t}=\frac{1}{h_{r} A}+\frac{L}{\lambda_{r} A}+\frac{1}{h_{j} A}=\left(\frac{1}{h_{r}}+\frac{L}{\lambda_{r}}+\frac{1}{h_{j}}\right) \frac{1}{A}
$$

sendo que as soma das resistências condutivas e convectivas correspondem, na ausência de incrustações, ao inverso do coeficiente total de troca térmica $(U)$, ou seja:

$$
\frac{1}{U}=\frac{1}{h_{r}}+\frac{L}{\lambda_{r}}+\frac{1}{h_{j}}=\frac{1}{h_{r}}+\frac{1}{\varphi}
$$


sendo $\varphi$ o coeficiente específico de transferência de calor do equipamento $\left(W / m^{2} K\right)$.

O primeiro termo do lado direito da eq.(4.22) $\left(h_{r}\right)$ depende apenas da velocidade de agitação e dos elementos que compõem o meio reacional e, portanto, pode ser escrito em função das propriedades físicas e de transporte do sistema (STOESSEL, 1997 e ZOGG, 2003). Desta forma, aplicando a correlação de Nusselt para o filme interno formado entre o meio reacional e a parede do reator obtém-se:

$$
N u=C \operatorname{Re}^{2 / 3} \operatorname{Pr}^{1 / 3}\left(\frac{\eta}{\eta_{w}}\right)^{0,14}
$$

onde $\eta$ e $\eta_{w}$ são, respectivamente, a viscosidade dinâmica do meio reacional (Pa.s) à temperatura $T_{r}$ e $T_{w}, C$ um fator geométrico dependente do tipo de agitador, e Re e $\operatorname{Pr}$ correlações de transporte calculadas em função das propriedades físicas do sistema e definidas como:

Número de Nusselt:

$$
N u=\frac{h_{r} d_{r}}{\lambda}
$$

Número de Reynolds: $\quad \operatorname{Re}=\frac{N d_{s}^{2} \rho}{\eta}$

Número de Prandtl: $\quad \operatorname{Pr}=\frac{\eta C_{p}}{\lambda}$

sendo $d_{r} \circ$ diâmetro interno do reator $(m), \lambda$ a condutividade térmica do meio reacional $(\mathrm{W} / \mathrm{mK}), \mathrm{N}$ o número de rotações por segundo do agitador $\left(\mathrm{s}^{-1}\right), \mathrm{d}_{\mathrm{s}} \mathrm{o}$ diâmetro do agitador, $\rho$ a densidade do meio reacional $\left(\mathrm{g} / \mathrm{m}^{3}\right)$ e $\mathrm{C}_{\mathrm{p}}$ a capacidade calorífica específica do meio reacional (J/gK).

Em geral, a razão entre as viscosidades pode ser desprezada, pois não são observadas variações drásticas entre ambos os valores. Agrupando as eqs.(4.23)(4.26) o coeficiente $h_{r}$ pode então ser re-escrito em função da geometria, das condições operacionais do reator e das propriedades físico-químicas do meio reacional: 
$h_{r}=C \frac{N^{2 / 3} d_{s}^{4 / 3}}{d_{r} g^{1 / 3}} \sqrt[3]{\frac{\rho^{2} \lambda^{2} C_{p} g}{\eta}}=z \gamma$

sendo $\mathrm{g}$ a aceleração da gravidade $\left(\mathrm{m} / \mathrm{s}^{2}\right), \mathrm{z}$ uma constante de transferência térmica calculada a partir das características geométricas do equipamento, e $\gamma$ uma constante física de transferência de calor $\left(\mathrm{W} / \mathrm{m}^{2} \mathrm{~K}\right)$ estimada a partir das propriedades físico-químicas, caso estas sejam conhecidas, ou obtida a partir do gráfico de Wilson, caso a reação seja conduzida em um reator calorimétrico comercial.

Uma equação análoga à eq.(4.27) para a camisa pode ser obtida apenas quando as características geométricas do reator são conhecidas. Entretanto, Zogg (2003) observa que a maioria dos calorímetros comerciais são compostos por duas camisas e, portanto, os modelos disponíveis na literatura não são adequados para descrever o comportamento de $h_{j}$ para estes tipos de reatores. Além disso, assim como $h_{r}, h_{j}$ também irá depender das principais propriedades físicas do fluido refrigerante. Consequentemente, de acordo com Stoessel (1997), em situações práticas a resistência condutiva oferecida pela parede $\left(L / \lambda_{r}\right)$ e a resistência convectiva oferecida pela camada limite térmica da camisa $\left(h_{j}\right)$ são estimadas em conjunto (parâmetro $\varphi$ ) a partir dos resultados experimentais coletados durante 0 resfriamento do reator, quando este se encontra preenchido com uma substância com propriedades físico-químicas conhecidas e com um nível acima do nível da camisa para evitar a interferência da área de troca térmica.

Desse modo, de acordo com Zogg (2003) a variação de U, durante um reação química, pode ser atribuída a dois fatores principais:

i) à variação de $h_{r}$ causada pelas mudanças nas propriedades físicas do meio reacional como, por exemplo, aumento da viscosidade;

ii) dependendo do sistema calorimétrico escolhido, $h_{j}$ pode variar devido as alterações das propriedades físicas do fluido refrigerante causadas pela variação de $T_{j}$.

Portanto, a eq.(4.22) é utilizada para estimar $U$ apenas quando as características geométricas do reator e as propriedades físico-químicas dos 
componentes do sistema são conhecidas. Como a estimação individual destas variáveis nem sempre é possível, em geral, algumas técnicas são utilizadas para obter, de forma direta, o valor da resistência térmica total. Desta forma, a eq.(4.20) é escrita de forma mais adequada se $Q_{j}$ for expressa em função do gradiente de temperatura $\left(T_{r}-T_{j}\right)$ e em função do coeficiente global de troca térmica, ou seja, combinando as eqs.(4.22), (4.21) e (4.20) obtém-se:

$$
Q_{j}=U A\left(T_{r}-T_{j}\right)
$$

onde UA é o coeficiente global de troca térmica $(\mathrm{W} / \mathrm{K})$.

Para condições não-adiabáticas $\left(Q_{j} \neq 0\right)$ e na ausência de perdas térmicas acentuadas, a taxa de transferência de calor para a camisa torna-se o termo mais importante para o cálculo do calor de reação $\left(Q_{r}\right)$. Por ser um termo crucial, grande parte das limitações relacionadas à calorimetria são decorrentes da dificuldade em estimar o perfil exato desta variável ao longo da reação, uma vez que para a sua correta quantificação é necessário conhecer também a evolução do coeficiente UA, cuja estimação nem sempre é uma tarefa simples.

De acordo com as eqs.(4.21) e (4.27), a dificuldade para predizer a evolução do coeficiente UA ao longo de uma reação de polimerização pode ser, basicamente, atribuída a três fatores:

i) devido às variações das propriedades físicas do meio reacional, principalmente, variações na viscosidade que, em geral, tendem a ser mais drásticas do que as variações da densidade, da condutividade térmica e da capacidade calorífica. Líquidos viscosos têm uma menor turbulência e, por conseguinte, menor transferência de calor;

ii) devido à variação da área efetiva de troca térmica causada pela alimentação de reagentes e pela agitação do meio reacional;

iii) a formação de filme polimérico ou o depósito de incrustações sobre a parede do reator representam sempre problemas adicionais que podem dificultar a troca térmica ao longo da reação (formação de filme) ou ao longo da vida útil do reator (formação de incrustações na camisa) 
Os efeitos de $h_{j}$ sobre UA podem ser minimizados aumentando a vazão do fluido de refrigeração, de modo a assegurar elevadas turbulências na camisa para favorecer a transferência de calor por convecção e, ao mesmo tempo, manter a perda de carga em valores aceitáveis. Adicionalmente, o aumento da turbulência na camisa retarda a formação de depósitos sobre a parede do reator devido ao arraste destes pelo fluido. A espessura $(L)$ e a condutividade térmica da parede do reator $\left(\lambda_{r}\right)$ pouco contribuem para a variação de UA, uma vez que ambos são parâmetros característicos do equipamento e do material de fabricação e, portanto, permanecem constantes ao longo da reação.

Consequentemente, quando o coeficiente global de troca térmica sofre grandes alterações durante a reação, a eq.(4.02) não pode ser utilizada para calcular $Q_{r}$, a menos que a variação temporal de UA seja conhecida. Comumente, as variações de UA são obtidas:

i) pelo uso do balanço de energia da camisa (calorimetria de balanço térmico). Neste caso, as vazões e as temperaturas de entrada e de saída da camisa devem ser conhecidas;

ii) por calibrações realizadas antes e depois de cada reação. $O$ valores iniciais e finais de UA são então usados para a obtenção de um perfil desejado de UA(t). As principais desvantagens desta técnica é que ela requer longos tempos de calibração, inviabilizando a sua aplicação em reatores de escala industrial, e os resultados são extremamente dependentes da qualidade da interpolação (de LUCA; SCALI, 2002);

iii) pela calorimetria de temperatura oscilatória (CARLOFF; PROSS; REICHERT, 1994; TIETZE; LÜDKE; REICHERT, 1996; BOU-DIAB et al., 2001; de LUCA; SCALI, 2002; SEMPERE et al., 2003; FREIRE; GIUDICI, 2004; GESTHUISEN et al, 2005). A calorimetria de temperatura oscilatória (TOC) é um método de identificação contínua da capacidade calorífica total do reator e do coeficiente de troca térmica, aplicado em reatores com sistemas de controle capazes de assegurar uma operação próxima à condição isotérmica. Este método é baseado no fato de que o fluxo de calor é, basicamente, a soma de duas variações: uma variação lenta, causada pelo calor de reação, e uma variação rápida, causada pela imposição de uma oscilação na temperatura da camisa ou na temperatura 
do reator. As oscilações de temperatura podem ser obtidas de duas maneiras distintas: a) impondo uma variação senoidal sobre o set point de $T_{r}$ obtida através de um sistema externo de controle de temperatura (de LUCA; SCALI, 2002), ou b) através do calor dissipado por uma resistência elétrica, inserida no meio reacional, e mantendo $T_{r}$ no set point (de LUCA; SCALI, 2002). De acordo com Othman (2000) este tipo de calorimetria é interessante para reatores laboratoriais, mas não é aplicável em reatores industriais, uma vez que nestes reatores pode ocorrer o surgimento de gradientes de temperatura devido a dificuldade de se obter um meio reacional perfeitamente agitado. Além disso, Gesthuisen et al. (2005) observa que, caso a reação apresente um aumento ou um decréscimo acentuado de $Q_{r}$, a calorimetria oscilatória não consegue desacoplar as variações de $T_{r}$ causadas pela oscilação das variações causadas pelo calor de reação. Portanto, este método pode não ser aplicável em reações conduzidas em regime batelada ou sob condições isoperibólicas.

iv) por observadores de estado (OTHMAN, 2000; BENAMOR; COLOMBIÉ; McKENNA, 2002; FREIRE et al, 2004; FREIRE; GIUDICI, 2004; GESTHUISEN et al, 2005; KRÄMER; GESTHUISEN, 2005). Neste método o calor de reação e o coeficiente global de troca térmica são estimados continuamente utilizando as medidas de $T_{r}$ coletadas ao longo da reação. Assim como a calorimetria oscilatória, a grande vantagem deste enfoque é a possibilidade de estimar $Q_{r}$ e UA sem a necessidade do balanço de energia da camisa. Por outro lado, esta técnica requer um ajuste frequente dos parâmetros de sintonia dos observadores, sem o qual não é possível estimar adequadamente as variáveis desconhecidas do processo. Adicionalmente, Krämer e Gesthuisen (2005) observam que em determinadas aplicações envolvendo o uso de observadores de estado não-lineares, em particular observadores operando em "cascata", a observabilidade e a estabilidade do observador ainda não foram demonstradas teoricamente.

v) pelo uso de relações empíricas que correlacionem o valor de $U$ com determinadas propriedades do meio reacional como, por exemplo, viscosidade (GLOOR; WARNER, 1996), teor de sólidos (SAENZ DE 
BURUAGA et al., 1997) ou conversão gravimétrica (FEVOTTE et al., 1998a).

Com relação à temperatura da camisa $\left(\mathrm{T}_{\mathrm{j}}\right)$, dependendo das condições operacionais do reator, algumas considerações importantes também devem ser observadas para a correta estimação de $Q_{j}$. Se a vazão do fluido de refrigeração for suficientemente alta, as temperaturas de entrada e de saída da camisa são aproximadamente iguais e, portanto, um valor médio, ou mesmo a temperatura de entrada ou a temperatura de saída, pode ser usado na eq.(4.28) sem incorrer em maiores erros. Por outro lado, reatores com volumes maiores combinado com um tempo de residência relativamente longo podem, eventualmente, apresentar variações acentuadas entre as temperaturas de entrada e de saída da camisa causadas pelo aumento de absorção de calor pelo meio reacional e/ou pelo aumento da perda térmica do fluido da camisa para o ambiente. Nestes casos, segundo Landau (1996), duas abordagens podem ser adotadas para o cálculo de $T_{j}$ :

i) $\quad T_{j}$ é igual a média logarítmica das temperaturas de entrada e saída da camisa, ou seja:

$$
T_{\mathrm{j}, \mathrm{ln}}=\frac{T_{\mathrm{j}, \text { out }}-T_{\mathrm{j}, \text { in }}}{\ln \left(\frac{T_{\mathrm{j}, \text { out }}}{T_{\mathrm{j}, \text { in }}}\right)}
$$

ii) $T_{j}$ é obtida a partir do balanço de energia aplicado sobre a camisa

De acordo com o autor, a primeira abordagem perde a precisão conforme a diferença $T_{j, \text { out }}-T_{j, \text { in }}$ aumenta, já que a média logarítmica é calculada assumindo um perfil específico entre $T_{r}$ e $T_{j}$ e uma superfície de troca linear como, por exemplo, um superfície tubular ou plana. Portanto, a temperatura logarítmica média é apenas uma aproximação para uma complexa variação de temperaturas que ocorre sobre a superfície de troca térmica causada pela vazão do fluido de refrigeração e pelo fluxo de calor proveniente do meio reacional. 


\subsubsection{Calor de agitação $\left(Q_{s}\right)$ e perdas térmicas $\left(Q_{\text {loss }}\right)$}

O calor introduzido no meio reacional devido à agitação $\left(Q_{s}\right)$ pode ser quantificado através da seguinte relação:

$Q_{s}=\operatorname{Ne} \rho N^{3} d_{s}^{5}$

sendo $\rho$ a densidade do meio reacional, $\mathrm{N}$ o número de rotações, por segundo, do agitador, $\mathrm{d}_{\mathrm{s}} \mathrm{O}$ diâmetro do agitador, e $\mathrm{Ne} u$ um fator adimensional (número de Newton) calculado em função do número de Reynolds. Algumas correlações experimentais para o cálculo de Ne são apresentadas por Tacă e Păunescu (2001).

Experimentalmente, a quantidade de calor introduzido no meio reacional devido à agitação é obtida na ausência de reação e mantendo-se a temperatura do reator constante. Nesta situação, o balanço térmico reduz-se à soma das contribuições das perdas térmicas e da energia dissipada pelo agitador, permitindo a estimação de $Q_{S}$ em função da frequência de agitação. A grande desvantagem deste método é a possibilidade das medidas serem afetadas pelas variações térmicas como, por exemplo, variações na temperatura ambiente (STOESSEL, 1997).

Como para a maioria das reações de polimerização em emulsão, em geral, são utilizadas baixas velocidades de agitação e as viscosidades e densidades são baixas ou moderadas, a contribuição de $Q_{s}$ é muito pequena quando comparada às demais taxas da eq.(4.02) e, portanto, este termo pode ser desconsiderado do balanço térmico.

A taxa de calor perdido para o ambiente $\left(Q_{\text {loss }}\right)$ contabiliza todos os tipos de troca térmica com 0 ambiente, incluindo as perdas pelo condensador. Sua importância para as estimativas de $Q_{r}$ aumenta à medida que a diferença $T_{r}-T_{a m b}$ aumenta. Como, na maioria dos casos, boa parte ou toda a superfície do reator é coberta pela camisa, a quantificação de $Q_{\text {loss }}$ reduz-se, basicamente, na quantificação da taxa de calor perdido pelo condensador $\left(Q_{c o n d}\right)$ que, por sua vez, requer o conhecimento da quantidade de monômero condensado e das temperaturas do vapor e do fluido que circulam pela serpentina, e que são obtidas apenas através da instalação de instrumentação adequada. Assim, uma forma de 
minimizar, ou eliminar, o impacto causado pelas perdas térmicas sobre as estimativas de $Q_{r}$ é realizar as reações em um reator completamente encamisado e sem a presença de condensadores $\left(Q_{\text {loss }} \approx 0\right)$.

Substituindo as eqs.(4.03), (4.05) e (4.28) na eq.(4.02), o balanço de energia do reator pode ser escrito da seguinte forma:

$$
\frac{d T_{\mathrm{r}}}{d t}=\frac{1}{\left(m C_{\mathrm{p}}\right)_{\mathrm{r}}}\left[Q_{\mathrm{r}}-U A\left(T_{\mathrm{r}}-T_{\mathrm{j}}\right)+\sum_{\mathrm{i}} F_{\mathrm{i}} C_{\mathrm{pi}}\left(T_{\text {feed }}-T_{\mathrm{r}}\right)-Q_{\text {loss }}\right]
$$

É importante ressaltar que a eq. (4.31) foi obtida considerando que o fluxo térmico através da parede do reator é constante. Entretanto, em determinadas situações como, por exemplo, na presença de reações químicas, este fluxo pode não ser constante e, portanto, o perfil de temperatura não apresentará mais um comportamento linear como aquele mostrado na Figura 4.2. Consequentemente, a parede do reator e ambas as camadas limites térmicas podem absorver parte do calor transferido do meio reacional à camisa e, portanto, as relações termodinâmicas e o balanço de energia devem ser regidos por equações diferenciais parciais que levem em conta as variações temporais e espaciais das variáveis analisadas (ZOGG, 2003).

Como em meios sólidos a transferência térmica ocorre exclusivamente por condução, a modelagem desta nova situação na parede é relativamente simples, pois a equação de Fourier e, consequentemente as eqs. (4.08) e (4.09), continuam válidas para descrever o fluxo térmico sobre a superfície da parede, contanto que a condutividade térmica $\left(\lambda_{r}\right)$ não dependa da temperatura. Modelos que descrevem a dinâmica dos fluxos térmicos na presença de acúmulo de calor, e os métodos para a solução do sistema de equações diferenciais parciais obtido foram apresentados por Karlsen e Villadsen (1987a e 1987b). Neste trabalho, os fluxos térmicos dinâmicos foram calculados desconsiderando-se a curvatura da parede do reator, as variações de $h_{r}$ e $h_{j}$, e o acúmulo de calor na camada limite térmica. Modelos mais precisos, nos quais são incluídos a geometria do reator, foram apresentados por Zaldívar; Hernández e Barcons (1996).

Com relação a transferência térmica no fluido de refrigeração e no meio reacional esta análise torna-se mais complexa, pois nestas regiões a transferência 
de calor ocorre tanto pela condução como pela convecção, e os perfis de temperatura nos filmes formados próximo à parede não são lineares mesmo considerando a hipótese de fluxo térmico estacionário. Esta análise torna-se ainda mais complexa caso os coeficientes $h_{r}$ e $h_{j}$ sofram alterações, uma vez que as propriedades físicas dos fluidos podem sofrer variações drásticas causadas pelas variações de temperatura.

Dessa forma, modelos que descrevam exatamente a transferência dinâmica de calor do meio reacional para o fluido de refrigeração dificilmente são encontrados na literatura. Para contornar esses problemas, em geral, é adotada a hipótese de estado estacionário e o fluxo $Q_{j}$ é quantificado através da eq.(4.28), ou os perfis de temperatura do sistema são obtidos por fluido dinâmica computacional (CFD) (ZOGG, 2003).

\subsection{Calorimetria - Tipos e classificações}

Os diferentes tipos de calorímetros disponíveis podem ser classificados quanto ao método de controle de $T_{r}$ e quanto ao método de medição e controle dos fluxos térmicos.

\subsubsection{Classificação quanto aos fluxos térmicos}

De acordo com o método de medição e controle dos fluxos térmicos, a calorimetria pode ser agrupada em quatro categorias conforme Regenass (1985), Zog (2003) e Zogg et al. (2004):

Calorimetria de fluxo de calor (Heat-flow reaction calorimeter): a temperatura do meio reacional $\left(T_{r}\right)$ é controlada variando a temperatura da camisa $\left(T_{j}\right)$ e mantendo a vazão do fluido de refrigeração suficientemente alta. Neste método, a taxa de transferência de calor entre o reator e a camisa é quantificada 
através da diferença $T_{r}-T_{j}$ multiplicada pela área efetiva e pelo coeficiente de troca térmica e, portanto, a sua aplicação requer que o valor do coeficiente UA seja conhecido antes e durante a reação. Grande parte dos calorímetros comerciais são baseados no princípio de fluxo térmico.

\section{Calorimetria de compensação térmica (Power-compensation reaction}

calorimeter): nesta técnica a temperatura da camisa é mantida constante através de um criostato externo, e a temperatura do meio reacional é controlada variando a potência dissipada por uma resistência elétrica introduzida no reator. Como a diferença entre $T_{r}$ e $T_{j}$ é mantida sempre constante, o "resfriamento" do reator é obtido reduzindo a potência dissipada pela termorresistência. A principal vantagem desta categoria, em relação à calorimetria de fluxo de calor, é que o calor de reação pode ser obtido diretamente da potência dissipada durante a compensação térmica e, portanto, não é necessário conhecer a evolução do coeficiente global de troca térmica ao longo da reação. Por outro lado, como o fluxo $Q_{j}$ é mantido constante, os sinais medidos tornam-se muito mais sensíveis à variação do coeficiente $h_{r}$ ou à variação da área efetiva de troca térmica quando comparado à calorimetria de fluxo térmico. Outras duas grandes desvantagens desta técnica são a possibilidade de formação de hot spots sobre a superfície da resistência elétrica, e a presença de sérios problemas com a linha base que, de acordo com Schildknecht (1981), são inerentes a estes tipos de calorímetros.

\section{Calorimetria de balanço térmico (heat-balance reaction calorimeter): a} temperatura do meio reacional $\left(T_{r}\right)$ é controlada variando a temperatura do fluido de refrigeração $\left(T_{j}\right)$. Nesta técnica, a dinâmica da camisa é considerada para a estimação das variáveis calorimétricas e, portanto, as temperaturas de entrada e de saída da camisa, e a vazão do fluido de refrigeração devem ser conhecidas. Como o balanço térmico é aplicado também para a camisa, o calor gerado pela reação é estimado sem a necessidade de longas calibrações ou técnicas complicadas para a obtenção do valor inicial e do perfil do coeficiente UA. A grande desvantagem desta técnica é que ela transfere o problema da estimativa do coeficiente UA para a estimativa da perda térmica pela camisa $\left(Q_{\text {loss, }}\right)$, caso esta não seja isolada termicamente, e, portanto, a influência da temperatura ambiente sobre o sinal medido é maior quando comparado a outras técnicas calorimétricas. Adicionalmente, 
Zogg (2003) observa que a vazão do fluido de arrefecimento deve satisfazer a dois requisitos difíceis de serem obtidos simultaneamente: a) por um lado, o fluido de refrigeração deve ter uma vazão suficientemente alta para que seja possível o controle de $\mathrm{T}_{\mathrm{r}}$ em um valor constante; b) por outro lado, ela deve ser baixa para criar uma diferença de temperatura suficientemente alta entre a entrada e a saída da camisa para que esta possa ser medida com precisão.

Calorímetros de Peltier (Peltier calorimeters): a temperatura do reator é controlada variando a potência dos elementos de Peltier. Elementos de Peltier são pequenos termoelementos (geralmente uma liga de semicondutores) conectados eletricamente em série. Algumas centenas destes termoelementos são colocados entre duas placas cerâmicas, formando um módulo de Peltier. Este tipo de calorímetro é construído colocando-se o reator em um banho termostático que substitui a camisa. No fundo do reator são instalados os elementos de Peltier e o restante do reator é isolado termicamente e, portanto, a saída de calor ocorre essencialmente através dos termoelementos. Ao contrário da calorimetria de compensação térmica, estes calorímetros podem ser usados tanto para o resfriamento quanto para o aquecimento. Neste método, a taxa de transferência de calor, do reator para o banho termostático, é quantificada a partir da potência elétrica e do gradiente de temperatura formado sobre os elementos de Peltier.

\subsubsection{Classificação quanto ao método de controle de $T_{r}$}

De acordo com a forma de controle da temperatura do meio reacional, a calorimetria pode ser classificada em três grupos e são descritos por Gesthuisen et al. (2005):

Calorimetria adiabática: nesta técnica a temperatura da camisa é controlada e mantida em um valor aproximadamente igual à temperatura do reator (Figura 4.3), minimizando, ou mesmo evitando, as perdas térmicas e a transferência de calor do meio reacional para o fluido de refrigeração $\left(Q_{j}=0\right)$, ou seja, todo o calor de reação é acumulado dentro do reator. Como não ocorrem trocas de calor com os 
arredores, a taxa de geração de calor é obtida diretamente da taxa de variação de $T_{r}$ $\left(Q_{r}=Q_{a c u m}\right)$. Desta forma, esta técnica normalmente é utilizada para a determinação de parâmetros cinéticos e termodinâmicos, e também constitui uma importante ferramenta para análise de risco de auto-aceleração térmica de reações que envolvam espécies reativas exotérmicas. Condições próximas à condição adiabática também podem ser obtidas em reações com elevadas taxas reacionais, pois nestes casos a reação é tão rápida que, durante o consumo dos reagentes, a quantidade de calor removida do, ou adicionada no, sistema é muito menor do que a quantidade de calor gerado pela reação. De acordo com Moritz (1989³ apud AL-HAJ ALI et al., 2007) a calorimetria adiabática é um método arriscado para reações altamente exotérmicas, já que todo o calor gerado pela reação é retido dentro do reator. Além disso, o aumento excessivo da temperatura do reator pode acabar favorecendo a ocorrência de reações secundárias, ou mesmo afetar o transporte de massa, dos diversos componentes, entre as diferentes fases que compõe o sistema. Portanto, calorímetros adiabáticos não são recomendados para a investigação de reações de polimerização, exceto quando a investigação tem por objetivo analisar o fenômeno de auto-aceleração da reação ou estudar os aspectos de segurança do reator.

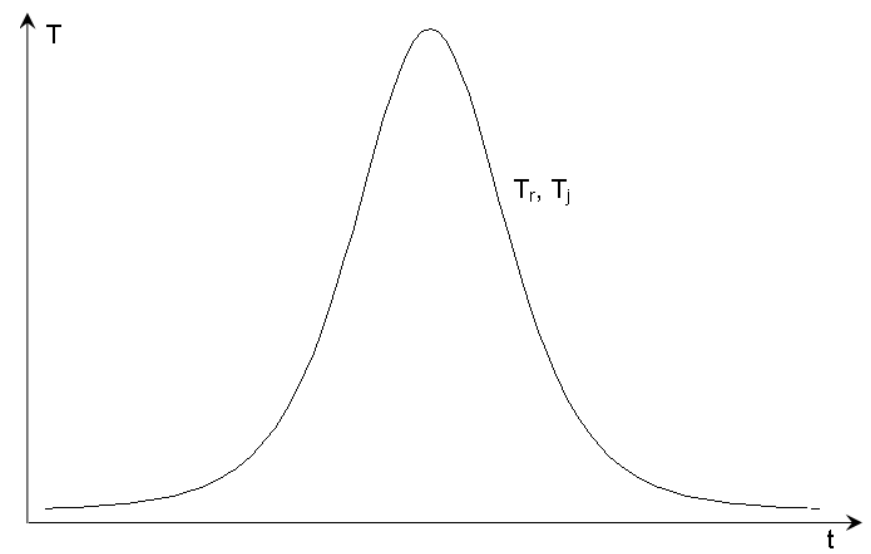

Figura 4.3 - Perfis de $T_{r}$ e $T_{j}$ - calorimetria adiabática

Calorimetria isoperibólica: nesta técnica, a temperatura da camisa é mantida em um valor constante, enquanto a temperatura do meio reacional é apenas uma variável medida, ou seja, ambas as temperaturas são independentes e possuem dinâmicas próprias (Figura 4.4). $O$ controle de $T_{j}$ é obtido utilizando uma

\footnotetext{
${ }^{3}$ MORITZ, H. U. in: Polymer Reaction Engineering, K-H. Reichert, W. Geiseler, Eds., VCH, Weinheim 1989, p. 248.
} 
vazão de fluido de refrigeração suficientemente alta ou um banho termostático e, portanto, a perda térmica pela camisa é muito baixa $\left(Q_{10 o s, j} \approx 0\right)$. Caso a diferença entre as temperaturas de entrada e saída da camisa seja pequena, o coeficiente de transferência térmica deve ser conhecido com boa precisão para que a taxa de calor gerado pela reação seja estimada adequadamente (calorimetria de fluxo térmico).

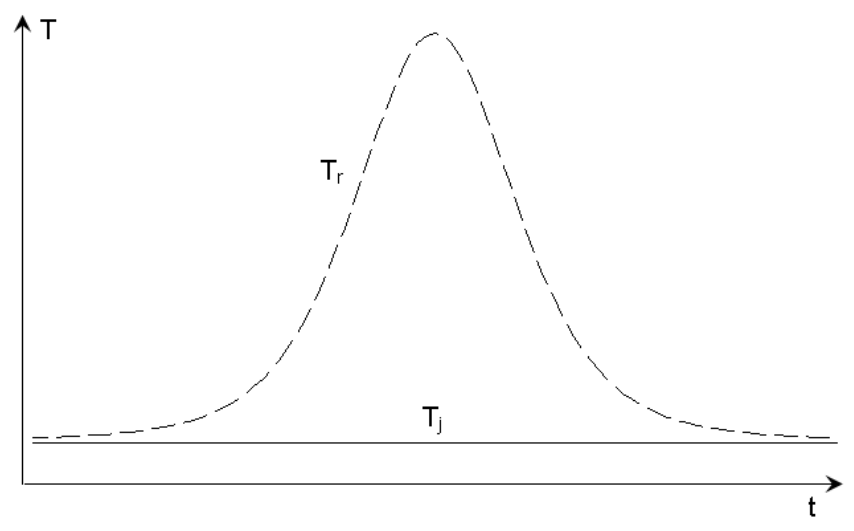

Figura 4.4 - Perfis de $T_{r}$ e $T_{j}$ - calorimetria isoperibólica

Calorimetria isotérmica: neste método, a temperatura do meio reacional é mantida constante controlando-se a temperatura da camisa e, portanto, o acúmulo de calor no reator é nulo $\left(Q_{a c u m}=0\right)$. Caso a diferença entre as temperaturas de entrada e de saída da camisa seja suficientemente alta, o coeficiente global de troca térmica pode ser obtido aplicando-se o balanço térmico sobre a camisa (calorimetria de balanço térmico).

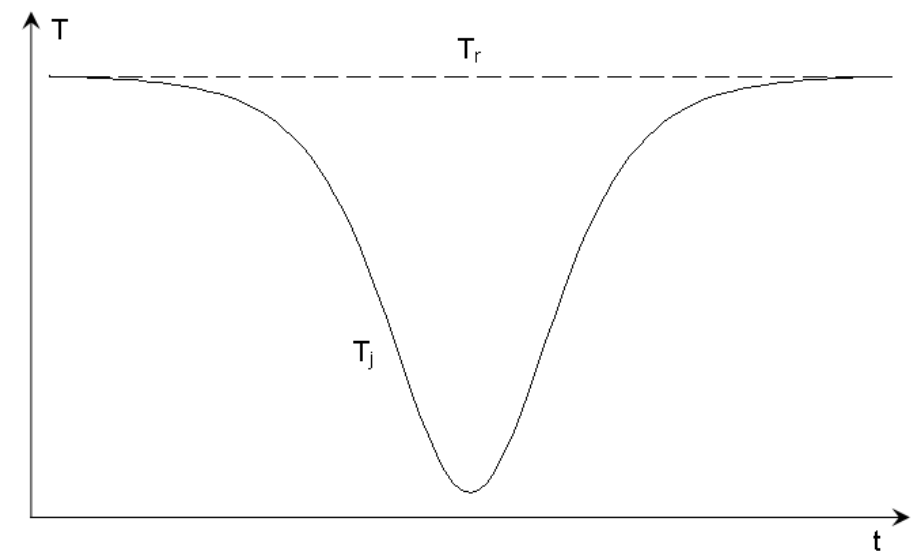

Figura 4.5 - Perfis de $T_{r}$ e $T_{j}$ - calorimetria isotérmica

As principais vantagens e desvantagens dos métodos calorimétricos são apresentadas na Tabela 4.1. 
Tabela 4.1 - Comparação entre os métodos calorimétricos (KAMMONA et al., 1999)

\begin{tabular}{|c|c|c|}
\hline Método & Vantagens & Desvantagens \\
\hline $\begin{array}{c}\text { Adiabático } \\
Q_{j}+Q_{\text {loss }}=0\end{array}$ & $\begin{array}{l}\text { 1. As variações de } \\
\text { temperatura são } \\
\text { proporcionais à conversão } \\
\text { 2. Equipamento } \\
\text { relativamente simples } \\
\text { 3. Bom para monitoramento } \\
\text { de reações rápidas }\end{array}$ & $\begin{array}{l}\text { 1. O aumento da temperatura do } \\
\text { meio reacional pode favorecer } \\
\text { reações secundárias } \\
\text { 2. Os efeitos da temperatura e da } \\
\text { concentração sobre a cinética da } \\
\text { reação podem ser discriminados } \\
\text { apenas através de modelos } \\
\text { matemáticos } \\
\text { 3. Método arriscado para reações } \\
\text { altamente exotérmicas } \\
\text { 4. Não aplicável para reações } \\
\text { endotérmicas } \\
\text { 5. Inviável em um ambiente } \\
\text { industrial }\end{array}$ \\
\hline $\begin{array}{l}\text { Isoperibólica } \\
\quad \mathrm{T}_{\mathrm{j}}=\text { cte }\end{array}$ & $\begin{array}{l}\text { 1. Equipamento } \\
\text { extremamente simples }\end{array}$ & $\begin{array}{l}\text { 1. Condições estritamente } \\
\text { adiabáticas ou isotérmicas são } \\
\text { impossíveis } \\
\text { 2. As cinéticas da reação são } \\
\text { influenciadas pelas variações de } \\
\text { temperatura e, portanto, estas } \\
\text { cinéticas devem ser determinadas } \\
\text { através de modelos matemáticos }\end{array}$ \\
\hline $\begin{array}{c}\text { Isotérmica } \\
\mathrm{Q}_{\text {acum }}=0\end{array}$ & $\begin{array}{l}\text { 1. A taxa de reação é } \\
\text { proporcional ao fluxo de calor } \\
\text { 2. Possibilidade de trabalhar } \\
\text { sob condições isotérmicas ou } \\
\text { adiabáticas } \\
\text { 3. As condições de reação e } \\
\text { o modo de operação são } \\
\text { semelhantes à reatores em } \\
\text { escala piloto ou industrial } \\
\text { 4. Os coeficientes de } \\
\text { transferência térmica são } \\
\text { detectáveis }\end{array}$ & $\begin{array}{l}\text { 1. A temperatura do meio reacional } \\
\text { deve ser medida com boa precisão } \\
\text { 2. O coeficiente de transferência } \\
\text { térmica deve ser obtido por } \\
\text { calibração } \\
\text { 3. Equipamento mais complexo. }\end{array}$ \\
\hline
\end{tabular}

Além das desvantagens apontadas na Tabela 4.1, Asua (2004) observa que a estimação das concentrações residuais de monômeros pela calorimetria em reações realizadas sob condições de avidez é pouco precisa, uma vez que sob estas condições, as concentrações de monômeros são muito baixas devido às elevadas conversões instantâneas. Portanto, o uso da calorimetria para o controle de reações conduzidas sob condições de avidez pode trazer severas consequências, já que as taxas de polimerização e as propriedades do polímero 
formado são extremamente dependentes das concentrações residuais de monômeros.

\subsection{Calorimetria - Aplicações}

Nomen; Sempere e Lerena (1993) e Nomen; Sempere e Cunha (1996) utilizaram a calorimetria de fluxo térmico para propor um método para a estimação do coeficiente global de troca térmica e para o cálculo das vazões mássicas do fluido de refrigeração do condensador, sob condições de refluxo e sem a necessidade instrumentações adicionais. O método foi validado utilizando os resultados experimentais coletados durante o aquecimento de solventes orgânicos, na ausência de reações químicas, e em temperaturas acima e abaixo do ponto de ebulição dos compostos analisados. Os resultados obtidos mostraram que o coeficiente global de troca térmica, obtido sob condições de refluxo, é bastante próximo daqueles obtidos em temperaturas abaixo do ponto de ebulição e com velocidade de agitação elevada.

Gugliotta et al. (1995) estimaram a conversão e a composição de copolímeros de acrilato de butila / estireno e acetato de vinila / acrilato de butila, obtidos durante reações em emulsão, a partir de medidas calorimétricas acopladas a um modelo matemático. As reações foram conduzidas em um calorímetro comercial RC1 (Mettler-Toledo), e os resultados preditos foram comparados com os resultados experimentais de conversão e composição acumulada obtidos por gravimetria, cromatografia gasosa e espectroscopia de ressonância magnética nuclear. A boa concordância entre os resultados preditos e experimentais mostrou que é possível utilizar a calorimetria para inferir em linha a conversão e a composição de copolímeros a partir do conhecimento prévio de apenas quatro parâmetros: as razões de reatividade, os coeficientes de partição dos monômeros entre as diferentes fases, as constantes de propagação e as entalpias de homopolimerização de cada monômero.

Saenz de Buruaga et al. (1996) utilizaram dados calorimétricos para implementar estratégias de controle em malha fechada da composição de 
copolímeros produzidos durante reações em emulsão mantendo, ao mesmo tempo, os limites de operação segura. A conversão global e a composição acumulada foram estimadas a partir das informações da taxa de calor gerado pela reação, das razões de reatividade, dos coeficientes de partição dos monômeros, e das entalpias de homopolimerização.

Févotte; Barudio e McKenna (1996) utilizaram a calorimetria para monitorar em linha a conversão e controlar determinadas propriedades macromoleculares de copolímeros de estireno / acrilato de butila obtidos durante reações em suspensão e em solução. As estimativas das variáveis de estados foram obtidas através de um filtro de Kalman estendido utilizando as informações calorimétricas, gravimétricas e densimétricas como vetor de medidas de entrada do observador de estado.

De la Rosa et al. (1996) utilizaram a microscopia eletrônica de transmissão e a calorimetria para obter informações sobre a cinética de reações de estireno, em emulsão, e à diferentes concentrações de emulsificante e de iniciador. As reações foram conduzidas em um reator calorimétrico comercial RC1 (Mettler-Toledo), e o coeficiente global de troca térmica foi obtido na etapa de pré-aquecimento aplicandose uma quantidade de energia conhecida e constante. Durante esta etapa, como não ocorrem reações e nenhum reagente é alimentado, o coeficiente UA pode ser estimado diretamente do balanço de energia durante o regime estacionário de $T_{r}$. As perdas térmicas também foram quantificadas durante a etapa de pré-aquecimento e foram consideradas como sendo a linha base que, no caso de um reator calorimétrico comercial, corresponde ao sinal inicial de $Q_{r}$ obtido na ausência de reação. De acordo com os autores, os resultados obtidos sugerem que o fim da etapa de nucleação de partículas (intervalo I) ocorre sempre no, ou após o, instante de máxima taxa de polimerização. Além disso, pelos resultados os autores não conseguiram verificar a existência do intervalo II na qual a taxa de polimerização é constante. Por outro lado, em um trabalho recentemente publicado por Lamb et al. (2005), as conclusões sugerem cautelas adicionais quando a calorimetria é utilizada para a estimação de propriedades cinéticas e termodinâmicas de partículas poliméricas com diâmetros muito pequenos e obtidas em sistemas heterogêneos, como aquelas obtidas durante uma reação de polimerização em emulsão de estireno, pois nesses casos, alguns fatores físicos como, por exemplo, solvatação e efeitos de superfície, podem acabar causando erros nas estimativas destas propriedades. 
Févotte et al. (1998a) e Févotte; Barudio e Guillot (1996) propuseram uma estratégia de calorimetria adaptativa baseada no emprego de medidas discretas de conversão gravimétrica e de um algorítimo de otimização, para a estimação do coeficiente $U$ e $Q_{\text {loss, }}$ e observadores de estado de Luenberger estendido, para a predição do calor de reação e das conversões. Apesar das dificuldades em modelar detalhadamente um processo de polimerização em emulsão, a estratégia adaptativa e o observador de estado apresentaram boa velocidade de convergência e resultados preditos bastante próximos daqueles obtidos experimentalmente por gravimetria e cromatografia gasosa. Posteriormente, esta técnica foi utilizada por Févotte et al. (1998b) para estimar e controlar a temperatura de transição vítrea de copolímeros de estireno / acrilato de butila produzidos em emulsão.

Sayer et al. (2000) utilizaram a calorimetria para estimar as concentrações residuais de metacrilato de metila e acrilato de butila durante reações semicontínuas de copolimerização em emulsão, conduzidas em um reator calorimétrico RC1 (Mettler-Toledo), e sob condições de avidez e semiavidez de monômeros. As concentrações residuais obtidas, por sua vez, foram usadas para implementar estratégias de controle ótimo da composição para verificar os efeitos destas estratégias sobre a distribuição de pesos moleculares e a fração de gel. Os resultados obtidos mostraram que, ao contrário do que foi reportado em alguns trabalhos da literatura, a formação de gel e a produção de polímeros com pesos moleculares menores são mais acentuadas em reações conduzidas em regime de avidez de monômeros. Na segunda parte do trabalho, os autores observaram ainda que é possível controlar simultaneamente a composição e a distribuição de pesos moleculares de copolímeros obtidos em processos conduzidos em regime de semiavidez de monômeros pois, nestas condições, o agente de transferência de cadeia não é afetado pelas limitações difusionais.

Santos et al. (2000) utilizaram a calorimetria adaptativa em conjunto com um observador de estado para obter, em tempo real, informações relacionadas à evolução da composição e da cinética de reações de copolimerização em emulsão de metacrilato de metila / acetato de vinila sob condições não isotérmicas. A metodologia utilizada permitiu obter excelente concordância entre os resultados experimentais e preditos, mesmo durante o efeito gel onde ocorre um aumento abrupto do calor de reação. 
Vicente; Leiza e Asua (2001) aplicaram um algoritmo de controle não-linear em malha fechada para controlar, simultaneamente, a composição molar acumulada e a distribuição de pesos moleculares (MWD) de copolímeros de estireno / n-acrilato de butila. O controle destas propriedades foi obtido mantendo-se a razão entre as concentrações dos comonômeros, presentes na fase polimérica, e as concentrações residuais de monômeros e de agente de transferência de cadeia (CTA) em valores que assegurassem a produção de polímeros com as propriedades desejadas. As concentrações residuais foram estimadas a partir das medidas do calor de reação fornecidas por um calorímetro RC1 (Mettler-Toledo) modificado. O algoritmo de controle utilizado foi semelhante àquele utilizado por Echevarría et al. (1998) para o controle da distribuição de pesos moleculares de homopolímeros de estireno obtidos em emulsão. Entretanto, neste último caso, a concentração residual de estireno foi obtida em linha via cromatografia em fase gasosa.

Posteriormente, o calorímetro modificado e os modelos desenvolvidos por Vicente; Leiza e Asua (2001) foram utilizados por Vicente et al. (2002) para a implementação de estratégias de controle ótimo e em malha aberta para a obtenção de copolímeros de metacrilato de metila / n-acrilato de butila com composições bem definidas e distribuições de pesos moleculares unimodais e bimodais. Os perfis ótimos das alimentações dos monômeros e do agente de transferência de cadeia foram obtidos por meio de um algoritmo de programação iterativa dinâmica (IDP).

Ubrich et al. (2001) maximizaram em linha a conversão de uma reação de esterificação de segunda ordem, conduzida em um reator isotérmico, otimizando as vazões de alimentação a partir dos dados calorimétricos e, ao mesmo tempo, mantendo as condições de segurança do processo. A evaporação do meio reacional, com posterior condensação da fase vapor, foi considerada como a maior responsável pelas perdas térmicas, e foi quantificada considerando que $\mathrm{Q}_{\text {loss }}$ é proporcional à pressão de vapor do sistema. $O$ fator de proporcionalidade foi obtido por tentativa e erro, e a pressão de vapor foi estimada pela equação de ClausiusClapeyron. Como as reações foram conduzidas em um reator calorimétrico comercial, os autores não encontraram maiores dificuldades para estimar o coeficiente UA.

Saenz de Buruaga et al. (1997) e Vicente; Leiza e Asua (2003) implementaram uma estratégia de controle, baseada em dados calorimétricos, para obter copolímeros em emulsão com composição e distribuição de pesos moleculares 
bem definidos e, simultaneamente, maximizar a produção. Para tornar as condições operacionais do reator mais próximas daquelas observadas em um processo industrial e, consequentemente, tornar a estratégia de controle mais realista, as reações foram conduzidas em um reator calorimétrico com capacidade limitada de remoção de calor. Como em um reator laboratorial, a máxima capacidade de remoção excede a máxima taxa de geração de calor, os autores impuseram um perfil de remoção de calor, por unidade de volume, obtido a partir dos dados coletados de um reator em escala industrial. A estimação do perfil do coeficiente $U$ foi obtida em função do teor de sólidos conforme método proposto por Saenz de Buruaga et al. (1997).

Fan e Alpay (2004) usaram a calorimetria para monitorar e controlar em linha uma reação de polimerização em emulsão de metacrilato de metila conduzida em um reator tubular com reciclo. Um filtro de Kalman estendido foi aplicado sobre os balanços de massa e de energia do processo para estimar a taxa de polimerização a partir das medidas das temperaturas do meio reacional e da camisa. Devido ao baixo teor de sólidos, o coeficiente global de troca térmica foi assumido constante ao longo da reação. As perdas térmicas das partes não encamisadas foram calculadas em experimentos realizados à parte e em conjunto com a taxa de calor adicionado / retirado pela bomba de reciclo. Entretanto, mais detalhes quanto à estimação das perdas térmicas não foram fornecidos.

Othman; Févotte e McKenna (2004) utilizaram a calorimetria em conjunto com um algoritmo de controle geométrico não-linear para a obtenção de cadeias poliméricas com composições bem definidas. As informações calorimétricas foram utilizadas para estimar a conversão global e para controlar as vazões de alimentação dos reagentes, de modo a manter as concentrações residuais dos monômeros abaixo da concentração de saturação. As estimativas das variáveis de estado foram obtidas através de um observador de estado não-linear de alto ganho aplicado sobre os balanços de massa e energia do processo. A estratégia de controle e os estados preditos foram validados usando os resultados experimentais coletados ao longo de reações de homo-, co- e terpolimerização em emulsão.

Freire et al. (2004) propuseram a utilização de um observador de estado não-linear de alto ganho para a estimação em cascata do coeficiente global de troca térmica e do calor de reação. A metodologia proposta foi validada a partir dos resultados obtidos durante as simulações de um modelo matemático detalhado de 
um processo de terpolimerização em emulsão de estireno / acrilato de butila / metacrilato de metila. A principal vantagem deste enfoque é que ambas as variáveis são estimadas usando apenas as medidas de temperatura e o balanço de energia do reator (calorimetria de fluxo térmico).

Azpeitia; Leiza e Asua (2005) utilizaram a calorimetria adiabática para analisar os efeitos de diversas variáveis operacionais de uma reação de polimerização em emulsão de acetato de vinila / acrilato de butila sobre os parâmetros de risco do processo. Os parâmetros escolhidos foram a temperatura de autoaceleração, o aumento adiabático de temperatura, e a máxima temperatura e pressão, uma vez que estes são os parâmetros necessários para estabelecer os limites de segurança das variáveis operacionais, considerando um cenário no qual possa ocorrer um aumento abrupto da taxa de reação em um reator operando em condições adiabáticas. $\mathrm{O}$ teor de sólidos elevado teve por objetivo tornar o látex e o processo o mais próximo daquele obtido em um processo industrial e, consequentemente, tornar as análises de risco mais realistas. De acordo com os autores, a temperatura de autoaceleração aumenta sempre que a taxa de polimerização inicial diminui, e ocorre sempre a uma temperatura menor que a temperatura do processo e, portanto, este fenômeno pode ocorrer em todos os processos industriais que envolvam o par de monômeros analisado.

Giordani et al. (2005) combinaram a calorimetria e redes neurais artificiais para estimar a composição de terpolímeros de metacrilato de metila/acrilato de butila/acrilato de metila formados durante reações semicontínuas em emulsão com elevados teores de sólidos. A aplicação de redes neurais, para a estimação das variáveis de estado de sistemas químicos, tem se tornado cada vez mais comum devido as não-linearidades geralmente encontradas nestes processos. O perfil do coeficiente global de troca térmica ao longo da reação foi obtido através da técnica de calorimetria adaptativa proposta por Févotte et al. (1998a).

Alhamad; Gomes e Romagnoli (2006) determinaram em linha a taxa de reação e a conversão de polímeros obtidos durante reações, em batelada e semibatelada, de copolimerização em emulsão de estireno / metacrilato de metila. As estimativas destas variáveis foram obtidas através de modelos calorimétricos combinados com um modelo dinâmico detalhado do processo.

Espósito et al. (2006) usaram a calorimetria isoperibólica e isotérmica para inferir a conversão de homopolímeros de acetato de vinila produzidos durante 
reações em emulsão conduzidas em regime batelada. O coeficiente global de troca térmica foi obtido através de calibrações realizadas antes e depois de cada reação, inserindo uma termorresistência no reator e aplicando uma voltagem conhecida até a temperatura do reator atingir um patamar estacionário. O perfil de UA, ao longo da reação, foi obtido em função da variação da conversão, uma vez que a viscosidade do látex aumenta com o aumento do teor de sólidos. Devido o longo tempo de residência do fluido de refrigeração, o balanço de energia da camisa também foi incluído para a estimação das variáveis de estado (calorimetria de balanço térmico). Os autores observaram que a calorimetria isoperibólica apresentou os melhores resultados quando comparada à calorimetria isotérmica, todavia, essa técnica implica em uma variação da temperatura do meio reacional muitas vezes não aceitável do ponto de vista da segurança do processo.

Gaulke; Pauer e Moritz (2006) utilizaram a calorimetria isoperibólica combinada com as transformadas de Fourier para determinar os fluxos de calor, utilizando apenas as curvas de temperatura obtidas pela dissipação controlada de calor por uma termorresistência elétrica inserida dentro do reator, e sem a necessidade de resolver explicitamente o balanço de energia.

Espósito et al. (2008) analisaram os efeitos da vazão do fluido de refrigeração sobre a conversão de reações de homopolimerização em emulsão de acetato de vinila. As estimativas de conversão foram obtidas através da calorimetria de fluxo térmico e da calorimetria de balanço térmico. Os resultados obtidos mostraram que para a calorimetria de fluxo térmico, independentemente do modo de operação do reator (isotérmico e isoperibólico), a conversão é pouco afetada pela vazão do fluido de refrigeração, enquanto para a calorimetria de balanço térmico melhores estimativas são obtidas quando a vazão do fluido de arrefecimento é baixa, uma vez que neste caso é necessário obter uma diferença de temperatura suficientemente alta entre a entrada e a saída da camisa para que esta possa ser medida com precisão, conforme observado por Zogg (2003).

Richner et al. (2008) utilizaram a calorimetria de temperatura oscilatória para estimar a capacidade calorífica de oito solventes orgânicos, cobrindo uma ampla faixa de viscosidades e condições experimentais. As capacidades caloríficas dos solventes foram determinadas a partir das amplitudes de oscilação e do deslocamento de fases da temperatura do reator, quando o calor dissipado por uma resistência elétrica e o fluido de refrigeração forçam uma ligeira oscilação da 
temperatura do meio reacional. Os resultados obtidos mostraram que a capacidade calorífica é extremamente dependente das condições operacionais, e desvios sistemáticos foram observados em seus valores quando comparados com aqueles apresentados na literatura.

\subsection{Conclusões Parciais}

Apesar de ser uma das técnicas de monitoramento mais antiga, a calorimetria é ainda um campo de pesquisa em crescente expansão e com aplicações em diversas áreas incluindo o desenvolvimento de processos químicos seguros.

A combinação das informações termodinâmicas e cinéticas, somada à facilidade de obtenção de medidas contínuas, devido à simplicidade dos sensores de temperatura e de vazão, torna a calorimetria única dentre as diversas ferramentas analíticas disponíveis sendo, portanto, amplamente utilizada no controle de processos químicos exotérmicos e em um vasto número de problemas para os quais não é possível encontrar soluções diretas ou de baixo custo através de outras técnicas analíticas. 


\section{MATERIAIS E MÉTODOS}

O principal objetivo desta seção é apresentar o aparato experimental, os reagentes, e as metodologias analíticas e computacionais empregadas para avaliar a aplicabilidade dos observadores de estado não-lineares, em conjunto com a calorimetria, para a predição das variáveis de estado dos dois casos analisados neste trabalho.

Para descrever os materiais e métodos empregados em cada um destes casos, esta seção será dividida em 2 subseções principais:

i) Subseção 5.1 - dedicada ao estudo de caso 1 (Hidrólise do Anidrido Acético). Esta subseção, por sua vez, é dividida em 3 subseções

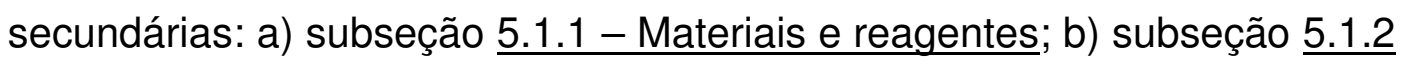
- Técnicas Analíticas onde são apresentadas as equações utilizadas para o cálculo dos valores experimentais do coeficiente global de troca térmica, da conversão e dos parâmetros da equação de Arrhenius; e c) subseção 5.1.3 - Técnicas Computacionais na qual são apresentados um breve resumo teórico sobre a análise de sensibilidade paramétrica de equações diferenciais ordinárias, e o espaço de estados sobre o qual será aplicado o observador de estado não-linear tipo Luenberger para a predição da conversão.

ii) Subseção 5.2 - dedicada ao estudo de caso 2 (Polimerização em Emulsão de Acetato de Vinila / Acrilato de Butila). Similarmente ao caso 1, esta subseção também é dividida em 3 subseções secundárias: a)

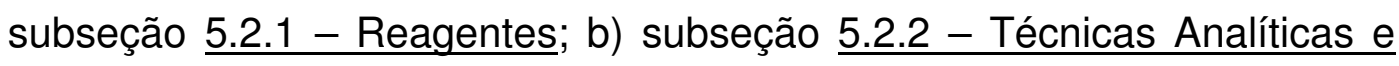
Caracterização do Látex onde são apresentados um resumo descrevendo o funcionamento dos equipamentos utilizados para a caracterização do látex; as equações para o cálculo dos valores experimentais de conversão, composição e concentração de partículas; e o procedimento e as equações utilizadas para a obtenção dos valores iniciais e finais de UA


apresentadas a aplicação dos conceitos de observadores de alto ganho 
para a estimação em "cascata" de UA e $Q_{r}$, e as equações para o cálculo dos valores preditos de conversão e composição.

\subsection{Hidrólise do anidrido acético}

A reação de hidrólise do anidrido acético foi escolhida como primeiro estudo de caso por se tratar de uma reação simples e clássica que permite ilustrar a aplicação da calorimetria para a estimação do estado de um processo. A simplicidade desse estudo de caso se deve, basicamente, a três fatores: a) a reação pode ser feita em um reator não-convencional; b) o perfil do coeficiente global de troca térmica é aproximadamente constante, uma vez que não ocorrem variações bruscas de viscosidade; e c) a reação do anidrido acético com água é uma reação rápida e extremamente exotérmica e, portanto, ideal para verificar a resposta dinâmica de um reator calorimétrico.

A hidrólise do anidrido acético é uma reação de substituição nucleofílica acílica (nucleophilic acyl substitution) e processa-se através de três reações irreversíveis: reação de adição (etapa lenta); reação de eliminação; e reação de transferência de próton para o solvente (ASPREY et al., 1996).

Adição



Eliminação

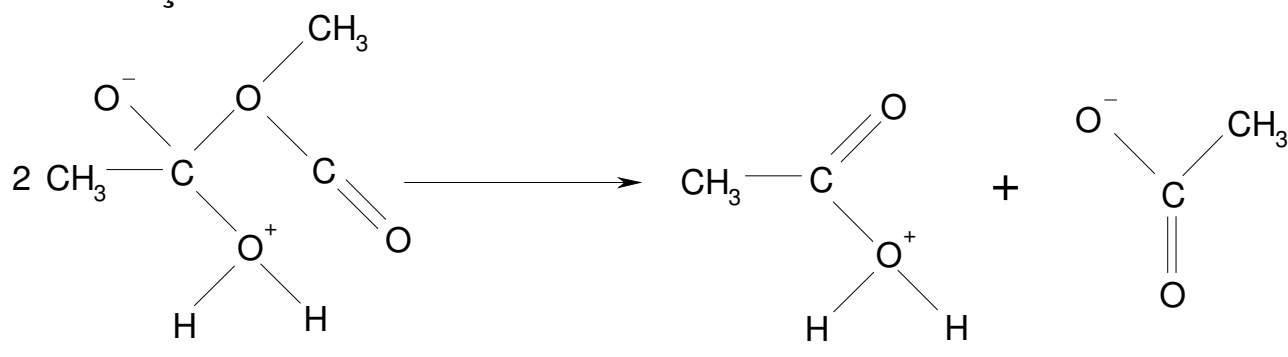


Transferência de próton

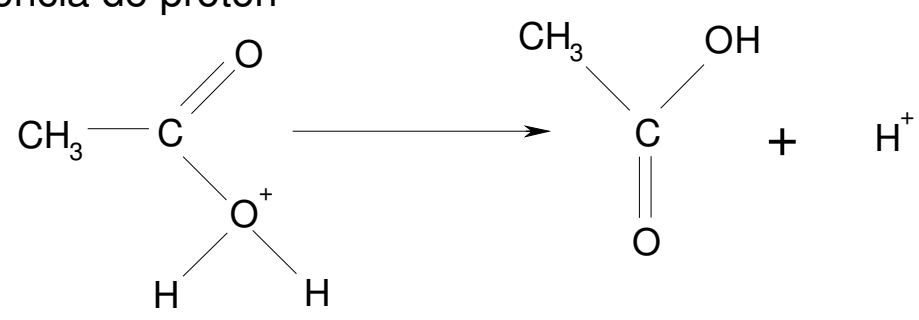

Desta forma, a equação global da reação de hidrólise do anidrido acético será dada por:

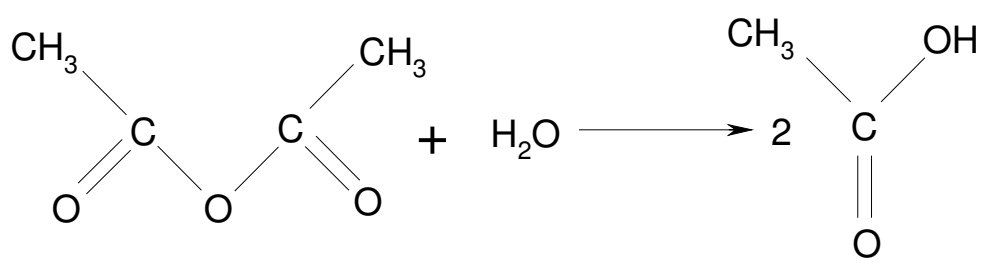

Caso o reator não seja isolado termicamente, a elevação de temperatura ocorre simultaneamente com a troca de calor com o ambiente a uma temperatura $T_{\text {amb. }}$ A temperatura do meio reacional sobe inicialmente, mas após o consumo completo do reagente limitante (anidrido acético) a temperatura passa a decrescer devido à troca térmica entre o ambiente e o reator.

\subsubsection{Materiais e reagentes}

A seguir são apresentados todos os materiais e reagentes utilizados durante a reação de hidrólise do anidrido acético. Todos os compostos químicos foram utilizados conforme comercializados sem qualquer tratamento prévio.
i) Anidrido acético (95\% de pureza)
ii) Água destilada e deionizada
iii) Agitador magnético
iv) Barra magnética (magnetita $-\mathrm{Fe}_{3} \mathrm{O}_{4}$ ) 


\begin{abstract}
v) Suporte universal
vi) Copo de poliestireno ("reator" não adiabático)

vii) Balão volumétrico ("reator" não adiabático)

viii) Garrafa térmica ("reator" adiabático não ideal)

ix) Termômetro digital de bolso modelo Q401B (Quimis) para uma faixa de medição entre $-50^{\circ} \mathrm{C}$ e $200^{\circ} \mathrm{C}$ e com comprimento de haste de $137 \mathrm{~mm}$.
\end{abstract}

Como a qualidade das predições depende em boa parte da precisão das medidas de temperatura, antes de iniciar os ensaios alguns testes foram realizados com o objetivo de verificar o tempo de resposta de cada termômetro e a precisão das medidas, a fim de que fosse possível escolher o termômetro mais adequado.

Nesta etapa, dois termômetros idênticos foram utilizados para medir a temperatura de fusão do gelo (aproximadamente $0^{\circ} \mathrm{C}$ ) e a temperatura de ebulição da água à pressão ambiente (aproximadamente $97,5^{\circ} \mathrm{C}$ para região de São Paulo). Os resultados obtidos são apresentados na Tabela 5.1 .

Tabela 5.1 - Calibração dos termômetros

\begin{tabular}{ccc}
\hline & Temperatura de fusão $\left({ }^{\circ} \mathrm{C}\right)$ & Temperatura de ebulição $\left({ }^{\circ} \mathrm{C}\right)$ \\
\hline Termômetro 1 & 0,1 & 97,8 \\
Termômetro 2 & 0,1 & 97,9 \\
\hline
\end{tabular}

O tempo de resposta e as temperaturas medidas foram bastante próximos, mas pela leve precisão do termômetro 1, com relação a temperatura de ebulição, este termômetro foi escolhido para ser utilizado durante a reação de hidrólise do anidrido acético.

\title{
5.1.2 Técnicas analíticas
}

O modelo matemático que descreve a reação de hidrólise do anidrido acético é obtido a partir da aplicação conjunta dos balanços de massa e energia tomando o reagente limitante (anidrido acético - AA) como base de cálculo.

Como o reator opera em batelada, o termo de acúmulo de matéria é igual ao termo cinético da reação e, portanto, o balanço de massa do sistema será dado por: 
$N_{A A 0} \frac{d X_{A A}}{d t}=\left(-r_{A A}\right) V$

sendo $\mathrm{N}_{\mathrm{AA} 0}, \mathrm{X}_{\mathrm{AA}}$ e $\left(-\mathrm{r}_{\mathrm{AA}}\right)$, respectivamente, o número de mols inicial, a conversão e a taxa de consumo do anidrido acético, e $\mathrm{V}$ o volume total de reagentes adicionado no reator (água + anidrido acético) considerando que a reação de hidrólise não provoca a contração ou a expansão do meio reacional.

Como o reator não é isolado termicamente, o balanço térmico inclui, essencialmente, as contribuições energéticas da reação e as trocas térmicas com o ambiente. Portanto, o balanço de energia pode ser escrito da seguinte forma:

$$
\left(m C_{p}\right)_{r} \frac{d T_{r}}{d t}=\left(-r_{A A}\right) V(-\Delta H)-U A\left(T_{r}-T_{a m b}\right)
$$

sendo $\left(\mathrm{mC}_{\mathrm{p}}\right)_{\mathrm{r}}$ a capacidade calorífica global do sistema (reagentes, produtos e reator), $(-\Delta \mathrm{H})$ a entalpia da reação de hidrólise do anidrido acético, UA o coeficiente global de troca térmica entre o ambiente e o meio reacional, e $T_{r}$ a temperatura do reator.

Como a reação de hidrólise é controlada pela etapa de adição, a taxa de reação do reagente limitante $\left(-r_{A A}\right)$ depende apenas da concentração dos reagentes e será dada por uma relação de primeira ordem com relação a cada um destes reagentes, ou seja:

$\left(-r_{A A}\right)=k C_{A A} C_{W}$

sendo $C_{A A}$ e $C_{W}$ as concentrações molares do anidrido acético e da água, respectivamente, e $\mathrm{k}$ a taxa específica de reação calculadas da seguinte forma:

$$
\begin{aligned}
& C_{A A}=\frac{N_{A A 0}}{V}\left(1-X_{A A}\right) \\
& C_{W}=\frac{N_{A A 0}}{V}\left(\frac{N_{W 0}}{N_{A A 0}}-X_{A A}\right)
\end{aligned}
$$


$k=k_{0} e^{-\frac{E}{R T_{r}}}$

sendo $N_{w_{0}}$ o número de mols inicial de água, $E$ a energia de ativação, $k_{0} \circ$ fator de frequência ou fator pré-exponencial, e $\mathrm{R}$ a constante universal dos gases.

Com essas informações adicionais e considerando que $T_{r}$ é a medida de saída, os balanços de massa e energia podem ser expressos em função da conversão e em espaço de estados pelo seguinte sistema dinâmico:

$$
\left\{\begin{aligned}
\frac{d X_{A A}}{d t}= & \frac{V}{N_{A A 0}} k_{0} \exp \left(-\frac{E}{R T_{r}}\right)\left(\frac{N_{A A 0}}{V}\right)^{2}\left(1-X_{A A}\right)\left(\frac{N_{W 0}}{N_{A A 0}}-X_{A A}\right) \\
\frac{d T_{r}}{d t}= & \frac{(-\Delta H) V}{\left(m C_{p}\right)_{r}} k_{0} \exp \left(-\frac{E}{R T_{r}}\right)\left(\frac{N_{A A 0}}{V}\right)^{2}\left(1-X_{A A}\right)\left(\frac{N_{W 0}}{N_{A A 0}}-X_{A A}\right)- \\
& \frac{U A}{\left(m C_{p}\right)_{r}}\left(T_{r}-T_{a m b}\right)
\end{aligned}\right.
$$

Portanto, a partir do sistema dinâmico representado pela eq.(5.07) é possível inferir rapidamente as variáveis de estado $\mathrm{X}_{\mathrm{AA}}$ e $\mathrm{T}_{\mathrm{r}}$, desde que todos os parâmetros sejam conhecidos. Com exceção do coeficiente UA que pode variar com o aumento da viscosidade do meio reacional, todos os demais parâmetros permanecem constantes ao longo da reação, ou dependem apenas da temperatura do reator, e podem ser estimados rapidamente a partir dos dados experimentais. Para a reação de hidrólise do anidrido acético, em particular, a viscosidade permanece muito baixa durante a reação e, portanto, apresentará pouca, ou nenhuma, influência sobre o valor final do coeficiente UA. Assim, este coeficiente dependerá apenas do material de fabricação do reator e, consequentemente, variará somente se a condutividade térmica do material for alterada. Dessa forma, tanto UA quanto os parâmetros da equação de Arrhenius podem ser estimados experimentalmente analisando-se as variações de $T_{r}$ em função do tempo. 
Sob condições não-adiabáticas, a lei da conservação de energia estabelece que as variações de temperatura do meio reacional são causadas, essencialmente, pelas contribuições do calor de reação e pelas trocas térmicas com o ambiente. Desta forma, o coeficiente global de troca térmica pode ser obtido a partir das medidas de temperatura durante o resfriamento do sistema, pois nesta região as variações de $T_{r}$ ocorrem, exclusivamente, devido às trocas de calor com o ambiente, uma vez que o reagente limitante já foi completamente consumido. Assim, o decréscimo de $T_{r}$ será governado pela seguinte equação:

$$
\left(m C_{p}\right)_{r} \frac{d T_{r}}{d t}=-U A\left(T_{r}-T_{a m b}\right)
$$

Integrando a eq.(5.08), do instante inicial ( $\left.\mathrm{t}_{0}\right)$ até um instante genérico $\mathrm{t}$, obtém-se:

$\ln \frac{T_{r}-T_{a m b}}{T_{r 0}-T_{a m b}}=-\frac{U A}{\left(m C_{p}\right)_{r}}\left(t-t_{0}\right)$

Ou seja, a inclinação do gráfico $\ln \left(T_{r}-T_{a m b}\right)$ versus o tempo corresponde ao termo $-\mathrm{UA} /\left(\mathrm{mC}_{\mathrm{p}}\right)_{\mathrm{r}}$ do qual o coeficiente UA pode ser rapidamente estimado, desde que a capacidade calorífica total do sistema seja conhecida.

Dispondo-se dos valores do coeficiente UA e dos parâmetros $(-\Delta \mathrm{H})$ e $\left(\mathrm{mC}_{\mathrm{p}}\right) \mathrm{r}$, a conversão do reagente limitante pode ser estimada combinando os balanços de massa e energia e assumindo que no instante final a conversão do anidrido acético seja de $100 \%$. Integrando a equação resultante do instante inicial $\left(\mathrm{t}_{0}\right)$ até o instante final $\left(\mathrm{t}_{\mathrm{f}}\right)$, a conversão experimental será calculada pela seguinte relação recursiva:

$$
X_{A A}^{i}=X_{A A}^{i+1}-\frac{\left(m C_{p}\right)_{r}\left(T_{r, i+1}-T_{r, i}\right)+U A \int_{t_{i}}^{t_{i+1}}\left(T_{r}-T_{a m b}\right) d t}{(-\Delta H) N_{A A 0}}
$$


ou seja, $X_{A A}$ é obtida do instante final $\left(X_{A A}=100 \%\right)$ até o instante inicial. $A$ integral da diferença $T_{r}-T_{a m b}$ é calculada para cada intervalo de tempo através da regra dos trapézios.

A taxa de consumo do reagente limitante pode ser estimada a partir do balanço de energia utilizando a entalpia de reação da literatura e o coeficiente de troca térmica estimado a partir da eq.(5.09).

$$
\left(-r_{A A}\right)=\frac{\left(m C_{p}\right)_{r} \frac{d T_{r}}{d t}+U A\left(T_{r}-T_{a m b}\right)}{V(-\Delta H)}
$$

Obtido os valores de (- $\left.\mathrm{r}_{\mathrm{AA}}\right)$, e sabendo que a taxa de reação é de primeira ordem em relação a concentração de cada um dos reagentes, a taxa de reação específica experimental (k) pode ser obtida de forma direta a partir da eq.(5.03), ou seja:

$$
k=\frac{\left(-r_{A A}\right)}{C_{A A} C_{W}}
$$

Calculando os valores de $\mathrm{k}$ para cada instante, e linearizando a eq.(5.06) obtém-se:

$$
\ln (k)=\ln \left(k_{0}\right)-\frac{E}{R} \frac{1}{T_{r}}
$$

Portanto, os parâmetros cinéticos da lei de Arrhenius serão os coeficientes linear e angular da interpolação linear do gráfico de $\ln (\mathrm{k})$ vs. $\left(1 / \mathrm{T}_{\mathrm{r}}\right)$.

Shatynski e Hanesian (1993) observam que pequenas variações na energia de ativação podem afetar consideravelmente a velocidade da reação, uma vez que este parâmetro está relacionado diretamente com a contabilização da fração de colisões com energia suficiente para que uma reação ocorra. Além disso, um aumento na temperatura do meio reacional poderá causar um aumento da energia cinética das partículas aumentando, consequentemente, a frequência de colisões. 
De acordo com as eqs.(5.11)-(5.13), a precisão das estimativas de $k_{0}$ e $E$ dependem da qualidade da estimativa do coeficiente UA e do cálculo das derivadas de temperatura. $O$ cálculo de valores de derivada a partir de dados experimentais sofre do problema de amplificação de erros. Por isso, é conveniente que a avaliação da derivada seja feita por diferentes métodos. Neste trabalho, serão testados três métodos para o cálculo das derivadas $\mathrm{dT}_{\mathrm{r}} / \mathrm{dt}$ : a) método 1 - diferenciação do polinômio interpolador (DPI); b) método 2 - filtro Savitzky-Golay para suavização e diferenciação de dados (FSG); e c) método 3 - diferenças finitas centradas (DFC).

\subsubsection{Método 1-Diferenciação do Polinômio Interpolador (DPI)}

O objetivo da interpolação polinomial é encontrar uma relação matemática capaz de descrever, ao mesmo tempo, o comportamento de um sistema de dados e a influência dos erros randômicos.

Dado um sistema genérico de pontos $\left(\mathrm{x}_{\mathrm{i}}, \mathrm{y}_{\mathrm{i}}\right)$ com $\mathrm{i}=1, \ldots, \mathrm{n}$, a dependência da variável y (variável dependente) em relação à variável $x$ (variável independente) pode ser expressa pelo seguinte polinômio:

$$
\hat{y}=a_{0}+a_{1} x+a_{2} x^{2}+\ldots+a_{k} x^{k}=\sum_{j=0}^{k} a_{j} x^{j}
$$

sendo $\mathrm{k}$ o grau do polinômio, $\hat{y}$ o valor predito de y pelo polinômio e $a_{0} \ldots a_{k}$ os coeficientes de regressão.

Os coeficientes desconhecidos $\left[\mathrm{a}_{0}, \ldots, \mathrm{a}_{\mathrm{k}}\right]$ são obtidos resolvendo as $\mathrm{n}$ equações normais que minimizam a soma dos quadrados da diferença entre os valores preditos e experimentais de y, ou seja:

$$
\frac{\partial}{\partial a_{j}}\left[\sum_{i}^{n}\left(\hat{y}_{i}-y_{i}\right)^{2}\right]=0 \quad j=0,1, \ldots, k
$$


Diversos softwares comerciais e gratuitos como, por exemplo, POLYMATH, MATLAB e OCTAVE, possuem rotinas que permitem encontrar os coeficientes de regressão de um sistema de dados.

As derivadas de $T_{r}$ (variável dependente) em relação ao tempo (variável independente) serão, portanto, obtidas pela seguinte relação:

$$
\frac{d T_{r}}{d t}=\sum_{j=0}^{k} j a_{j} x^{j-1}
$$

\subsubsection{Método 2 - Filtro Savitzky-Golay (FSG)}

O filtro Savitzky-Golay ou polinômio de suavização digital (DISPO) define uma família de filtros low-pass capazes de suavizar e derivar um sistema de pontos igualmente espaçados.

Este método consiste, essencialmente, em encontrar os coeficientes de regressão de um polinômio local de j-ésima ordem ou os coeficientes de regressão da derivada deste polinômio em função dos $k>j+1$ pontos adjacentes, e determinar o valor suavizado para cada ponto. A estratégia de suavização é baseada no método dos mínimos quadrados parciais aplicado sobre o polinômio que interpola um determinado número de pontos consecutivos pertencentes a uma mesma janela móvel.

Baseado em Press et al. (1992), considere um sistema genérico de pontos $\left(\mathrm{t}_{\mathrm{i}}, \mathrm{f}_{\mathrm{i}}\right),-\mathrm{n}_{\mathrm{L}} \leq \mathrm{i} \leq \mathrm{n}_{\mathrm{R}}$, igualmente espaçados. O conceito básico do filtro é substituir cada valor $f_{i}$ por uma combinação linear $g_{i}$ de si próprio e de um determinado número de pontos vizinhos, ou seja:

$$
g_{i}=\sum_{n=-n_{L}}^{n_{R}} c_{n} f_{i+n}
$$

sendo $n_{L}$ e $n_{R}$, respectivamente, o número de pontos à esquerda e à direita do iésimo ponto. 
Os coeficientes $c_{n}$ para cada ponto são obtidos pelo método dos mínimos quadrados parciais usando os pontos compreendidos no intervalo $\left[f_{-n L}, f_{n R}\right]$ e um polinômio de grau $r$ definido por:

$$
P_{i}=a_{0}+a_{i} i+a_{2} i^{2}+\ldots+a_{r} i^{r}=\sum_{k=0}^{r} a_{k} i^{k}
$$

A soma dos quadrados dos desvios do sistema de dados (S) será uma função dos $r+1$ coeficientes de regressão desconhecidos $\left(a_{k}\right)$ e será dada por:

$$
S=\sum_{i=-n_{L}}^{n_{R}}\left(P_{i}-f_{i}\right)^{2}
$$

Os coeficientes de regressão são obtidos pelo método usual, ou seja, resolvendo as $r+1$ equações normais que minimizam $S\left(\partial S / \partial a_{i}=0\right)$. Os elementos da matriz do sistema algébrico obtido na minimização (matriz de projeto) serão dados por:

$$
A_{i j}=i^{j} \quad i=-n_{L}, \ldots, n_{R} \quad j=0, \ldots, r
$$

e os elementos do vetor a em função do vetor $\mathbf{f}$ por:

$$
\left(\mathbf{A}^{T} \cdot \mathbf{A}\right) \cdot \mathbf{a}=\mathbf{A}^{T} \cdot \mathbf{f}
$$

ou

$$
\mathbf{a}=\left(\mathbf{A}^{T} \cdot \mathbf{A}\right)^{-1}\left(\mathbf{A}^{T} \cdot \mathbf{f}\right)
$$

Na eq.(5.22) os produtos $\mathbf{A}^{\top}$. $\mathbf{A}$ e $\mathbf{A}^{\top}$.f, em função dos elementos da matriz $\mathbf{A}$ e do vetor $\mathbf{f}$, serão dados pelas seguintes relações: 


$$
\begin{aligned}
\left\{\mathbf{A}^{T} \cdot \mathbf{A}\right\}_{i j} & =\sum_{k=-n_{L}}^{n_{R}} A_{k i} A_{k j}=\sum_{k=-n_{L}}^{n_{R}} k^{i+j} \\
\left\{\mathbf{A}^{T} \cdot \mathbf{f}\right\}_{j} & =\sum_{k=-n_{L}}^{n_{R}} A_{k j} f_{k}=\sum_{k=-n_{L}}^{n_{R}} k^{j} f_{k}
\end{aligned}
$$

Uma vez que o coeficiente $c_{n}$ é o componente $a_{0}$ quando f é substituído pelo vetor unitário $e_{n},-n_{L} \leq n \leq n_{R}, c_{n}$ será dado por:

$$
c_{n}=\left\{\left(\mathbf{A}^{T} \cdot \mathbf{A}\right)^{-1} \cdot\left(\mathbf{A}^{T} \cdot \mathbf{e}_{n}\right)\right\}_{0}=\sum_{m=0}^{r}\left\{\left(\mathbf{A}^{T} \cdot \mathbf{A}\right)^{-1}\right\}_{0 m} n^{m}
$$

Desta forma, as derivadas numéricas são obtidas a partir do polinômio de convolução $g_{\mathrm{i}}$ multiplicado por $\mathrm{m}$ ! para se obter os coeficientes da derivada de $\mathrm{m}$ ésima ordem, ou seja:

$$
\frac{d g_{i}}{d t}=m ! \sum_{m=0}^{r}\left\{\left(\mathbf{A}^{T} \cdot \mathbf{A}\right)^{-1}\right\}_{0 m} n^{m}
$$

Para o método 2 o coeficiente de correlação $\left(R^{2}\right)$ será dado por:

$$
R^{2}=1-\frac{n-1}{n-(r-1)} \frac{\sum\left(f_{i}-g_{i}\right)^{2}}{\sum\left(f_{i}-\bar{f}_{i}\right)^{2}}
$$

sendo $\mathrm{n}$ o número total de pontos utilizados $\left(\mathrm{n}_{\mathrm{L}}+\mathrm{n}_{\mathrm{R}}\right)$, r o grau do polinômio, e $\bar{f}_{i}$ a média dos dados originais.

Para o método 1 (DPI), o coeficiente de correlação pode ser obtido diretamente do programa utilizado para a interpolação polinomial. Mais informações quanto ao filtro Savitzky-Golay podem ser encontradas em Savitzky e Golay (1964), Press et al. (1992), Luo et al. (2005), Luo; Ying e Bai (2005) e Staggs (2005). 


\subsubsection{Método 3 - Diferenças Finitas Centradas (DFC)}

O método das diferenças finitas centradas é um método de resolução numérica de equações diferenciais baseado na aproximação das derivadas por quocientes de diferença. As fórmulas de aproximação são obtidas do desenvolvimento da expansão em série de Taylor da função derivada e são dadas pelas seguintes relações:

Ponto inicial $\left.\quad \frac{d T_{r}}{d t}\right|_{t_{0}}=\frac{-3 T_{r}\left(t_{1}\right)+4 T_{r}\left(t_{2}\right)-T_{r}\left(t_{3}\right)}{2 \Delta t}$

Pontos interiores $\left.\frac{d T_{r}}{d t}\right|_{t_{j}}=\frac{T_{r}\left(t_{j+1}\right)-T_{r}\left(t_{j-1}\right)}{2 \Delta t}$

Ponto final $\left.\quad \frac{d T_{r}}{d t}\right|_{t_{n}}=\frac{T_{r}\left(t_{n-2}\right)-4 T_{r}\left(t_{n-1}\right)+T_{r}\left(t_{n}\right)}{2 \Delta t}$

\subsubsection{Técnicas computacionais}

Com relação ao projeto de um observador para a predição das variáveis de estado da reação de hidrólise do anidrido acético, em face do exposto na subseção anterior, fica claro que a utilização dos parâmetros $k_{0}$, E e UA, obtidos da literatura ou por calibração, pode acabar ocasionando erros significativos nas estimativas dos estados, uma vez que estes parâmetros são fortemente dependentes das condições experimentais, principalmente, da temperatura do meio reacional. Desta forma, o projeto de um observador de estado para a predição dos valores de conversão deve conter uma rotina de atualização do parâmetro global UA levando em conta a presença de incertezas nos valores dos parâmetros $\mathrm{k}_{0}$ e E. Melhor ainda se estes parâmetros forem estimados juntamente com $\mathrm{X}_{\mathrm{AA}}$ e UA, ou seja, o sistema não-linear dado pela eq.(5.07) é representado agora pelo seguinte sistema aumentado: 


$$
\left\{\begin{array}{l}
\frac{d X_{A A}}{d t}=\frac{V}{N_{A A 0}} k_{0} \exp \left(-\frac{E}{R T_{r}}\right)\left(\frac{N_{A A 0}}{V}\right)^{2}\left(1-X_{A A}\right)\left(\frac{N_{W 0}}{N_{A A 0}}-X_{A A}\right) \\
\frac{d T_{r}}{d t}=\frac{(-\Delta H) V}{\left(m C_{p}\right)_{r}} k_{0} \exp \left(-\frac{E}{R T_{r}}\right)\left(\frac{N_{A A 0}}{V}\right)^{2}\left(1-X_{A A}\right)\left(\frac{N_{W 0}}{N_{A A 0}}-X_{A A}\right)-\frac{U A}{\left(m C_{p}\right)_{r}}\left(T_{r}-T_{a m b}\right) \\
\dot{k}_{0}=0 \\
\dot{E}=0 \\
U \dot{A}=0 \\
y=T_{r}
\end{array}\right.
$$

Para saber se $\mathrm{X}_{\mathrm{AA}}$ e os parâmetros $\mathrm{k}_{0}$, $\mathrm{E}$ e UA podem ser estimados simultaneamente a partir das medidas de temperatura, a observabilidade do sistema (5.31) é analisada a seguir e está baseada em Freire (2003).

Observabilidade (sistema 5.31) - Seja o vetor de estados $\mathbf{x}=\left[\begin{array}{l}X_{A A} \\ T_{r}\end{array} k_{0} E U A\right]^{\top}$ aumentado com a presença dos parâmetros $\mathrm{k}_{0}$, E e UA. A partir da definição desse vetor, consideram-se os seguintes estados iniciais:

$$
\begin{aligned}
& \mathbf{x}_{\mathbf{1}}=\left[\begin{array}{lllll}
\mathrm{X}_{\mathrm{AA}, 1} & \mathrm{~T}_{\mathrm{r}, 1} & \mathrm{k}_{0,1} & \mathrm{E}_{1} & \mathrm{UA}_{1}
\end{array}\right]^{\top}
\end{aligned}
$$

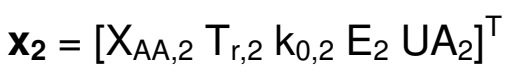

Impondo $T_{r, 1}=T_{r, 2}=T_{r}$, a única possibilidade de se ter $y\left(x_{1}\right)=y\left(x_{2}\right)$ e as trajetórias da evolução de ambos os estados pertencendo ao mesmo espaço vetorial é obtida caso $\mathrm{x}_{1}=\mathrm{x}_{2}$. Pode-se, por exemplo, escolher um par $\left(\mathrm{k}_{0,1}, \mathrm{E}_{1}\right) \neq\left(\mathrm{k}_{0,2}, \mathrm{E}_{2}\right)$ tal que:

$$
k_{0,1} \exp \left(-\frac{E_{1}}{R T_{r}}\right)=k_{0,2} \exp \left(-\frac{E_{2}}{R T_{r}}\right)
$$

Entretanto, como $T_{r}$ varia com o tempo, isso levaria os estados $x_{1}$ e $x_{2}$ a evoluírem de formas distintas. O mesmo ocorre com o parâmetro UA. Dessa forma, fica claro que o sistema (5.31) é observável.

Alguns aspectos sobre a observabilidade dos parâmetros cinéticos $\mathrm{k}_{0}$ e $\mathrm{E}$ e do coeficiente de troca térmica UA, importantes no projeto do observador de estado, 
não necessitam de conceitos teóricos para serem especificados. Analisando-se o sistema (5.31), fica claro que a única possibilidade de se estimar em linha os parâmetros cinéticos encontra-se dentro do intervalo em que ocorre reação. Em outras palavras, $k_{0}$ e $E$ farão parte do balanço energético enquanto houver a contribuição cinética da reação, ou seja, $X_{A A}<1$. Isso não ocorre com o coeficiente UA, uma vez que o termo de troca de calor com o ambiente contribui para o acúmulo de energia enquanto a diferença entre $T_{r}$ e $T_{a m b}$ for diferente de zero. Essas características do sistema (5.31) impõe limitações significativas na estimativa em linha dos parâmetros cinéticos. Adicionalmente, a presença de incertezas nos parâmetros $k_{0}$ e $E$ podem afetar consideravelmente as estimativas dos estados preditos pelo sistema (5.31) e, portanto, é necessário verificar como a conversão e a temperatura do reator serão afetadas por estes parâmetros e pelo coeficiente UA. Esta análise é feita através da análise de sensibilidade paramétrica de $X_{A A}$ e $T_{r}$ com relação aos parâmetros $\mathrm{k}_{0}$, E e UA.

\subsubsection{Análise de sensibilidade}

Atualmente, grande parte dos modelos matemáticos usados em engenharia são descritos por sistemas de equações algébrico-diferenciais (EDA) que, em conjunto com o rápido desenvolvimento da área computacional, tem permitido investigar diversos fenômenos físicos de forma cada vez mais realista. Entretanto, estes modelos frequentemente estão associados a parâmetros cujos valores nem sempre são conhecidos, ou são conhecidos apenas para determinadas condições experimentais. Desta forma, é necessário analisar a sensibilidade do sistema de equações algébrico-diferenciais com relação a estes parâmetros.

Diversas razões justificam a análise de sensibilidade de um modelo cinético. Primeiro, para conhecer os efeitos das incertezas presentes no sistema de parâmetros sobre a cinética e determinar quais são os parâmetros mais críticos. Segundo, a análise de sensibilidade permite identificar os parâmetros com pouca influência sobre as estimativas possibilitando, portanto, a simplificação do modelo. Terceiro, os coeficientes de sensibilidade são necessários na maioria dos procedimentos de estimação paramétrica (VALKO; VAJDA, 1984). 
Além disso, Petzold et al. (2006) observam que os resultados da análise de sensibilidade podem ser aplicados em outras áreas da ciência e engenharia como, por exemplo, modelagem, otimização, estimação paramétrica, controle ótimo, análise de incertezas e planejamento de experimentos.

Um modo usual de se obter as sensibilidades de um sistema dinâmico é através da integração numérica do sistema de equações de sensibilidade resultante da derivação do sistema de equações algébrico-diferenciais com relação aos parâmetros de interesse (SCHLEGEL et al., 2004).

Vários trabalhos voltados ao desenvolvimento de métodos e algoritmos para a análise de sensibilidade têm sido reportados na literatura como, por exemplo, o método da função de Green para o cálculo da sensibilidade de um sistema composto por diversos modelos cinéticos (HWANG et al., 1978; DOUGHERTY; HWANG; RABITZ, 1979; RABITZ, 1981); algoritmo semi-implícito de Runge-Kutta usado em conjunto com o método da decomposição direta (VALKO; VAJDA, 1984); método da extrapolação com passo simples para análise de sensibilidade de um sistema de EAD linearmente implícitos (SCHLEGEL et al., 2004); e método adjunto (CAO; LI; PETZOLD, 2002; CAO et al., 2003).

Recentes publicações têm demonstrado que os coeficientes de sensibilidade de um sistema composto por equações algébrico-diferenciais podem ser obtidos de forma simples pelo método da diferenciação automática (MALY; PETZOLD, 1996; LI; PETZOLD, 1999; LI; PETZOLD, 2000; LI; PETZOLD; ZHU, 2000; PETZOLD et al., 2006).

Baseado em Li e Petzold (1999), considere um sistema de equação algébrico-diferencial genérico:

$$
F\left(t, y, y^{\prime}, p\right)=0, \quad y(0)=y_{0}
$$

com y $\in R^{n y}, \mathrm{p} \in R^{n p}$, onde $\mathrm{n}_{\mathrm{y}}$ é o número de variáveis dependentes y (dimensão do sistema de EAD's), e $n_{p}$ é o número de parâmetros presentes no sistema de equações algébrico-diferencial.

A análise de sensibilidade implica em encontrar as derivadas da solução y com relação a cada parâmetro, ou seja: 
$F\left(t, y, y^{\prime}, p\right)=0$

$\frac{\partial F}{\partial y} s_{i}+\frac{\partial F}{\partial y^{\prime}} s_{i}^{\prime}+\frac{\partial F}{\partial p}=0, \quad i=1, \ldots, n_{p}$

sendo $s_{\mathrm{i}}$ a derivada da solução y com relação a cada parâmetro dada por:

$s_{i}=\frac{d y}{d p_{i}}$

A eq.(5.37) produz $n_{s}=n_{p} \cdot n_{y}$ equações de sensibilidade adicionais que junto com o sistema original resulta no seguinte sistema:

$$
F\left(t, Y, Y^{\prime}, p\right)=\left[\begin{array}{c}
F(t, y, p) \\
\frac{\partial F}{\partial y} s_{1}+\frac{\partial F}{\partial y^{\prime}} s_{1}^{\prime}+\frac{\partial F}{\partial p_{1}} \\
\vdots \\
\frac{\partial F}{\partial y} s_{n p}+\frac{\partial F}{\partial y^{\prime}} s_{n p}^{\prime}+\frac{\partial F}{\partial p_{n p}}
\end{array}\right]=0, \quad Y(0)=\left[\begin{array}{c}
y_{0} \\
\frac{d y_{0}}{d p_{1}} \\
\vdots \\
\frac{d y_{0}}{d p_{n p}}
\end{array}\right]
$$

O sistema representado pela eq.(5.38) é resolvido pelo método das diferenças finitas para trás (backward differentiation formula - BDF) de k-ésima ordem com passo $h_{n+1}$ resultando no seguinte sistema não-linear:

$G\left(Y_{n+1}\right)=F\left(t_{n+1}, Y_{n+1}, Y_{n+1}^{\prime(0)}-\frac{\alpha_{s}}{h_{n+1}}\left(Y_{n+1}-Y_{n+1}^{(0)}\right), p\right)=0$

onde $Y_{n+1}^{(0)}$ e $Y_{n+1}^{(0)}$ são os valores preditos de $Y_{n+1}$ e $Y_{n+1}^{\prime}$, respectivamente, obtidos através da extrapolação polinomial dos valores passados. O parâmetro $\alpha_{s}$ é um coeficiente fixo e a sua equação é apresentada em Brenan; Campbell e Petzold (1989 4 apud LI; PETZOLD, 1999).

Aplicando o método de Newton sobre o sistema não-linear obtém-se o seguinte procedimento iterativo:

\footnotetext{
${ }^{4}$ BRENAN, K. E.; CAMPBELL, S. L.; PETZOLD, L. R. Numerical Solution of Initial-Value Problems in Differential-Algebraic Equation. $2^{\text {nd }}$ ed. New York: Elsevier, 1996.
} 
$Y_{n+1}^{(k+1)}=Y_{n+1}^{(k)}-\mathbf{J}^{-1} G\left(Y_{n+1}^{(k)}\right)$

sendo

$$
\begin{aligned}
& \mathbf{J}=\left[\begin{array}{ccccc}
J & & & & \\
J_{1} & J & & & \\
J_{2} & 0 & J & & \\
\vdots & \vdots & \vdots & \ddots & \\
J_{n_{p}} & 0 & \cdots & 0 & J
\end{array}\right] \\
& J=\frac{\alpha_{s}}{h_{n+1}} \frac{\partial F}{\partial y^{\prime}}+\frac{\partial F}{\partial y^{\prime}} \\
& J_{i}=\frac{\partial J}{\partial y} s_{i}+\frac{\partial J}{\partial p_{i}}
\end{aligned}
$$

Este método foi implementado em Fortran 77 por Li e Petzold (1999) resultando no solver DASPK 3.0. Detalhes adicionais quanto ao desenvolvimento e funcionamento do solver podem ser encontrados na literatura citada.

\subsection{Polimerização em emulsão}

Os ensaios foram conduzidos em uma unidade experimental automatizada composta por: um reator de $3 \mathrm{~L}$ encamisado e em aço inox 316 para alta pressão (Büchi Glass); um agitador mecânico tipo âncora (até $500.000 \mathrm{cP}$ ) Büchi Glass modelo bmd 800, conectado a um motor com variador de velocidades; linha de nitrogênio para a purga da atmosfera do reator; válvulas solenóides e de membrana; aquecedor indutivo (Coelma) com bomba de recirculação, responsável pela circulação do fluido de refrigeração e aquecimento na camisa do reator; compressor para o fornecimento de ar comprimido responsável pela abertura e fechamento da válvula de membrana do sistema de troca térmica; e termorresistências. Os dados 
são coletados ao longo da reação por uma placa de aquisição de dados e o controle das condições operacionais é feito via software com interface em LabView. São feitas aquisições das temperaturas do meio reacional e da entrada e da saída da camisa, via sensores PT100, e do sistema de alimentação, composto por bombas dosadoras (Prominent) e balanças (Marte). Na Figura 5.1 é apresentada uma representação simplificada da unidade experimental utilizada nos ensaios. Nesta mesma figura é apresentado também a localização dos termopares tipo $K$ responsáveis pela aquisição das temperaturas de entrada e de saída da camisa. O uso desses termopares teve por objetivo obter uma segunda medida de temperatura nesses pontos para verificar a presença de eventuais perdas térmicas, uma vez que os sensores PT100 estão localizados razoavelmente distantes da entrada e da saída da camisa.

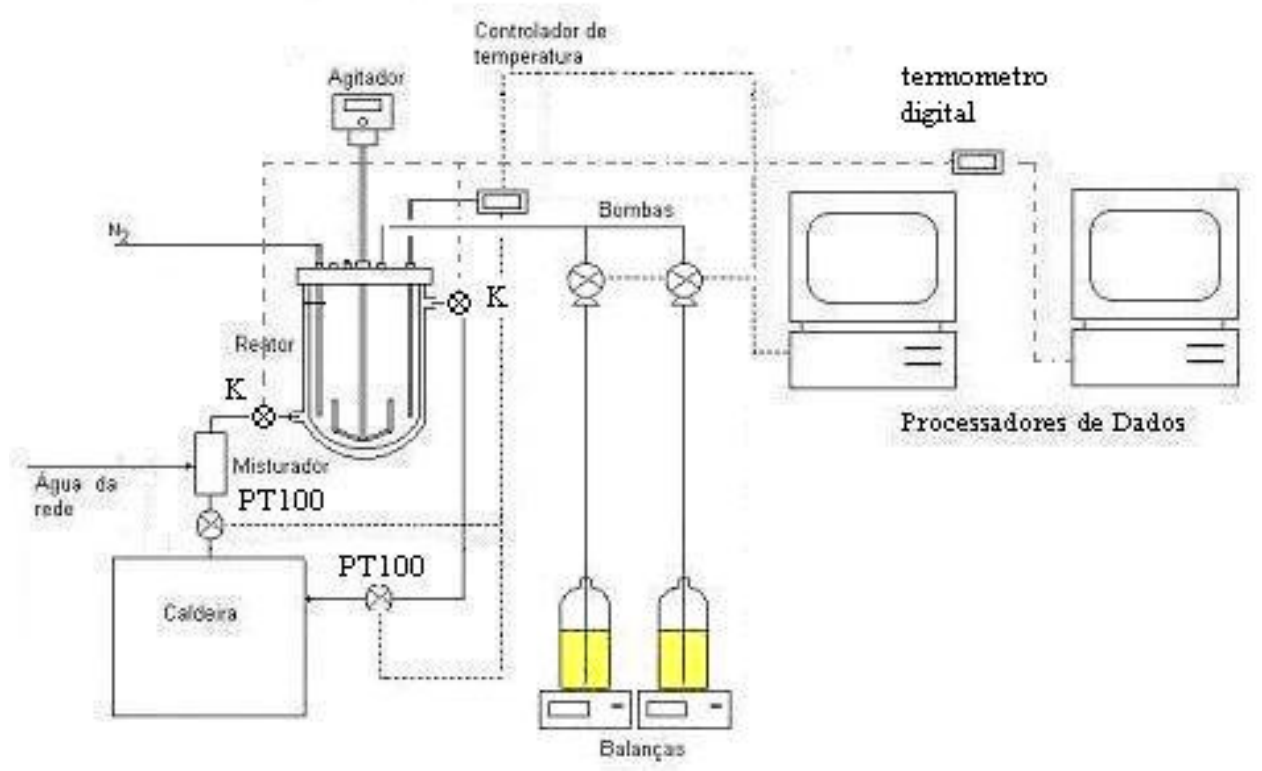

Figura 5.1 - Representação simplificada da unidade experimental

Os termopares tipo K são conectados o mais próximo possível da entrada e da saída da camisa através de válvulas de engate rápido adaptadas para esse fim. Esses termopares, por sua vez, são conectados a um termômetro digital portátil tipo $\mathrm{K} / \mathrm{J}$ com 4 canais modelo TH-096 (Instrutherm). O termômetro é ligado a um computador via cabo conversor RS-232 para USB, e o registro das temperaturas é feito via software de aquisição de dados (Lutron) modelo SW-U801-WIN. 


\subsubsection{Reagentes}

A seguir são apresentados os reagentes utilizados nas reações. Todos os compostos listados abaixo foram utilizados como comercializados sem qualquer tratamento prévio.

i) Água destilada e deionizada: utilizada como fase contínua do látex.

ii) Lauril sulfato de sódio (SLS): emulsificante aniônico utilizado para estabilização iônica das partículas, para auxiliar na dispersão da fase orgânica na fase contínua, e para promover a formação dos primeiros centros de nucleação de partículas (micelas).

iii) Persulfato de potássio: iniciador térmico utilizado para a geração dos radicais responsáveis pela quebra das ligações sigma das moléculas de monômero, iniciando a reação de polimerização propriamente dita.

iv) Carbonato de sódio: agente tamponante utilizado para evitar ou minimizar a acidificação do meio reacional e, consequentemente, evitar a hidrólise dos monômeros.

v) Acetato de vinila e acrilato de butila (doação BASF): monômeros líquidos e incolores com grau técnico de pureza e inibidor.

vi) Hidroquinona: atua como inibidor interrompendo a reação de polimerização das amostras coletadas. Adquire coloração castanha quando exposta ao ar devido ao processo de oxidação da hidroquinona a p-benzoquinona.

\subsubsection{Técnicas analíticas e caracterização do látex}

Nessa subseção são apresentados um resumo descrevendo o funcionamento dos equipamentos utilizados para a caracterização do látex, as equações para o cálculo dos valores experimentais de conversão, composição e concentração de partículas, e o procedimento e as equações utilizadas para a obtenção dos valores iniciais e finais de UA e $\left(\mathrm{mC}_{\mathrm{p}}\right)_{\mathrm{r}}$. 
5.2.2.1 Cromatografia em fase gasosa

As concentrações residuais dos monômeros foram obtidas por um cromatógrafo em fase gasosa modelo GC-17a (Shimadzu), equipado com um detector de ionização de chamas (FID) e um amostrador automático Headspace modelo HSS 4a (Shimadzu).

As curvas de calibração utilizadas para a quantificação das concentrações residuais dos monômeros foram obtidas através do método das adições. De acordo com este método, quantidades conhecidas dos compostos de interesse são adicionadas a quantidades conhecidas da amostra e cromatografadas. As áreas obtidas são então utilizadas para a confecção de uma curva de calibração que correlacione as áreas normalizadas com as frações mássicas dos compostos de interesse. As amostras analisadas neste procedimento devem ser cromatografadas sob as mesmas condições utilizadas durante as análises das amostras desconhecidas. As condições cromatográficas utilizadas são apresentadas na Tabela 5.2 .

Tabela 5.2 - Cromatografia / condições operacionais (método VABA094A.MET)

\begin{tabular}{lr}
\hline \multicolumn{1}{c}{ Parâmetros } & \multicolumn{1}{c}{ Valor } \\
\hline Temperatura do injetor & $240^{\circ} \mathrm{C}$ \\
Temperatura da coluna & $40^{\circ} \mathrm{C}-240^{\circ} \mathrm{C}$ \\
Temperatura do detector & $260^{\circ} \mathrm{C}$ \\
Pressão do ar sintético para o headspace & $3 \mathrm{kgf} / \mathrm{cm}^{2}$ \\
Pressão do ar sintético para chama & $30 \mathrm{kPa}$ \\
Pressão de hidrogênio para a chama & $50 \mathrm{kPa}$ \\
Pressão na entrada da coluna & $80 \mathrm{kPa}$ \\
Vazão de hélio na coluna & $1,00138 \mathrm{~mL} / \mathrm{min}$ \\
Razão de split & $1: 10$ \\
Volume de injeção & $1 \mu \mathrm{L}$ \\
\hline
\end{tabular}

Com relação ao número de pontos usados na elaboração das curvas de calibração, Soares (2001) observa que seis pontos para cada analito já são suficientes, pois o uso de um número maior de pontos apresentará pouco efeito sobre a faixa de confiabilidade da curva de calibração, ao contrário do que ocorre quando um número de pontos menor é utilizado. Por outro lado, em processos de polimerização as concentrações dos monômeros variam ao longo da reação e, 
portanto, a curva de calibração deve, necessariamente, abranger desde altas concentrações (instantes iniciais da reação) até baixas concentrações (regiões de conversão elevada). Assim, para a confecção das curvas de calibração foram utilizadas 14 soluções mães a partir das quais foram obtidas as amostras de trabalho. As curvas de calibração para o acetato de vinila e para o acrilato de butila são apresentadas na Figura 5.2.
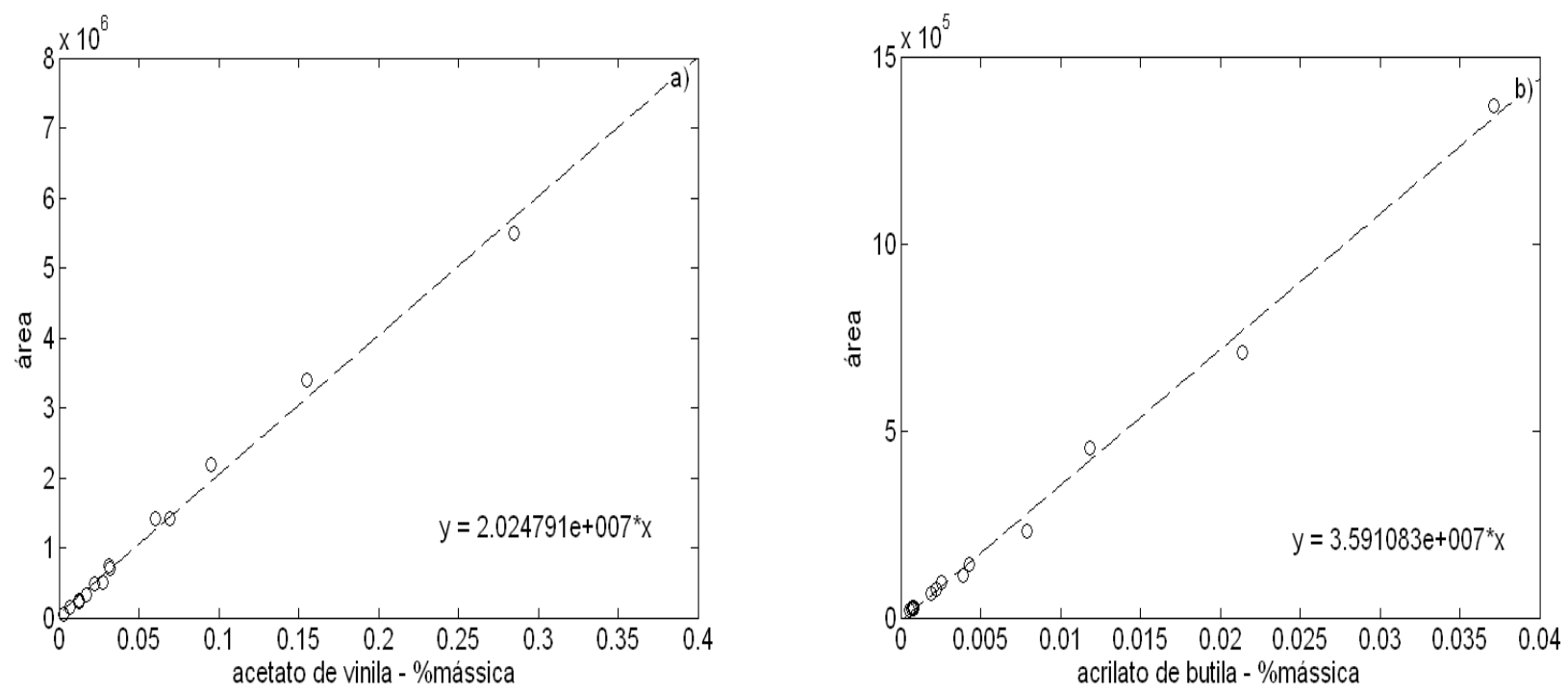

Figura 5.2 - Curvas de calibração: a) acetato de vinila e b) acrilato de butila

5.2.2.2 Difração dinâmica de luz (DLS)

A difração dinâmica de luz foi utilizada para determinar o diâmetro médio das partículas poliméricas usado no cálculo do número de partículas por grama de látex.

O equipamento utilizado (Coulter N4 Plus) determina o diâmetro médio a partir da incidência de um feixe de laser sobre a amostra. A luz espalhada durante a passagem das partículas pelo feixe de luz é captada por um cabo de fibra óptica posicionado em um determinado ângulo e transmitida por um tubo fotomultiplicador e, em seguida, para um amplificador / discriminador onde é transformada em um sinal elétrico. Na Figura 5.3 é apresentada um diagrama funcional do equipamento. 


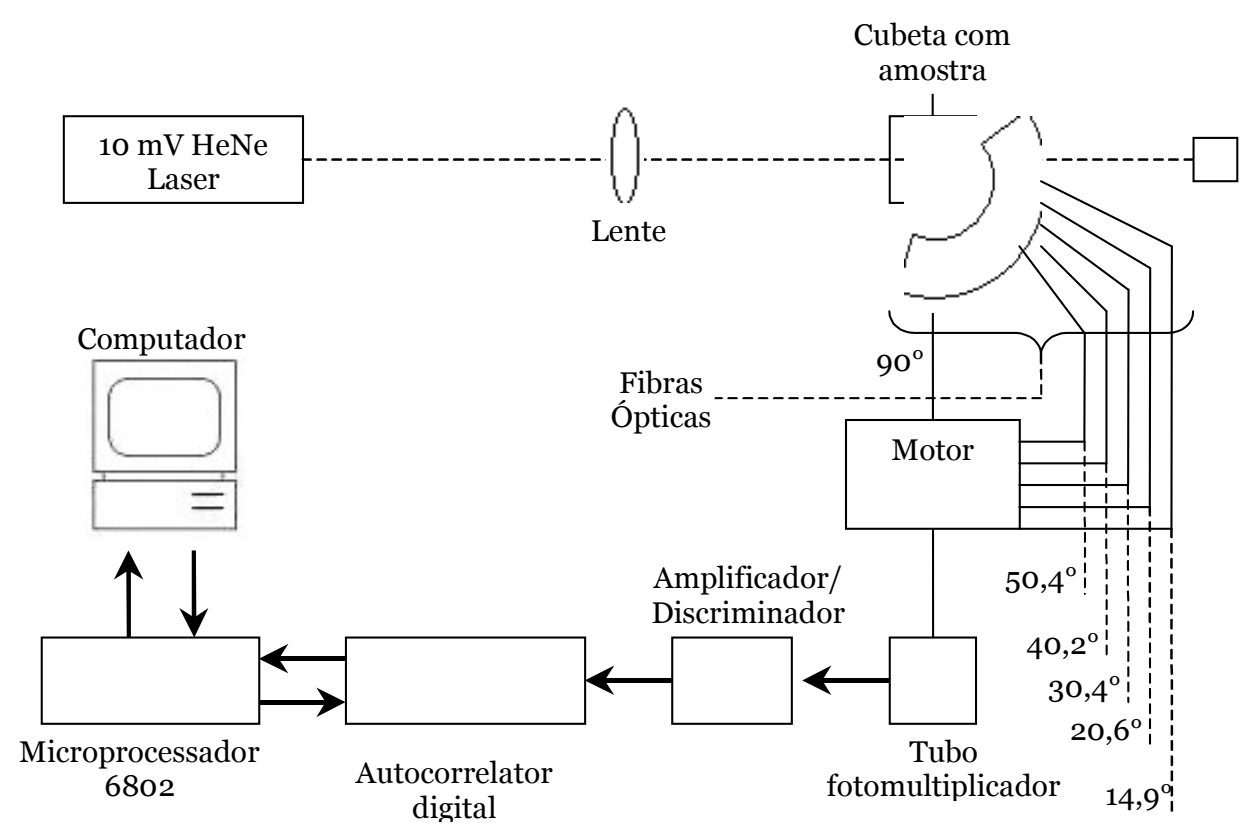

Figura 5.3 - Difração dinâmica de luz: diagrama funcional

Como as partículas mudam de posição no fluido devido ao movimento Browniano, o tipo de interferência e a intensidade da luz detectada pelo detector mudam a cada instante. As partículas maiores mudam de posição mais lentamente causando uma flutuação de intensidade mais lenta, enquanto as partículas menores movimentam-se com uma velocidade maior causando rápidas flutuações de intensidade. Portanto, estas flutuações na intensidade estão relacionadas diretamente com a taxa de difusão das partículas na amostra.

Conhecendo-se a temperatura, a viscosidade, o índice de refração do meio diluente e calculando o coeficiente de difusão, o tamanho médio das partículas pode ser obtido a partir da equação de Stokes-Einstein:

$D\left(d_{p}\right)=\frac{k_{B} T}{3 \pi \eta d_{p}}$

sendo $D\left(d_{p}\right)$ o coeficiente de difusão de uma partícula com diâmetro $d_{p}$, $k_{B}$ a constante de Boltzman $\left(1,38 \times 10^{-16} \mathrm{erg} / \mathrm{K}\right), \mathrm{T}$ a temperatura em Kelvin, $\eta$ a viscosidade do diluente e $d_{p}$ o diâmetro hidrodinâmico equivalente.

O coeficiente de difusão é obtido a partir das flutuações de intensidade da luz espalhada e da frequência destas flutuações, utilizando-se para isto uma função de autocorrelação definida por: 
$G\left(t_{a}\right)=\left\langle I(t) \times I\left(t+t_{a}\right)\right\rangle$

sendo $G\left(t_{a}\right)$ a função de autocorrelação, $I(t)$ a intensidade detectada no instante $t$, $I\left(t+t_{a}\right)$ a intensidade detectada no instante $t+t_{a}, t_{a}$ o tempo de atraso, e a quantidade contida entre < > uma média no tempo.

Se a função de autocorrelação tem um valor alto em $t_{a}$, isto significa que não ocorreram variações de intensidade muito acentuadas no intervalo de tempo analisado. Portanto, uma função de autocorrelação que apresente um valor elevado por um longo intervalo de tempo indica grandes partículas movendo-se lentamente no feixe de luz. Calculando a função de autocorrelação para uma faixa longa de $t_{a}$ 's é encontrada uma medida quantitativa das rápidas flutuações. Esta quantidade medida na escala de tempo das flutuações (tempo de decaimento) é diretamente relacionado ao tamanho da partícula. O inverso do tempo de decaimento é a constante de decaimento $(\Gamma)$. Para partículas monodispersas:

$G\left(t_{a}\right) \propto \exp ^{-2 \Gamma t_{a}}$

A constante $\Gamma$ é igual a $\mathrm{DK}^{2}$, onde $\mathrm{D}$ é o coeficiente de difusão e:

$K=\frac{4 \pi n}{\lambda} \sin \left(\frac{\theta}{2}\right)$

sendo $\mathrm{n} o$ índice de refração do diluente, $\lambda \circ$ comprimento de onda do laser e $\theta \circ$ ângulo da luz espalhada.

Para amostras polidispersas, a função de autocorrelação é a soma das exponenciais para cada tamanho de componente. A análise unimodal utiliza para seu cálculo somente ângulos de $90^{\circ}$ e fornece uma medida do tamanho médio das partículas e uma medida da polidispersidade ou largura da PSD. A análise interpreta a distribuição da amostra como uma log-normal e fornece o tamanho médio e o desvio padrão dos tamanhos de partículas em função dessa distribuição. Portanto, para amostras multimodais ou que tenham a forma de uma PSD diferente de uma log-normal, a análise unimodal não permite conhecer a PSD, apesar de fornecer uma ideia bastante precisa da evolução do tamanho médio das partículas. 


\subsubsection{Conversão}

As conversões foram obtidas a partir das medidas gravimétrica (grav) e a partir das concentrações residuais dos monômeros fornecidas pela cromatografia gasosa (GC), e foram calculadas de duas formas distintas:

i) Considerando a quantidade de monômero já alimentada no reator até o instante da retirada da amostra: conversão instantânea $\left(x_{\text {inst }}\right)$ :

$$
\begin{aligned}
& x_{\text {inst }}^{G C}(t)=\frac{f_{p}(t)}{f_{m}(t)} \\
& x_{\text {inst }}^{\text {grav }}(t)=\frac{f_{p}^{\text {grav }}(t)}{f_{m}(t)}
\end{aligned}
$$

ii) Considerando a quantidade total de monômeros a ser alimentada no reator: conversão global $\left(x_{g}\right)$

$$
\begin{aligned}
& x_{g}^{G C}(t)=\frac{f_{p}(t)}{f_{m T}} \\
& x_{g}^{\text {grav }}(t)=\frac{f_{p}^{\text {grav }}(t)}{f_{m T}}
\end{aligned}
$$

sendo $f_{p}(t)$ a fração mássica de polímero formada até $o$ instante $t, f_{m}(t)$ a fração mássica total de monômero adicionado no reator até o instante $t$, e $f_{m T}$ a fração mássica total de monômero usado na formulação.

A fração mássica gravimétrica de polímero $\left(f_{p}^{\text {grav }}\right)$ é calculada a partir da massa de resíduo seco (RS) obtida pela evaporação da fase líquida da amostra levada à estufa (LA), descontadas a massa de hidroquinona (HID) e a fração de sólidos não poliméricos (emulsificante e iniciador) $\left(f_{\text {snp }}\right)$, ou seja: 


$$
f_{p}^{g r a v}(t)=\frac{(R S-H I D)}{L A}-f_{s n p}
$$

A fração mássica cromatográfica de polímero $\left(f_{p}\right)$ é calculada subtraindo a fração mássica total de monômero alimentado até o instante $t$ da fração mássica total de monômero não reagido ( $\left.f_{\text {res }}\right)$, ou seja:

$$
f_{p}(t)=f_{m}(t)-f_{\text {res }}(t)
$$

A fração mássica residual total de monômeros, por sua vez, é determinada pela soma das frações mássicas residuais de cada monômero, ou seja:

$$
f_{\text {res }}(t)=\sum_{i=A, B} f_{\text {res }}^{i}(t)
$$

A fração mássica residual individual é calculada a partir da fração mássica de monômero não reagido $\left(f_{G C}^{i}\right)$ e da fração mássica de látex $\left(f_{G C}^{L A}\right)$ presentes nas amostras cromatografadas segundo as relações:

$$
\begin{gathered}
f_{\text {res }}^{i}(t)=\frac{f_{G C}^{i}(t)}{f_{G C}^{L A}(t)} \\
f_{G C}^{i}(t)=\frac{A_{i}(t)}{\phi_{i}}
\end{gathered}
$$

$$
f_{G C}^{L A}(t)=\frac{m_{L A}(t)}{\left(m_{L A}(t)+m_{w}(t)\right)}
$$

sendo $A_{i}(t)$ a área do pico cromatográfico do monômero i para a amostra retirada no instante $\mathrm{t}, \phi_{\mathrm{i}} \mathrm{O}$ coeficiente angular da curva de calibração do monômero i (Figura 5.2), e $m_{L A}(t)$ e $m_{w}(t)$ as massas de látex e água, respectivamente, presentes na amostra retirada no instante $t$. 


\subsubsection{Composição mássica acumulada}

A composição de um copolímero corresponde à fração, molar ou mássica, de cada monômero incorporado na cadeia polimérica. Quanto maior a diferença entre as razões de reatividade dos monômeros, maior será a variação das quantidades relativas dos monômeros presentes no meio reacional. Como a composição do copolímero é dependente destas quantidades relativas, estas variações farão com que a composição do copolímero varie ao longo da reação. A variação de composição é conhecida como deriva de composição (composition drift), e desvios acentuados neste parâmetro podem causar problemas de compatibilidade entre as cadeias do polímero alterando as qualidades mecânicas do produto final.

Neste trabalho a composição mássica acumulada foi calculada em relação ao acetato de vinila $\left(\mathrm{y}_{\mathrm{A}}\right)$ usando as conversões instantâneas obtidas a partir dos teores residuais de monômeros obtidos por cromatografia gasosa, ou seja:

$$
y_{A}(t)=f_{C A}^{A} \frac{x_{i n s t}^{A}(t)}{x_{i n s t}^{G C}(t)}
$$

sendo $f_{C A}^{A}$ a fração mássica de acetato de vinila $(\mathrm{A})$ na corrente de alimentação e $x_{i n s t}^{A}$ a conversão instantânea de acetato de vinila calculada da seguinte forma:

$$
x_{\text {inst }}^{A}(t)=\frac{f_{C A}^{A} f_{m}(t)-f_{\text {res }}^{A}(t)}{f_{C A}^{A} f_{m}(t)}
$$

\subsubsection{Número de partículas}

O número de partículas por grama de látex foi calculado a partir do diâmetro médio das partículas $\left(\bar{d}_{p}\right)$ obtido por difração dinâmica de luz e a partir da conversão instantânea. 
Como a determinação de $\bar{d}_{p}$ requer baixas concentrações de polímeros, o monômero difunde-se das partículas para a fase aquosa assegurando que o diâmetro medido seja o diâmetro das partículas não inchadas com monômeros. Portanto, o volume médio da partícula polimérica $\left(v_{p}\right)$ pode ser calculado da seguinte forma:

$$
v_{p}(t)=\frac{4}{3} \pi\left(\frac{\bar{d}_{p}(t)}{2}\right)^{3}
$$

Desta forma, o número de partículas por grama de látex será dado por:

$$
N_{p}(t)=\frac{x_{i n s t}^{G C}(t) f_{m}(t)}{v_{p}(t) \rho_{p o l}(t)}
$$

sendo $\rho_{\mathrm{pol}}$ a densidade do copolímero.

\subsubsection{Coeficiente de troca térmica e capacidade calorífica total}

Os valores experimentais de $\mathrm{UA}$ e $\left(\mathrm{mC}_{\mathrm{p}}\right)_{\mathrm{r}}$ foram obtidos antes e depois de cada reação através de uma resistência elétrica imersa no meio reacional e ligada a uma fonte de alimentação (Variac).

Neste tipo de calibração, uma voltagem elétrica (140V) é aplicada e mantida constante durante um dado intervalo de tempo até a temperatura do reator atingir um patamar estacionário. Então, um novo aumento na voltagem (220V) é aplicado e mantido constante até a temperatura do reator atingir um novo estado estacionário. A resistência elétrica é então desligada, e a temperatura do meio reacional diminui até entrar em equilíbrio térmico com a camisa.

Uma vez que o calor introduzido no meio reacional pela fonte externa é diferente de zero, o balanço de energia será dado por: 


$$
\left(m C_{p}\right)_{r} \frac{d T_{r}}{d t}=Q_{r}+\sum_{i} F_{i} C_{p i}\left(T_{\text {feed }}-T_{r}\right)-U A\left(T_{r}-T_{j}\right)-Q_{\text {loss }}+V_{e} i_{e}
$$

sendo $V_{e} e i_{e}$, respectivamente, a voltagem e a corrente elétrica fornecidas pela fonte de alimentação.

O valor de $Q_{\text {loss }}$ é considerado desprezível quando comparado à contribuição dos demais termos do balanço. A voltagem fornecida ao resistor é obtida diretamente pela leitura da fonte de alimentação, e a corrente elétrica é obtida a partir de um multímetro conectado à fonte de alimentação.

Como este procedimento é aplicado tanto no começo quanto no fim da reação, o calor de reação $\left(Q_{r}\right)$ e o calor sensível de alimentação $\left(Q_{\text {feed }}\right)$ são iguais a zero e, portanto, o valor do coeficiente UA pode ser estimado rapidamente a partir dos dados de temperatura da região estacionária $\left(\mathrm{dT}_{\Gamma} / \mathrm{dt}=0\right)$ através da relação:

$$
U A=\frac{V_{e} i_{e}}{\left(T_{r}-T_{j}\right)}
$$

Usando o valor de UA obtido pela eq.(5.63), a capacidade calorífica total do reator pode ser estimada a partir das medidas de temperatura da região de resfriamento onde a variação de $T_{r}$ é causada exclusivamente pela troca térmica entre o meio reacional e a camisa, ou seja:

$$
\left(m C_{p}\right)_{r} \frac{d T_{r}}{d t}=-U A\left(T_{r}-T_{j}\right)
$$

Integrando a eq.(5.64) deste o instante em que a resistência elétrica é desligada $\left(T_{r}\left(t_{0}\right)=T_{r 0}\right)$ até um instante genérico t obtém-se:

$$
\ln \left(\frac{T_{r}-T_{j}}{T_{r 0}-T_{j}}\right)=-\frac{U A}{\left(m C_{p}\right)_{r}}\left(t-t_{0}\right)
$$

Ou seja, a capacidade calorífica total do reator é estimada a partir do coeficiente angular do gráfico de $\ln \left[\left(T_{r}-T_{j}\right) /\left(T_{r 0}-T_{j}\right)\right]$ em função de (t- $\left.t_{0}\right)$. 


\subsubsection{Técnicas computacionais}

Dentre os diversos métodos e sensores disponíveis, a calorimetria tem sido uma das técnicas mais utilizadas para o monitoramento e o controle de reatores de polimerização devido, principalmente, a sua natureza não-invasiva e a facilidade na obtenção de medidas contínuas de temperatura e vazão que, quando combinadas com o balanço de energia do reator, permitem estimar rapidamente a evolução das variáveis de estado do processo.

Entretanto, apesar da sua aparente simplicidade, a calorimetria sofre com sérias limitações quanto à aplicabilidade prática, pois a estimação de $Q_{r}$ requer que todos os termos envolvidos no balanço de energia sejam conhecidos o que, em geral, nem sempre é possível, uma vez que o coeficiente de troca térmica pode estar sujeito a variações temporais difíceis de serem mensuradas.

Para contornar este problema BenAmor; Colombié e McKenna (2002) e Freire et al. (2004) propuseram a utilização de observadores de estado de alto ganho para a estimação conjunta de $Q_{r}$ e UA sem a necessidade de maiores informações a respeito das características geométricas do reator, do teor de sólidos ou da variação da área de troca térmica efetiva. $\mathrm{Na}$ verdade as variações destas propriedades e das demais condições da reação são contabilizadas indiretamente nos parâmetros de sintonia do observador, já que estes parâmetros são os responsáveis direto pela minimização da diferença entre os valores preditos e medidos da variável de saída do sistema dinâmico. Portanto, o sucesso deste enfoque requer a obtenção de parâmetros de sintonia capazes de acompanhar tais variações e, ao mesmo tempo, minimizar o tempo computacional dispendido e a presença de ruídos nas estimativas dos estados.

Partindo da eq.(4.31) e sabendo que a temperatura do reator $\left(T_{r}\right)$ é medida em linha, BenAmor; Colombié e McKenna (2002) e Freire et al. (2004) propuseram o seguinte sistema dinâmico aumentado pela presença das dinâmicas de $Q_{r}$ e UA: 


$$
(\Sigma)\left\{\begin{array}{l}
\frac{d T_{\mathrm{r}}}{d t}=\frac{Q_{\mathrm{r}}}{\left(m C_{\mathrm{p}}\right)_{\mathrm{r}}}-\frac{U A}{\left(m C_{\mathrm{p}}\right)_{\mathrm{r}}}\left(T_{\mathrm{r}}-T_{\mathrm{j}}\right)+\frac{\sum_{i} F_{\mathrm{i}} C_{\mathrm{pi}}}{\left(m C_{\mathrm{p}}\right)_{\mathrm{r}}}\left(T_{\text {feed }}-T_{\mathrm{r}}\right)-\frac{Q_{\text {loss }}}{\left(m C_{\mathrm{p}}\right)_{\mathrm{r}}} \\
\frac{d U A}{d t}=\varepsilon_{1}(t) \\
y=T_{\mathrm{r}}(t)
\end{array}\right.
$$

sendo y a medida de saída do sistema e $\varepsilon_{1}(\mathrm{t})$ e $\varepsilon_{2}(\mathrm{t})$ constantes infinitesimais representando as dinâmicas desconhecidas de $Q_{r}$ e UA, respectivamente, e descritos por um simples modelo de Randon Walk, definido originalmente para processos aleatórios.

Definindo o vetor de estados do sistema dado pela eq.(5.66) como sendo $\mathbf{X}=\left[\begin{array}{lll}T_{r} & Q_{r} & \cup A\end{array}\right]^{\top}$, aumentado pela presença dos parâmetros $Q_{r}$ e UA, selecionam-se os seguintes estados iniciais: $x_{1}=\left[\begin{array}{lll}T_{r 1} & Q_{r 1} & \cup A_{1}\end{array}\right]^{\top}$ e $x_{2}=\left[\begin{array}{lll}T_{r 2} & Q_{r 2} & \cup A_{2}\end{array}\right]^{\top}$. Impondo $T_{r 1}=T_{r 2}=T_{r}$, e escolhendo-se os pares $\left(T_{r 1}, Q_{r 1}\right)$ e $\left(T_{r 2}, Q_{r 2}\right)$ de tal forma que $Q_{r 1}-$ $U A_{1}\left(T_{r}-T_{j}\right)=Q_{r 2}-U A_{2}\left(T_{r}-T_{j}\right)$, conclui-se:

i) Se $\left(T_{r}-T_{j}\right)$ variar ao longo da reação, o sistema ( $\left.\Sigma\right)$ é observável;

ii) Se $\left(T_{r}-T_{j}\right)$ for constante ao longo da reação, o sistema $(\Sigma)$ não será observável

Portanto, caso os valores iniciais de $Q_{r}$ e UA sejam desconhecidos e a diferença entre $T_{r}$ e $T_{j}$ for muito próxima a uma constante, mesmo que durante alguns instantes, o sistema dado pela eq.(5.66) não será observável e, portanto, não será possível distinguir $Q_{\mathrm{r}}$ e UA usando apenas as informações de temperatura.

Para contornar este problema, os autores propuseram dividir o sistema $(\Sigma)$ em dois novos subsistemas, cada qual responsável pela estimação de uma das dinâmicas desconhecidas, ou seja: 


$$
\left(\Sigma_{1}\right)\left\{\begin{array}{l}
\frac{d T_{r}}{d t}=\frac{Q_{r}}{\left(m C_{p}\right)_{r}}+\frac{1}{\left(m C_{p}\right)_{r}}\left[-v_{1}\left(T_{r}-T_{j}\right)+\sum_{i} F_{i} C_{p i}\left(T_{\text {feed }}-T_{r}\right)-Q_{\text {loss }}\right. \\
y=\mathcal{E}_{1}(t) \\
y=T_{r}
\end{array}\right.
$$

onde $v_{1}$ é a medida de entrada do sistema $\left(\Sigma_{1}\right)(U A)$.

$$
\left(\Sigma_{2}\right)\left\{\begin{array}{l}
\frac{d T_{r}}{d t}=-\frac{U A\left(T_{r}-T_{j}\right)}{\left(m C_{p}\right)_{r}}+\frac{1}{\left(m C_{p}\right)_{r}}\left[v_{2}+\sum_{i} F_{i} C_{p i}\left(T_{\text {feed }}-T_{r}\right)-Q_{\text {loss }}\right] \\
\frac{d U A}{d t}=\varepsilon_{2}(t) \\
y=T_{r}
\end{array}\right.
$$

onde $v_{2}$ é a medida de entrada do sistema $\left(\Sigma_{2}\right)\left(Q_{r}\right)$.

Aplicando os conceitos de observador de estado não-linear de alto ganho, apresentados na subseção 3.3.9, sobre os subsistemas $\left(\Sigma_{1}\right)$ e $\left(\Sigma_{2}\right)$, e seguindo a notação proposta por BenAmor; Colombié e McKenna (2002), o projeto dos observadores de estado usados para a estimação de $Q_{r}$ e UA é apresentado a seguir.

5.2.3.1 Observador de estado para o calor de reação $\left(Q_{r}\right)$

Antes de iniciar a construção do observador propriamente dito, é necessário verificar a observabilidade do sistema $\left(\Sigma_{1}\right)$. Representando matricialmente o sistema (5.67), obtém-se 


$$
\begin{aligned}
& {\left[\begin{array}{l}
\dot{T}_{r} \\
\dot{Q}_{r}
\end{array}\right]=\left[\begin{array}{cc}
0 & \frac{1}{\left(m C_{p}\right)_{r}} \\
0 & 0
\end{array}\right]\left[\begin{array}{l}
T_{r} \\
Q_{r}
\end{array}\right]+\left[\begin{array}{c}
-v_{1}\left(T_{r}-T_{j}\right)+\sum_{i} F_{i} C_{p i}\left(T_{\text {feed }}-T_{r}\right)-Q_{\text {loss }} \\
\left(m C_{p}\right)_{r} \\
\varepsilon_{1}(t)
\end{array}\right]} \\
& y=\mathbf{C}\left[\begin{array}{l}
T_{r} \\
Q_{r}
\end{array}\right]=\left[\begin{array}{ll}
1 & 0
\end{array}\right]\left[\begin{array}{l}
T_{r} \\
Q_{r}
\end{array}\right]
\end{aligned}
$$

Como o sistema formado pelas eqs.(5.69a) e (5.69b) é linear, a observabilidade do sistema pode ser analisada segundo o Teorema 3.2, ou seja, a seguinte relação deve ser satisfeita:

$$
\operatorname{posto}(\mathbf{Q})=\left(\begin{array}{c}
\mathbf{C} \\
\mathbf{C A}
\end{array}\right)=2
$$

Como para o sistema (5.69):

$$
\left[\begin{array}{c}
\mathbf{C} \\
\mathbf{C A}
\end{array}\right]=\left[\begin{array}{cc}
1 & 0 \\
0 & \frac{1}{\left(m C_{p}\right)_{r}}
\end{array}\right]
$$

o sistema $\left(\Sigma_{1}\right)$ será observável se, e somente se, $\left(m C_{p}\right)_{r} \neq 0$. Como esta condição é fisicamente sempre verdadeira, então o sistema $\left(\Sigma_{1}\right)$ será sempre observável.

Retomando os conceitos e definições apresentados na seção 3, observa-se que o o sistema formado pelas eqs.(5.69a) e (5.69b) já está na forma canônica de observabilidade e, portanto, o observador de alto ganho para a variável $Q_{r}$ pode ser obtido sem a necessidade de aplicar uma mudança de coordenadas de estado. Mais precisamente, o sistema $\left(\Sigma_{1}\right)$ pode ser re-escrito na seguinte forma canônica:

$$
\left\{\begin{array}{l}
\dot{\mathbf{x}}=a(t) \mathbf{A} \mathbf{x}+\varphi(u, y) \\
y=\mathbf{C} \mathbf{x}=x_{1}=T_{r}
\end{array}\right.
$$

onde: 
$a(t)=\frac{1}{\left(m C_{p}\right)_{r}}$

$\mathbf{A}=\left[\begin{array}{ll}0 & 1 \\ 0 & 0\end{array}\right]$

$\mathbf{C}=\left[\begin{array}{ll}1 & 0\end{array}\right]$

$\varphi(u, y)=\left[\begin{array}{c}\frac{1}{\left(m C_{p}\right)_{r}}\left(-u_{1} y+u_{2}-u_{3} y+u_{4}-u_{5}\right) \\ 0\end{array}\right]$

e $\mathbf{x}$ e u são, respectivamente, o vetor das variáveis de estado e o vetor das medidas de entrada, dados por:

$\mathbf{x}=\left[\begin{array}{l}x_{1} \\ x_{2}\end{array}\right]=\left[\begin{array}{l}T_{r} \\ Q_{r}\end{array}\right]$

$\mathbf{u}=\left[\begin{array}{lll}u_{1} & \ldots & u_{5}\end{array}\right]^{T}=\left[\begin{array}{llllll}v_{1} & v_{1} T_{j} & \sum_{i} F_{i} C_{p i} & \sum_{i} F_{i} C_{p i} T_{\text {feed }} & Q_{\text {loss }}\end{array}\right]^{T}$

Tomando uma parâmetro $\theta_{1}>0 \mathrm{e}$

$\mathbf{S}_{\theta_{1}}=\left[\begin{array}{cc}\frac{1}{\theta_{1}} & -\frac{1}{\theta_{1}^{2}} \\ -\frac{1}{\theta_{1}^{2}} & \frac{2}{\theta_{1}^{3}}\end{array}\right]$

a solução única da equação algébrica de Lyapunov:

$\theta_{1} \mathbf{S}_{\theta 1}+\mathbf{A}^{T} \mathbf{S}_{\theta 1}+\mathbf{S}_{\theta 1} \mathbf{A}=\mathbf{C}^{T} \mathbf{C}$ 
o observador não-linear de $Q_{r}$ será dado pelo seguinte sistema:

$$
\left[\begin{array}{l}
\hat{T}_{r} \\
\hat{Q}_{r}
\end{array}\right]=\left[\begin{array}{cc}
0 & \frac{1}{\left(m C_{p}\right)_{r}} \\
0 & 0
\end{array}\right]\left[\begin{array}{l}
\hat{T}_{r} \\
\hat{Q}_{r}
\end{array}\right]+\varphi(u, y)-\boldsymbol{\Gamma}(t) \mathbf{S}_{\theta 1}^{-1} \mathbf{C}^{T}(\mathbf{C x}(t)-y(t))
$$

onde:

$$
\boldsymbol{\Gamma}(t)=\left[\begin{array}{cc}
1 & 0 \\
0 & \frac{1}{a(t)}
\end{array}\right]
$$

Fazendo as manipulações algébricas necessárias, o observador para o sistema $\left(\Sigma_{1}\right)$ será dado por:

$$
\left(O_{1}\right)\left\{\begin{aligned}
\frac{d \hat{T}_{r}}{d t}= & \frac{\hat{Q}_{r}}{\left(m C_{p}\right)_{r}}+\frac{1}{\left(m C_{p}\right)_{r}}\left[-v_{1}\left(\hat{T}_{r}-T_{j}\right)+\sum_{i} F_{i} C_{p i}\left(T_{\text {feed }}-\hat{T}_{r}\right)-Q_{\text {loss }}\right]- \\
& 2 \theta_{1}\left(\hat{T}_{r}-T_{r}\right) \\
\frac{d \hat{Q}_{r}}{d t}= & -\theta_{1}^{2}\left(m C_{p}\right)_{r}\left(\hat{T}_{r}-T_{r}\right)
\end{aligned}\right.
$$

5.2.3.2 Observador de estado para o coeficiente de troca térmica (UA)

Definindo $\mathbf{x}$ como o vetor das variáveis de estado:

$$
\mathbf{x}=\left[\begin{array}{l}
x_{1} \\
x_{2}
\end{array}\right]=\left[\begin{array}{c}
T_{r} \\
U A
\end{array}\right]
$$

e u o vetor das medidas de entrada: 
$\mathbf{u}=\left[\begin{array}{lll}u_{1} & \ldots & u_{5}\end{array}\right]^{T}=\left[\begin{array}{llllll}T_{j} & \frac{v_{2}}{\left(m C_{p}\right)_{r}} & \frac{\sum_{i} F_{i} C_{p i}}{\left(m C_{p}\right)_{r}} & \frac{\sum_{i} F_{i} C_{p i} T_{\text {feed }}}{\left(m C_{p}\right)_{r}} & \frac{Q_{\text {loss }}}{\left(m C_{p}\right)_{r}}\end{array}\right]^{T}$

o sistema $\left(\Sigma_{2}\right)$ pode ser representado pelo seguinte sistema de estado afim (Stateaffine systems):

$\left\{\begin{array}{l}\dot{\mathbf{x}}=\mathbf{A}(u, y) \mathbf{x}+\varphi^{\prime}(u, y) \\ y=\mathbf{C x}=x_{1}\end{array}\right.$

onde:

$$
\begin{aligned}
& \mathbf{A}(u, y)=\left[\begin{array}{cc}
0 & a(t)\left(y-u_{1}\right) \\
0 & 0
\end{array}\right] \\
& a(t)=\frac{1}{\left(m C_{p}\right)_{r}} \\
& \varphi^{\prime}(u, y)=\left[\begin{array}{c}
u_{2}-u_{3} y+u_{4}-u_{5} \\
0
\end{array}\right]
\end{aligned}
$$

Dessa forma, ao contrário do sistema $\left(\Sigma_{1}\right)$, o sistema $\left(\Sigma_{2}\right)$ não é linear e, portanto, o projeto de um observador de alto ganho para a estimação do coeficiente UA requer que o sistema (5.86) seja uniformemente observável.

Considere duas medidas de saída $y$ e $\bar{y}$ e as respectivas trajetórias do sistema $\left(\Sigma_{2}\right)$ inicializadas em $x_{0}$ e $\bar{x}_{0}$ denotados por $x_{u}\left(t, x_{0}\right)$ e $\bar{x}_{u}\left(t, \bar{x}_{0}\right)$, deve-se demonstrar que se $y=\bar{y}$, então $x=\bar{x}$. 


$$
\begin{aligned}
& y=\bar{y} \leftrightarrow x_{1}=\bar{x}_{1} \leftrightarrow \dot{x}_{1}=\bar{x}_{1} \\
& \leftrightarrow a(t)\left(y-u_{1}\right) x_{2}+u_{2}-u_{3} y+u_{4}-u_{5}=a(t)\left(\bar{y}-u_{1}\right) \bar{x}_{2}+u_{2}-u_{3} \bar{y}+u_{4}-u_{5} \\
& \leftrightarrow\left(y-u_{1}\right) x_{2}=\left(y-u_{1}\right) \bar{x}_{2} \quad \text { para } \quad a(t) \neq 0 \\
& \leftrightarrow x_{2}=\bar{x}_{2} \quad \text { para } \quad\left(y-u_{1}\right) \neq 0
\end{aligned}
$$

Como $a(t)=1 /\left(m C_{p}\right)_{r}>0$, então o sistema $\left(\Sigma_{2}\right)$ é observável se, e somente se, $y \neq u_{1}$, ou seja, $T_{r} \neq T_{j}$. Portanto, se $U$ é um conjunto de medidas de entrada na qual $T_{r} \neq T_{j}$, então o sistema $\left(\Sigma_{2}\right)$ será uniformemente observável em relação a esse conjunto.

Aplicando a mudança de coordenadas:

$\boldsymbol{\Phi}(\mathbf{x})=\mathbf{z}=\left[\begin{array}{c}z_{1} \\ z_{2}\end{array}\right]=\left[\begin{array}{c}x_{1} \\ -\frac{\left(x_{1}-T_{j}\right) x_{2}}{\left(m C_{p}\right)_{r}}\end{array}\right]$

e sendo:

$\mathbf{S}_{\theta 2}=\left[\begin{array}{cc}\frac{1}{\theta_{2}} & -\frac{1}{\theta_{2}^{2}} \\ -\frac{1}{\theta_{2}^{2}} & \frac{2}{\theta_{2}^{3}}\end{array}\right], \quad \theta_{2}>0$

a solução única da equação algébrica de Lyapunov:

$$
\theta_{2} \mathbf{S}_{\theta 2}+\mathbf{A}^{T} \mathbf{S}_{\theta 2}+\mathbf{S}_{\theta 2} \mathbf{A}=\mathbf{C}^{T} \mathbf{C}
$$

o ganho do observador será dado por:

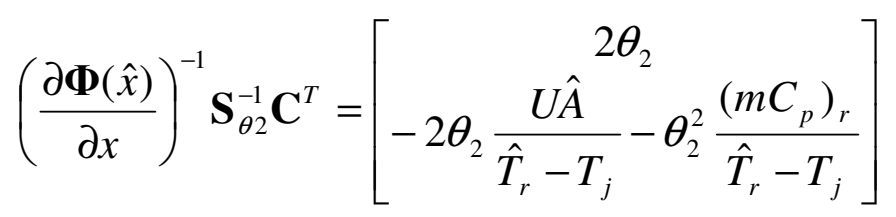


Portanto, o observador para o sistema $\left(\Sigma_{2}\right)$ será dado por:

$\left(O_{2}\right)\left\{\begin{array}{l}\frac{d \hat{T}_{r}}{d t}=\frac{v_{2}}{\left(m C_{p}\right)_{r}}+\frac{1}{\left(m C_{p}\right)_{r}}\left[-U \hat{A}\left(\hat{T}_{r}-T_{j}\right)+\sum_{i} F_{i} C_{p i}\left(T_{\text {feed }}-\hat{T}_{r}\right)-Q_{\text {loss }}\right]- \\ \frac{2 \theta_{2}\left(\hat{T}_{r}-T_{r}\right)}{\frac{d U \hat{A}}{d t}=} \frac{1}{\left(\hat{T}_{r}-T_{j}\right)}\left[2 \theta_{2} U \hat{A}+\theta_{2}^{2}\left(m C_{p}\right)_{r}\right]\left(\hat{T}_{r}-T_{r}\right)\end{array}\right.$

Dessa maneira, a estimativa do observador de $Q_{r}\left(O_{1}\right)$ em um instante $k$, $\hat{Q}_{r}\left(t_{k}\right)$, torna-se a entrada do observador de UA no instante seguinte para a estimativa de $U \hat{A}\left(t_{k+1}\right)$ e assim consecutivamente.

\subsubsection{Estimativas da conversão e da composição}

Utilizando as predições de $Q_{r}$ obtidas pelo sistema (5.83), as informações relacionadas com a conversão e a composição podem ser rapidamente estimadas. Vicente; Leiza e Asua (2001) desenvolveram um modelo, baseado na calorimetria, para estimar em linha a conversão e, simultaneamente, controlar a evolução da composição e da distribuição do pesos moleculares (MWD) de copolímeros lineares obtidos durante reações semicontínuas em emulsão. Esse método é baseado em um observador em malha aberta, responsável pelas estimativas das quantidades de monômeros e CTA não reagidos, e nas razões de reatividade e nos coeficientes de partição dos monômeros entre as diferentes fases, considerando que a polimerização na fase aquosa seja desprezível.

Dessa forma, o balanço material para os monômeros pode ser escrito em função do calor gerado pela reação, das razões de reatividade e das entalpias de homopolimerização dos monômeros segundo as equações: 


$$
\begin{aligned}
& \frac{d A}{d t}=F_{A}-\frac{\hat{Q}_{r}}{\left[\left(-\Delta H_{A}\right)+\left(-\Delta H_{B}\right) \frac{1-y_{A, \text { inst }}}{y_{A, \text { inst }}}\right]} \\
& \frac{d B}{d t}=F_{B}-\frac{\hat{Q}_{r}}{\left[\left(-\Delta H_{A}\right) \frac{y_{A, \text { inst }}}{1-y_{A, \text { inst }}}+\left(-\Delta H_{B}\right)\right]}
\end{aligned}
$$

sendo $F_{i}$ e $\left(-\Delta H_{i}\right)$, respectivamente, a vazão instantânea de alimentação e a entalpia de homopolimerização do monômero $i$, e $y_{A, \text { inst }}$ a composição instantânea do copolímero obtida pela equação de Mayo-Lewis:

$$
y_{A, \text { inst }}=\frac{\left(r_{A}+\frac{[B]_{p}}{[A]_{p}}\right)}{\left[r_{A}+2 \frac{[B]_{p}}{[A]_{p}}+r_{B}\left(\frac{[B]_{p}}{[A]_{p}}\right)^{2}\right]}
$$

onde $[i]_{p}$ é a concentração de monômero i na fase polimérica estimada pelo algoritmo proposto por Omi et al. (1985).

Resolvendo as Eqs. (5.96)-(5.98) é possível obter a quantidade de monômero não reagido que, por sua vez, pode ser usada para inferir a conversão global $\left(x_{g}\right)$, a conversão instantânea $\left(x_{\text {inst }}\right)$ e a composição mássica acumulada do monômero $A\left(y_{A}\right)$, segundo as equações:

$$
\begin{aligned}
& x_{g}=\frac{\left(A_{0}+\int_{0}^{t} F_{A} d t+B_{0}+\int_{0}^{t} F_{B} d t-A-B\right)}{\left(A_{T}+B_{T}\right)} \\
& x_{\text {inst }}=\frac{\left(A_{0}+\int_{0}^{t} F_{A} d t+B_{0}+\int_{0}^{t} F_{B} d t-A-B\right)}{\left(A_{0}+\int_{0}^{t} F_{A} d t+B_{0}+\int_{0}^{t} F_{B} d t\right)}
\end{aligned}
$$




$$
y_{A}=\frac{\left(A_{0}+\int_{0}^{t} F_{A} d t-A\right)}{\left(A_{0}+\int_{0}^{t} F_{A} d t-A+B_{0}+\int_{0}^{t} F_{B} d t-B\right)}
$$

sendo $A_{0}$ e $B_{0}$ as massas iniciais dos monômeros na carga inicial, $A$ (acetato de vinila) e $B$ (acrilato de butila) as quantidades não reagidas de monômeros presentes no reator obtidas pelas eqs. (5.96) e (5.97), $F_{A}$ e $F_{B}$ as vazões de alimentação dos monômeros $A$ e $B$, respectivamente, e $A_{T}$ e $B_{T}$ as quantidades totais de monômeros $A$ e $B$ da formulação.

O procedimento computacional é ilustrado na Figura 5.4.

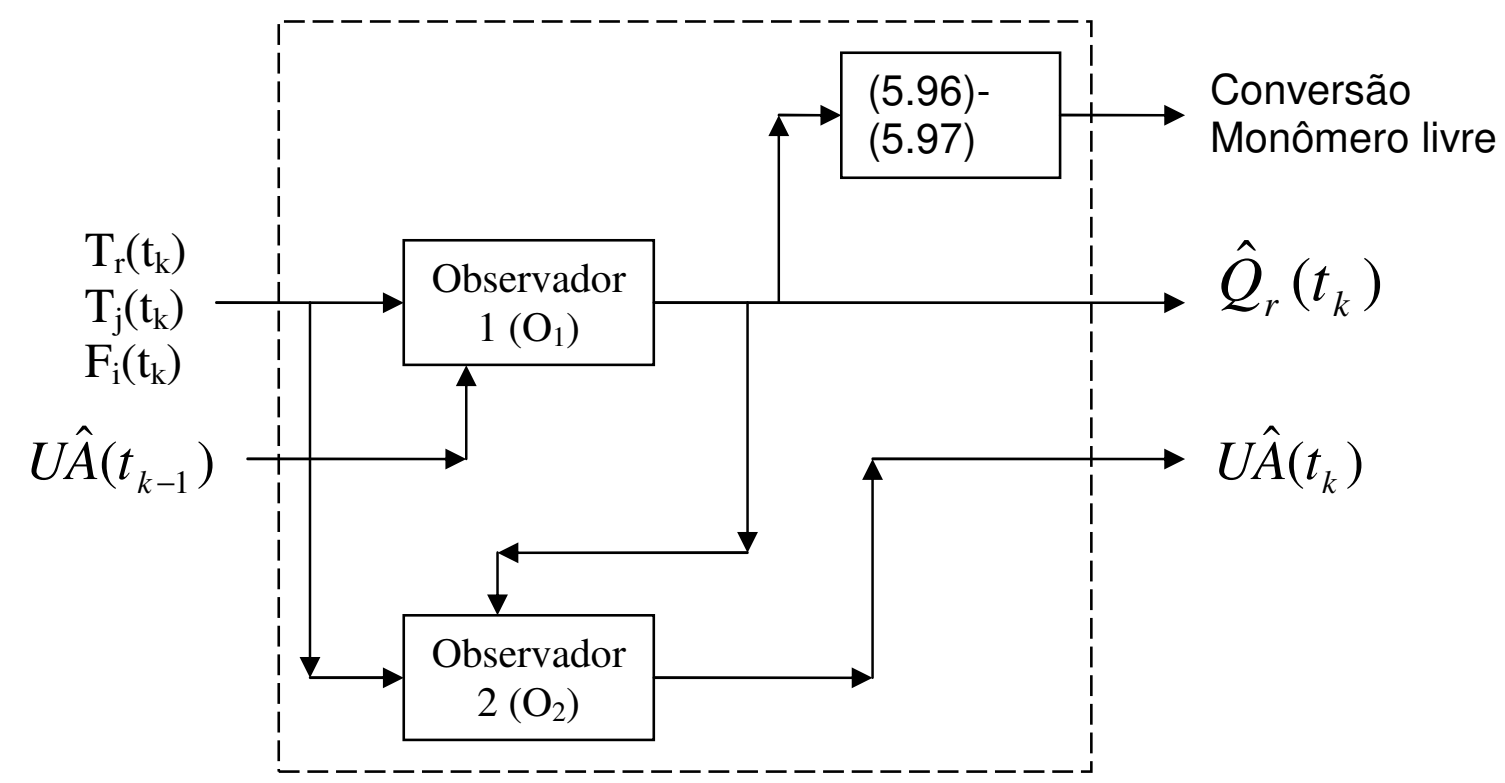

Figura 5.4 - Procedimento computacional dos observadores de estado em cascata e do balanço de massa no instante $t_{k}$ 


\section{RESULTADOS E DISCUSSÕES: HIDRÓLISE DO ANIDRIDO ACÉTICO}

Nesta seção as metodologias analíticas e os algoritmos de estimativa apresentados na subseção 5.1 são aplicados ao primeiro estudo de caso proposto (reação de hidrólise do anidrido acético).

Para descrever passo a passo a aplicação das metodologias para a coleta dos dados e para o cálculo das variáveis de estado do processo, esta seção será subdividida da seguinte forma:

i) Subseção 6.1 Dados experimentais: nesta subseção são apresentados uma breve descrição do procedimento experimental usado para a coleta dos dados, os volumes e as massas de cada reagente e reator, e a capacidade calorífica total da cada sistema empregado nas reações de hidrólise. Todos os demais dados (peso molecular, densidade, entalpia e a capacidade calorífica individual dos reagentes e reatores) obtidos da literatura estão apresentados no Apêndice A - Banco de Dados.

ii) Subseção 6.2 Coeficientes de troca térmica e conversões iniciais: nesta subseção os valores experimentais do coeficiente UA e da conversão inicial, obtidos a partir das eqs.(5.09) e (5.10), respectivamente, são apresentados e discutidos.

iii) Subseção 6.3 Parâmetros da equação de Arrhenius: nesta subseção os parâmetros da equação de Arrhenius obtidos para cada sistema e usando as três metodologias para o cálculo das derivadas de temperatura são apresentados e comparados. Adicionalmente, os valores experimentais de $\mathrm{k}_{0}$ e $\mathrm{E}$, estimados no presente trabalho, são comparados com alguns valores reportados na literatura para análise da precisão das metodologias analíticas utilizadas e justificativas de eventuais desvios observados.

iv) Subseção 6.4 Análise de sensibilidade e observador de estado: nesta subseção os perfis de sensibilidade das variáveis de estado $X_{A A}$ e $T_{r}$ em relação aos parâmetros UA, $k_{0}$ e E são apresentados e analisados. Esta análise tem por objetivo identificar quais os parâmetros mais críticos e 
quais os parâmetros com pouca influência sobre as estimativas dos estados do processo. Em seguida, baseado na análise de sensibilidade paramétrica, o observador de estado proposto para a reação de hidrólise do anidrido acético é apresentado em conjunto com uma análise da robustez deste observador frente à presença de incertezas no parâmetro crítico determinado pela análise de sensibilidade. Para finalizar, os valores de conversão e temperatura experimentais e preditos pelo balanço de massa, pelo balanço de energia e pelo observador de estado são comparados e analisados.

v) Subseção 6.5 Conclusões: subseção dedicada a apresentar um apanhado geral sobre os principais resultados apresentados na seção 6 .

\subsection{Dados experimentais}

As reações de hidrólise do anidrido acético foram conduzidas com excesso de água deionizada em três diferentes tipos de "reatores" não-adiabáticos: a) um copo de poliestireno (sistema 1); b) balão volumétrico (sistema 2); e c) garrafa térmica ou frasco de Dewar (sistema 3). Todos os reatores foram mantidos à temperatura ambiente, e o meio reacional agitado com um agitador magnético.

Os dois primeiros sistemas foram escolhidos para simular um reator nãoadiabático, enquanto o sistema 3 foi escolhido para simular um reator adiabático não-ideal. As temperaturas do meio reacional foram coletadas a cada intervalo de 30 segundos usando um termômetro digital.

Os volumes dos reagentes, e as massas dos recipientes e do agitador magnético (magnetita) são apresentados na Tabela 6.1. Como no sistema 3 o fluxo térmico ocorre apenas entre o meio reacional e a ampola, a massa da garrafa térmica foi calculada desconsiderando o invólucro externo e assumindo que a massa da ampola corresponde a $10 \%$ da massa total medida. 
Tabela 6.1 - Reagentes e reatores: volumes e massas

\begin{tabular}{ccc}
\hline & Volume $(\mathrm{mL})$ & Massa $(\mathrm{g})$ \\
\hline Água deionizada & 150 & \\
Anidrido Acético & 90 & 6,68 \\
Copo de poliestireno & - & 80,10 \\
Balão volumétrico & - & 23,59 \\
Garrafa térmica & - & 4,40 \\
Agitador magnético & & \\
\hline
\end{tabular}

Usando as medidas de temperatura e os dados apresentados nas Tabelas 6.1, A.1, A.2 e A.3, obtém-se a capacidade calorífica total para cada sistema e cujos valores são apresentados na Tabela 6.2.

Tabela 6.2 - Capacidade calorífica total

\begin{tabular}{lc}
\hline \multicolumn{1}{c}{ Sistema $\mathrm{n}^{\circ}$} & $\left(\mathrm{mC}_{\mathrm{p}}\right)_{\mathrm{r}}(\mathrm{J} / \mathrm{K})$ \\
\hline Sistema 1 (copo de poliestireno) & 804,59 \\
Sistema 2 (balão volumétrico) & 853,01 \\
Sistema 3 (garrafa térmica) & 812,51 \\
\hline
\end{tabular}

\subsection{Coeficientes de troca térmica e conversões iniciais}

Como na região de resfriamento o reagente limitante já foi completamente consumido, as variações de temperatura ocorrem devido a troca de calor do meio reacional com o ambiente. Portanto, o coeficiente UA pode ser estimado a partir da inclinação do gráfico de $\ln \left(T_{r}-T_{a m b}\right)$ versus tempo (Figura 6.1). A capacidade calorífica total do sistema, usado na eq.(5.09), foi calculada somando-se as capacidades caloríficas do reator, do agitador magnético e as médias das capacidades caloríficas da água e do ácido acético. A contribuição do anidrido acético sobre o valor final de $\left(\mathrm{mC}_{\mathrm{p}}\right)_{\mathrm{r}}$ não foi contabilizada, pois na região de resfriamento foi considerada a hipótese de consumo completo deste reagente.

Os valores estimados de UA são reportados na Tabela 6.3, e as regressões lineares apresentadas na Figura 6.1 apresentaram elevados coeficientes de regressão (entre 0,997 a 0,999). 

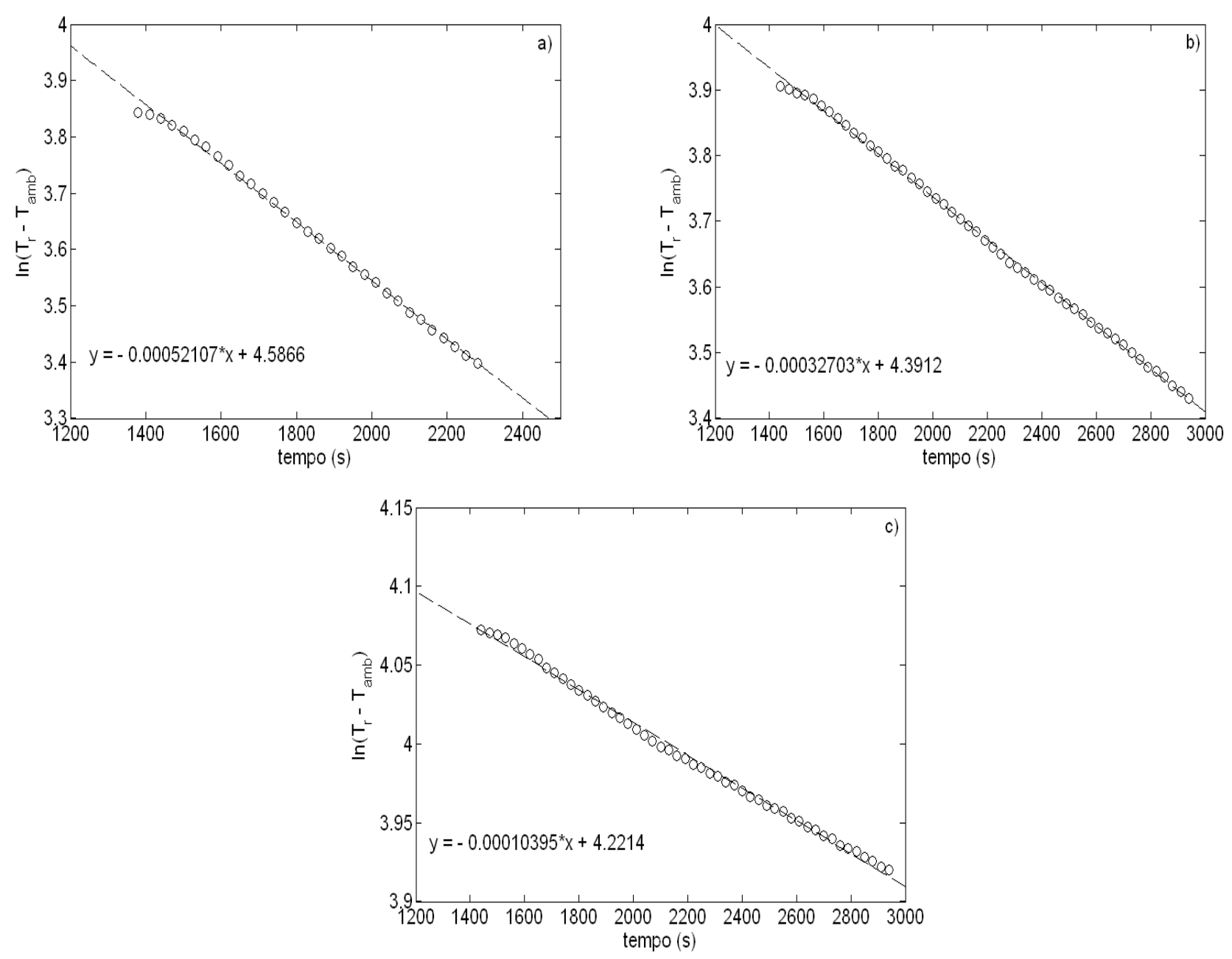

Figura 6.1 - Estimação gráfica do coeficiente UA do: a) sistema 1, b) sistema 2, c) sistema 3

Tabela 6.3 - Coeficientes globais de troca térmica experimentais

\begin{tabular}{cc}
\hline Sistema $\mathrm{n}^{\circ}$ & $\mathrm{UA}(\mathrm{W} / \mathrm{K})$ \\
\hline 1 & 0,424 \\
2 & 0,280 \\
3 & 0,0846 \\
\hline
\end{tabular}

Comparando os valores estimados de UA (Tabela 6.3) observa-se que a troca térmica do sistema 2 é ligeiramente menor do que aquela obtida para o sistema 1. Isto ocorre, pois a capacidade calorífica total do sistema 2 é maior do que a capacidade calorífica total do sistema 1 (Tabela 6.2) e, consequentemente, a retenção de calor será maior do que a retenção de calor do copo de poliestireno. Além disso, o gargalo do balão volumétrico restringe a área de contato, entre o meio reacional e o ambiente, sendo um componente adicional que dificultará a perda de calor do reator. 
É importante lembrar que, como a garrafa térmica permaneceu aberta ao longo da reação, o sistema 3 não é completamente adiabático e, portanto, apresentará um coeficiente de troca térmica ligeiramente maior que zero. Adicionalmente, a garrafa térmica pode apresentar uma pequena perda de calor por condução na junção entre a ampola e o invólucro externo.

Usando as estimativas de UA (Tabela 6.3), os valores experimentais de conversão podem ser rapidamente estimados através da relação recursiva dada pela eq.(5.10). Como todas as reações foram conduzidas com excesso de água, as conversões foram calculadas do instante final (conversão de 100\%) até o instante inicial.

Os valores iniciais de conversão podem fornecer informações qualitativas importantes com relação às estimativas de UA e com relação à pureza dos reagentes. Valores iniciais muito diferentes de zero, podem indicar um grau de pureza diferente daquele fornecido pelo fabricante ou problemas na estimativa do coeficiente UA, uma vez que a conversão e o coeficiente de troca térmica são diretamente proporcionais. As conversões iniciais dos três sistemas analisados são listados na Tabela 6.4 .

Tabela 6.4-Conversões iniciais

\begin{tabular}{cc}
\hline${\text { Sistema } \mathrm{n}^{\circ}}^{\circ}$ & $\mathrm{X}_{\mathrm{AA}}$ inicial \\
\hline 1 & $6,33 \%$ \\
3 & $4,94 \%$ \\
3 & $5,72 \%$ \\
\hline
\end{tabular}

Como pode ser observado na Tabela 6.4, os valores iniciais de conversão estão muito acima de zero indicando, possivelmente, uma subestimação do coeficiente UA, ou mesmo variações nos valores de $\left(\mathrm{mC}_{\mathrm{p}}\right)_{\mathrm{r}}$ e/ou UA, durante a reação de hidrólise, devido às alterações nas propriedades físicas do sistema causadas pelas variações de temperatura. Entretanto, vale lembrar que $\mathrm{o}$ anidrido acético é extremamente higroscópico e, portanto, dependendo do tempo de estocagem e da quantidade de vezes que o reagente teve contato com a umidade ambiente, a pureza "real" do anidrido pode ser diferente daquela fornecida pelo fabricante. Esta hipótese é razoável pois as conversões iniciais, para os três sistemas, são bastante próximas uma das outras. Apesar disto, os valores iniciais de conversão são aceitáveis. 


\subsection{Parâmetros da equação de Arrhenius}

Com relação aos parâmetros da equação de Arrhenius, conforme citado na subseção 5.1, a qualidade das estimativas de $k_{0}$ e $E$ dependente fortemente da qualidade da estimativa da taxa de reação. Portanto, antes de obter estes parâmetros, é apresentada uma comparação das estimativas de (-r $\left.\mathrm{r}_{\mathrm{A}}\right)$ utilizando os três métodos para o cálculo das derivadas de temperatura apresentados na subseção 5.1.2.

As Figuras 6.2 - 6.4 apresentam uma comparação entre os valores experimentais de $T_{r}$ e aqueles obtidos por interpolação polinomial e pelo Filtro Savitzky-Golay (Figuras 6.2a, 6.3a e 6.4a), e uma comparação entre os resíduos da diferença entre os valores experimentais e preditos pela interpolação e pelo filtro (Figuras 6.2b, 6.3b e 6.4b). Nas mesmas figuras são apresentadas ainda uma comparação entre as derivadas de temperatura (Figuras 6.2c, 6.3c e 6.4c) e as taxas de reação (Figuras $6.2 \mathrm{~d}, 6.3 \mathrm{~d}$ e $6.4 \mathrm{~d}$ ) calculadas pelos três métodos analisados.

As interpolações polinomiais (IP) do método 1 foram obtidas dividindo os dados de temperatura em três diferentes regiões. A primeira região é composta pelos dados de temperatura durante o consumo do reagente limitante, na qual é observado um aumento de $T_{r}$ devido ao calor dissipado pela reação. O segundo grupo é composto pelos dados de temperatura próximo ao instante de máxima conversão e início do decréscimo de $T_{r}$. O último grupo é composto pelos dados de temperatura da região de resfriamento. Esta divisão por regiões foi adotada, pois mesmo que exista um único polinômio que interpole exatamente os dados de temperatura, este polinômio não necessariamente será obtido apenas aumentando o grau do polinômio interpolador. Talvez nestes casos, outras técnicas de interpolação devem ser utilizadas para se obter o polinômio desejado. Além disso, polinômios com grau elevado podem apresentar um comportamento oscilatório, ou seja, se um polinômio for interpolado usando $n$ pontos, a função obtida pode divergir nos pontos intermediários ou quando a variável independente tende a valores muito altos. 

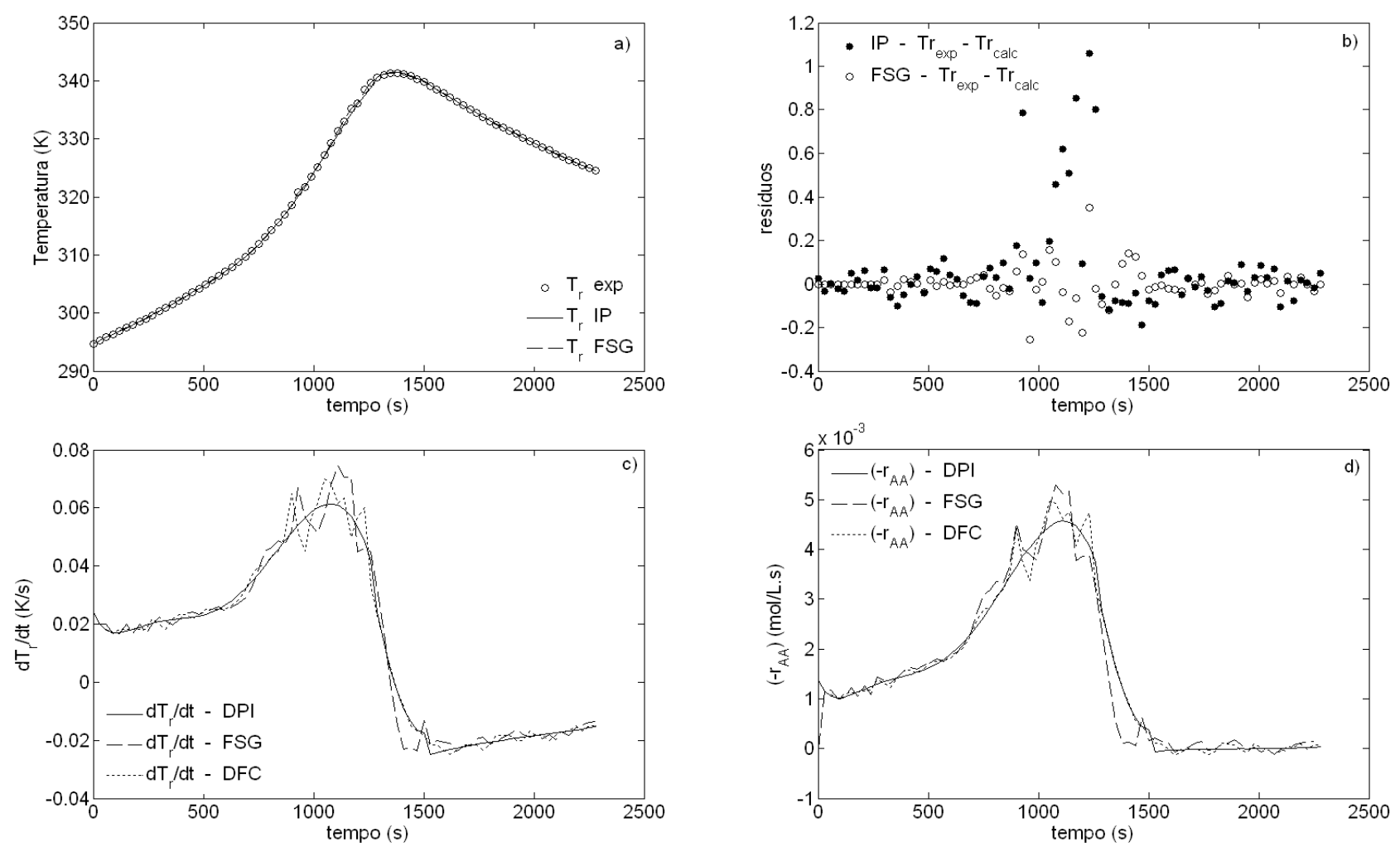

Figura 6.2 - Copo de poliestireno: comparação entre a) $T_{r}$ experimental e temperaturas ajustadas por IP e FSG, b) resíduos, c) derivadas de temperatura, e d) taxas de reação
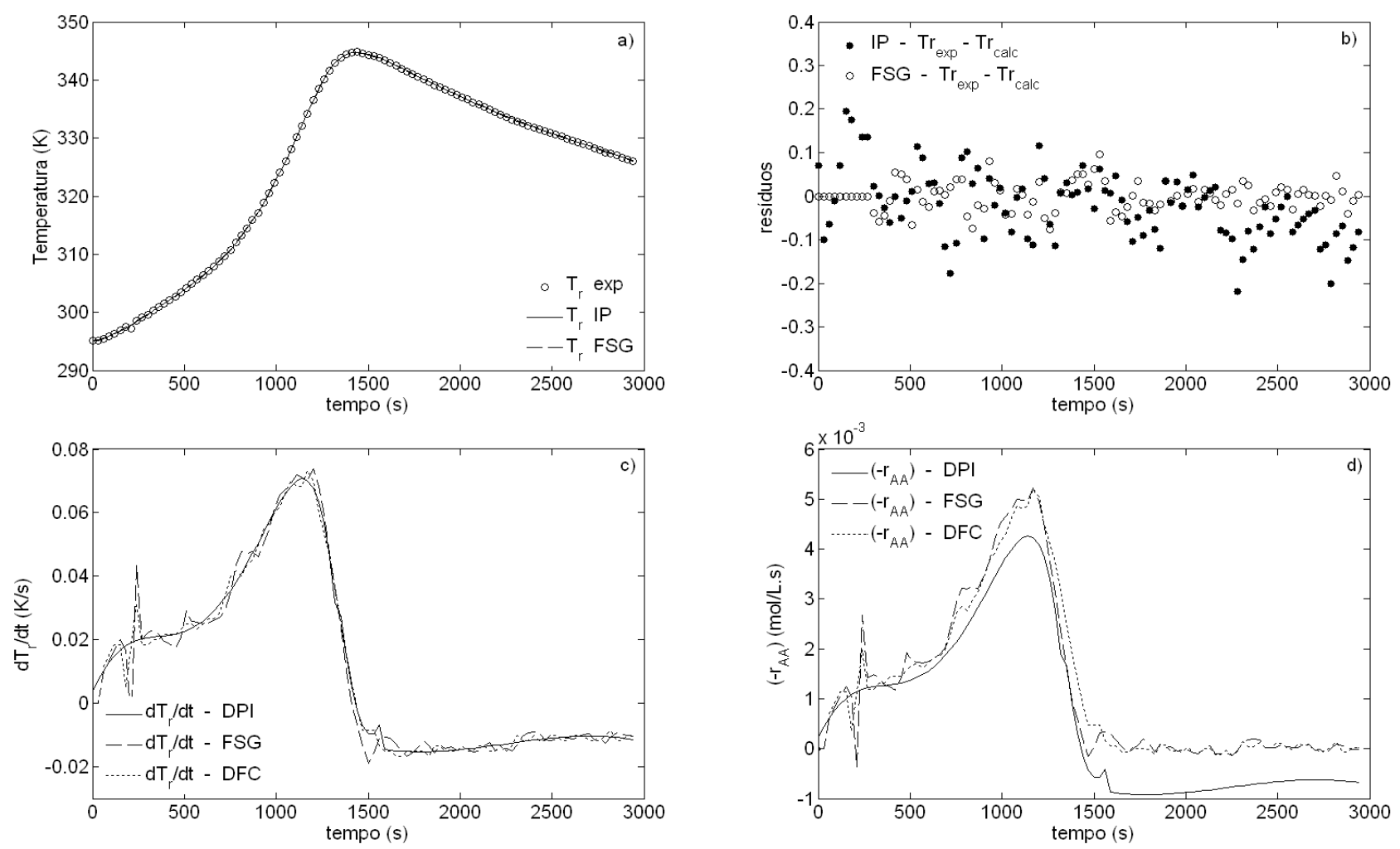

Figura 6.3 - Balão volumétrico: comparação entre a) $T_{r}$ experimental e temperaturas ajustadas por IP e FSG, b) resíduos, c) derivadas de temperatura, e d) taxas de reação 

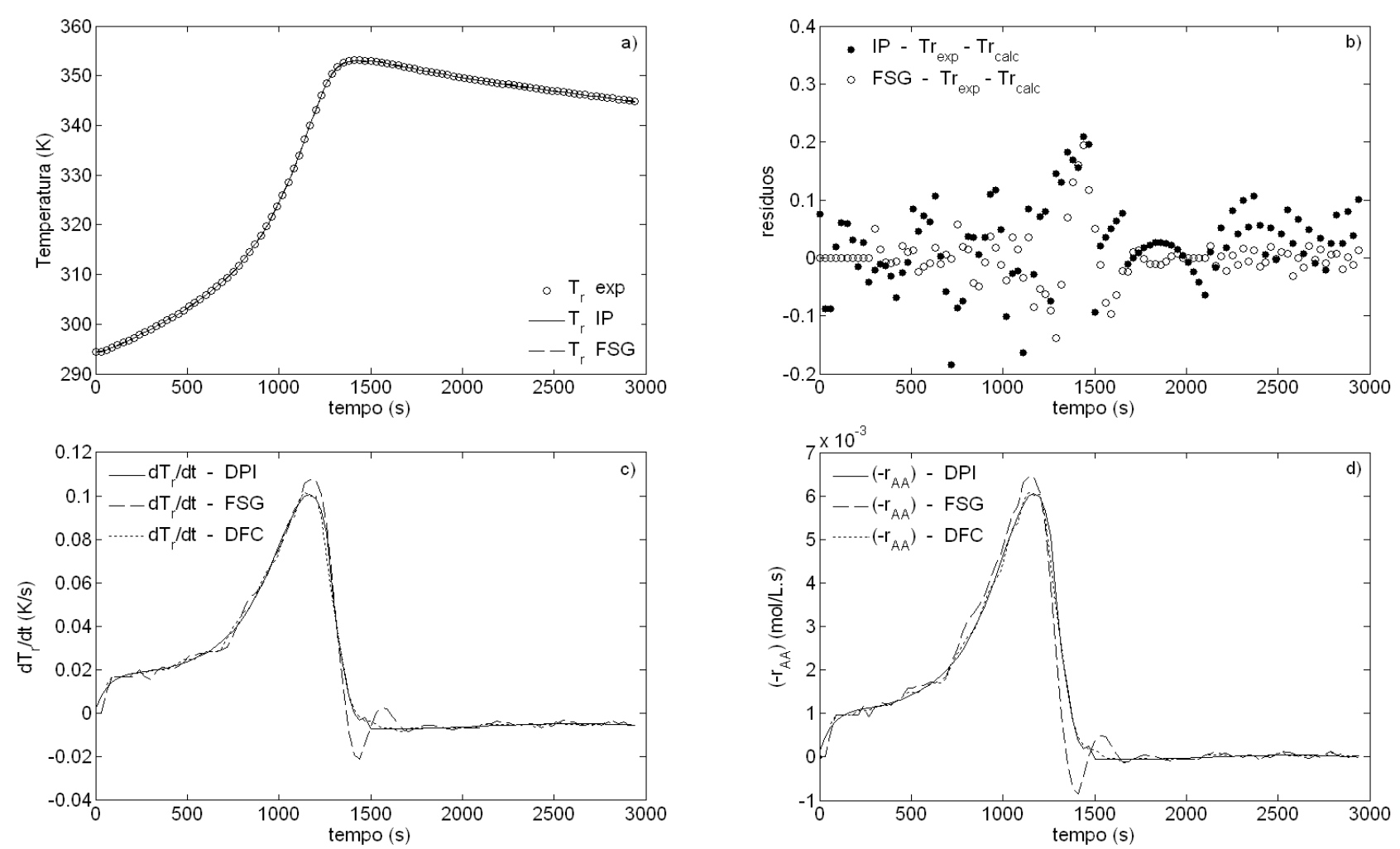

Figura 6.4 - Garrafa térmica: comparação entre a) $T_{r}$ experimental e temperaturas ajustadas por IP e FSG, b) resíduos, c) derivadas de temperatura, e d) taxas de reação

Os dados de temperatura foram interpolados utilizando-se polinômios de grau 8, 3 e 4 para as regiões 1, 2 e 3, respectivamente, e os coeficientes de ajuste variaram de 0,993 a valores acima de 0,999. Com relação ao filtro Savitzky-Golay foram utilizados 10 pontos à esquerda, 0 pontos à direita e polinômios de grau 3 em todos os casos analisados. Os coeficientes de correlação obtidos neste método foram superiores a 0,999.

Embora os perfis de temperatura obtidos pela interpolação polinomial (IP) sejam bastante semelhantes àqueles obtidos pelos filtro Savitzky-Golay (FSG) (Figuras 6.2a, 6.3a e 6.4a), as Figuras 6.2b, 6.3b e 6.4b mostram que o erro de aproximação obtido pelo filtro é ligeiramente menor do que o erro de aproximação da interpolação polinomial. No método 2 foram obtidos melhores precisões, pois neste método é utilizado uma quantidade menor de pontos e, portanto, o polinômio obtido tende a aproximar melhor os dados de temperatura (melhores coeficientes de ajuste). Nas Figuras 6.2b, 6.3b e 6.4b observa-se ainda que, para ambos os métodos, os desvios aumentam conforme a temperatura se aproxima do máximo valor. Isto ocorre devido à mudança na taxa de curvatura do perfil de $T_{r}$. 
Consequentemente, as derivadas de temperatura (Figuras 6.2c, 6.3c e 6.4c) e as taxas de reação (Figuras 6.2d, 6.3d e 6.4d) apresentam um comportamento mais oscilatório na região compreendida entre 1000 segundos e 1500 segundos, principalmente, para o copo de poliestireno onde o decréscimo de temperatura é mais brusco devido ao maior coeficiente de troca térmica. Entretanto, como estes desvios se intensificam próximo da região de máxima conversão, espera-se que estas oscilações não afetem as estimativas de $\mathrm{k}_{0}$ e $E$, já que para conversões abaixo de $100 \%$ os valores de $\left(-r_{A A}\right)$ calculados pelos três métodos são bastante semelhantes.

Apesar da base teórica da interpolação polinomial e do filtro Savitzky-Golay ser a mesma (mínimos quadrados parciais), a principal vantagem deste último método é que ele não requer o conhecimento prévio do perfil de $T_{r}$ como no caso da interpolação polinomial. Assim, a aplicação do método 2 é ideal quando a predição dos estados do processo devem ser feitos em tempo real.

Baseado nas medidas de temperatura, conversão e taxas de reação, os parâmetros da equação de Arrhenius podem ser rapidamente inferidos a partir da eq.(5.13). As Figuras 6.5, 6.6 e 6.7 mostram um gráfico típico dado pela eq.(5.13), no qual o coeficiente angular corresponde ao parâmetro (-E/R) e o coeficiente linear ao fator de freqüência $\left(k_{0}\right)$. Os coeficientes de ajuste e os parâmetros cinéticos, obtidos pelos três métodos de cálculo de $\mathrm{dT}_{\mathrm{r}} / \mathrm{dt}$, são listados na Tabela 6.5. Os valores de $E$ e $k_{0}$ reportados na literatura são apresentados na Tabela 6.6 e foram extraídos de Asprey et al. (1996) e Shatynski e Hanesian (1993).

É importante notar que na Tabela 6.6 alguns fatores pré-exponenciais foram obtidos assumindo a hipótese que, na presença de excesso de água, a taxa de reação depende apenas da concentração de anidrido acético (reação de pseudoprimeira ordem, $\mathrm{s}^{-1}$ ) e, portanto, para fins de comparação, estes parâmetros devem ser convertidos para constantes de segunda ordem ( $\mathrm{L} / \mathrm{mol} . \mathrm{s})$ dividindo-se o valor de ko pela concentração de água, quando disponível. 

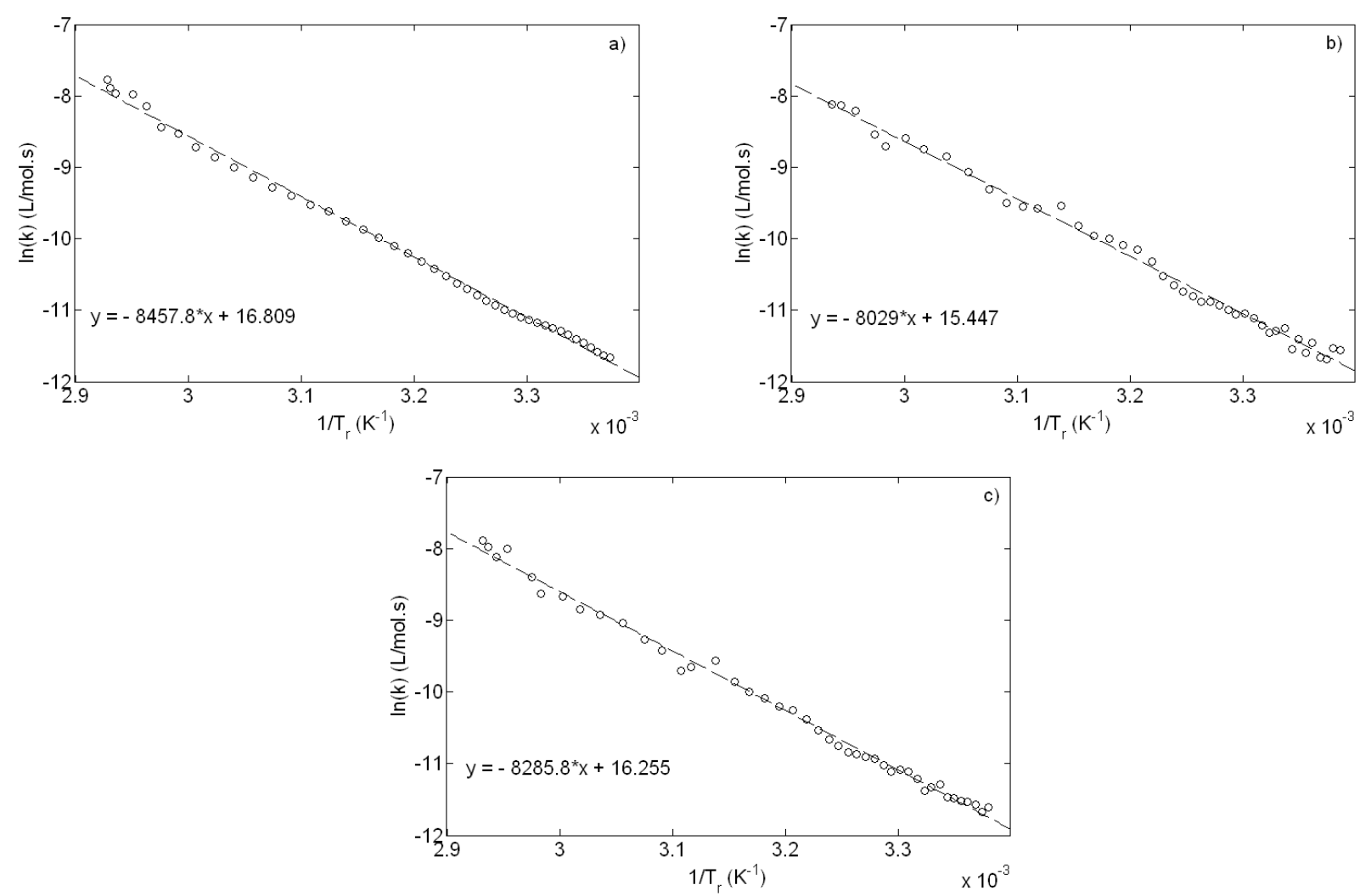

Figura 6.5 - Gráfico de Arrhenius para o sistema 1 usando o a) método 1 (DPI), b) método 2 (FSG), c) método 3 (DFC)
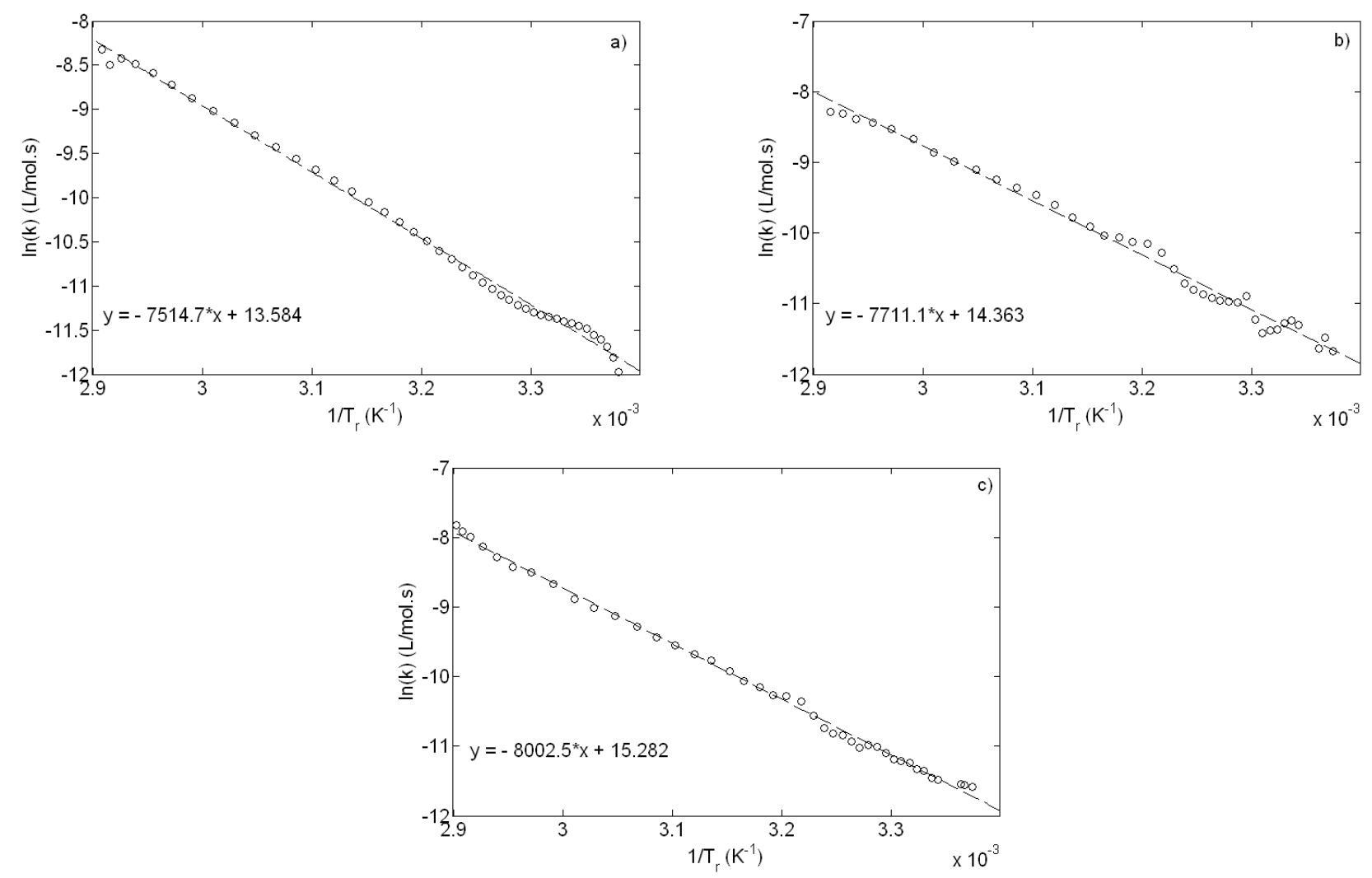

Figura 6.6 - Gráfico de Arrhenius para o sistema 2 usando o a) método 1 (DPI), b) método 2 (FSG), c) método 3 (DFC) 

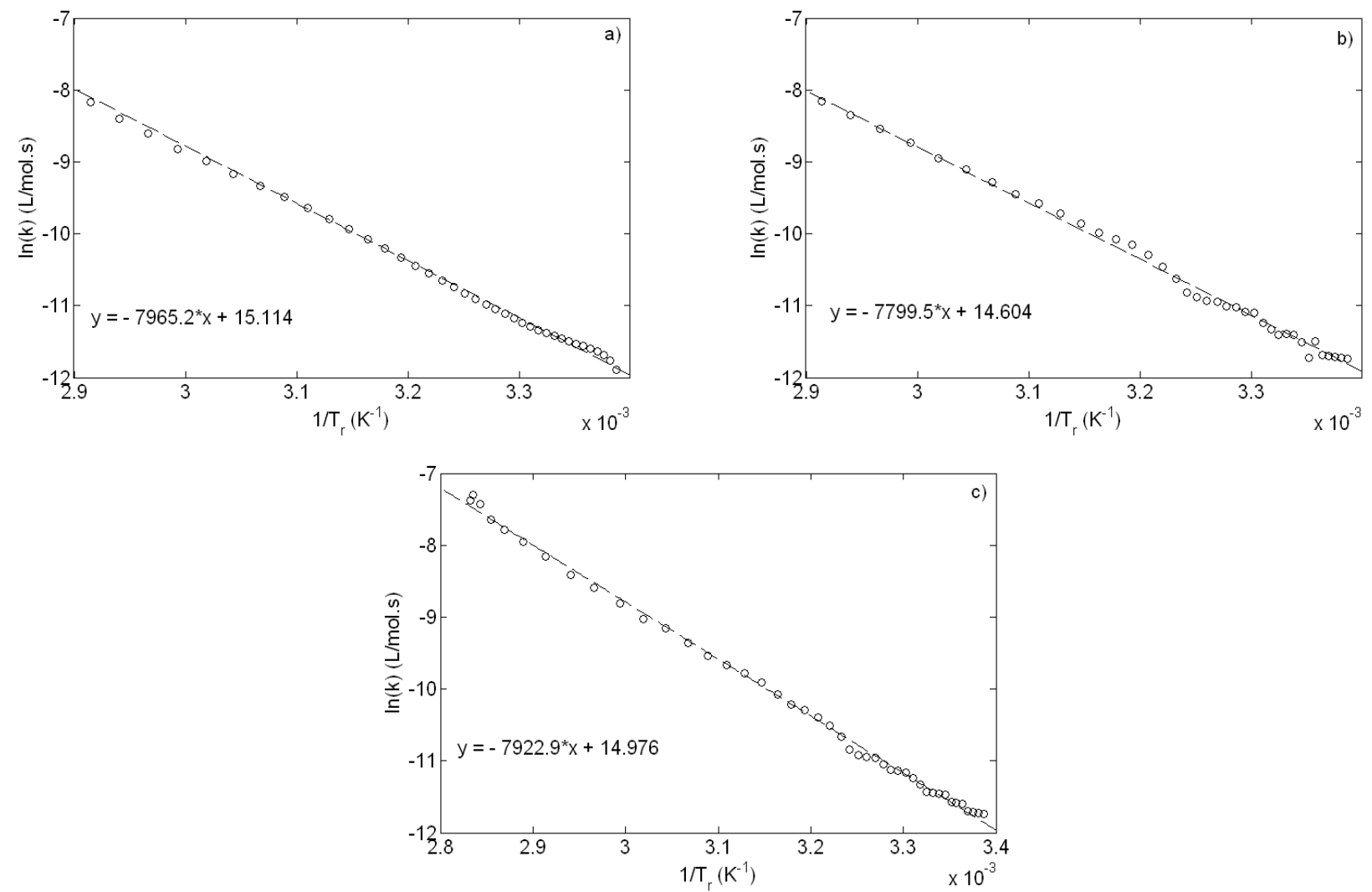

Figura 6.7 - Gráfico de Arrhenius para o sistema 3 usando o a) método 1 (DPI), b) método 2 (FSG), c) método 3 (DFC)

Tabela 6.5 - Parâmetros cinéticos experimentais

\begin{tabular}{ccccc}
\hline Sistema $\mathrm{n}^{\circ}$ & Método & $\mathrm{R}^{2}$ & $\ln \left(\mathrm{k}_{0}\right)(\mathrm{L} / \mathrm{mol} . \mathrm{s})$ & $\mathrm{E}(\mathrm{kJ} / \mathrm{mol})$ \\
\hline \multirow{3}{*}{1} & DPI & 0,997 & 16,81 & 70,3 \\
& FSG & 0,992 & 15,45 & 66,8 \\
& DFC & 0,994 & 16,25 & 68,9 \\
\hline \multirow{2}{*}{2} & DPI & 0,996 & 13,58 & 62,5 \\
& FSG & 0,990 & 14,36 & 64,1 \\
& DFC & 0,997 & 15,28 & 66,5 \\
\hline \multirow{2}{*}{3} & DPI & 0,998 & 15,11 & 66,2 \\
& FSG & 0,996 & 14,60 & 64,8 \\
& DFC & 0,998 & 14,98 & 65,9 \\
\hline
\end{tabular}

Comparando os valores apresentados na Tabela 6.5, observa-se que as estimativas de $\mathrm{k}_{0}$ e $\mathrm{E}$ são bastante similares independentemente do reator e do método usado para o cálculo das derivadas de temperatura. A similaridade entre as estimativas de $k_{0}$ e $E$ já era esperada, uma vez que que as derivadas de temperatura (Figuras 6.2c, 6.3c e 6.4c) e as taxas de reação (Figuras 6.2d, 6.3d e 6.4d) são praticamente idênticas durante 0 consumo do reagente limitante, independentemente do método usado para o cálculo das derivadas. Uma diferença um pouco mais acentuada é observada quando o método 1 (DPI) é aplicado sobre 
os dados do sistema 2. Isto pode ser atribuído à presença de variações nas medidas de $T_{r}$, causando um aumento no comportamento oscilatório de $d T_{r} / d t$ (Figura 6.3c), e que são captadas pelos métodos 2 e 3 mas não pelo método 1. Desta forma, a velocidade de reação predita pelo método 1 será menor do que aquelas preditas pelo filtro e pela diferenciação numérica.

Tabela 6.6 - Parâmetros da equação de Arrhenius reportados na literatura

\begin{tabular}{lccc}
\hline & $\mathrm{E}(\mathrm{kJ} / \mathrm{mol})$ & $\ln \left(\mathrm{k}_{0}\right)$ & Unidades de $\mathrm{k}_{0}$ \\
\hline Rivett e Sidgwick (1910) & 43,2 & & \\
Marek (1954) & 57,8 & & \\
Marmers (1965) & 68,7 & & \\
Dyne et al. (1967) & 49,4 & & \\
King e Glasser (1985) & 39,8 & 9,93 & $\mathrm{~s}^{-1}$ \\
Bisio e Kabel (1985) & 46,5 & 12,80 & $\mathrm{~s}^{-1}$ \\
Shatynski e Hanesian (1993) & 46,9 & 12,74 & $\mathrm{~s}^{-1}$ \\
Haji e Erkey (2005) & 53,6 & 15,48 & $\mathrm{~s}^{-1}$ \\
Glasser e Williams (1971) & 45,3 & 7,95 & $\mathrm{~L} /(\mathrm{mol} . \mathrm{s})$ \\
Eldrich e Piret (1950) & 43,2 & 7,53 & $\mathrm{~L} /(\mathrm{mol} . \mathrm{s})$ \\
Cleland e Wilhelms (1956) & 44,4 & 7,80 & $\mathrm{~L} /(\mathrm{mol} . \mathrm{s})$ \\
Asprey et al. (1996) & 45,7 & 7,66 & $\mathrm{~L} /(\mathrm{mol} . \mathrm{s})$ \\
\hline
\end{tabular}

Entretanto, comparando os valores das Tabelas 6.5 e 6.6, observa-se que os valores estimados de $\mathrm{k}_{0}$ e $\mathrm{E}$ são sempre maiores do que aqueles reportados na literatura. Fisicamente, isso significa que a taxa de consumo do reagente limitante obtido neste trabalho ocorre mais lentamente, pois a formação do estado de transição requer a transposição de uma barreira energética maior. Esta situação pode ser vista graficamente na Figura 6.8, na qual é apresentada uma comparação entre as taxas específicas de reação calculadas usando os valores de $k_{0}$ e $E$ das Tabelas 6.5 e 6.6 e as medidas de temperatura coletadas durante os ensaios. Comparando os perfis de $\mathrm{k}$ apresentados na Figura 6.8 observa-se que:

i) Apesar de apresentarem uma pequeno deslocamento, os perfis de $k$ seguem uma mesma tendência quando estes são calculados a partir das estimativas de $k_{0}$ e $E$ obtidas em reações de hidrólise do anidrido acético nas quais são usadas a proporção estequiométrica (Tabela 6.6).

ii) Usando as estimativas de $\mathrm{k}_{0}$ e $\mathrm{E}$ obtidas em reações de hidrólise do anidrido acético nas quais são usadas uma proporção estequiométrica de aproximadamente 8 mols de água e $1 \mathrm{~mol}$ de anidrido acético (Tabela 
6.5), obtém-se uma taxa de reação menor, principalmente, para baixas temperaturas.


Figura 6.8 - Comparação entre os gráficos de Arrhenius para o a) sistema 1, b) sistema 2, e c) sistema 3, usando os valores de $\mathrm{k}_{0}$ e $\mathrm{E}$ obtidos por DPI, FSG e DFC e aqueles reportados na literatura

Uma possível explicação para esta diferença pode ser encontrada em Morrison e Boyd (1973). De acordo com os autores, reações de substituição nucleofílica acílica processam-se em duas etapas (adição e substituição), conforme apresentado na Figura 6.9. Na primeira etapa (adição), o nucleófilo (Z) adiciona-se à carbonila formando um intermediário tetraédrico, isto é, o carbono $\mathrm{sp}^{2}$ da carbonila transforma-se em um carbono $\mathrm{sp}^{3}$. A etapa 2 (substituição ou eliminação) envolve a transformação do intermediário tetraédrico pela eliminação do grupo de saída (W), ou seja, o processo resulta na substituição de $\mathrm{W}$ por Z. A velocidade total da reação depende, geralmente, da velocidade de ambas as etapas, mas a primeira é a etapa mais importante. Esta primeira etapa, formação de um intermediário tetraédrico, é afetada pelos mesmos fatores que afetam a adição de aldeídos e cetonas, ou seja, a 
etapa de adição é favorecida pela retirada de elétrons, o que estabiliza o desenvolvimento da carga negativa; e é dificultada pela presença de grupos funcionais volumosos que devem ficar muito aglomerados no estado de transição. $O$ segundo passo depende apenas da basicidade do grupo de saída (:W).



Figura 6.9 - Substituição nucleofílica acílica

Em meios ácidos, um próton $\mathrm{H}^{+}$liga-se ao oxigênio do grupo carbonil o que faz com que este grupo torne-se ainda mais suscetível ao ataque do nucleófilo. $O$ oxigênio pode agora atrair os elétrons da ligação $\pi$ formando um estado de transição positivamente carregado (Figura 6.10).

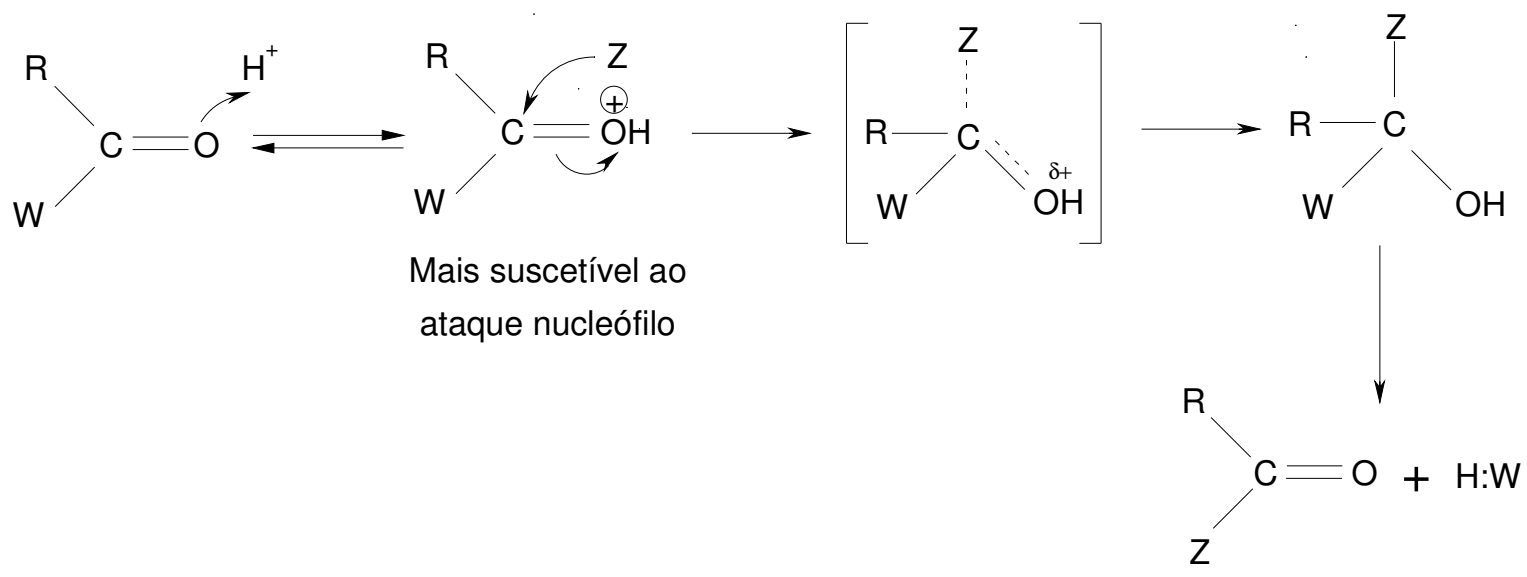

Figura 6.10 - Substituição nucleofílica acílica catalisada por ácido

Desta forma, compreende-se que os derivados dos ácidos carboxílicos como, por exemplo, o anidrido acético, são mais facilmente hidrolisados em soluções ácidas ou alcalinas do que em soluções neutras: a solução alcalina fornece íons hidroxilas $\left(\mathrm{OH}^{-}\right)$(Figura 6.11), que atua como reagente fortemente nucleófilo; soluções ácidas fornecem prótons $\mathrm{H}^{+}$(Figura 6.12) que, ao ligarem-se ao oxigênio 
do grupo carbonil, tornam a molécula vulnerável ao ataque do nucleófilo fraco (água).

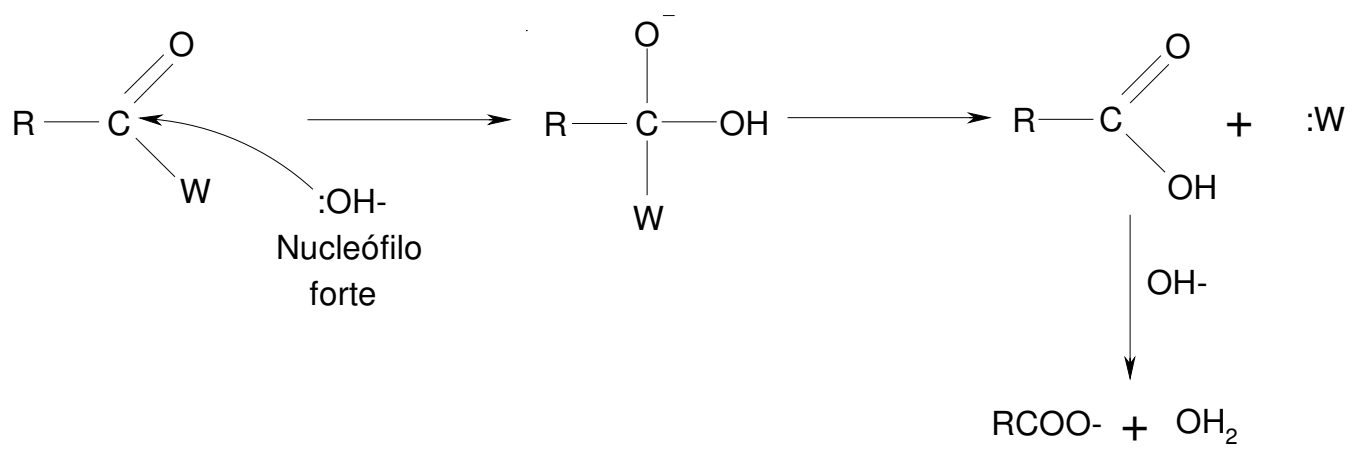

Figura 6.11 - Hidrólise alcalina



Figura 6.12 - Hidrólise ácida

Ou seja, as reações de hidrólise de derivados de ácidos carboxílicos, aparentemente, são "auto-catalizadas" pela acidez do meio reacional, e o uso de excesso de água torna o pH da solução mais neutra "dificultando" a formação do estado de transição. Por outro lado, como os parâmetros $k_{0}$ e E da Tabela 6.5 foram aqueles obtidos experimentalmente, estes são o que melhor representam as condições das reações e, portanto, serão os valores utilizados em todas as simulações.

A Figura 6.13 apresenta uma comparação entre os perfis experimentais de $\mathrm{T}_{\mathrm{r}}$ (Figuras 6.13a, 6.13c e 6.13e) e $\mathrm{X}_{\mathrm{AA}}$ (Figuras 6.13b, 6.13d e 6.13f) e os perfis preditos pelos balanços de massa e energia utilizando os valores de UA, da Tabela 6.3, e os parâmetros cinéticos da Tabela 6.5. 

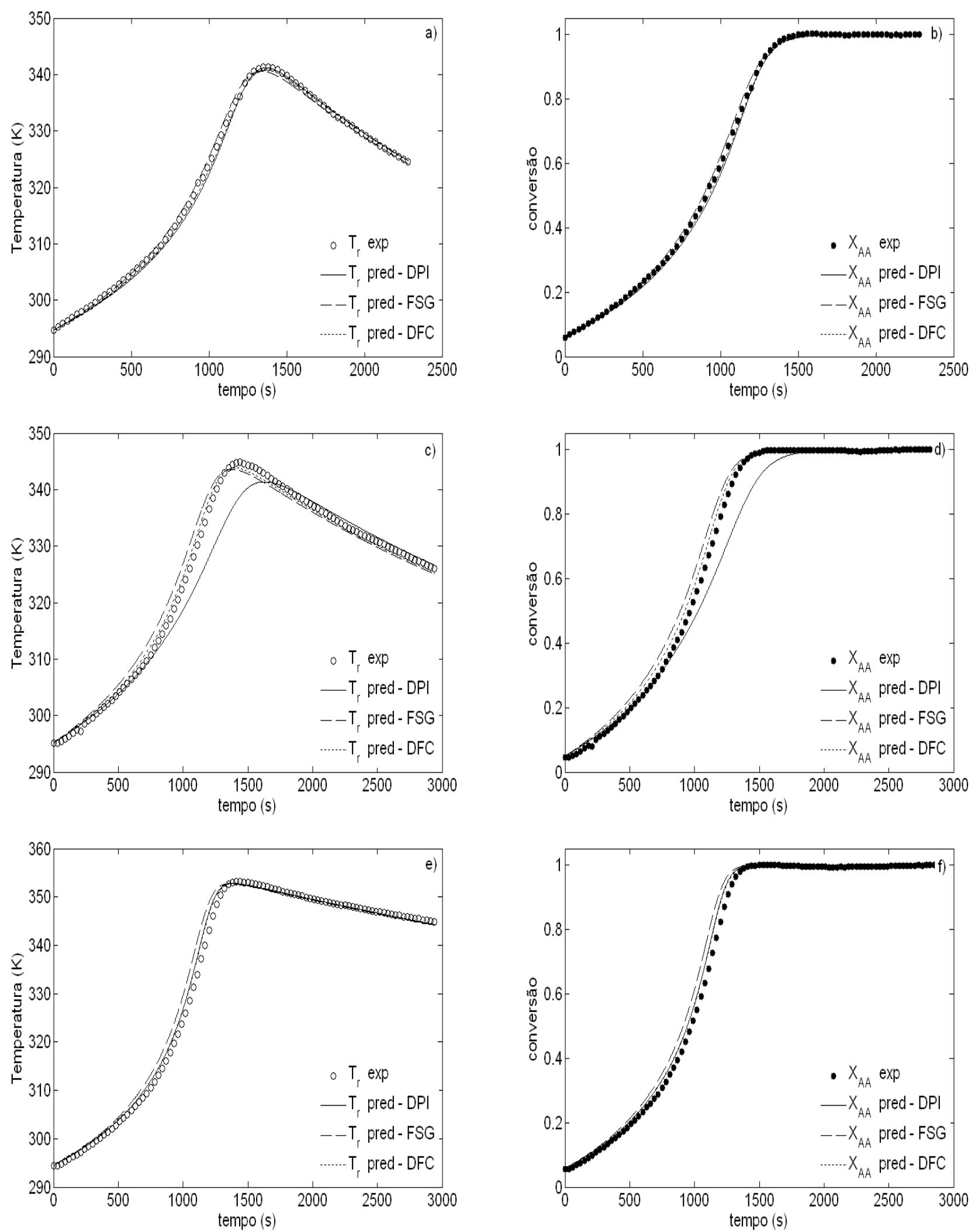

Figura 6.13 - Valores experimentais e preditos de: a) temperatura e b) conversão para o sistema $1, \mathrm{c}$ ) temperatura e d) conversão para o sistema 2, e) temperatura e f) conversão para o sistema 3 
Na Figura 6.13 observa-se que, em geral, as estimativas de UA, $k_{0}$ e $E$ possibilitaram boa concordância entre os valores experimentais e preditos de conversão e temperatura, independentemente do método usado para o cálculo das derivadas $d T_{r} / d t$, exceto quando o método 1 (DPI) é aplicado sobre o sistema 2. Do ponto de vista prático, isto significa que um simples método de diferenciação numérica é capaz de fornecer estimativas realistas de $k_{0}$ e $E$ não sendo necessário, portanto, o uso de ferramentas computacionais sofisticadas.

Em relação ao sistema 2 (Figuras $6.13 \mathrm{c}$ e $6.13 \mathrm{~d}$ ), como para os demais métodos ( $F S G$ e $D P I)$ as predições de $T_{r}$ e $X_{A A}$ apresentaram boa concordância com os respectivos valores experimentais, os desvios observados no método de interpolação polinomial não podem ser atribuídos a erros na estimativa do coeficiente UA, mas possivelmente aos desvios nas estimativas de $k_{0}$ e $E$ observados na Tabela 6.5. Nesta tabela, comparando os valores dos parâmetros da equação de Arrhenius obtidos pelos três métodos, observa-se que:

i) $\quad \mathrm{k}_{0}$ é subestimado pelo método $1 \mathrm{em}$, aproximadamente, $7 \%$ em relação ao método 2 , e em $11 \%$ em relação ao método 3;

ii) E é subestimado pelo método $1 \mathrm{em}$, aproximadamente, $3 \%$ em relação ao método 2 , e em $6 \%$ em relação ao método 3.

Portanto, do ponto de vista do projeto de um observador de estado, isto significa que, idealmente, todos os três parâmetros ( $k_{0}, E$ e UA) devem ser atualizados ao longo da reação, já que erros em $\mathrm{k}_{0}$ e $\mathrm{E}$ podem acabar ocasionando desvios acentuados nas estimativas de conversão e temperatura. Entretanto, caso as variáveis de estado sejam pouco sensíveis a determinados parâmetros, esta baixa sensibilidade pode acabar dificultando a sintonia do observador e, consequentemente, as estimativas dos estados e dos parâmetros críticos do processo. Desta forma, antes de iniciar o projeto do observador, é necessário avaliar a influência de cada parâmetro do modelo sobre as estimativas de conversão e temperatura. Esta influência é determinada através da análise de sensibilidade paramétrica e é apresentada na subseção seguinte. 


\subsection{Análise de sensibilidade e observador de estado}

As equações diferenciais do modelo de hidrólise e as equações dos coeficientes de sensibilidade foram resolvidas utilizando o solver DASPK 3.0 (Ll; PETZOLD, 1999). O programa DASPK 3.0 é um código desenvolvido em Fortran usado para quantificar a magnitude da dependência das predições de um sistema de equações algébrico-diferenciais a determinados parâmetros e condições iniciais.

O código oferece várias opções de métodos para a resolução do sistema de EDAs e das equações de sensibilidade dependendo da complexidade do caso analisado. Neste trabalho, as sensibilidades foram obtidas usando o método padrão e um fator de perturbação de $1,0 \times 10^{-2}$. Os perfis de sensibilidade obtidos são apresentados nas Figuras 6.14-6.16.

Com relação aos parâmetros cinéticos (Figuras $6.14 c-6.14 f, 6.15 c-6.15 f$, $6.16 c-6.16 f)$, as curvas de sensibilidade podem ser claramente divididas em três regiões distintas refletindo o que pode ser facilmente compreendido analisando-se a Figura 6.13.

Durante os primeiros 500 segundos (região I), como a temperatura do meio reacional é muito próxima da temperatura ambiente (Figuras 6.13a, 6.13c e 6.13e), a frequência de colisões é muito baixa e, portanto, apenas uma pequena fração das moléculas presentes no meio reacional apresentarão uma energia de impacto suficiente para transpor a energia de ativação e formar 0 estado de transição. Consequentemente, as sensibilidades de $\mathrm{X}_{\mathrm{AA}}$ e $\mathrm{T}_{\mathrm{r}}$ em relação a estes parâmetros são próximas de zero, além de apresentarem um lento aumento durante este intervalo.

Entretanto, por ser uma reação extremamente exotérmica, parte do calor gerado pela hidrólise durante o primeiro intervalo é acumulada no sistema causando um brusco aumento da conversão (Figuras 6.13b, 6.13d e 6.13f) e da temperatura do meio reacional (Figuras 6.13a, 6.13c e 6.13e) entre 500 e 1500 segundos (região II). De acordo com a teoria das colisões, o aumento da temperatura causa um aumento da energia de impacto da colisão aumentando a probabilidade de mais moléculas excederem a energia de ativação. Portanto, durante o intervalo II tanto a conversão quanto a temperatura serão mais sensíveis aos parâmetros $\mathrm{k}_{0}$ e $\mathrm{E}$. 

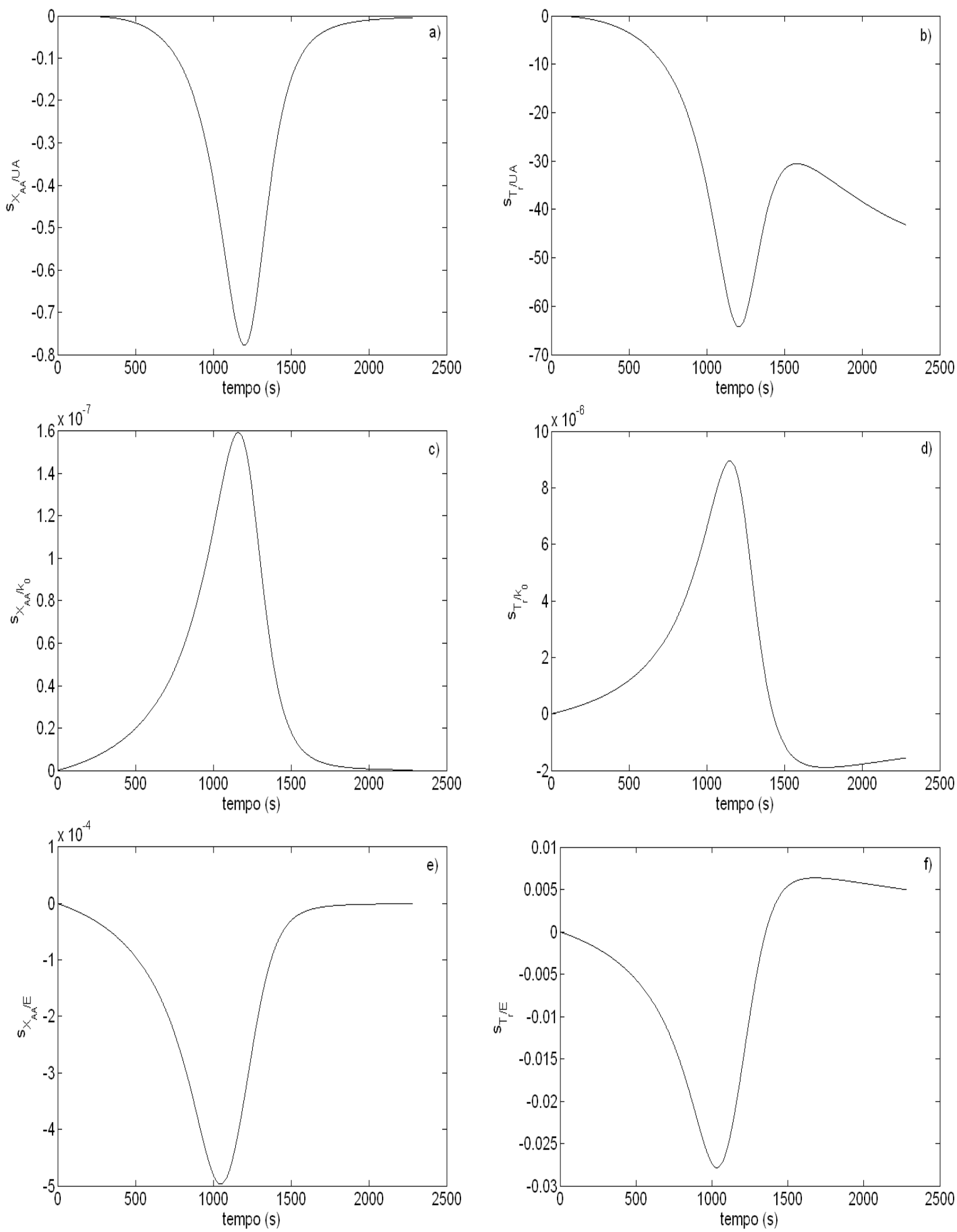

Figura 6.14 - Sistema 1: sensibilidade de a) $X_{A A}$ e b) $T_{r}$ em relação ao coeficiente UA, c) $X_{A A}$ e d) $T_{r}$ em relação ao parâmetro $k_{0}$, e) $X_{A A}$ e f) $T_{r}$ em relação ao parâmetro $\mathrm{E}$ 

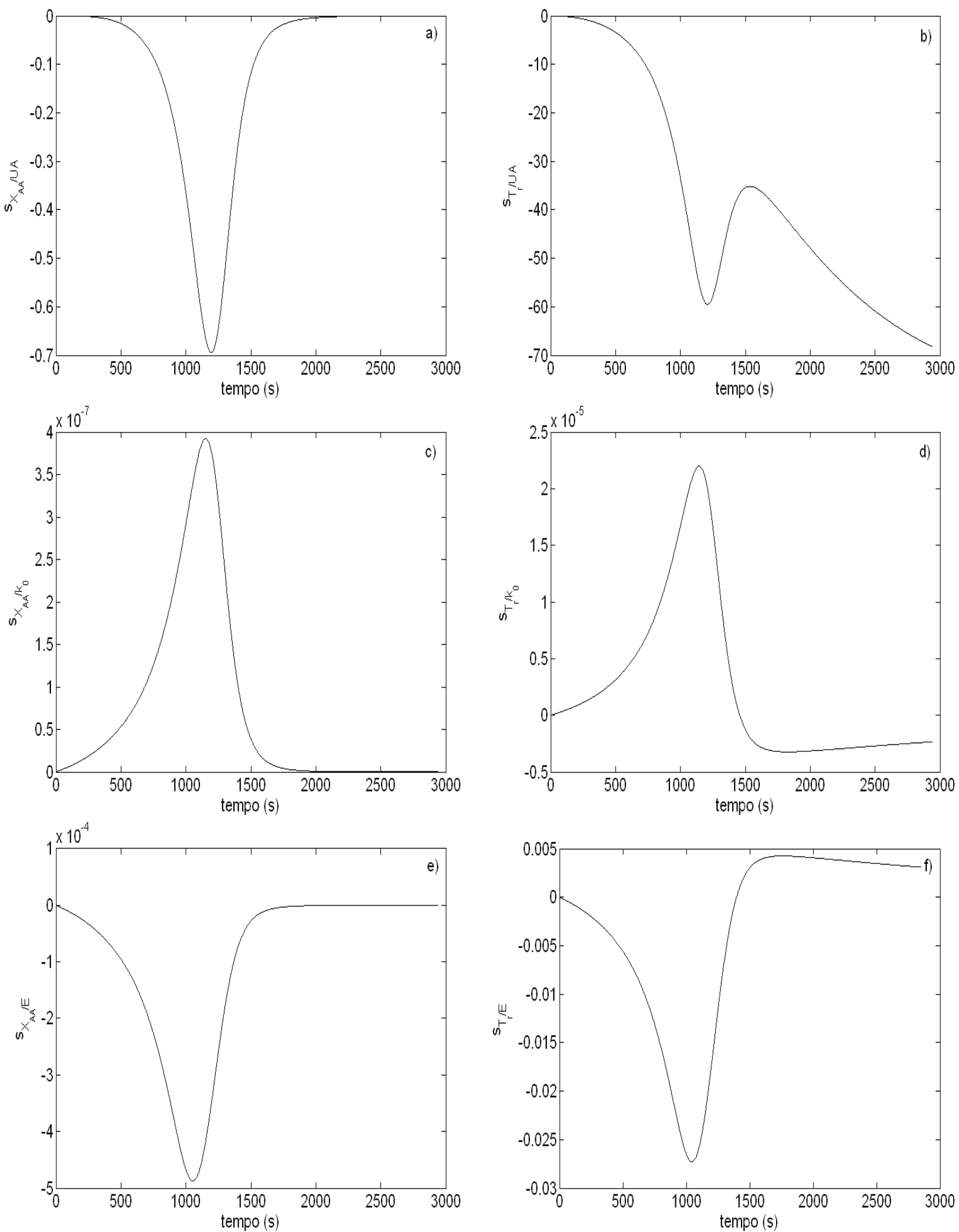

Figura 6.15 - Sistema 2: sensibilidade de a) $X_{A A}$ e b) $T_{r}$ em relação ao coeficiente $U A$, c) $X_{A A}$ e d) $T_{r}$ em relação ao parâmetro $k_{0}$, e) $X_{A A}$ e f) $T_{r}$ em relação ao parâmetro $\mathrm{E}$ 

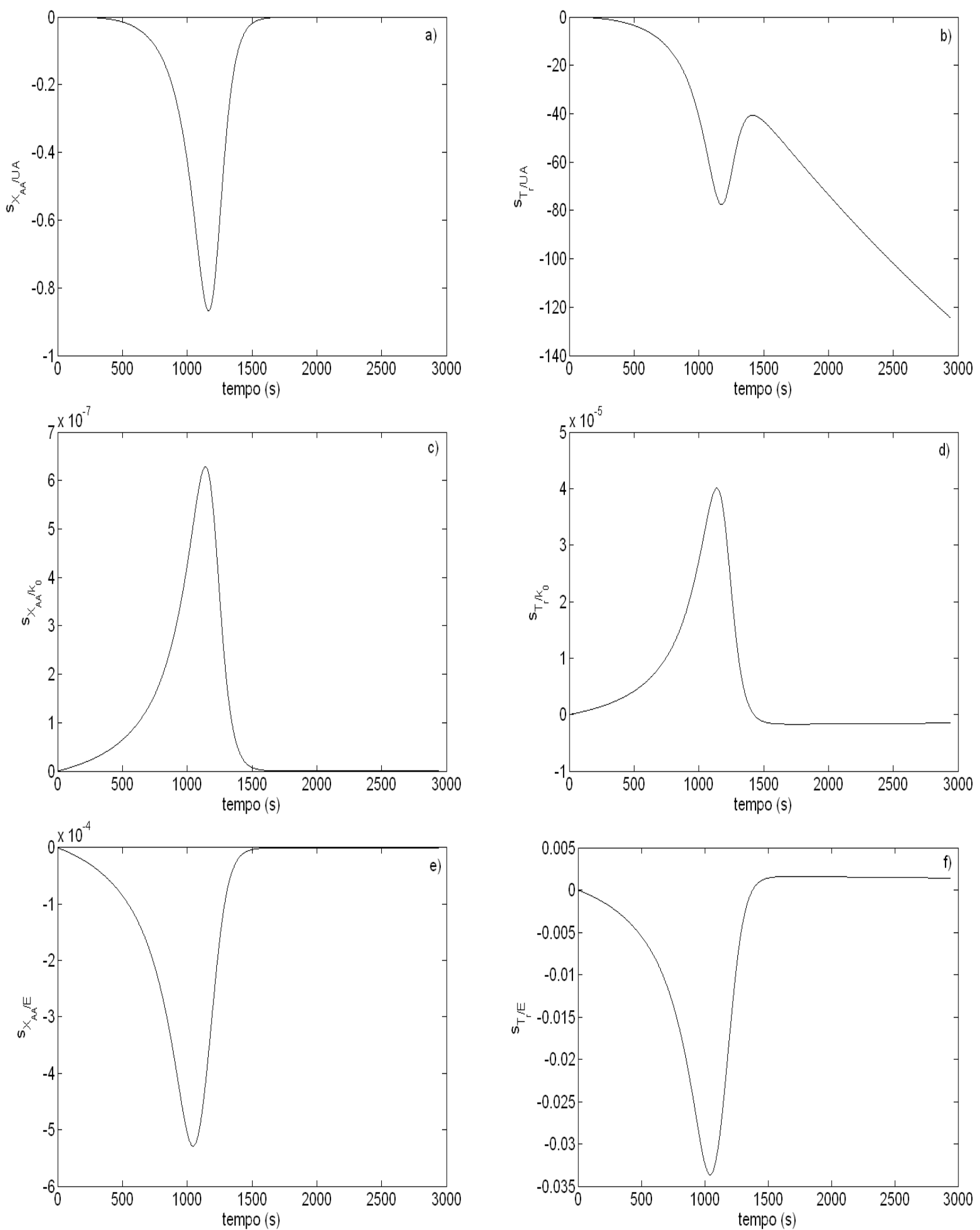

Figura 6.16 - Sistema 3: sensibilidade de a) $X_{A A}$ e b) $T_{r}$ em relação ao coeficiente $U A$, c) $X_{A A}$ e d) $T_{r}$ em relação ao parâmetro $k_{0}$, e) $X_{A A}$ e f) $T_{r}$ em relação ao parâmetro $\mathrm{E}$ 
Em termos absolutos, as Figuras 6.14c - 6.14f, 6.15c-6.15f e 6.16c - 6.16f indicam também que as variáveis de estado são mais sensíveis à energia de ativação do que ao fator pré-exponencial. Isto ocorre, pois, de acordo com a eq.(5.07), a dependência da velocidade de reação com $\mathrm{k}_{0}$ é linear enquanto que a dependência com $\mathrm{E}$ é exponencial.

$\mathrm{Na}$ terceira região ( $\mathrm{t}>1500$ segundos), como 0 anidrido acético foi completamente consumido, o termo cinético dos balanços de massa e energia é igual a zero e, portanto, a sensibilidade de ambos os estados em relação aos parâmetros $\mathrm{k}_{0}$ e $\mathrm{E}$ decresce até valores próximos de zero conforme a conversão se aproxima dos $100 \%$.

Uma análise similar pode ser feita para explicar os perfis de sensibilidade de $\mathrm{X}_{\mathrm{AA}}$ e $\mathrm{T}_{\mathrm{r}}$ em relação ao coeficiente UA (Figuras 6.14a, 6.15a e 6.16a). É importante ressaltar que, apesar da conversão não depender explicitamente do coeficiente UA, $\mathrm{X}_{\mathrm{AA}}$ depende da temperatura do meio reacional que por sua vez depende de UA.

Durante os primeiros 500 segundos (região I) como a temperatura do meio reacional é muito próxima da temperatura ambiente (Figuras 6.13a, 6.13c e 6.13e), a troca térmica entre 0 meio reacional e 0 ambiente será muito baixa. Consequentemente, tanto $X_{A A}$ quanto $T_{r}$ serão pouco sensíveis às incertezas no coeficiente UA. Entretanto, com o aumento brusco da temperatura do meio reacional, observado entre 500 e 1500 segundos (região II), as trocas térmicas tornam-se mais intensas, aumentando a contribuição do coeficiente UA sobre as estimativas de conversão e temperatura e, consequentemente, aumentando a sensibilidade destas variáveis em relação a este parâmetro.

$\mathrm{Na}$ terceira região ( $\mathrm{t}>1500$ segundos), como o reagente limitante foi completamente consumido, a derivada $\mathrm{dX}_{\mathrm{AA}} / \mathrm{dt}$ é igual a zero e, portanto, SXAA/UA tende a valores próximos de zero, ao contrário da sensibilidade de $T_{r}$ em relação ao coeficiente UA que permanece relativamente alta, uma vez que $T_{r}>T_{a m b}$.

Comparando as sensibilidades obtidas para cada sistema, outras informações podem ser extraídas das Figuras 6.14, 6.15 e 6.16. Primeiro, as sensibilidades das variáveis de estado em relação ao parâmetro $E$ apresentam praticamente a mesma magnitude. Isto ocorre, pois $E$ aparece no expoente de uma função exponencial negativa e as medidas de temperatura e os valores de energia de ativação são bastante próximos para os três casos analisados. Portanto, não serão observados grandes diferenças entre os perfis de sensibilidade obtidos para 
os três sistemas. Segundo, as sensibilidades dos estados em relação ao parâmetro $\mathrm{k}_{0}$ aumentam conforme o coeficiente de troca térmica diminui, ou seja, $\mathrm{S}_{X A A / k 0}(\mathrm{~S} 3)>\mathrm{S}_{\mathrm{XAA} / k 0}(\mathrm{~S} 2)>\mathrm{S}_{\mathrm{XAA} / \mathrm{k} 0}(\mathrm{~S} 1)$ e $\mathrm{S}_{\mathrm{Tr} / k 0}(\mathrm{~S} 3)>\mathrm{S}_{\mathrm{Tr} / k 0}(\mathrm{~S} 2)>\mathrm{S}_{\mathrm{Tr} / k 0}(\mathrm{~S} 1)$. Isto ocorre, pois $\mathrm{k}_{0}$ é uma parâmetro que aparece multiplicando o termo cinético dos balanços de massa e energia e, portanto, conforme a troca térmica diminui as predições de $T_{r} e$ $\mathrm{X}_{\mathrm{AA}}$ estarão cada vez mais sujeitas à influência de $\mathrm{k}_{0}$. Fisicamente, este fato pode ser interpretado da seguinte forma: quanto menor a troca térmica, maior a quantidade de energia acumulada no sistema, portanto maior o aumento de temperatura durante a reação, e mais rápida será a variação de conversão. Terceiro, as sensibilidades das variáveis de estado em relação ao coeficiente UA apresentam praticamente a mesma magnitude durante o período de consumo do anidrido acético. Após o consumo completo do reagente limitante, as sensibilidade de $\mathrm{X}_{\mathrm{AA}}$ tendem a zero e as sensibilidade de $T_{r}$ aumentam conforme o coeficiente de troca térmica diminui, ou seja, $\mathrm{S}_{\mathrm{Tr} / \mathrm{UA}}(\mathrm{S} 3)>\mathrm{S}_{\mathrm{Tr} / \mathrm{A} A}(\mathrm{~S} 2)>\mathrm{S}_{\mathrm{Tr} / \mathrm{UA}}(\mathrm{S} 1)$. Isto ocorre, pois durante 0 consumo do reagente limitante, as trocas térmicas são contrabalançadas pelo calor gerado pela reação de hidrólise. Após o consumo, como as variações de temperatura ocorrem exclusivamente devido às trocas de calor com o ambiente, menores valores de UA implicam em uma variação mais lenta de temperatura e, portanto, maiores sensibilidades de $T_{r}$ em relação a este coeficiente.

Em termos absolutos, tanto a conversão quanto a temperatura são mais sensíveis ao coeficiente UA do que aos parâmetros da equação de Arrhenius, como era de se esperar, afinal este parâmetro aparece multiplicando diretamente a diferença $T_{r}-T_{a m b}$. Isto significa, que o coeficiente UA é o parâmetro mais crítico para as estimativas das variáveis de estado do processo. Consequentemente, as dinâmicas de $\mathrm{k}_{0}$ e E podem ser desconsideradas do sistema dinâmico simplificando o trabalho de sintonia do observador de estado.

Aplicando o observador não-linear dado pela eq.(3.43) sobre o sistema dinâmico (5.31) e excluindo as dinâmicas de $\mathrm{k}_{0}$ e E, o observador para a reação de hidrólise do anidrido acético pode ser escrito como: 


$$
\left[\begin{array}{l}
U \dot{\hat{A}} \\
\dot{\hat{X}}_{A A} \\
\dot{\hat{T}}_{r}
\end{array}\right]=\left[\begin{array}{l}
0 \\
f_{1}\left(U \hat{A}, \hat{X}_{A A}, \hat{T}_{r}, \alpha\right) \\
f_{2}\left(U \hat{A}, \hat{X}_{A A}, \hat{T}_{r}, \alpha\right)
\end{array}\right]+\left[\begin{array}{lll}
\frac{\partial \Phi_{1}(\hat{x})}{\partial U \hat{A}} & \frac{\partial \Phi_{1}(\hat{x})}{\partial \hat{X}_{A A}} & \frac{\partial \Phi_{1}(\hat{x})}{\partial \hat{T}_{r}} \\
\frac{\partial \Phi_{2}(\hat{x})}{\partial U \hat{A}} & \frac{\partial \Phi_{2}(\hat{x})}{\partial \hat{X}_{A A}} & \frac{\partial \Phi_{2}(\hat{x})}{\partial \hat{T}_{r}} \\
\frac{\partial \Phi_{3}(\hat{x})}{\partial U \hat{A}} & \frac{\partial \Phi_{3}(\hat{x})}{\partial \hat{X}_{A A}} & \frac{\partial \Phi_{3}(\hat{x})}{\partial \hat{T}_{r}}
\end{array}\right]{ }^{-1} \mathbf{K}\left(T_{r}-\hat{T}_{r}\right)
$$

onde $\alpha$ é uma constante que engloba todos os parâmetros do modelo e $\mathbf{K}$ é o vetor de ganho do observador ajustado por tentativa e erro.

Para verificar a acurácia numérica e a robustez do observador não-linear (6.01) na presença de incertezas no parâmetro UA, serão analisadas três situações hipotéticas:

i) CASO 1: o coeficiente global de troca térmica inicial usado no observador de estado é igual ao coeficiente UA experimental;

ii) CASO 2: o coeficiente global de troca térmica inicial usado no observador é $50 \%$ menor do que o coeficiente UA experimental;

iii) CASO 3: o coeficiente global de troca térmica inicial usado no observador é $50 \%$ maior do que o coeficiente UA experimental.

A Figura 6.17 apresenta as evoluções dos perfis do coeficiente UA para os três casos analisados. Na Figura 6.18 as conversões e as temperaturas fornecidas pelo observador são comparadas com os valores experimentais e com os valores preditos pelos balanços de massa e energia. Os valores de $k_{0}$ e $E$ utilizados foram aqueles obtidos pelas diferenças finitas centradas para o cálculo das derivadas de temperatura. Para o caso 1, como o coeficiente global de troca térmica é igual ao valor experimental do coeficiente $U A$, as predições de $X_{A A}$ e $T_{r}$ são similares às predições do balanço de massa e energia e, portanto, não são apresentadas na Figura 6.18.

A Figura 6.17 mostra que a sintonia adequada do observador possibilita a convergência do perfil de UA para o seu valor experimental, antes que as oscilações neste coeficiente causem problemas nas estimativas dos estados. Além disso, apesar da lenta convergência e da presença de oscilações durante os primeiros 500 segundos, as predições de $\mathrm{T}_{\mathrm{r}}$ (Figuras 6.18a, 6.18c e 6.18e) e $\mathrm{X}_{\mathrm{AA}}$ (Figuras 6.18b, 
6.18d e 6.18f) são bastante próximas daqueles obtidos experimentalmente e pelos balanços de massa e energia. Isto ocorre, pois nos instantes iniciais as sensibilidades de $\mathrm{X}_{\mathrm{AA}}$ e $T_{\mathrm{r}}$ em relação ao parâmetro UA são baixas.

Para finalizar, os gráficos apresentados na Figura 6.18 mostram que as estimativas experimentais de $k_{0}$, E e UA permitiram boa concordância entre os valores experimentais e preditos de conversão e temperatura.
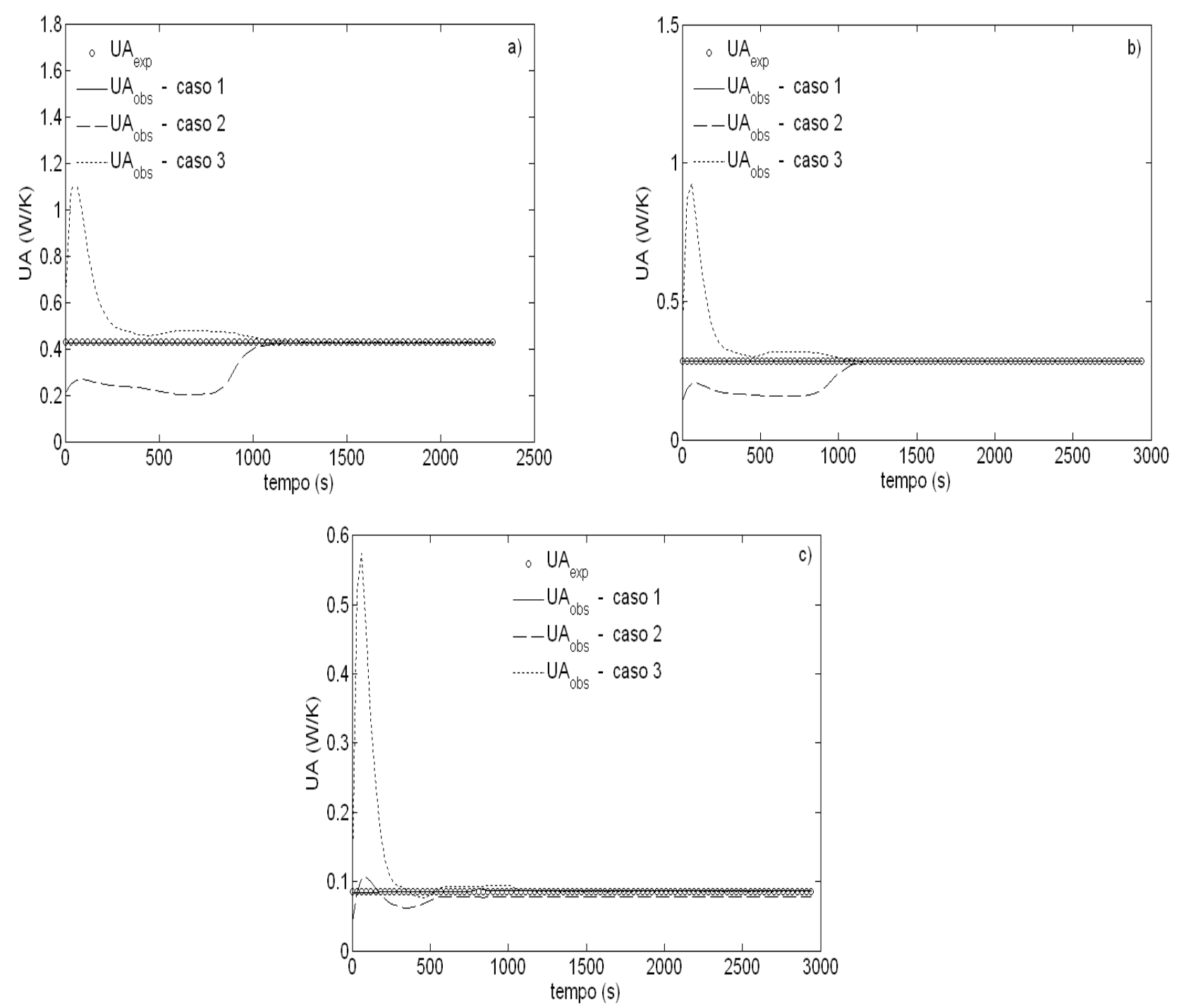

Figura 6.17 - Coeficiente global de troca térmica experimental de predito pelo observador de estado para a) copo de poliestireno, b) balão volumétrico, c) garrafa térmica 

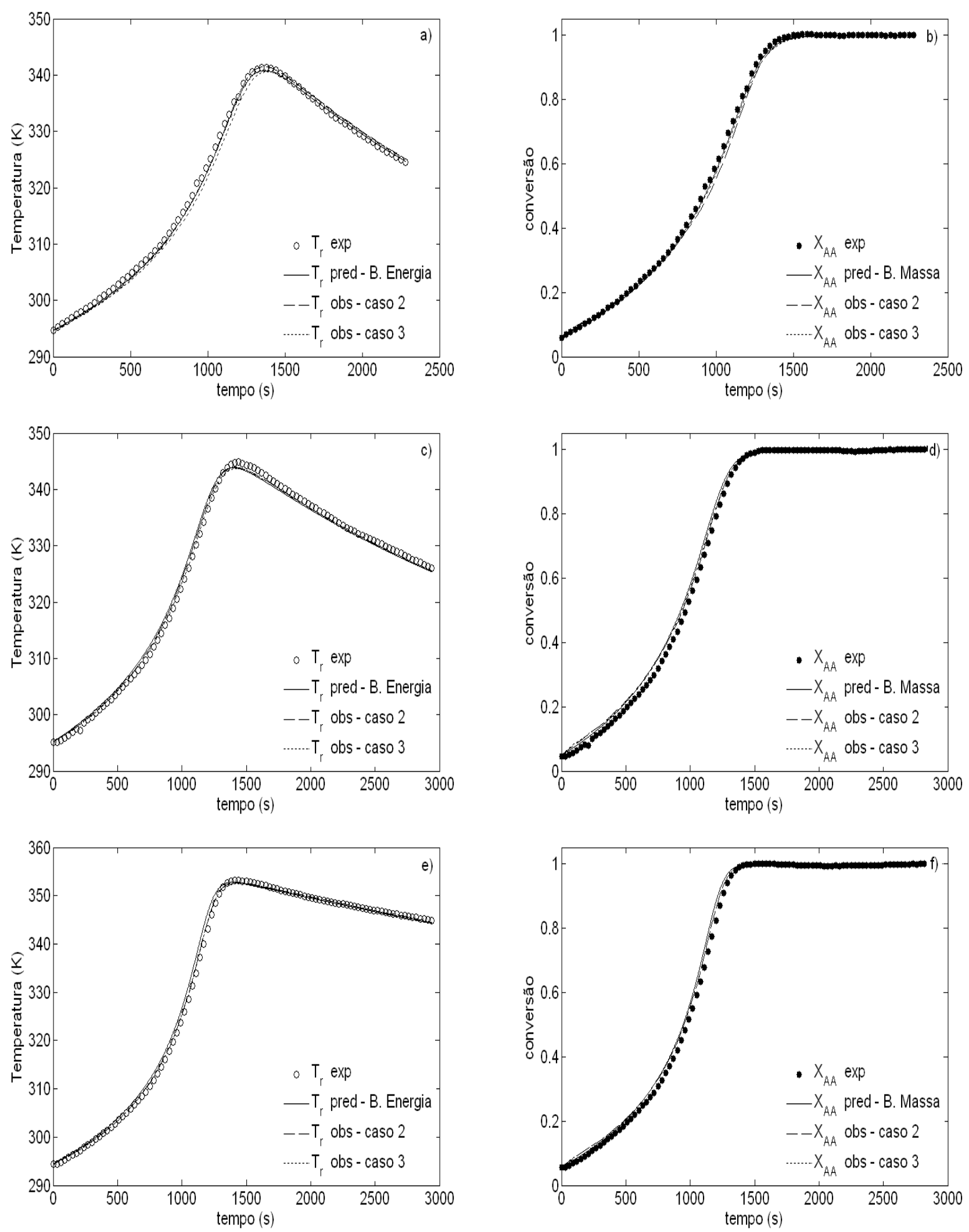

Figura 6.18 - Valores experimentais e preditos de a) temperatura e b) conversão para o sistema 1, c) temperatura e d) conversão para o sistema 2, e) temperatura e conversão para o sistema 3. 


\subsection{Conclusões Parciais}

Esta primeira fase do projeto teve como principais objetivos: a) avaliar o desempenho e a capacidade preditiva de um observador de estado não-linear tipo Luenberger para a estimação dos estados de uma simples reação de hidrólise de anidrido acético conduzida em três diferentes tipos de recipientes, e b) avaliar três diferentes metodologias para o cálculo da taxa de reação de hidrólise, uma vez que a qualidade das estimativas dos parâmetros da equação de Arrhenius são extremamente dependentes da precisão desta variável. Estas análises evidenciaram que, independentemente do método de cálculo das derivadas de temperatura, as estimativas do fator de frequência e da energia de ativação são bastante próximas, pois não são verificadas diferenças acentuadas nos perfis da velocidade de reação previstos pelos três métodos analisados. Do ponto de vista prático, isto significa que uma simples método de diferenciação numérica como, por exemplo, diferenças finitas centradas, é capaz de fornecer estimativas realistas de $\mathrm{k}_{0}$ e $E$ não sendo necessário, portanto, o uso de ferramentas computacionais sofisticadas.

Com relação às análises envolvendo o uso de observadores de estado, observou-se que as estimativas de conversão e temperatura, em condições nãoadiabática e adiabática não-ideal, são mais sensíveis à presença de incertezas no coeficiente de troca térmica, principalmente, quando a diferença entre a temperatura do meio reacional e a temperatura ambiente é elevada. Por outro lado, mesmo que este coeficiente não seja exatamente conhecido durante os instantes iniciais de reação, a sintonia adequada do observador de estado permite a convergência deste parâmetro para o seu valor "real" antes que as incertezas afetem as predições do observador. Desta forma, a possibilidade de estimar a conversão sem o conhecimento prévio do coeficiente UA, que também é estimado ao longo do processo, demonstra a contribuição que os observadores de estado podem ter em problemas reais. 


\section{RESULTADOS E DISCUSSÕES: POLIMERIZAÇÃO EM EMULSÃO}

Nesta seção as metodologias analíticas e os algorítimos de estimativa apresentados na subseção 5.2 são aplicados ao segundo estudo de caso proposto: copolimerização em emulsão de acetato de vinila / acrilato de butila.

Para descrever passo a passo a aplicação das metodologias para o tratamento dos dados e para o cálculo das variáveis de estado do processo, esta seção será subdividida da seguinte forma:

i) Subseção 7.1 Formulações e condições experimentais: nesta subseção é apresentada uma breve descrição das formulações e das condições experimentais utilizadas nas reações de polimerização. Os demais dados necessários para as simulações foram obtidos da literatura e são apresentados no Apêndice A - Banco de Dados.

ii) Subseção 7.2 Temperaturas: remoção de distúrbios e perdas térmicas: nesta subseção o polinômio de suavização digital (DISPO) ou filtro Savitzky-Golay, apresentado na subseção 5.1.2.2, é aplicado sobre a temperatura do meio reacional e sobre a temperatura média da camisa para a remoção de eventuais distúrbios. Como este filtro é pouco seletivo, ou seja, incapaz de diferenciar o que é sinal do que é ruído, o número de pontos e o grau do polinômio são escolhidos de modo a minimizar a distorção do sinal e, consequentemente, a perda de informações úteis. Em seguida, as temperaturas de entrada e de saída da camisa medidas pelo sensor PT100 são comparadas com as medidas coletadas pelo termopar tipo $\mathrm{K}$ para verificar a presença de eventuais diferenças entre as medidas fornecidas pelos sensores PT100 e aquelas efetivamente observadas na entrada e saída da camisa (perdas térmicas).

iii) Subseção 7.3 Coeficiente de troca térmica e capacidade calorífica total: nesta subseção os valores experimentais de UA e $\left(\mathrm{mC}_{\mathrm{p}}\right)_{\mathrm{r}}$ obtidos através das calibrações realizadas antes e depois de cada reação, segundo a metodologia descrita na subseção 5.2.2.6, são apresentados e discutidos. 
iv) Subseção 7.4 Calorimetria em cascata: nesta subseção os perfis da temperatura do reator $\left(T_{r}\right)$, do coeficiente global de troca térmica (UA) e do calor de reação $\left(Q_{r}\right)$ preditos pelos observadores de estado de alto ganho operando em "cascata" são apresentados e comparados com os valores experimentais. As estimativas de $Q_{r}$ fornecidas pela calorimetria em cascata são utilizadas para o cálculo dos valores preditos de conversão global $\left(x_{g}\right)$, conversão instantânea $\left(x_{\text {inst }}\right)$ e composição mássica acumulada de acetato de vinila $\left(\mathrm{y}_{\mathrm{A}}\right)$ que, por sua vez, são comparados com os respectivos valores experimentais obtidos a partir dos teores de monômero residual medidos pela cromatografia em fase gasosa.

v) Subseção 7.5 Calorimetria em cascata - Análise do efeito das incertezas: nesta subseção é apresentado e discutido o comportamento da calorimetria em cascata frente às incertezas no coeficiente UA e $\left(\mathrm{mC}_{\mathrm{p}}\right)_{\mathrm{r}}$ $e$ às variações nos parâmetros de sintonia.

vi) Subseção 7.6 Estimação de $\boldsymbol{Q}_{\mathbf{r}}$ via balanço de energia: devido as limitações da calorimetria em cascata, causadas principalmente pela necessidade de ajustes frequentes dos parâmetros de sintonia, esta seção tem por objetivo analisar a viabilidade de se utilizar diretamente o balanço de energia do reator para a estimação do calor gerado pela reação.

vii) Subseção 7.7 Remoção de distúrbios e predição em linha das variáveis de estado: esta subseção tem por objetivo apresentar 0 programa desenvolvido para a suavização e predição em linha das variáveis de estado calorimétricas. As saídas fornecidas pelo programa são comparadas com as medidas experimentais e com as predições obtidas durante as simulações off line para comprovar a eficiência do programa proposto.

viii) Subseção 7.8 Conclusões: esta subseção tem por objetivo apresentar um apanhado geral e as considerações finais sobre os principais resultados apresentados na seção 7 . 


\subsection{Formulações e condições experimentais}

O desempenho da calorimetria em cascata foi avaliado a partir dos resultados experimentais obtidos durante seis reações de copolimerização em emulsão de acetato de vinila (VA) / acrilato de butila (BA), conduzidas em um reator tipo tanque agitado operando em regime semicontínuo, batelada e com alimentação intermitente, e seguindo as formulações apresentadas nas Tabelas 7.1 a 7.4. Os monômeros acetato de vinila e acrilato de butila foram escolhidos devido a ocorrência de acentuada deriva da composição (composition drift) na ausência ou na aplicação inadequada do controle de composição.

Tabela 7.1 - Formulação: reações em batelada

\begin{tabular}{cccc}
\hline Reagentes & Ensaio: RC01A & Ensaio: RC01B & Ensaio: RC01C \\
& Carga inicial $(\mathrm{g})$ & Carga inicial $(\mathrm{g})$ & Carga inicial $(\mathrm{g})$ \\
\hline Água & 2257,10 & 2200,70 & 2200,60 \\
SLS & 33,63 & 9,73 & 9,43 \\
Carbonato de sódio & 3,99 & 4,60 & 4,53 \\
Persulfato de potássio & 16,39 & 8,91 & 8,50 \\
Acetato de vinila & 460,21 & 457,60 & 454,50 \\
Acrilato de butila & 86,40 & 81,12 & 83,70 \\
\hline
\end{tabular}

Tabela 7.2 - Formulação: ensaio RC01D (semicontínuo)

\begin{tabular}{cccc}
\hline Reagentes & Carga inicial $(\mathrm{g})$ & Alimentação 1 $(\mathrm{g})$ & Alimentação 2 $(\mathrm{g})$ \\
\hline Agua & 2000,10 & & 200,47 \\
SLS & 9,40 & & \\
Carbonato de sódio & 4,50 & & 8,54 \\
Persulfato de potássio & & 457,18 & \\
Acetato de vinila & & 80,66 & \\
Acrilato de butila & & & \\
\hline
\end{tabular}

Tabela 7.3 - Formulação: ensaio RC01E (semicontínuo)

\begin{tabular}{cccc}
\hline Reagentes $(\mathrm{g})$ & Carga inicial $(\mathrm{g})$ & Alimentação 1 (g) & Alimentação 2 (g) \\
\hline Água & 2005,60 & & 200,57 \\
SLS & 9,44 & & \\
Carbonato de sódio & 4,52 & & 8,53 \\
Persulfato de potássio & & 456,16 & \\
Acetato de vinila & & 81,79 & \\
Acrilato de butila & & & \\
\hline
\end{tabular}


Tabela 7.4 - Formulação: ensaio RC01F (intermitente)

\begin{tabular}{cccc}
\hline Reagentes & \multirow{2}{*}{ Carga inicial $(\mathrm{g})$} & \multicolumn{2}{c}{ Adição de acrilato de butila } \\
& & Tempo $(\mathrm{min})$ & Massa BA $(\mathrm{g})$ \\
\hline Água & 2200,10 & 7 & 16,1 \\
SLS & 9,54 & 12 & 16,35 \\
Carbonato de sódio & 4,65 & 18 & 16,5 \\
Persulfato de potássio & 8,88 & 24 & 16,25 \\
Acetato de vinila & 457,90 & & \\
Acrilato de butila & 17,57 & & \\
\hline
\end{tabular}

Todos os reagentes foram usados conforme recebidos, e a carga inicial e as alimentações foram purgadas com nitrogênio por um período de 60 minutos. As reações foram conduzidas em um ambiente com nitrogênio, e a temperatura do reator e a velocidade de agitação foram mantidas constantes a $55^{\circ} \mathrm{C}$ e $200 \mathrm{rpm}$, respectivamente. Nas reações semicontínuas, a mistura de monômeros e a solução de iniciador foram alimentadas a uma taxa constante durante os primeiros 90 minutos de reação.

O teor de sólidos final para todos os ensaios é de, aproximadamente, $20 \%$ e, portanto, para as reações em batelada e com alimentação intermitente não se espera grandes variações do coeficiente global de troca térmica (UA), uma vez que a viscosidade do meio reacional permanecerá muito baixa ao longo de toda a reação. Por outro lado, para a série de reações semicontínuas espera-se um aumento acentuado do coeficiente UA durante o período de alimentação dos reagentes devido ao aumento da área efetiva de troca térmica.

\subsection{Temperaturas: remoção de distúrbios e perdas térmicas}

Em geral, a confiabilidade dos resultados analíticos é vitalmente dependente da qualidade das medidas fornecidas pelos sensores e instrumentos analíticos. Entretanto, grande parte destas medidas podem sofrer a interferência de distúrbios dificultando a interpretação e as predições das propriedades associadas a estes sinais. Dessa forma, a aplicação de técnicas de processamento de sinais analíticos é essencial para uma melhor avaliação do desempenho dos métodos 
computacionais empregados nas estimativas das variáveis de estado de um processo.

Processamento de sinais refere-se a uma variedade de operações aplicadas sobre um sequência de medidas contínuas (analógicas) ou discretas (digitais), a fim de assegurar a qualidade da informação que se destina a transmitir. Com relação às medidas digitais, o processamento de sinais inclui uma ampla gama de métodos de filtragem (filtro Savitzky-Golay, diferenciação, média móvel, técnica de filtragem casada (matched filtering), interpolação, e filtro de Kalman) e transformações de domínio (transformadas de Fourier, transformadas de Hadamard, e transformadas wavelet) que, em geral, tem por objetivo separar a parte útil do sinal da parte que não contém nenhuma informação relevante (distúrbio), usando, para isso, modelos explícitos ou implícitos capazes de distinguir estas duas componentes (WENTZELL; BROWN, 2000).

Dentre estes métodos, o filtro Savitzky-Golay é um dos algoritmos mais utilizados para a suavização de sinais analíticos e também encontra-se incorporado em grande parte dos softwares comerciais para tratamento de dados. A idéia básica deste filtro é fazer uma aproximação polinomial de ordem $r$ dos $n_{L}+n_{R}+1$ pontos obtidos a partir de $n_{L}$ pontos à esquerda (pontos passados) e $n_{R}$ pontos à direita (pontos futuros) de uma dado ponto $\left(t_{k}, m_{k}\right)$ pertencente a um sistema genérico de pontos $\left(t_{i}, m_{i}\right)$ com $1 \leq i \leq n$, ou seja, o processo é controlado, basicamente, por dois parâmetros: o grau do polinômio (r) e o número de pontos usados para computar cada valor filtrado. Este método é superior à técnica da média móvel, porque tende a preservar as características dos dados, tais como, a altura e a largura dos sinais, que, em geral, são removidas pela média móvel.

As Figuras 7.1 e 7.2 apresentam o efeito do número de pontos passados (Figura 7.1) e o efeito do grau do polinômio interpolador (Figura 7.2) sobre a filtragem da temperatura média da camisa. Como o propósito final do projeto é a estimação em tempo real das variáveis de estado, em ambos os casos $n_{R}$ é sempre igual a zero $\left(n_{R}=0\right)$, pois implementar um filtro que dependa de pontos futuros irá causar atrasos nas predições das variáveis de estado e, portanto, as saídas fornecidas pelo programa não corresponderão mais ao estado atual do processo. As temperaturas filtradas são indicadas na legenda pela sigla SG seguida, entre parêntesis, pelo número de pontos à esquerda, número de pontos à direita, e pelo grau do polinômio, respectivamente. 

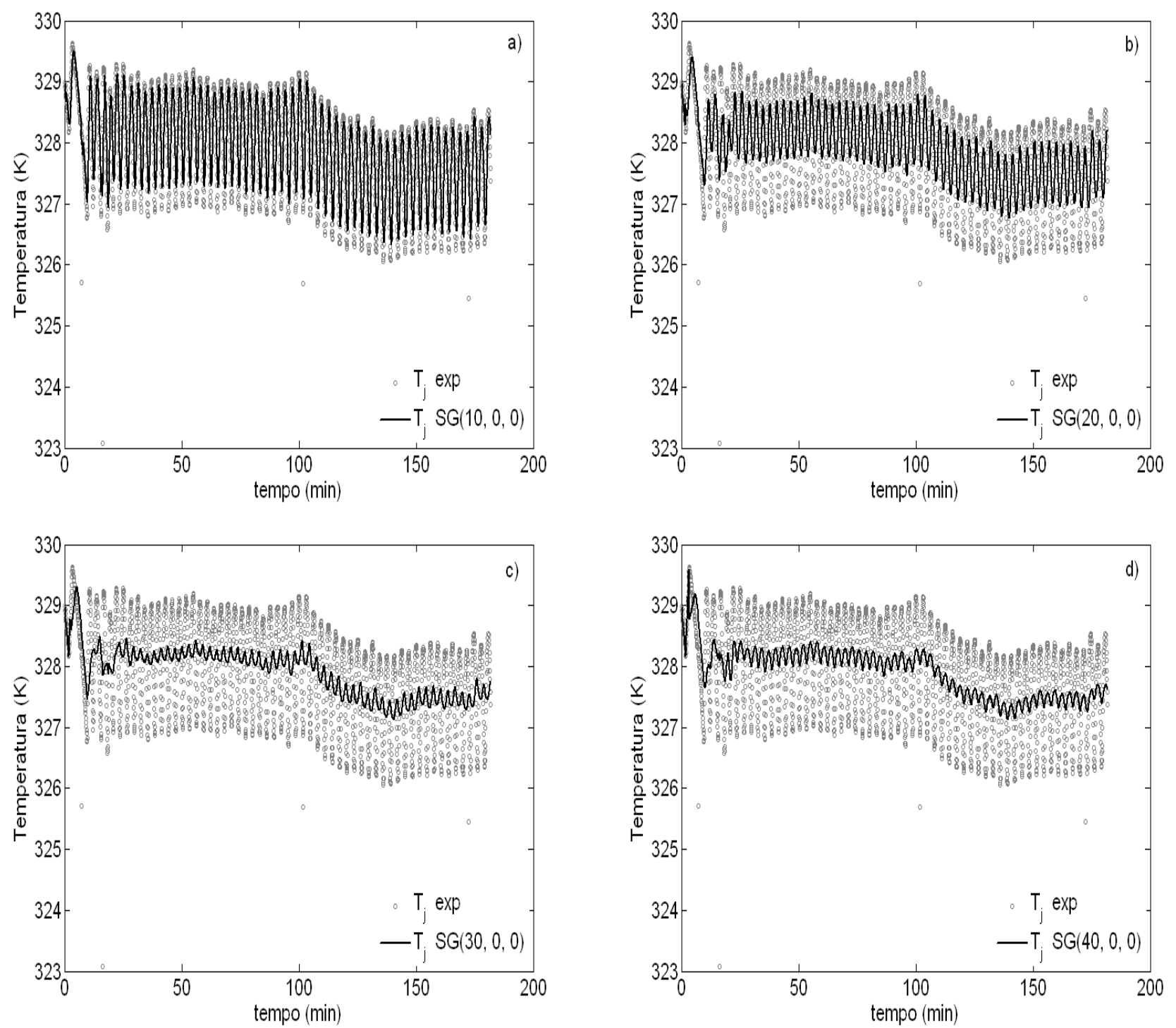

Figura 7.1 - Efeito do número de pontos passados sobre a filtragem das medidas de temperatura a) $n_{L}=10$ pontos, b) $n_{L}=20$ pontos, c) $n_{L}=30$ pontos, d) $n_{L}=40$ pontos.

De um modo geral, o filtro Savitzky-Golay é pouco sensível à largura do intervalo, pois o novo ponto (medida filtrada) é obtido através do ajuste dos pontos de um intervalo móvel por um polinômio e não pela simples média das medidas vizinhas, possibilitando que este filtro seja aplicado a sinais analíticos com picos estreitos. Entretanto, a medida que o grau do polinômio interpolador e o número de pontos utilizados no intervalo aumentam, observa-se uma acentuada perda de informações úteis (Figuras 7.1b, 7.1c, 7.1d) e um aumento na distorção do sinal (Figura 7.2b). Isto ocorre, pois as técnicas de suavização de ruídos, com exceção dos filtros baseados na transformada de Fourier (filtros de remoção seletiva de ruídos), atuam diretamente sobre o sinal analítico e não sobre as frequências que compõem tais sinais. Consequentemente, estes tipos de filtros são pouco seletivos, 
isto é, incapazes de diferenciar o que é sinal do que é distúrbio e, portanto, durante a suavização uma parte da informação útil contida no sinal é simultaneamente removida. A baixa seletividade do filtro Savitzky-Golay pode ser observada nas Figuras 7.2c e 7.2d onde, apesar do bom ajuste das informações úteis, o aumento do grau do polinômio tende a incorporar também os distúrbios.


Figura 7.2 - Efeito do grau do polinômio sobre a filtragem das medidas de temperatura a) $r=1, b) r=2$, c) $r=3, d) r=5$

Dessa forma, para evitar perdas de informações e assegurar, ao mesmo tempo, uma remoção eficiente dos distúrbios, as temperaturas do reator e da camisa foram filtradas utilizando-se 30 pontos passados $\left(n_{L}=30\right)$ e polinômio de ordem 1 . Os efeitos do filtro sobre as medidas de temperatura são apresentados nas Figuras 7.3 (reações em batelada) e 7.4 (reações semicontínuas e intermitente). 

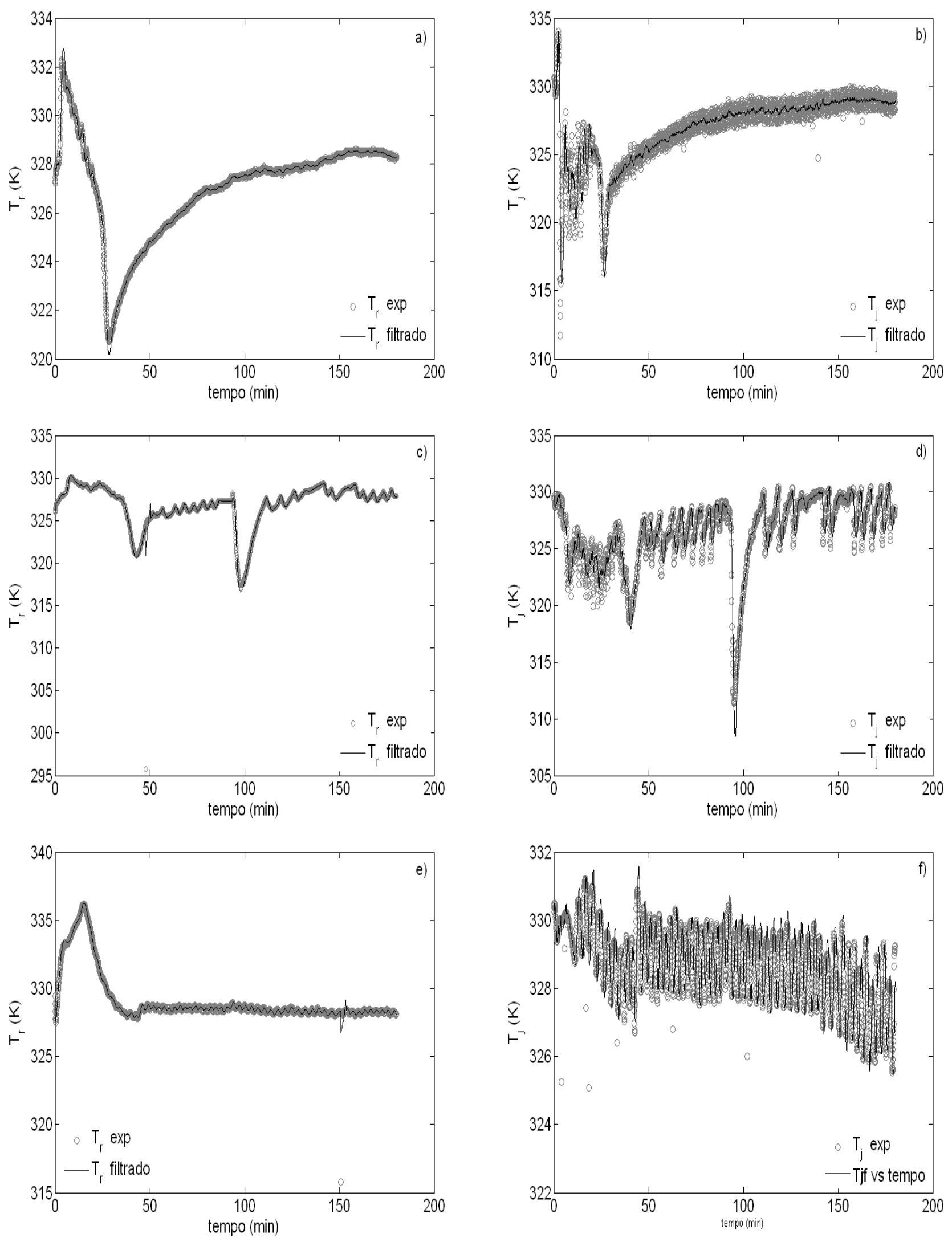

Figura 7.3 - Reações em batelada: remoção de distúrbios das medidas de a) $T_{r}$ e b) $T_{j}$ do ensaio RC01A, c) $T_{r}$ e d) $T_{j}$ do ensaio RC01B, e) $T_{r}$ e $T_{j}$ do ensaio RC01C 



Figura 7.4 - Reações intermitente e semicontínuas: remoção de distúrbios das medidas de a) $T_{r}$ e b) $T_{j}$ do ensaio RC01F, c) $T_{r}$ e $T_{j}$ do ensaio RC01D, e) $T_{r}$ e $T_{j}$ do ensaio RC01E 
Nas Figuras 7.3 e 7.4 nota-se que as temperaturas da camisa estão mais sujeitas à presença de distúrbios, e a aplicação do filtro sobre estas medidas permitiu manter uma relação sinal/distúrbio razoavelmente alta. As oscilações de $\mathrm{T}_{\mathrm{j}}$, observadas nas Figuras 7.3b, 7.3d, 7.3f, 7.4b, 7.4d e 7.4f, são causadas pelo sistema de controle on/off das vazões do fluido de refrigeração e aquecimento do reator, porém estas oscilações apresentam pouco efeito sobre a temperatura do meio reacional devido à inércia da parede e à elevada taxa de calor gerado pelas reações, principalmente, quando estas são conduzidas em batelada.

Com relação às temperaturas do reator, apesar de apresentarem pouco ou nenhum distúrbio, as medidas de $T_{r}$ obtidas pelo filtro ficaram bastante próximas das medidas originais indicando que essa técnica de filtragem pode ser utilizada em linha de forma preventiva, pois não é observada uma perda perceptível de informação, desde que o número de pontos e o grau do polinômio sejam selecionados adequadamente.

$\mathrm{Na}$ Figura 7.5 as temperaturas de entrada e de saída da camisa, medidas pelo sensor PT100, são comparadas com as medidas fornecidas pelo termopar tipo K. Todas as temperaturas foram previamente filtradas pelo filtro Savitzky-Golay usando 30 pontos à esquerda e polinômio de ordem 1 .

Comparando as temperaturas medidas pelos dois sensores, observa-se que os valores fornecidos pelo sensor PT100 são ligeiramente maiores ou próximos daqueles fornecidos pelo termopar tipo $\mathrm{K}$ indicando que não ocorrem perdas térmicas significativas e, portanto, as temperaturas fornecidas pelos sensores PT100 são bastante confiáveis, apesar destes sensores estarem distantes da entrada e da saída da camisa. Esta similaridade entre ambas as medidas já era esperada, pois 0 tempo de residência do fluido de refrigeração, entre o ponto no qual se encontra o sensor PT100 e a entrada/saída da camisa, é muito baixo devido à vazão elevada. 

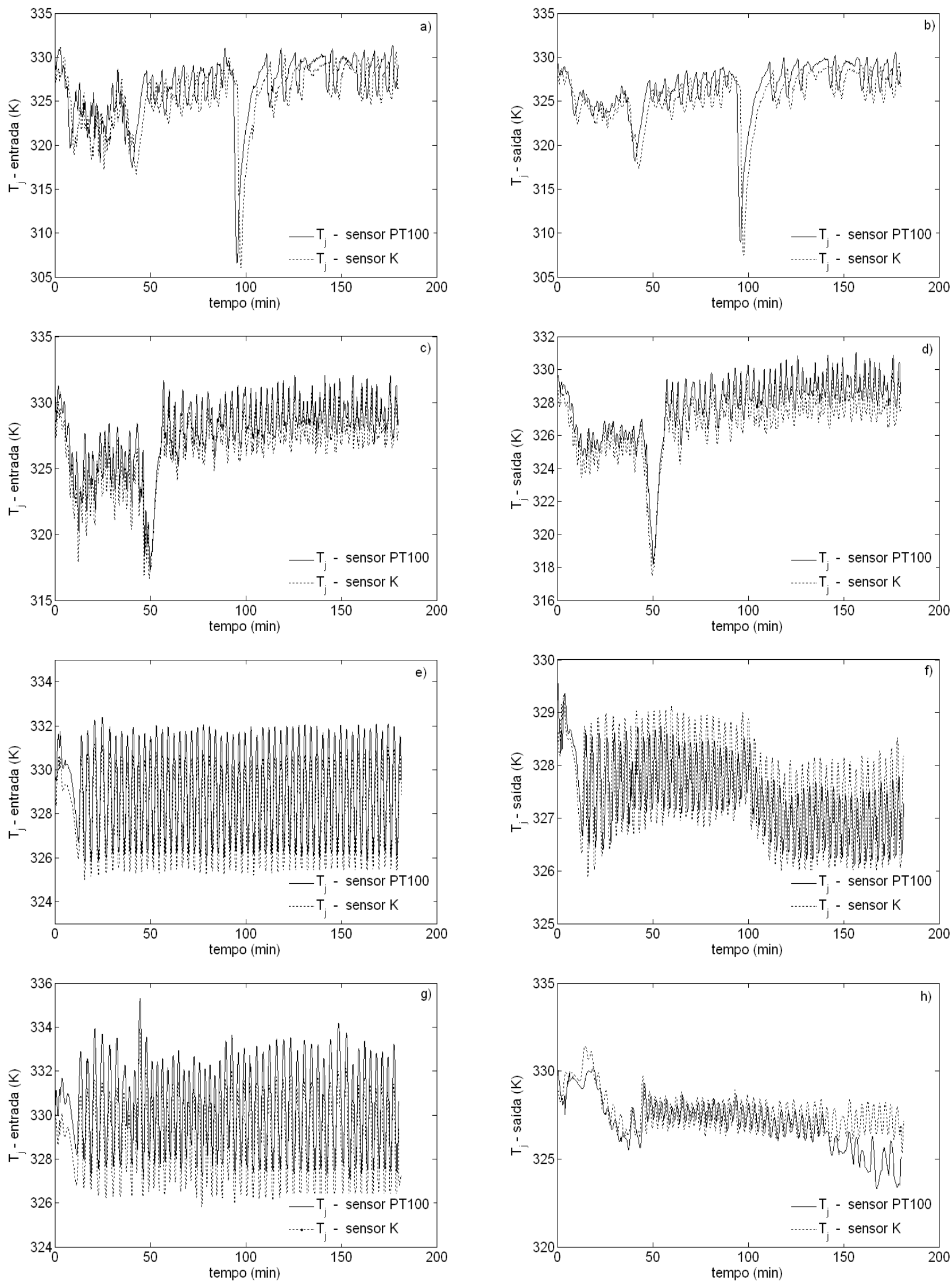

Figura 7.5 - Temperaturas de entrada $\left(\mathrm{T}_{\mathrm{j}, \mathrm{in}}\right)$ e de saída $\left(\mathrm{T}_{\mathrm{j}, \mathrm{out}}\right)$ da camisa medidas pelos sensores PT100 e K para os ensaios RC01B a) $T_{j, \text { in }}$ e b) $T_{j, \text { out }}, R C 01 \mathrm{~F} \mathrm{c}$ ) $T_{j, \text { in }}$ e d) $T_{j, \text { out }}, R C 01 E$ e) $T_{j, \text { in }}$ ef) $T_{j, \text { out }}$, e RC01C g) $T_{j, \text { in }}$ e h) $T_{j, \text { out }}$ 


\subsection{Coeficiente de troca térmica e capacidade calorífica total}

Os valores experimentais de UA e $\left(\mathrm{mC}_{\mathrm{p}}\right)_{\mathrm{r}}$ foram obtidos através de calibrações realizadas antes (carga inicial) e depois (látex) de cada reação segundo o procedimento descrito na seção 5.2.2.6. As voltagens e as correntes fornecidas à resistência elétrica pela fonte de alimentação e a potência dissipada pelo resistor em cada etapa são apresentadas na Tabela 7.5. Para o primeiro degrau de temperatura, a fonte de alimentação é acionada somente após $T_{r}$ atingir um valor estável. Para os demais ensaios (RC01A, RC01B e RC01F) não foi possível obter dois degraus de temperatura devido à baixa voltagem e, portanto, os valores de $\mathrm{V}_{\mathrm{e}}$, $\mathrm{i}_{\mathrm{e}} \mathrm{e} P$ destas reações não são apresentados na Tabela 7.5.

Tabela 7.5 - Calibração para estimação de UA e $\left(\mathrm{mC}_{\mathrm{p}}\right)_{\mathrm{r}}$ : potências dissipadas

\begin{tabular}{cccc|ccc}
\hline \multirow{2}{*}{ Ensaio } & \multicolumn{3}{c}{ Carga inicial } & \multicolumn{3}{c}{ Látex } \\
& $\mathrm{V}_{\mathrm{e}}(\mathrm{V})$ & $\mathrm{i}_{\mathrm{e}}(\mathrm{A})$ & $\mathrm{P}(\mathrm{W})$ & $\mathrm{V}_{\mathrm{e}}(\mathrm{V})$ & $\mathrm{i}_{\mathrm{e}}(\mathrm{A})$ & $\mathrm{P}(\mathrm{W})$ \\
\hline \multirow{3}{*}{$\mathrm{RC01D}$} & 84 & 0,37 & 31,45 & 84 & 0,37 & 31,45 \\
& 131 & 0,58 & 75,98 & 131 & 0,58 & 75,98 \\
& 0 & 0 & 0 & 0 & 0 & 0 \\
\hline \multirow{3}{*}{$\mathrm{RC01E}$} & 84 & 0,37 & 31,45 & 84 & 0,37 & 31,45 \\
& 131 & 0,58 & 75,98 & 131 & 0,58 & 75,98 \\
& 0 & 0 & 0 & 0 & 0 & 0 \\
\hline \multirow{2}{*}{$\mathrm{RC01C}$} & 140 & 0,66 & 92,40 & 140 & 0,68 & 95,20 \\
& 220 & 1,03 & 226,60 & 220 & 1,04 & 228,80 \\
& 0 & 0 & 0 & 0 & 0 & 0 \\
\hline
\end{tabular}

Na Figura 7.6 é apresentada a estimação gráfica de $\left(\mathrm{mC}_{\mathrm{p}}\right)_{\mathrm{r}}$ da carga inicial e do látex dos ensaios RC01D (Figuras 7.6a e 7.6b), RC01E (Figuras 7.6c e 7.6d) e RC01C (Figuras 7.6e e 7.6f). Os dados plotados na Figura 7.6 foram calculados através da eq.(5.65). Os valores dos coeficientes UA, obtidos a partir da eq.(5.63), e os valores de $\left(\mathrm{mC}_{\mathrm{p}}\right)_{\mathrm{r}}$, obtidos a partir dos coeficientes angulares das retas da Figura 7.6, são apresentados na Tabela 7.6. Nesta tabela são apresentados ainda, a área efetiva de troca térmica $(\mathrm{A})$, calculada desconsiderando-se o aumento causado pela agitação do meio reacional, e o coeficiente de troca térmica (U) desse conjunto de reações. Na Figura 7.7 os perfis de $T_{r}$ preditos pela eq.(5.62), usando os valores de UA, $\left(\mathrm{mC}_{\mathrm{p}}\right)_{\mathrm{r}}, \mathrm{V}_{\mathrm{e}} \mathrm{e} \mathrm{i}_{\mathrm{e}}$ das Tabelas 7.5 e 7.6, são comparados com as medidas experimentais. Nesta figura são apresentadas ainda as medidas experimentais de $T_{j}$ 
para demonstrar o efeito da potência dissipada pela resistência sobre as rampas de temperatura.
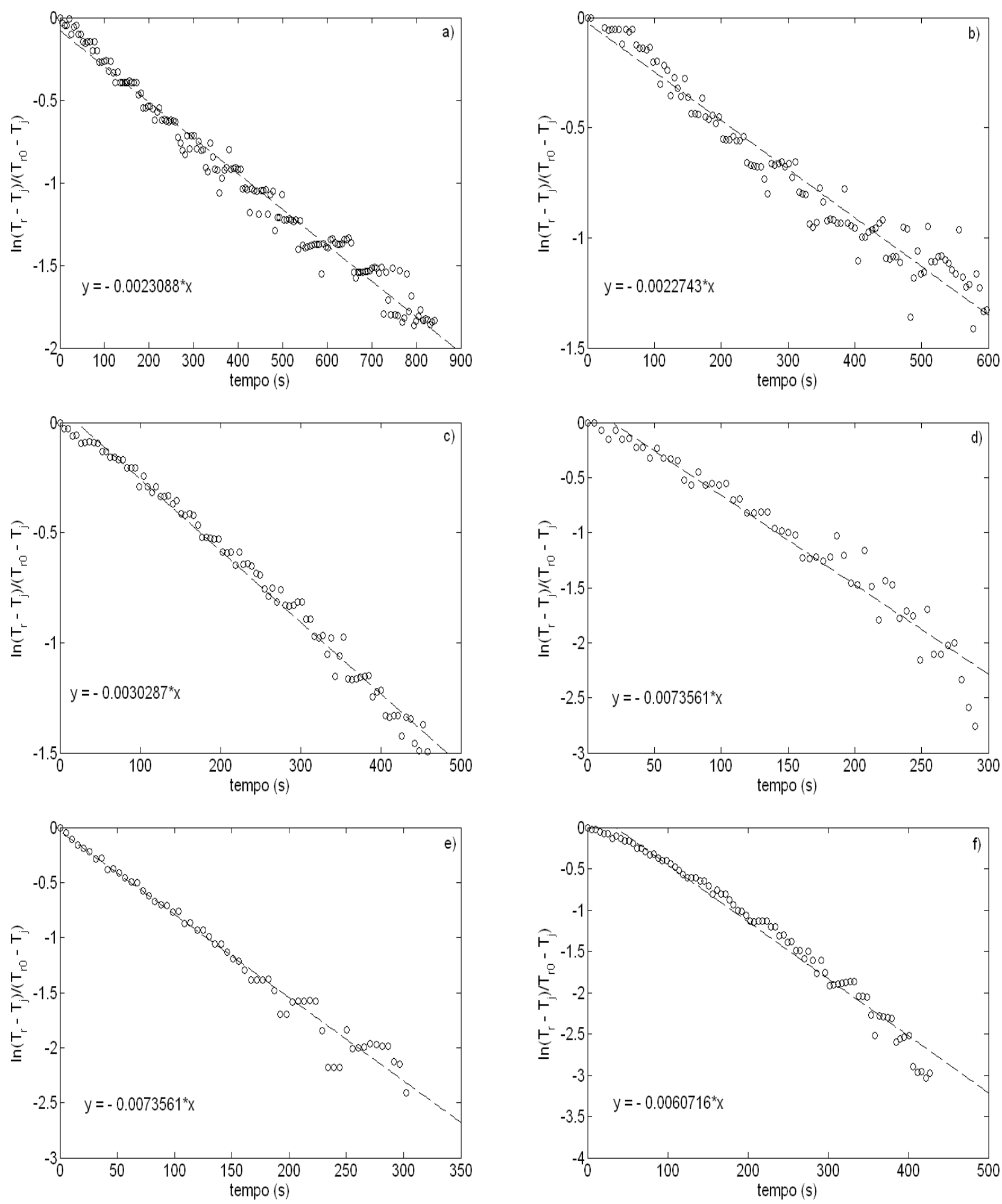

Figura 7.6 - Determinação gráfica de $\left(\mathrm{mC}_{\mathrm{p}}\right)_{\mathrm{r}}$ da a) carga inicial e b) látex da reação $\mathrm{RC01D}, \mathrm{c}$ ) carga inicial e d) látex da reação $\mathrm{RC01E}$, e) carga inicial e f) látex da reação $\mathrm{RC01C}$ 
Tabela 7.6 - Valores inciais e finais de UA e $\left(\mathrm{mC}_{\mathrm{p}}\right)_{\mathrm{r}}$

\begin{tabular}{|c|c|c|c|c|c|c|}
\hline Ensaio & \multicolumn{3}{|c|}{ Carga inicial } & \multicolumn{3}{|c|}{ Látex } \\
\hline \multirow{4}{*}{ RC01D } & $U A^{(*)}$ & 44,22 & $\mathrm{~J} / \mathrm{K} . \mathrm{s}$ & $U A^{(*)}$ & 73,48 & $\mathrm{~J} / \mathrm{K} . \mathrm{s}$ \\
\hline & $\left(m C_{p}\right)_{r}$ & 19152,14 & $\mathrm{~J} / \mathrm{K}$ & $\left(\mathrm{mC}_{\mathrm{p}}\right)_{\mathrm{r}}$ & 32309,21 & $\mathrm{~J} / \mathrm{K}$ \\
\hline & A & 0,07 & $\mathrm{~m}^{2}$ & A & 0,09 & $\mathrm{~m}^{2}$ \\
\hline & U & 631,71 & $\mathrm{~W} / \mathrm{m}^{2} \cdot \mathrm{K}$ & U & 816,44 & $\mathrm{~W} / \mathrm{m}^{2} . \mathrm{K}$ \\
\hline \multirow{4}{*}{ RC01E } & $U A^{(*)}$ & 36,42 & $\mathrm{~J} / \mathrm{K} . \mathrm{s}$ & $U A^{(*)}$ & 70,56 & $\mathrm{~J} / \mathrm{K} . \mathrm{s}$ \\
\hline & $\left(m C_{p}\right)_{r}$ & 12024,84 & $\mathrm{~J} / \mathrm{K}$ & $\left(\mathrm{mC}_{\mathrm{p}}\right)_{\mathrm{r}}$ & 9592,13 & $\mathrm{~J} / \mathrm{K}$ \\
\hline & A & 0,07 & $\mathrm{~m}^{2}$ & A & 0,09 & $\mathrm{~m}^{2}$ \\
\hline & $U$ & 520,29 & $\mathrm{~W} / \mathrm{m}^{2} \cdot \mathrm{K}$ & $U$ & 784,00 & $\mathrm{~W} / \mathrm{m}^{2} \cdot \mathrm{K}$ \\
\hline \multirow{4}{*}{$\mathrm{RC} 01 \mathrm{C}$} & $U A^{(*)}$ & 86,05 & $\mathrm{~J} / \mathrm{K} . \mathrm{s}$ & $U A^{(*)}$ & 82,51 & $\mathrm{~J} / \mathrm{K} . \mathrm{s}$ \\
\hline & $\left(m C_{p}\right)_{r}$ & 11128,75 & $\mathrm{~J} / \mathrm{K}$ & $\left(\mathrm{mC}_{\mathrm{p}}\right)_{\mathrm{r}}$ & 13588,93 & $\mathrm{~J} / \mathrm{K}$ \\
\hline & A & 0,09 & $\mathrm{~m}^{2}$ & A & 0,09 & $\mathrm{~m}^{2}$ \\
\hline & $U$ & 956,11 & $\mathrm{~W} / \mathrm{m}^{2} \cdot \mathrm{K}$ & $U$ & 916,78 & $\mathrm{~W} / \mathrm{m}^{2} . \mathrm{K}$ \\
\hline
\end{tabular}

T) média das medidas obtidas em cada patamar estacionário de temperatura

Comparando as estimativas experimentais do coeficiente UA apresentadas na Tabela 7.6 nota-se que, para reações semicontínuas (RC01D e RC01E), os valores de UA são bastante similares e, em ambos os casos, os valores finais de UA são, aproximadamente, duas vezes maior do que os respectivos valores iniciais. Este aumento já era esperado, pois látices com teor de sólidos abaixo de $25 \%$ apresentam uma queda de UA pouco expressiva, conforme demonstrado por Saenz de Buruaga et al. (1997). Isto significa que para reações semicontínuas e com teor de sólidos muito baixo, o efeito do aumento da área de troca térmica sobre UA será muito mais pronunciado do que o efeito causado pelo aumento da viscosidade do meio reacional.

Entretanto, apesar da aparente consistência entre as estimativas de UA, observando os valores do coeficiente $U$ e as estimativas de $\left(m C_{p}\right)_{r}$ (Tabela 7.6) e comparando as medidas experimentais e os perfis preditos de $T_{r}$ (Figuras $7.7 \mathrm{a}-$ 7.7d), percebe-se que:

i) Os valores finais do coeficiente de troca térmica (U) são sempre maiores do que os valores iniciais, contrariando a tendência natural de queda deste coeficiente causada pelo ligeiro aumento da viscosidade do meio reacional.

ii) Os valores iniciais e finais de $\left(\mathrm{mC}_{\mathrm{p}}\right)_{\mathrm{r}}$ são muito diferentes e não seguem uma mesma tendência, apesar das reações RC01D e RC01E apresentarem formulações idênticas. 



Figura 7.7 - Rampas de temperatura experimental e predita para a) carga inicial e b) látex (reação RC01D), c) carga inicial e d) látex (reação RC01E), e) carga inicial e f) látex (reação RC01C) 
iii) Os perfis preditos de $T_{r}$ apresentam um aumento mais lento (Figuras $7.7 \mathrm{a}$ e 7.7b) e um aumento mais rápido (Figuras $7.7 \mathrm{c}$ e $7.7 \mathrm{~d}$ ) do que as medidas experimentais de temperatura, indicando uma subestimação e/ou superestimação de $U A$ e $\left(\mathrm{mC}_{\mathrm{p}}\right)_{\text {r }}$.

Os erros citados nos itens i) a iii) podem ser atribuídos a dois fatores. Primeiro, a carga inicial usada nas reações semicontínuas não é suficiente para cobrir toda a superfície da resistência elétrica e, portanto, parte da potência dissipada é perdida. Segundo, as tensões fornecidas à resistência elétrica são suficientes apenas para gerar uma sequência de degraus de temperatura de $0,5^{\circ} \mathrm{C}$ $(84 \mathrm{~V})$ e $1,5^{\circ} \mathrm{C}(131 \mathrm{~V})$ (Figuras $7.7 \mathrm{~b}$ e $7.7 \mathrm{~d}$ ) acima da temperatura da camisa e, portanto, as medidas de $T_{r}$ estarão mais sujeitas às variações de $T_{j}$.

Devido à natureza determinística da calorimetria em cascata, pequenas variações nas condições iniciais podem causar acentuadas perturbações na condição final, uma vez que esta classe de modelos é inadequada quando não é possível definir exatamente as condições iniciais. Dessa forma, conclui-se que a utilização dos parâmetros apresentados na Tabela 7.6 nos observadores de alto ganho podem causar sérios problemas durante a estimação das variáveis de estado.

Como para o ensaio RC01C o uso de tensões maiores possibilitou excelente concordância entre as medidas experimentais e preditas de $T_{r}$, as estimativas obtidas para este ensaio serão utilizadas para obter os valores corrigidos de $\mathrm{UA} \mathrm{e}\left(\mathrm{mC}_{\mathrm{p}}\right)_{\mathrm{r}}$ para as reações semicontínuas, usando as seguintes equações:

$$
\begin{aligned}
& U A^{(\text {corr })}=U A^{(\text {base })} \frac{A^{(i)}}{A^{(\text {base })}} \\
& \left(m C_{p}\right)_{r}^{(\text {corr })}=\left(m C_{p}\right)_{r}^{(\text {base })} \frac{m^{(i)}}{m^{(\text {base })}}
\end{aligned}
$$

onde os índices i, corr e base representam, respectivamente, a reação i (RC01D ou $\mathrm{RC} 01 \mathrm{E})$, corrigido e reação base (RC01C).

$\mathrm{Na}$ eq.(7.02) $\mathrm{m}$ representa a massa total do sistema (componentes químicos, reator e sensores). A massa dos reagentes é obtida somando-se as 
massas das Tabelas 7.2 e 7.3, e a massa do reator e dos componentes "secos" foram medidos a parte, obtendo-se um valor aproximado de $16 \mathrm{~kg}$.

É importante lembrar que os valores iniciais corrigidos de $\left(\mathrm{mC}_{\mathrm{p}}\right)_{\mathrm{r}}$ apresentarão um pequeno erro, pois estes valores são calculados a partir das estimativas de um ensaio em batelada no qual os monômeros já estão presentes. Entretanto, como a maior contribuição para o resultado desta variável deve-se aos componentes não-reativos, o erro será pouco significativo. Para os demais ensaios (RC01A, RC01B e RC01F), como as formulações são bastante similares àquela utilizada no ensaio RC01C, não se espera grandes mudanças nos valores de UA e $\left(\mathrm{mC}_{\mathrm{p}}\right)_{\mathrm{r}} \mathrm{e}$, portanto, para estas quatro reações serão utilizadas as estimativas obtidas na reação $\mathrm{RC} 01 \mathrm{C}$.

Os valores corrigidos de UA e $\left(\mathrm{mC}_{\mathrm{p}}\right)_{\mathrm{r}}$ para as reações semicontínuas são apresentados na Tabela 7.7. Na Figura 7.8 os perfis preditos de $T_{r}$, fornecidos pelo balanço de energia usando as estimativas corrigidas apresentadas na Tabela 7.7, são comparados com as medidas experimentais

Tabela 7.7 - UA e $\left(\mathrm{mC}_{\mathrm{p}}\right)_{\mathrm{r}}$ : estimativas corrigidas

\begin{tabular}{cccc|ccc}
\hline Ensaio & \multicolumn{3}{c}{ Carga inicial } & \multicolumn{3}{c}{ Látex } \\
\hline \multirow{2}{*}{ RC01D } & UA & 65,90 & $\mathrm{~J} / \mathrm{K} . \mathrm{s}$ & $\mathrm{UA}$ & 82,51 & $\mathrm{~J} / \mathrm{K} . \mathrm{s}$ \\
& $\left(\mathrm{mC}_{\mathrm{p}}\right)_{\mathrm{r}}$ & 10685,52 & $\mathrm{~J} / \mathrm{K}$ & $\left(\mathrm{mC_{p }}\right)_{\mathrm{r}}$ & 13588,66 & $\mathrm{~J} / \mathrm{K}$ \\
\hline \multirow{2}{*}{$\mathrm{RC01E}$} & $\mathrm{UA}$ & 65,90 & $\mathrm{~J} / \mathrm{K} . \mathrm{s}$ & $\cup A$ & 82,51 & $\mathrm{~J} / \mathrm{K} . \mathrm{s}$ \\
& $\left(\mathrm{mC}_{\mathrm{p}}\right)_{\mathrm{r}}$ & 10685,52 & $\mathrm{~J} / \mathrm{K}$ & $\left(\mathrm{mC}_{\mathrm{p}}\right)_{\mathrm{r}}$ & 13588,66 & $\mathrm{~J} / \mathrm{K}$ \\
\hline
\end{tabular}

Na Figura 7.8 observa-se que a correção das estimativas de UA e $\left(m C_{p}\right)_{r}$ possibilitou boa concordância entre os perfis preditos e as medidas experimentais de temperatura obtidas durante as calibrações realizadas após as reações (Figuras $7.8 \mathrm{~b}$ e $7.8 \mathrm{~d}$ ). Isso ocorre pois os valores finais da viscosidade, da composição do meio reacional e da área de troca térmica das reações semicontínuas são praticamente idênticas a da reação RC01C e, portanto, as medidas de UA e $\left(\mathrm{mC}_{\mathrm{p}}\right)_{\mathrm{r}}$ devem ser, necessariamente, as mesmas para três reações. Por outro lado, comparando as medidas experimentais de temperatura com os valores de $T_{r}$ preditos pelo balanço de energia (Figuras 7.8a e 7.8c), percebe-se que a utilização das estimativas corrigidas de $\mathrm{UA}$ e $\left(\mathrm{mC}_{\mathrm{p}}\right)_{\mathrm{r}}$ para carga inicial causaram uma ligeira piora das predições de temperatura. Uma possível justificativa para a diferença observada entre as duas medidas é a proximidade física entre a resistência elétrica 
e o sensor de temperatura. Como ambos os componentes estão próximos, parte do calor dissipado pela parte não imersa da resistência acaba aquecendo o sensor de temperatura e, portanto, as rampas experimentais de temperatura serão maiores do que as rampas que seriam obtidas caso a resistência estivesse totalmente imersa. Portanto, apesar das estimativas corrigidas da carga inicial aparentemente não fecharem o balanço de energia, os valores apresentados na Tabela 7.7 são fisicamente mais coerentes do que aqueles apresentados na Tabela 7.6 e, portanto, serão os valores utilizados durante as simulações.


Figura 7.8 - Rampas de temperatura experimental e predita (corrigida) para a) carga inicial e b) látex (reação RC01D), c) carga inicial e d) látex (reação RC01E) 


\subsection{Calorimetria em cascata}

Nesta subseção as estimativas de $T_{r}$, UA e $Q_{r}$, fornecidas pelas eqs.(5.83) e (5.95), e as estimativas da conversão global $\left(x_{g}\right)$, da conversão instantânea $\left(x_{\text {inst }}\right)$ e da composição mássica acumulada de acetato de vinila $\left(\mathrm{y}_{\mathrm{A}}\right)$, obtidas pelas eqs.(5.99)-(5.101), são apresentadas e comparadas com os respectivos valores experimentais. Os resultados experimentais de $Q_{r}, y_{A}, x_{g}$ e $x_{i n s t}$ foram calculados a partir dos teores de monômeros residuais fornecidos pela cromatografia gasosa e são representados por pontos discretos. Os resultados preditos são representados por linhas contínuas e foram obtidos implementado as equações da calorimetria em cascata e do balanço de massa em Fortran 90 e utilizando as mesmas formulações apresentadas nas Tabelas 7.1 - 7.4. Os parâmetros de sintonia dos observadores $\mathrm{O}_{1}\left(\theta_{1}\right)$ e $\mathrm{O}_{2}\left(\theta_{2}\right)$ foram obtidos por tentativa e erro e são apresentados nas Tabelas $7.8-7.10$.

Tabela 7.8 - Parâmetros de sintonia $\left(\theta_{1}\right)$ para o observador $\mathrm{O}_{1}$

\begin{tabular}{lccccccc}
\hline \multicolumn{2}{c}{ tempo } & RC01A & RC01B & RC01C & RC01D & RC01E & RC01F \\
\hline $0-5$ & $\min$ & 0,015 & 0,050 & 0,250 & 0,020 & 0,200 & 0,900 \\
$5-10$ & $\min$ & 0,015 & 0,005 & 0,250 & 0,020 & 0,200 & 0,700 \\
$10-15$ & $\mathrm{~min}$ & 0,015 & 0,007 & 0,300 & 0,010 & 0,030 & 0,003 \\
$15-20$ & $\mathrm{~min}$ & 0,015 & 0,010 & 0,300 & 0,010 & 0,030 & 0,003 \\
$20-25$ & $\mathrm{~min}$ & 0,015 & 0,010 & 0,500 & 0,002 & 0,030 & 0,004 \\
$25-30$ & $\mathrm{~min}$ & 0,015 & 0,007 & 0,500 & 0,002 & 0,030 & 0,010 \\
$30-35$ & $\mathrm{~min}$ & 0,015 & 0,020 & 0,500 & 0,002 & 0,009 & 0,015 \\
$35-40$ & $\mathrm{~min}$ & 0,015 & 0,007 & 0,500 & 0,002 & 0,009 & 0,015 \\
$40-50$ & $\mathrm{~min}$ & 0,015 & 0,003 & 0,025 & 0,003 & 0,009 & 0,008 \\
$50-60$ & $\mathrm{~min}$ & 0,015 & 0,003 & 0,025 & 0,0025 & 0,009 & 0,008 \\
$60-70$ & $\mathrm{~min}$ & 0,008 & 0,003 & 0,025 & 0,004 & 0,009 & 0,008 \\
$70-80$ & $\mathrm{~min}$ & 0,008 & 0,002 & 0,025 & 0,004 & 0,008 & 0,008 \\
$80-90$ & $\mathrm{~min}$ & 0,008 & 0,001 & 0,025 & 0,004 & 0,008 & 0,008 \\
$90-100$ & $\mathrm{~min}$ & 0,008 & 0,003 & 0,025 & 0,004 & 0,008 & 0,008 \\
$100-180 \mathrm{~min}$ & 0,008 & 0,003 & 0,020 & 0,008 & 0,008 & 0,009 \\
\hline
\end{tabular}

Tabela 7.9 - Parâmetros de sintonia $\left(\theta_{2}\right)$ para o observador $\mathrm{O}_{2}$

\begin{tabular}{cccc}
\hline Reação & $0-50$ minutos & $50-180$ minutos & $\theta_{2}(\mathrm{t}=180 \mathrm{~min})$ \\
\hline RC01A & $5,0 \times 10^{-8}$ & Variação linear & $6,0 \times 10^{-6}$ \\
RC01B & $5,0 \times 10^{-8}$ & Variação linear & $5,0 \times 10^{-6}$ \\
RC01C & $5,0 \times 10^{-8}$ & Variação linear & $1,0 \times 10^{-5}$ \\
RC01F & $5,0 \times 10^{-8}$ & Variação linear & $8,0 \times 10^{-6}$ \\
\hline
\end{tabular}


Tabela 7.10 - Parâmetros de sintonia $\left(\theta_{2}\right)$ para o observador $\mathrm{O}_{2}$

\begin{tabular}{lcccccc}
\hline Reação & $\begin{array}{c}0-10 \\
\min \end{array}$ & $\begin{array}{c}10-20 \\
\min \end{array}$ & $\begin{array}{c}20-40 \\
\min \end{array}$ & $\begin{array}{c}40-100 \\
\min \end{array}$ & $\begin{array}{c}100-110 \\
\min \end{array}$ & $\begin{array}{c}110-180 \\
\min \end{array}$ \\
\hline RC01D & $5.0 \times 10^{-8}$ & $5.0 \times 10^{-7}$ & $5.0 \times 10^{-6}$ & $4.0 \times 10^{-4}$ & $5.0 \times 10^{-6}$ & $8.0 \times 10^{-7}$ \\
RC01E & $5.0 \times 10^{-8}$ & $5.0 \times 10^{-7}$ & $5.0 \times 10^{-6}$ & $6.0 \times 10^{-4}$ & $5.0 \times 10^{-6}$ & $8.0 \times 10^{-7}$ \\
\hline
\end{tabular}

A Figura 7.9 apresenta uma comparação entre os perfis preditos e as medidas experimentais de $T_{r}$ coletadas durante as reações conduzidas em batelada (Figuras 7.9a - 7.9c), em regime semicontínuo (Figuras 7.9e e 7.9f), e com alimentação intermitente de acrilato de butila (Figura 7.9d). Nessa figura são apresentadas ainda as temperaturas médias da camisa do reator.

Devido à ausência de condensadores e ao sistema de controle on/off do fluido de refrigeração, o controle de temperatura do meio reacional é pouco eficiente causando um aumento abrupto de $T_{r}$ após o início da reação, principalmente, para as reações conduzidas em batelada (Figuras 7.9a - 7.9c). Portanto, de certa forma, durante o período de reação o reator opera sob condições isoperibólicas, uma vez que não são observadas variações acentuadas de $T_{j}$. Dessa forma, a qualidade das estimativas de $Q_{r}$ fornecidas pela calorimetria em cascata (calorimetria de fluxo térmico) é extremamente dependente da precisão das estimativas de UA.

Para reações conduzidas em regime semicontínuo, o segundo aumento abrupto de $T_{r}$ (Figuras 7.9e e 7.9f), próximo aos 100 minutos de reação, é causado pelo aumento da taxa de conversão do acetato de vinila acumulado ao longo do tempo devido ao consumo preferencial do acrilato de butila $\left(r_{A} \ll<r_{B}\right)$.

Após o consumo completo dos monômeros, o reator opera em condições próximas à isotérmica devido à baixa perda térmica para o ambiente. Portanto, nesta região espera-se que as estimativas de UA sejam pouco influenciadas pelo parâmetro de sintonia do observador $O_{1}\left(\theta_{1}\right)$, já que $Q_{r}=0$.

Comparando as medidas experimentais de temperatura com os valores de $T_{r}$ preditos pela calorimetria em cascata (Figura 7.9), percebe-se que os valores estimados são, em geral, mais afetados pelas oscilações de $T_{j}$ do que as medidas experimentais. Isto ocorre, pois as reações foram conduzidas em um reator projetado para suportar uma pressão máxima de 60 bar e, portanto, as hipóteses de fluxo térmico constante e inércia oferecida pela parede à transferência térmica desprezível, adotadas durante a modelagem da taxa de calor transferido do meio reacional à camisa de refrigeração $\left(Q_{\mathrm{j}}\right)$, podem não ser válidas para o reator utilizado 

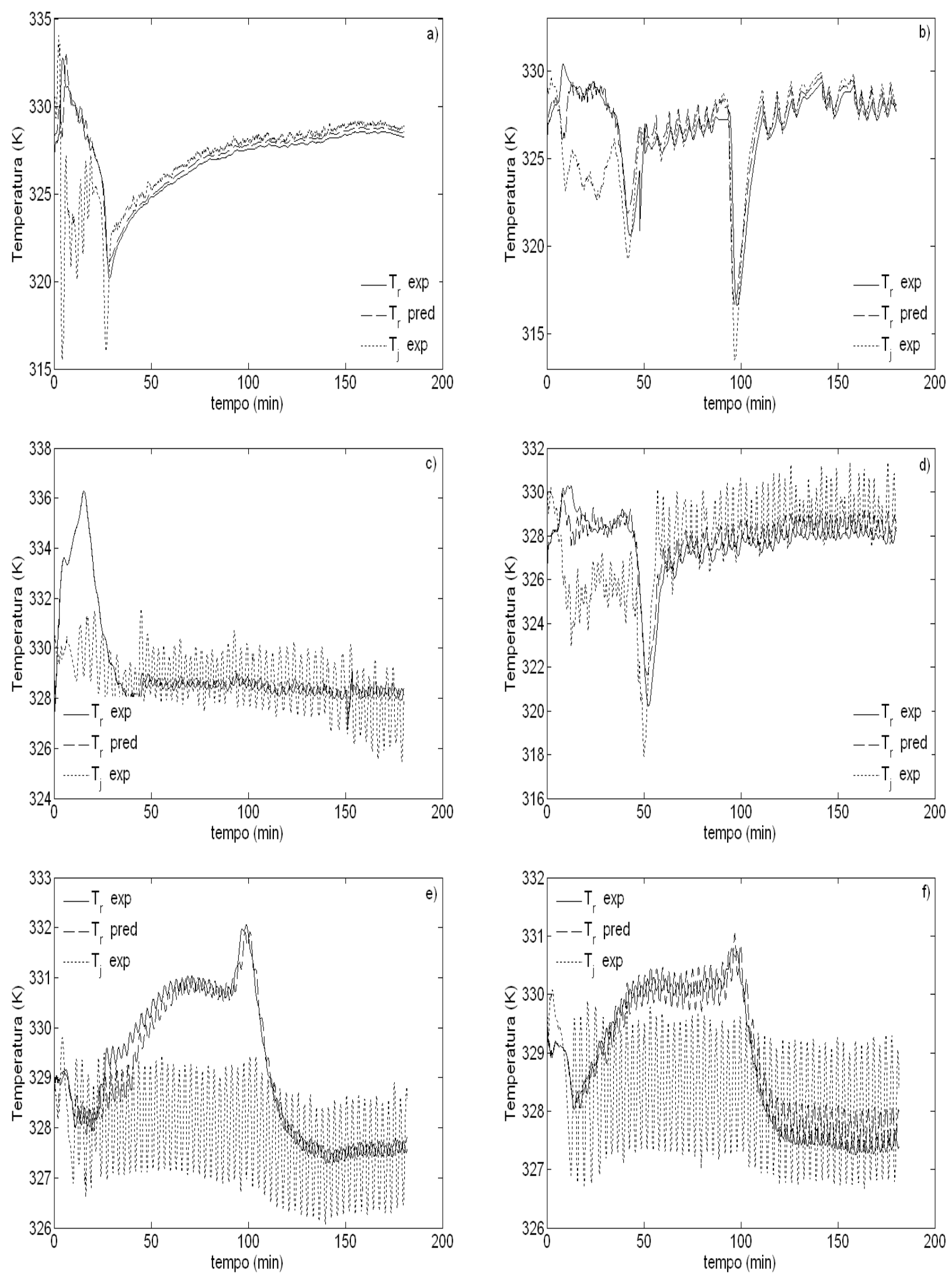

Figura 7.9 - Evolução de $T_{r}$ e $T_{j}$ durante as reações a) RC01A (batelada), b) RC01B (batelada), c) RC01C (batelada), d) RC01F (intermitente), e) RC01D (semicontínuo), f) RC01E (semicontínuo) 
nessa série de reações. Entretanto, a adoção da hipótese de fluxo dinâmico e a inclusão da inércia da parede podem complicar demasiadamente as estimativas de $\mathrm{Q}_{\mathrm{r}}$ devido à introdução de variáveis de difícil mensuração, tais como as temperaturas da superfície interna e externa da parede do reator.

$\mathrm{Na}$ Figura 7.10 as medidas experimentais de $\mathrm{Q}_{\mathrm{r}}$ são comparadas com os resultados preditos fornecidos pela calorimetria em cascata. Na Figura 7.11 são apresentadas as medidas experimentais do número de partículas por grama de látex $\left(\mathrm{N}_{\mathrm{p}}\right)$ calculadas a partir dos diâmetros médios obtidos por difração dinâmica de luz (COULTER N4 PLUS).

Para reações em batelada e com alimentação intermitente, como a massa total de monômeros é toda adicionada já na carga inicial, o calor de reação (Figuras 7.10a - 7.10d) excede a máxima capacidade de remoção térmica do reator causando um brusco aumento da temperatura do meio reacional (Figuras 7.9a 7.9d). Entretanto, observa-se que o aumento de temperatura das reações RC01B e RC01F, durante o período de reação, é menor do que o aumento de temperatura das reações $\mathrm{RC} 01 \mathrm{~A}$ e RC01C. Adicionalmente, durante os primeiros 5 minutos, as temperaturas do primeiro conjunto de reações (Figuras 7.9b e 7.9d) é menor do que a temperatura da camisa, apesar dos dados experimentais de $Q_{r}$ (Figuras 7.10b e 7.10d) indicarem uma taxa de geração de calor muito maior do que aquela observada nas duas outras reações em batelada (Figuras 7.10a e 7.10c). Consequentemente, a calorimetria em cascata não consegue predizer a geração de calor durante os primeiros 5 minutos de reação, uma vez que $T_{r}<T_{j}$. Por outro lado, sabe-se que o aumento ou a presença de um número elevado de partículas de polímero leva a um aumento na taxa de polimerização que, por sua vez, é acompanhada por uma aumento de $\mathrm{Q}_{\mathrm{r}}$. Comparando as Figuras $7.11 \mathrm{a}-7.11 \mathrm{~d}$, observa-se que a concentração de partículas das reações RC01B e RC01F é menor do que a concentração de partículas das reações RC01A e RC01C causado, provavelmente, pela perda de emulsificante durante a inertização da carga inicial ou pela maior taxa de terminação de radicais oligoméricos na fase aquosa. Portanto, o calor de reação inicial das reações $\mathrm{RC01B}$ e RC01F não pode ser maior do que o valor inicial de $Q_{r}$ das reações RC01A e RC01C, explicando o menor aumento de temperatura de ambas as reações. 



Figura 7.10 - Comparação entre os valores preditos e experimentais de $Q_{r}$ das reações a) RC01A (batelada), b) RC01B (batelada), c) RC01C (batelada), d) RC01F (intermitente), e) RC01D (semicontínuo), f) RC01E (semicontínuo) 



Figura 7.11 - Evolução do número de partículas por grama de látex durante as reações a) RC01A (batelada), b) RC01B (batelada), c) RC01C (batelada), d) RC01F (intermitente), e) RC01D (semicontínuo), f) RC01E (semicontínuo) 
Com relação às reações semicontínuas, tanto as medidas experimentais quanto os perfis preditos de $Q_{r}$ (Figuras 7.10e e 7.10f) refletem exatamente os três estágios de uma reação de polimerização em emulsão.

Os primeiros 40 minutos de reação correspondem ao estágio I caracterizado pela nucleação de partículas ( $N_{p}$ elevado - Figuras 7.11e e 7.11 f, e $x_{\text {inst }}<40 \%$ Figuras 7.13 e e 7.13f) e pelo aumento da taxa de polimerização e, portanto, este intervalo de tempo é marcado pelo aumento da temperatura do reator (Figuras 7.9e e 7.9f) e pelo aumento do calor de reação (Figuras 7.10e e 7.10f). Após o consumo de todas as micelas (estágio II), a taxa de polimerização é, aproximadamente, constante e, consequentemente, o intervalo entre 40 - 90 minutos é caracterizado pelo perfil aproximadamente constante de $Q_{r}$ (Figuras 7.10e e 7.10f) e $T_{r}$ (Figuras $7.9 \mathrm{e}$ e $7.11 \mathrm{f}$ ). Ao final do período de alimentação ( $\mathrm{t}>90$ minutos), todo o monômero residual encontra-se, basicamente, dentro das partículas poliméricas onde é totalmente ou parcialmente convertido em polímero. Portanto, os 90 minutos finais de reação correspondem ao estágio III caracterizado pela queda drástica da taxa de polimerização e do calor de reação (Figuras 7.10e e 7.10f) e pelo equilíbrio térmico entre o meio reacional e a camisa (Figuras 7.9e e 7.9f).

Na Figura 7.12 é apresentada a evolução dos perfis preditos do coeficiente global de troca térmica fornecidos pela calorimetria em cascata.

Para reações em batelada (Figuras 7.12a - 7.12c) e com alimentação intermitente (Figura 7.12d), os valores preditos de UA apresentam uma pequena queda, após os 50 minutos iniciais de reação, causada pelo aumento da viscosidade e pela deposição de filme polimérico sobre a parede do reator. Este comportamento está de acordo com as estimativas experimentais de UA obtidas através das calibrações $\left(U A_{\text {inicial }}>U A_{\text {final }}\right)$ (Tabela 7.6). Além disso, esses perfis são bastante similares a alguns perfis de UA em função do teor de sólidos reportados na literatura, como aqueles apresentados por Saenz de Buruaga et al. (1997). Por outro lado, para reações semicontínuas, nota-se que a calorimetria em cascata prediz um perfil crescente de UA apenas para a reação RC01E (Figura 7.12f). Devido ao baixo teor de sólidos dessa série de reações, o efeito do aumento da área de troca térmica deveria ser muito mais acentuado do que o efeito causado pelo aumento da viscosidade do meio reacional e, portanto, esperava-se um contínuo aumento do coeficiente UA, durante a alimentação dos reagentes, seguido por uma ligeira queda ao término do período de alimentação. Vários parâmetros de sintonia $\theta_{1}$ e $\theta_{2}$ foram 



Figura 7.12 - Evolução dos perfis preditos do coeficiente UA durante as reações a) RC01A (batelada), b) RC01B (batelada), c) RC01C (batelada), d) RC01F (intermitente), e) RC01D (semicontínuo), f) RC01E (semicontínuo) 
testados para a reação $\mathrm{RC} 01 \mathrm{D}$, porém nenhum destes parâmetros foram capazes de fornecer estimativas consistentes de UA sem prejudicar as predições das demais variáveis de estado.

$\mathrm{Na}$ Figura 7.13 as medidas de conversão fornecidas pela calorimetria em cascata são comparadas com as medidas experimentais de conversão calculadas a partir dos dados cromatográficos (GC) e a partir dos dados gravimétricos (grav). Como nos ensaios em batelada (Figuras 7.13a - 7.13c) e com alimentação intermitente (Figura 7.13d) a conversão instantânea é idêntica à conversão global essas medidas não são apresentadas nas Figuras 7.13a-7.13d.

Em geral, as medidas experimentais de conversão global cromatográfica $\left(x_{g}\right.$ GC) apresentaram boa concordância com os valores preditos pelo balanço de massa. Para a reação com alimentação intermitente (Figura 7.13d), as oscilações das medidas cromatográficas de conversão global $\left(x_{g} G C\right)$ observadas nos 20 minutos iniciais de reação deve-se, provavelmente, ao aumento no número ou no tamanho das gotas de monômeros causado pela adição intermitente do acrilato de butila e, portanto, as medidas de conversão obtidas via cromatografia gasosa são pouco confiáveis durante este intervalo de tempo. Para reação RC01B (Figura 7.13b) nota-se que a taxa de conversão obtido por cromatografia tende a ser mais lenta do que a taxa de conversão da reação RC01C (Figura 7.13c) obtida pela mesma técnica, apesar de ambos os ensaios apresentarem a mesma formulação. Além disso, flutuações mais acentuadas na concentração de partículas (Figura 7.11b) foram verificadas neste ensaio, e os valores preditos de conversão global tendem a divergir dos valores experimentais após os 40 minutos de reação, pois sendo a taxa de geração de calor muito mais lenta, a temperatura do reator é aproximadamente igual à temperatura da camisa (Figura 7.9b) e, portanto, a calorimetria em cascata não consegue observar adequadamente as flutuações das medidas experimentais de $Q_{r}$ (Figura 7.10b) após esse instante.

Para os ensaios conduzidos em regime semicontínuo (Figuras $7.13 \mathrm{e}$ e 7.13f) observa-se uma baixa conversão global durante os instantes iniciais de reação. A lenta taxa de conversão deve-se à baixa temperatura de set point utilizada nesses ensaios. Com uma temperatura menor, a decomposição térmica do iniciador também será menor e, portanto, menos radicais serão formados. Isto poderia ter 

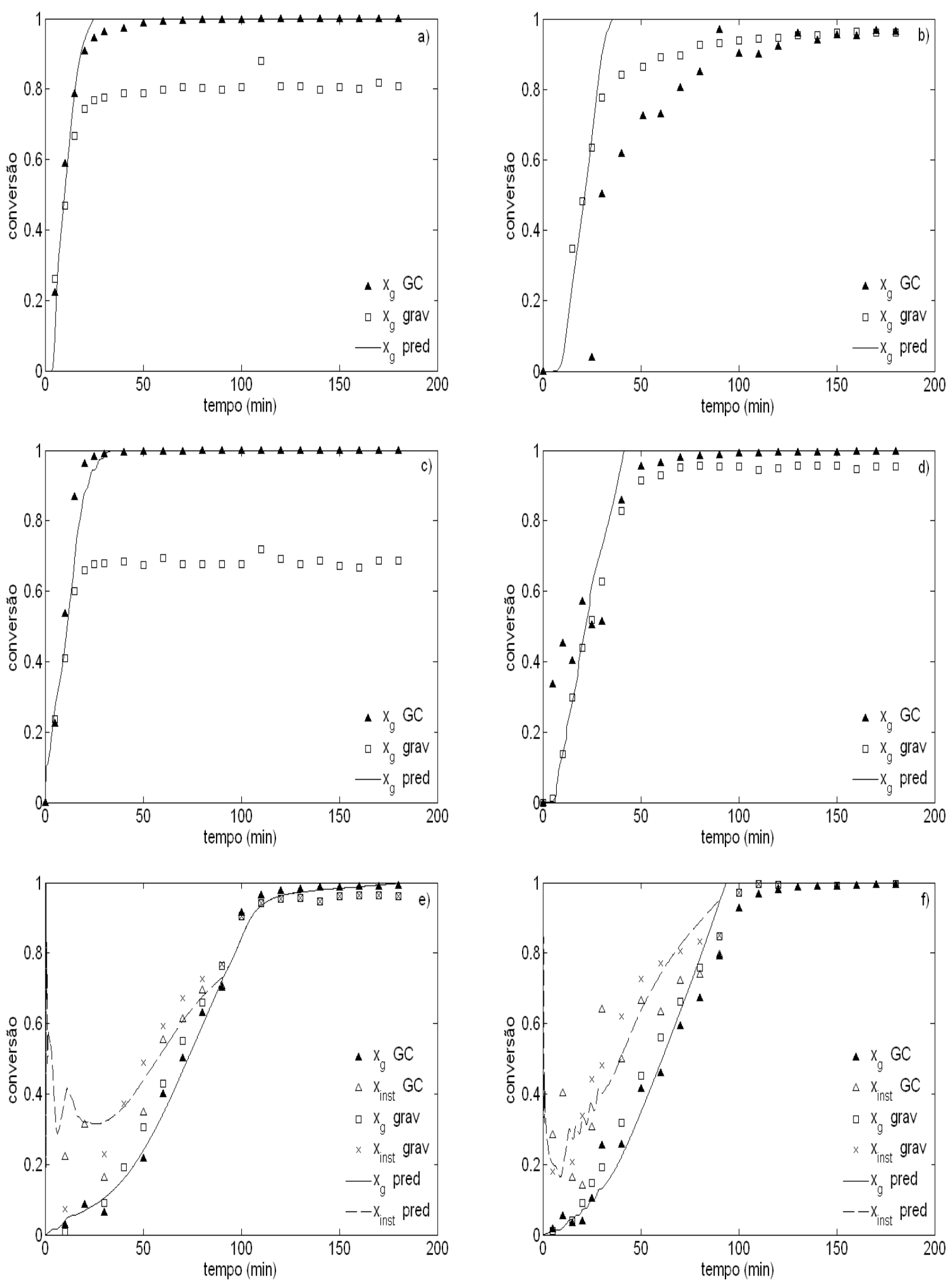

Figura 7.13 - Evolução das conversões preditas, gravimétricas e cromatográficas durante as reações a) RC01A (batelada), b) RC01B (batelada), c) RC01C (batelada), d) RC01F (intermitente), e) RC01D (semicontínuo), f) RC01E (semicontínuo) 
sido evitado utilizando temperaturas mais altas ou um par redox como iniciador. Com relação às conversões instantâneas (Figuras 7.13e e 7.13f), observa-se uma ligeiro desvio entre os valores preditos e experimentais. Isso ocorre, pois a conversão instantânea, ao contrário da conversão global, será muito mais afetada pelas predições das concentrações residuais de monômeros, principalmente, durante os primeiros minutos de reação onde a vazão acumulada ainda é muito baixa. Adicionalmente, a diferença observada entre os valores preditos e experimentais de $X_{\text {inst }}$ pode também ser explicada em função da qualidade das estimativas de $Q_{r}$. Durante os primeiros minutos de reação, como o calor liberado pela reação é muito baixo, as predições de $Q_{r}$ (Figuras 7.10e e 7.10f) ficam muito sujeitas às oscilações de $T_{j}$ causando um descompasso entre as concentrações residuais, experimentais e preditas, de monômeros e, consequentemente, entre as conversões instantâneas.

$\mathrm{Na}$ Figura 7.14 é apresentada uma comparação entre a composição mássica acumulada, calculada em relação ao acetato de vinila $\left(\mathrm{y}_{\mathrm{A}}\right)$ a partir dos dados de monômeros residuais medidos por cromatografia gasosa, e os valores preditos calculados pelo método proposto por Vicente et al (2001).

Observando as Figuras 7.13 e 7.14, nota-se que os mesmos problemas e aspectos verificados nas simulações das conversões ocorrem nas predições dos perfis de composição. Para os ensaios em batelada RC01A e RC01C (Figuras 7.14a e 7.14c) não são observadas grandes diferenças entre as medidas experimentais e preditas de $\mathrm{y}_{\mathrm{A}}$, uma vez que para esse conjunto de reações foi observada excelente concordância entre as medidas experimentais e preditas de $\mathrm{Q}_{\mathrm{r}}$ (Figuras 7.10a e 7.10c) e $x_{g}$ (Figuras 7.13a e 7.13c). Entretanto, para as demais reações (Figuras 7.14b, 7.14d, 7.14e e 7.14f) o método adotado falha na predição da composição no início da reação, porém com o transcorrer do tempo, ambos os resultados são praticamente idênticos.

Para as reações semicontínuas, a dificuldade para estimar as composições iniciais provém das mesmas causas responsáveis pelos problemas encontrados durante a estimação das conversões instantâneas. Para as reações RC01B e RC01F (Figuras 7.14b e 7.14d), os desvios da composição são causados, provavelmente, pelos baixos valores de $Q_{r}$ preditos pela calorimetria em cascata durante os primeiros 5 minutos de reação (Figuras 7.10b e 7.10d).

De um modo geral, grande parte dos problemas encontrados durante a implementação da calorimetria em cascata estão relacionados à correta sintonia do 

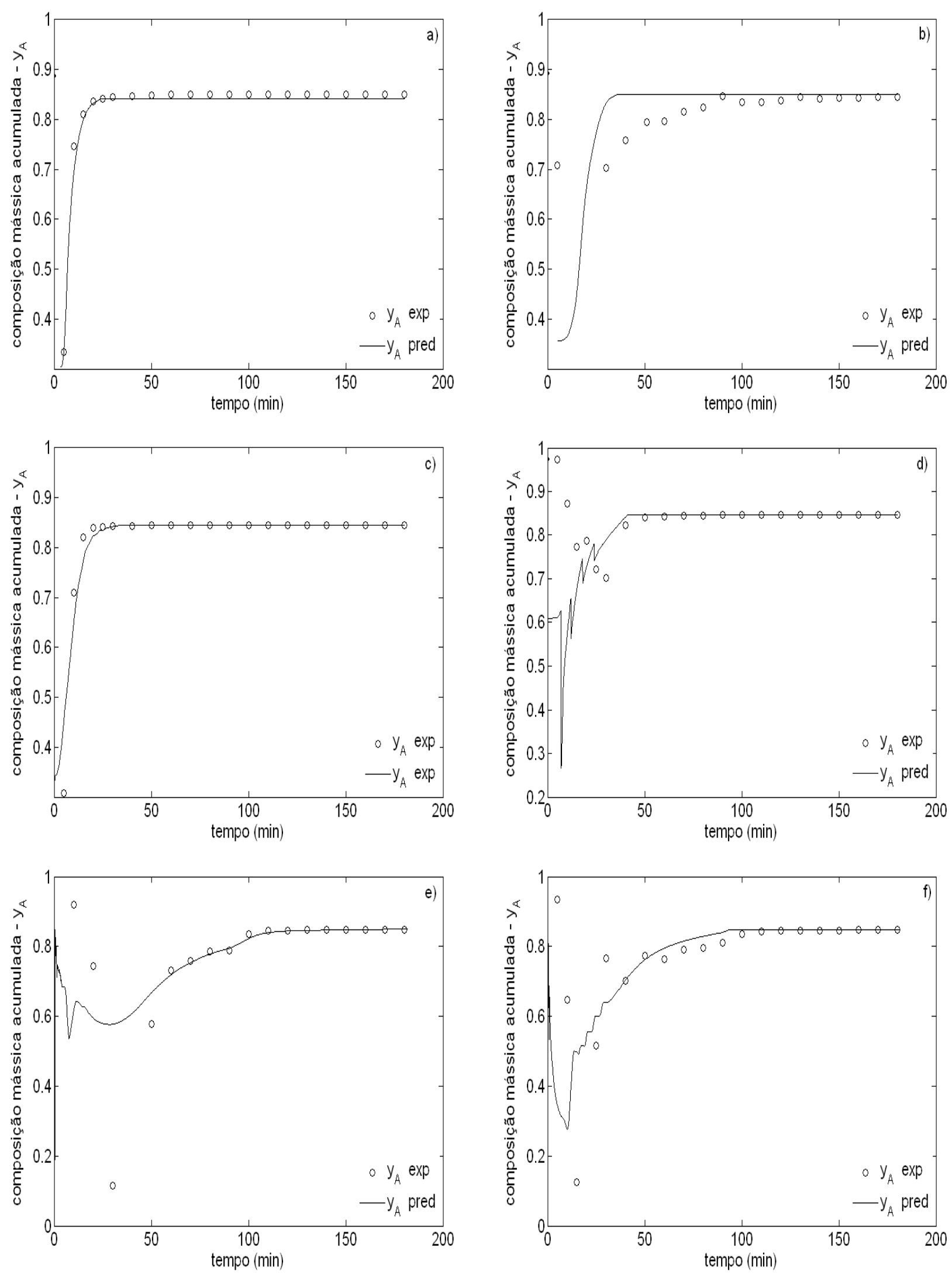

Figura 7.14 - Evolução da composição experimental e predita durante as reações a) RC01A (batelada), b) RC01B (batelada), c) RC01C (batelada), d) RC01F (intermitente), e) RC01D (semicontínuo), f) RC01E (semicontínuo) 
observador $\mathrm{O}_{2}$ para os casos semicontínuos de modo a assegurar a estimação de um perfil de UA fisicamente coerente. A dificuldade de prever a evolução deste coeficiente deve-se ao termo $\left(T_{r}-T_{j}\right)$ que permanece baixo durante boa parte do tempo.

Por estas razões, nas simulações a seguir será feita uma análise do comportamento das variáveis de estado considerando um perfil dinâmico para UA previamente definido (Figura 7.15). O perfil proposto para o coeficiente UA foi obtido usando os valores experimentais apresentados na Tabela 7.7 e supondo que o coeficiente de troca térmica permanece constante após o término das alimentações. A Tabela 7.11 apresenta os novos parâmetros de sintonia para o observador $\mathrm{O}_{1}$, e nas Figuras 7.16 e 7.17 as medidas experimentais de $T_{r}, Q_{r}, x_{g}, x_{i n s t}$ e $y_{A}$ são comparadas com os respectivos perfis preditos.

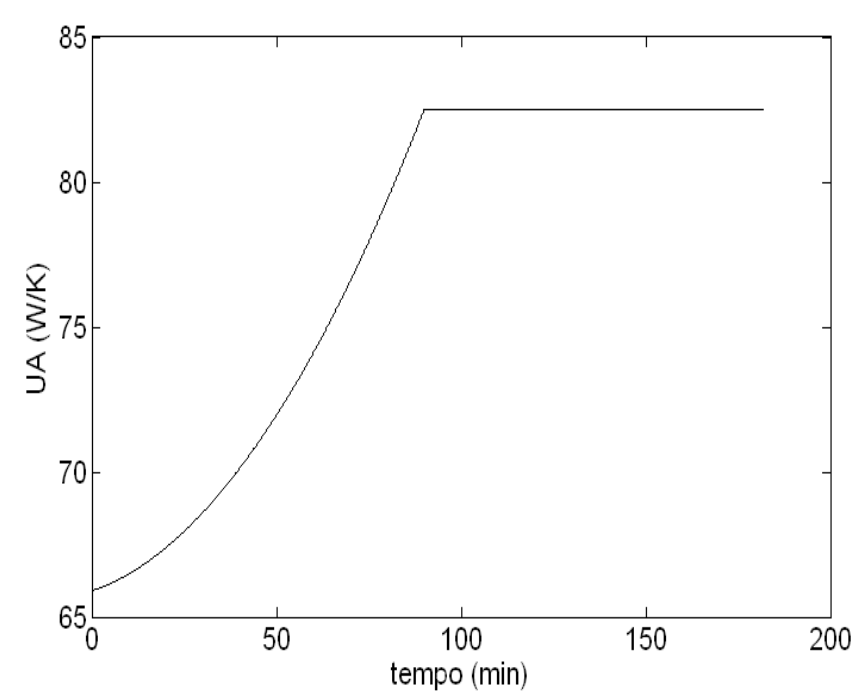

Figura 7.15 - Perfil dinâmico proposto para o coeficiente UA

Tabela 7.11 - Parâmetros de sintonia $\theta_{1}$ / perfil polinomial de UA

\begin{tabular}{llcc}
\hline & tempo & RC01D & RC01E \\
\hline $0-10$ & $\min$ & 0,007 & 0,100 \\
$10-20$ & $\min$ & 0,004 & 0,010 \\
$20-30$ & $\min$ & 0,004 & 0,015 \\
$30-40$ & $\min$ & 0,004 & 0,007 \\
$40-50$ & $\min$ & 0,003 & 0,007 \\
$50-60$ & $\min$ & 0,003 & 0,002 \\
$60-70$ & $\min$ & 0,001 & 0,002 \\
$70-80$ & $\min$ & 0,001 & 0,002 \\
$80-90$ & $\min$ & 0,001 & 0,002 \\
$90-100$ & $\min$ & 0,001 & 0,002 \\
$100-180 \mathrm{~min}$ & 0,010 & 0,008 \\
\hline
\end{tabular}


Comparando os resultados mostrados nas Figuras 7.9e, 7.10e, 7.13e, 7.14e com os resultados apresentados na Fig. 7.16 fica claro que a fixação de um perfil para o coeficiente de troca térmica piorou as estimativas das variáveis desconhecidas da reação RC01D. Isso significa que, neste caso, os valores "reais" de UA (inicial e final) são menores do que os valores apresentados na Tabela 7.7 ou UA não segue um perfil crescente devido, provavelmente, a um acúmulo maior de calor no sistema, justificando os menores valores preditos de $T_{r}$.


Figura 7.16 - Reação RC01D: evolução da a) temperatura, b) calor de reação, c) conversões, e d) composição mássica experimentais e preditas usando um perfil de UA imposto

Para o ensaio RC01E, como esperado, a imposição de um perfil crescente para o coeficiente UA não alterou as estimativas das variáveis desconhecidas 
(Figura 7.17), pois um perfil semelhante também é obtido quando este coeficiente é estimado pelo observador $\mathrm{O}_{2}$. Porém, para que as estimativas não se desviassem muito das medidas experimentais, foi necessário reajustar os parâmetros de sintonia do observador $\mathrm{O}_{1}$ (Tabela 7.11).
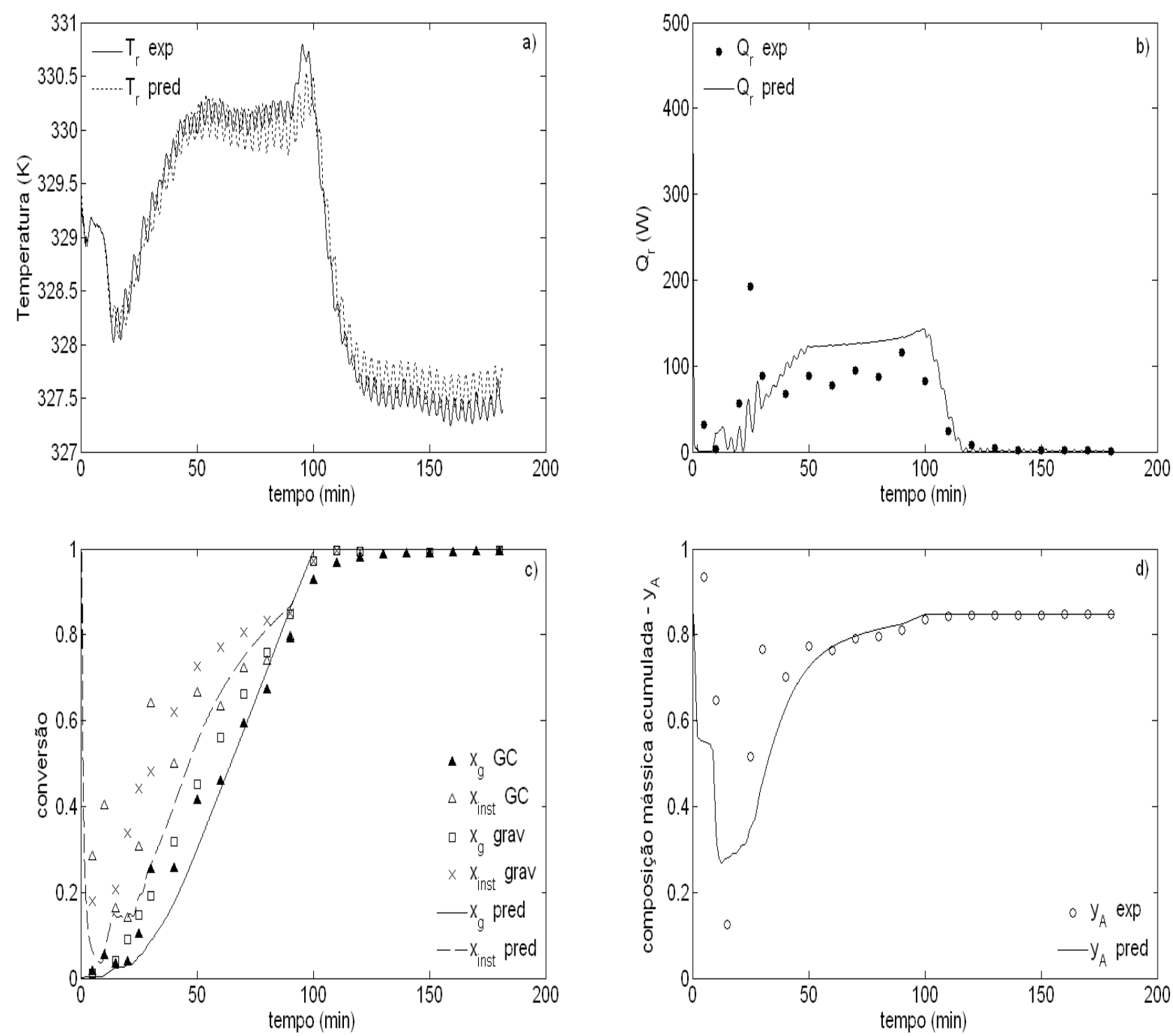

Figura 7.17 - Reação RC01E: evolução da a) temperatura, b) calor de reação, c) conversões, e d) composição mássica experimentais e preditas usando um perfil de UA imposto

Portanto, as comparações entre os dados experimentais e preditos mostraram que:

i) As estimativas fornecidas pela calorimetria em cascata são extremamente dependentes dos parâmetros de sintonia, cujo ajuste é imprescindível para a correta observação das variáveis de estado do processo. Essa 
dependência é inerente ao método e pode ser observada em alguns trabalhos da literatura, incluindo Févotte et al (1998), BenAmor; Colombié e McKenna (2002) e Freire et al. (2004).

ii) As variações aleatórias associadas às variáveis manipuladas do processo como, por exemplo, temperatura da camisa e vazão de alimentação dos reagentes, são indiretamente contabilizadas nos parâmetros de sintonia e, portanto, mesmo que as reações apresentem uma receita base idêntica, os parâmetros de sintonia podem não ser os mesmos.

iii) A calorimetria em cascata requer que o valor inicial do coeficiente UA seja conhecido com boa precisão. Apesar do método utilizado nesse trabalho ter fornecido boas estimativas iniciais de UA, esta abordagem requer um tempo demasiadamente longo ( 90 minutos) inviabilizando a sua utilização em um reator de escala industrial.

iv) A sintonia da calorimetria em cascata, quando aplicada em um caso real, não é uma tarefa simples, pois as variáveis $T_{r}, Q_{r}$ e $U A$ estão intrinsecamente ligadas e, portanto, muitas vezes para a estimação correta de uma ou duas destas variáveis é necessário sacrificar a predição de outra.

A necessidade de ajustes frequentes dos parâmetros de sintonia pode se apresentar como uma desvantagem da utilização da calorimetria em cascata, principalmente, se o objetivo final é a estimação em tempo real das variáveis de estado. Soma-se a isso o fato de não existir um método formal de ajuste baseado apenas nas medidas de saída do observador ou sem que seja necessária a obtenção de amostras ao longo da reação. Entretanto, apesar destas dificuldades, para reatores comuns (não calorimétricos) esta é uma das poucas técnicas existentes para a estimação do calor de reação.

Alguns esforços têm sido dedicados ao desenvolvimento de técnicas para o ajuste dos parâmetros de sintonia de observadores de estado não-lineares de alto ganho. Recentemente, Röbenack (2004) e Röbenack e Lynch (2007) propuseram a utilização da diferenciação automática disponível nos pacotes ADOL-C e TADIFF, ambos para linguagem $\mathrm{C}$, e ADOL (Fortran) para o ajuste dos parâmetros de sintonia desta classe de observadores. Entretanto, a técnica é desenvolvida considerando apenas um sistema de observadores e, portanto, este método talvez 
tenha que sofrer algumas adaptações para sintonizar adequadamente observadores de estado de alto ganho operando em cascata.

Diante do exposto anteriormente e tendo em vista a natureza determinística dos modelos usados na calorimetria em cascata conclui-se que a qualidade das predições são fortemente dependentes dos parâmetros de sintonia e das estimativas iniciais de UA e $\left(m C_{p}\right)$ r. Dessa forma, a seguir serão apresentados os efeitos da presença de variações nos parâmetros de sintonia e de incertezas nos valores experimentais de $\mathrm{UA}$ e $\left(\mathrm{mC}_{\mathrm{p}}\right)_{\mathrm{r}}$ sobre as estimativas fornecidas pela calorimetria em cascata.

\subsection{Calorimetria em cascata - Análise do efeito das incertezas}

Para explorar os efeitos das incertezas dos valores experimentais de UA e $\left(\mathrm{mC}_{\mathrm{p}}\right)_{\mathrm{r}}$ sobre as estimativas da calorimetria em cascata serão analisadas quatro situações hipotéticas utilizando os dados obtidos nos ensaios RC01A (batelada) e RC01E (semicontínuo) e os mesmos parâmetros de sintonia usados durante a simulação da calorimetria em cascata (Tabelas 7.8-7.10):

i) CASO A1: o coeficiente global de troca térmica inicial usado na calorimetria em cascata é $50 \%$ menor do que o coeficiente UA experimental;

ii) CASO A2: o coeficiente global de troca térmica inicial usado na calorimetria em cascata é $50 \%$ maior do que o coeficiente UA experimental;

iii) CASO A3: as medidas, inicial e final, de $\left(\mathrm{mC}_{\mathrm{p}}\right)_{\mathrm{r}}$ usadas na calorimetria em cascata são $50 \%$ menores do que aquelas obtidas experimentalmente;

iv) CASO A4: as medidas, inicial e final, de $\left(\mathrm{mC}_{\mathrm{p}}\right)_{\mathrm{r}}$ usadas na calorimetria em cascata são $50 \%$ maiores do que aquelas obtidas experimentalmente.

As Figuras 7.18 e 7.19 apresentam as curvas de temperatura, calor de reação, coeficiente global de troca térmica, conversão e composição para os casos A1 e A2. 

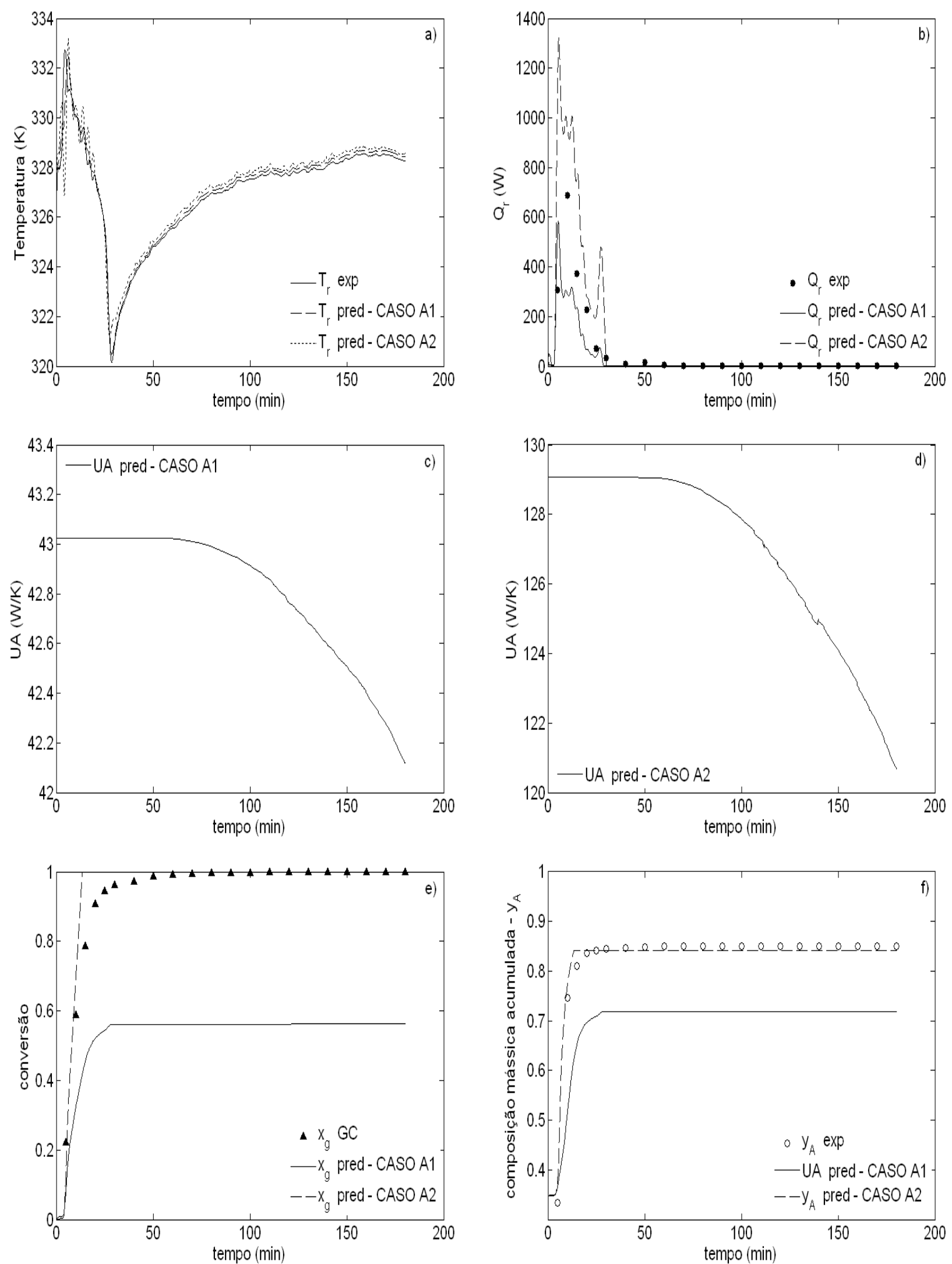

Figura 7.18 - Reação RC01A (batelada): efeito das incertezas de UA sobre as estimativas de a) temperatura, b) calor de reação, c) coeficiente UA (caso A1), d) coeficiente UA (caso A2), e) conversão, f) composição 

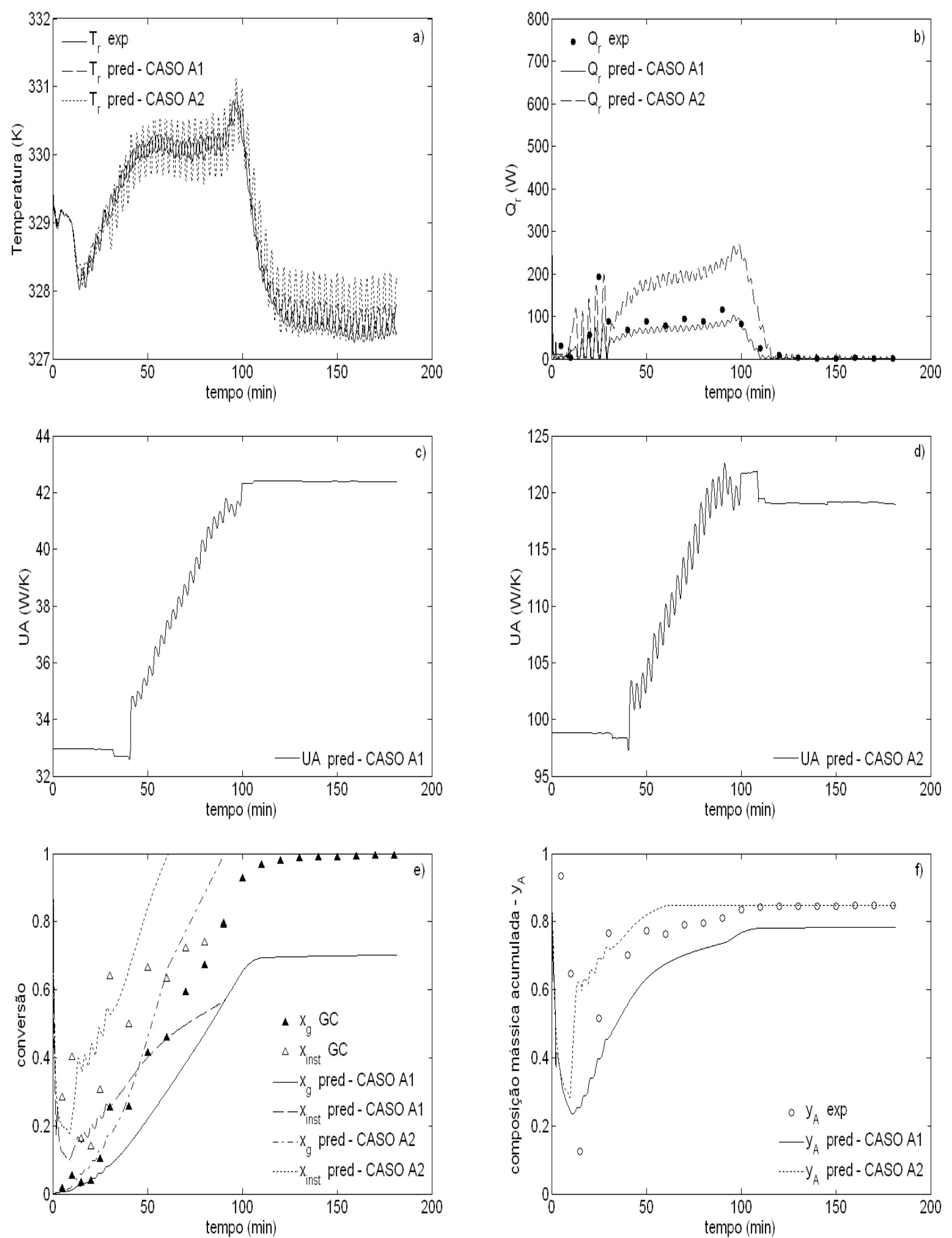

Figura 7.19 - Reação RC01E (semicontínua): efeito das incertezas de UA sobre as estimativas de a) temperatura, b) calor de reação, c) coeficiente UA (caso A1), d) coeficiente UA (caso A2), e) conversão, f) composição 
Nessas figuras verifica-se que o uso de estimativas iniciais de UA incorretas prejudica todas as estimativas das variáveis desconhecidas, principalmente, as estimativas do calor de reação (Figuras 7.18b e 7.19b), da conversão (Figuras 7.18e e 7.19e) e da composição (Figuras 7.18 e $7.19 f$ ). Isto ocorre, pois os parâmetros de sintonia obtidos minimizam a diferença $\left(\hat{T}_{r}-T_{r}\right)$ fornecendo boas estimativas de $T_{r}$ (Figuras 7.18a e 7.19a) e, em contrapartida, predizendo valores de $Q_{r}$ menores, quando o valor inicial de UA é subestimado, ou maiores, quando o valor inicial de UA é superestimado. Este problema poderia ser resolvido reajustando os parâmetros $\theta_{1}$ e $\theta_{2}$ em valores capazes de assegurar a convergência dos perfis preditos de UA para os respectivos valores reais. Porém, não foi possível encontrar tais parâmetros, pois os perfis de UA nesses casos variam ao longo do tempo, ao contrário do observado nas reações de hidrólise do anidrido acético.

Nas Figuras 7.20 e 7.21 são apresentados os perfis de temperatura, do calor de reação, do coeficiente global de troca térmica, da conversão e da composição para os casos A3 e A4. Verifica-se nestas figuras que a presença de erros nos valores experimentais de $\left(\mathrm{mC}_{\mathrm{p}}\right)_{\mathrm{r}}$ afetam muito pouco as predições das variáveis desconhecidas do processo. Um efeito mais acentuado é observado sobre as estimativas do coeficiente global de troca térmica (Figuras 7.20c e 7.21c). Para reações em batelada, como os efeitos das incertezas do parâmetro $\left(\mathrm{mC}_{\mathrm{p}}\right)_{\mathrm{r}}$ sobre o coeficiente UA (Figura 7.20c) ocorrem apenas após a conversão completa dos monômeros, as predições do calor de reação (Figura 7.20b), da conversão (Figura 7.20d) e da composição (Figura 7.20e) serão pouco afetados. Por outro lado, para reações semicontínuas (Figura 7.21), as incertezas no parâmetro $\left(\mathrm{mC}_{\mathrm{p}}\right)_{\mathrm{r}}$ afetam as estimativas do coeficiente UA (Figura 7.21c) já durante o período de alimentação dos monômeros (conversão < 100\%) e, portanto, um desvio uma pouco mais acentuado é observado nas predições de conversão e composição.

Dessa forma, assim como nas reações de hidrólise do anidrido acético, as predições da calorimetria em cascata são mais sensíveis ao coeficiente UA, como era de se esperar, pois este parâmetro aparece multiplicando diretamente a diferença $\left(T_{r}-T_{j}\right)$ no balanço de energia. Entretanto, devido ao seu comportamento variável ao longo da reação, a resintonia dos observadores de estado é muito mais complicada, acentuando a importância das medidas iniciais e finais de UA obtidas durante as calibrações. 

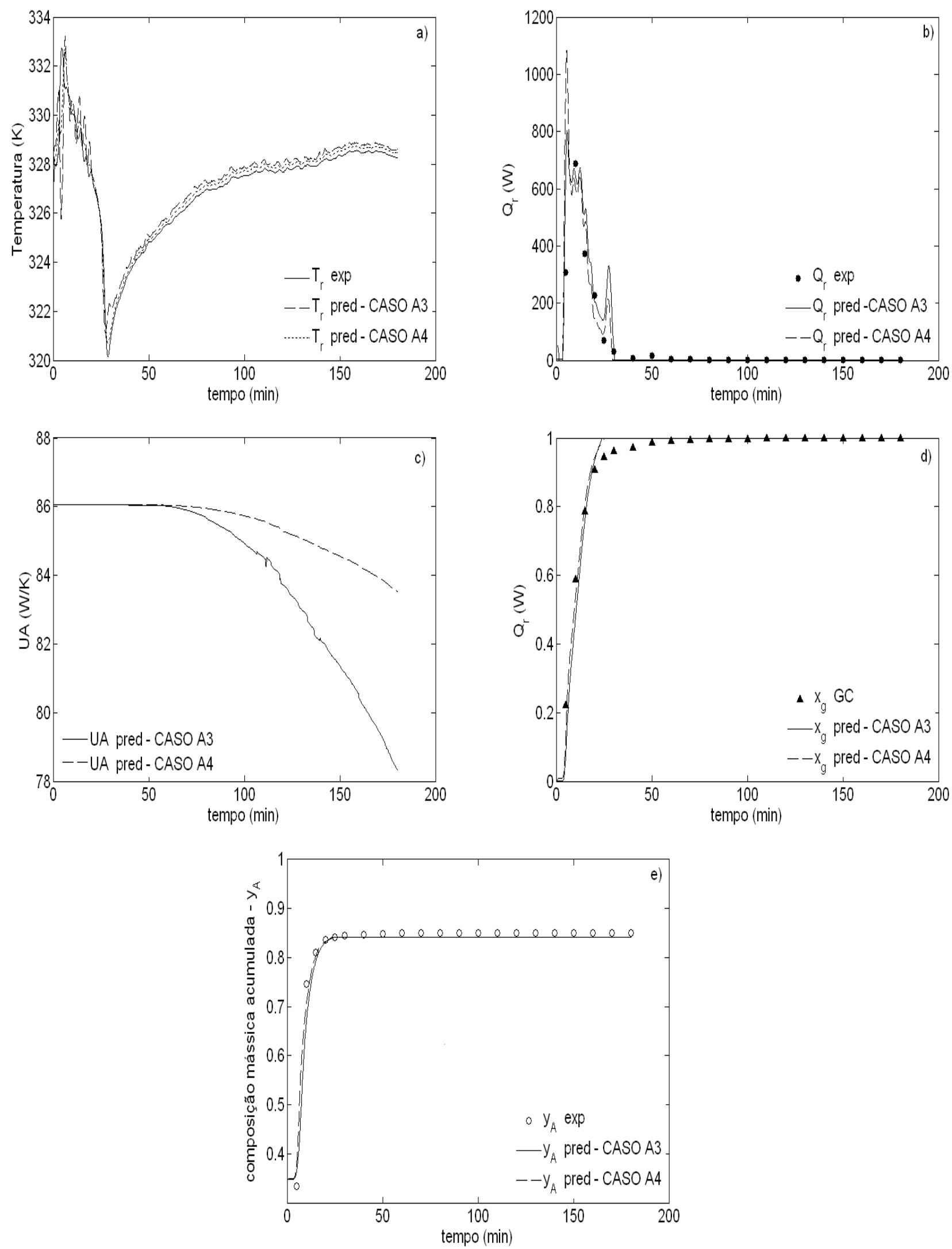

Figura 7.20 - Reação RC01A (batelada): efeito das incertezas de $\left(\mathrm{mC}_{\mathrm{p}}\right)_{\mathrm{r}}$ sobre as estimativas de a) temperatura, b) calor de reação, c) coeficiente global de troca térmica, d) conversão, e) composição 

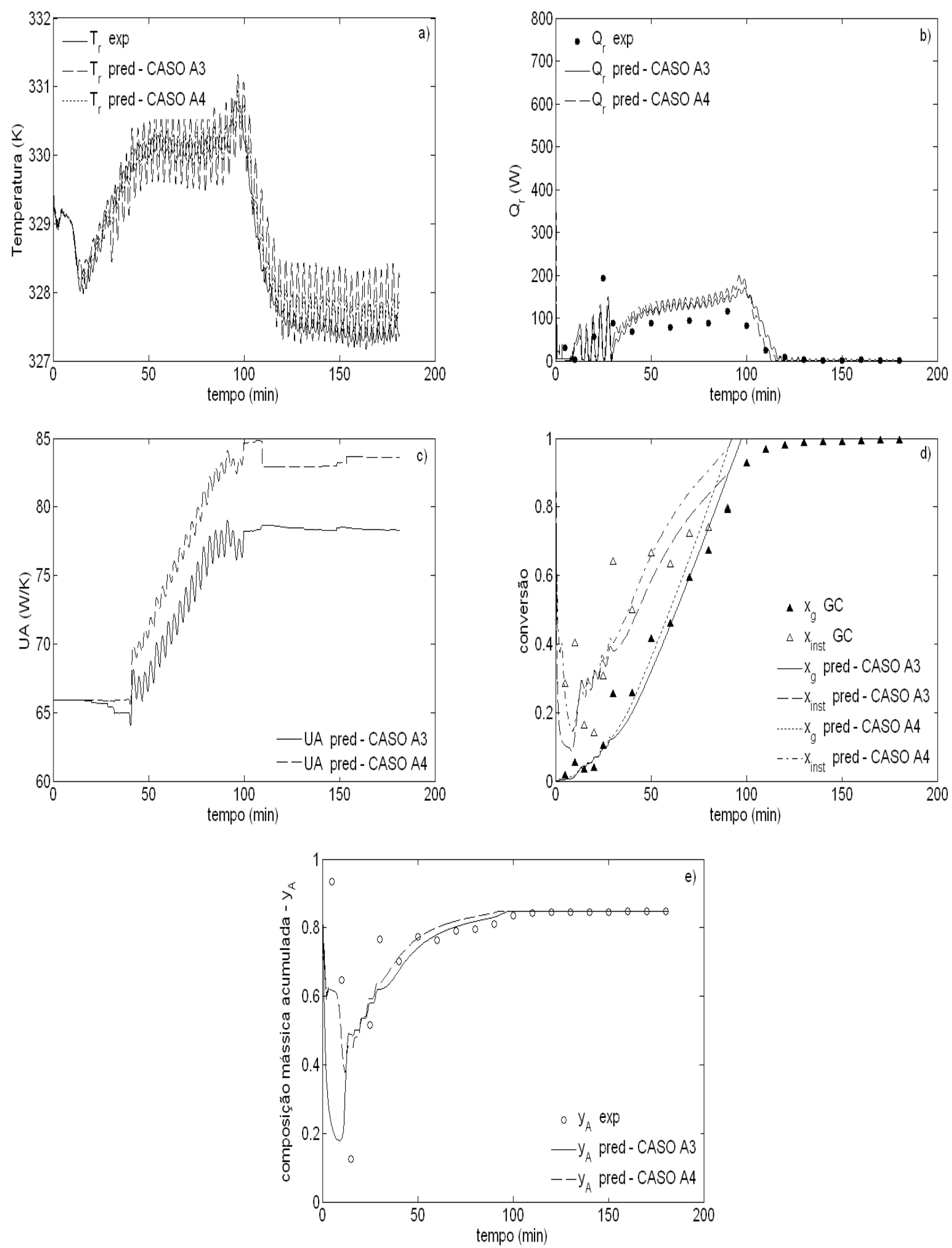

Figura 7.21 - Reação RC01E (semicontínua): efeito das incertezas de $\left(\mathrm{mC}_{\mathrm{p}}\right)_{\mathrm{r}}$ sobre as estimativas de a) temperatura, b) calor de reação, c) coeficiente global de troca térmica, d) conversão, e) composição 
Com relação à sensibilidade das variáveis desconhecidas em relação aos parâmetros de sintonia, também serão analisados quatro casos utilizando os dados obtidos nos ensaios RC01A (batelada) e RC01E (semicontínuo):

i) CASO B1: aumento de $30 \%$ no valor de todos os parâmetros de sintonia do observador $\mathrm{O}_{1}\left(\theta_{1}\right)$;

ii) CASO B2: aumento de $30 \%$ no valor de todos os parâmetros de sintonia do observador $\mathrm{O}_{2}\left(\theta_{2}\right)$;

iii) CASO B3: aumento de $200 \%$ no valor do parâmetro de sintonia $\theta_{1}$ usado no intervalo 10-20 minutos, para reação em batelada, e no intervalo 30-40 minutos, para reação semicontínua;

iv) CASO B4: aumento de $200 \%$ nos valores dos parâmetros de sintonia $\theta_{2}$ usados no intervalo 50-100 minutos, para reação em batelada, e no intervalo 40-100 minutos, para reação semicontínua.

As Figuras 7.22 e 7.23 apresentam as curvas de temperatura, do calor de reação, do coeficiente global de troca térmica, da conversão e da composição para os casos B1 e B2, B3 e B4, respectivamente. Nessas figuras também são apresentados os perfis preditos das variáveis desconhecidas usando os parâmetros de sintonia originalmente obtidos (Tabelas 7.8-7.10) e são identificados pela expressão CASO B0.

De um modo geral, nas Figuras 7.22 e 7.23 observa-se que as predições são pouco sensíveis aos parâmetros de sintonia. Um efeito um pouco mais acentuado é observado sobre as estimativas do coeficiente global de troca térmica (Figuras 7.22c e 7.23c), mesmo quando são alterados apenas os parâmetros de sintonia do observador $\mathrm{O}_{1}$ (casos B1 e B3). Isso significa que, aparentemente, o coeficiente UA é bastante sensível ao sinal de entrada $Q_{r}$, já que pequenas alterações no calor de reação, causadas pela mudança dos parâmetros de sintonia do observador $\mathrm{O}_{1}$, tem como consequência uma resposta mais enérgica por parte do observador $\mathrm{O}_{2}$. Além disso, como as estimativas fornecidas pela calorimetria em cascata no instante $\mathrm{t}-1$ são usadas como sinais de entrada do observador no instante seguinte, uma pequena alteração no valor de $\theta_{1}$, em um determinado intervalo de tempo (CASO B1), irá se propagar em cascata até o final da reação. Este efeito pode ser observado na Figura 7.22c onde se observa um ligeiro desvio do coeficiente UA após o consumo completo dos monômeros $\left(Q_{r}=0\right)$. 

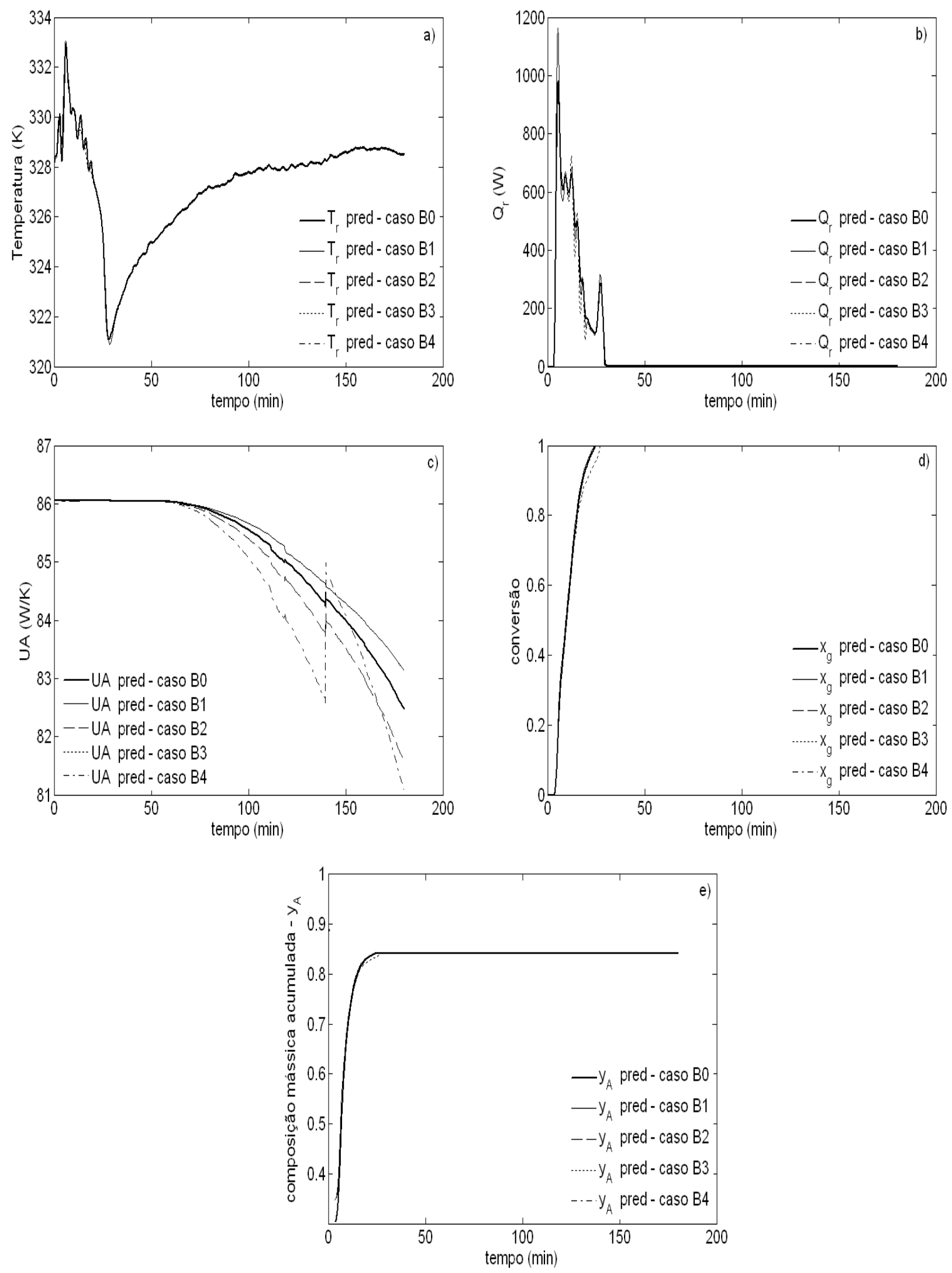

Figura 7.22 - Reação RC01A (batelada): sensibilidade das estimativas de a) temperatura, b) calor de reação, c) coeficiente global de troca térmica, d) conversão, e e) composição com relação aos parâmetros de sintonia 

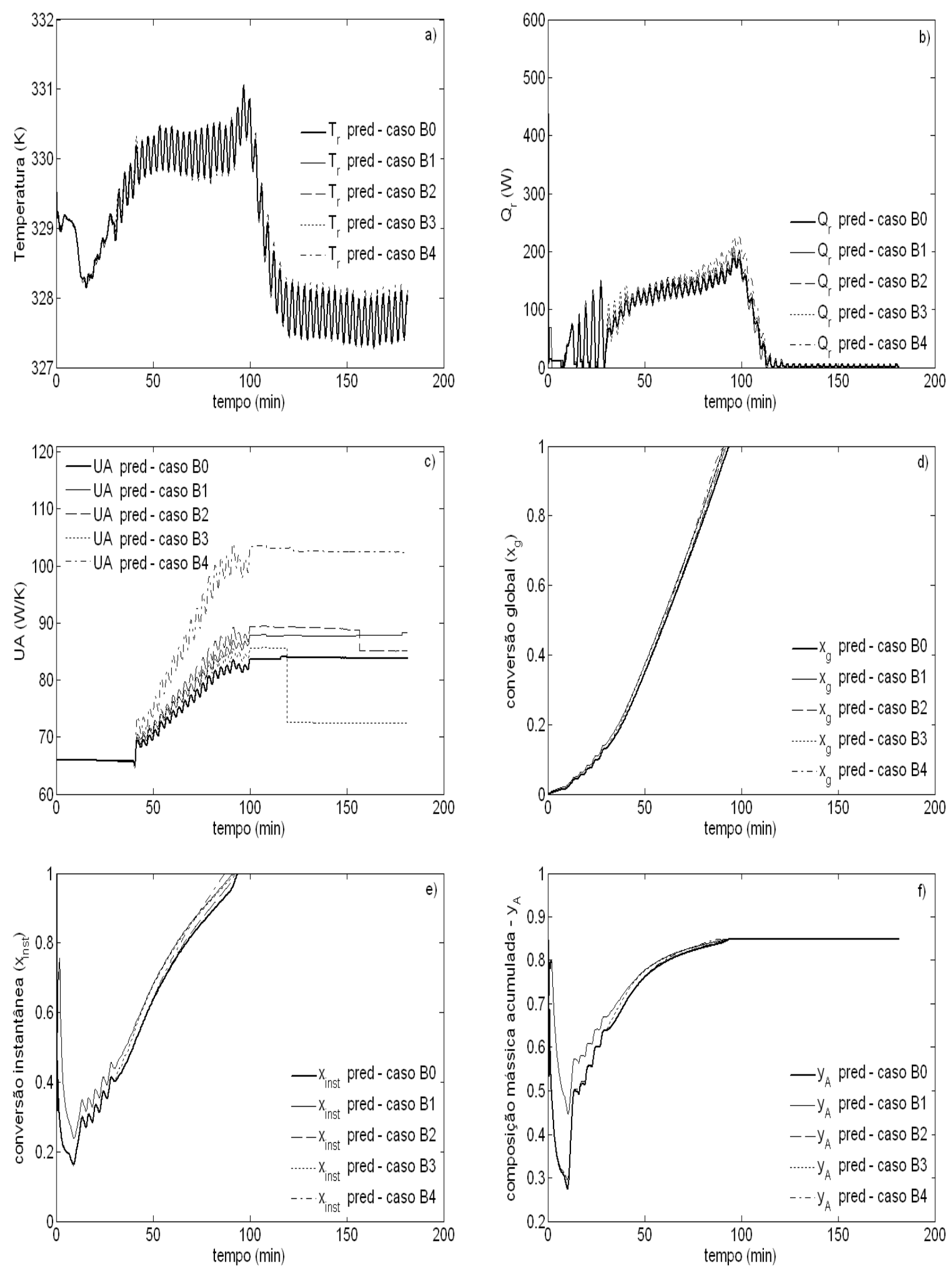

Figura 7.23 - Reação RC01E (semicontínua): sensibilidade das estimativas de a) temperatura, b) calor de reação, c) coeficiente global de troca térmica, d) conversão global, e) conversão instantânea, e f) composição com relação aos parâmetros de sintonia 


\subsection{Estimação de $Q_{r}$ via balanço de energia}

Tendo em vista que um dos principais objetivos da calorimetria é a estimação em tempo real dos estados de um dado processo, a técnica de predição da conversão e da composição baseada na calorimetria em cascata não fornece resultados concretos a respeito da aplicabilidade prática desta técnica devido, em grande parte, a necessidade de ajustes frequentes dos parâmetros de sintonia.

Para contornar este problema, uma alternativa bastante simples é a utilização do próprio balanço térmico do reator (eq. 4.02) para estimar a taxa de geração de calor, desde que os perfis de $Q_{\text {loss }}$ e UA sejam conhecidos. Caso as perdas para o ambiente sejam desprezíveis, o problema da estimativa resume-se em conhecer o perfil de UA. Se $U$ variar pouco durante a reação, uma simples interpolação polinomial entre os valores iniciais e finais de UA pode ser suficiente para descrever o comportamento desta variável ao longo da reação. Entretanto, caso os valores iniciais e finais de UA sejam muito diferentes ou este coeficiente apresente um perfil diferente de um perfil linear, esse método falha e não pode ser usado para a estimação em linha do calor de reação, justificando assim o uso de técnicas de estimação mais sofisticadas ou a atualização temporal de UA através de medidas suplementares coletadas ao longo do processo.

A fim de se obter um perfil de troca térmica o mais realista possível, nesta parte do projeto a evolução de $U$ ao longo da reação é calculada em função do teor de sólidos (eq. 7.03) conforme proposto por Saenz de Buruaga et al. (1997).

$$
U=U_{0}+\left(U_{f}-U_{0}\right) \phi_{p}^{n}
$$

sendo $U_{0}$ e $U_{f}$, respectivamente, o valor inicial e o valor final de $U$ da reação $R C 01 C$ (Tabela 7.6), n um parâmetro ajustável, e $\phi_{p}$ a fração de sólidos do látex onde $\phi_{p}=1$ corresponde ao teor total de sólidos, neste caso a $20 \%$ da massa total.

Devido à indisponibilidade do valor de $U$ para as frações intermediárias de sólidos, na eq.(7.03) o valor de $n(n=1,75)$ foi obtido por tentativa de modo a se chegar a um perfil de $U$ o mais próximo daquele apresentado por Saenz de Buruaga et al. (1997). Este perfil é apresentado na Figura 7.24. 


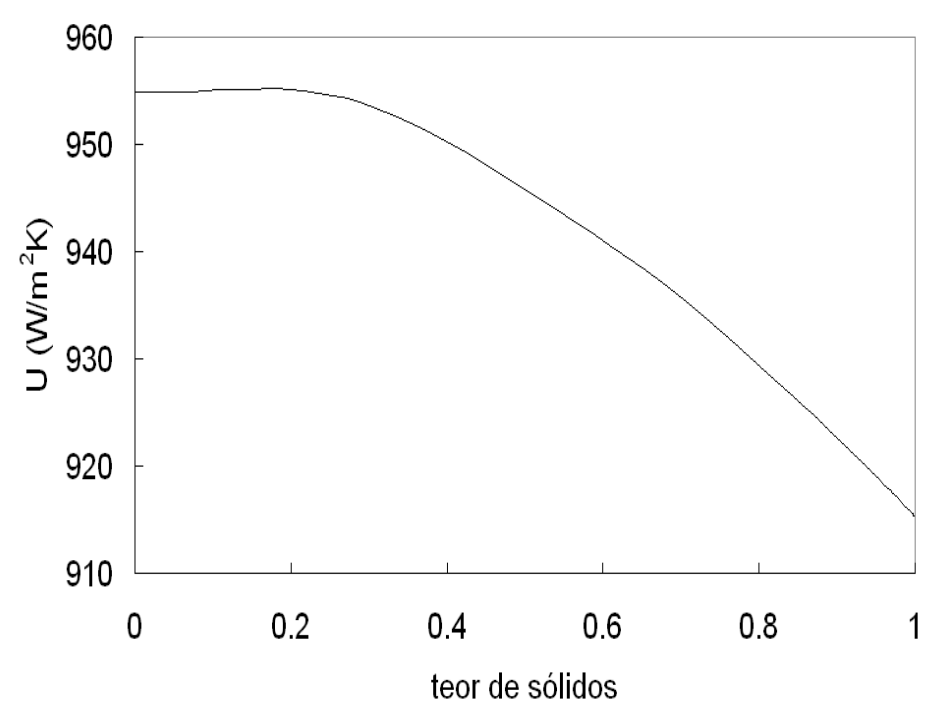

Figura 7.24 - Evolução do coeficiente U em função do teor de sólidos

Para as reações semicontínuas, a variação da área de troca térmica foi calculada levando-se em conta a variação da altura do meio reacional causada pela alimentação dos reagentes. Adicionalmente, para minimizar os efeitos das oscilações das temperaturas (Figuras 7.3 e 7.4) e das alimentações instantâneas sobre as estimativas de $Q_{r}$, estas medidas foram previamente suavizadas pelo filtro Savitzky-Golay usando os valores de $n_{L}$ e $r$ apresentados na Tabela 7.12. As derivadas de temperatura do termo de acúmulo da eq.(4.31) foram calculadas pelo método das diferenças finitas centradas.

Tabela 7.12 - Filtro Savitzky-Golay: parâmetros de suavização

\begin{tabular}{ccccccccc}
\hline \multirow{2}{*}{ Ensaio } & \multicolumn{2}{c}{$\mathrm{T}_{\mathrm{r}}$} & \multicolumn{3}{c}{$\mathrm{T}_{\mathrm{j}}$} & \multicolumn{2}{c}{$\begin{array}{c}\text { Vazão instantânea 1 } \\
\text { monômeros }\end{array}$} & \multicolumn{2}{c}{$\begin{array}{c}\text { Vazão instantânea 2 } \\
\text { solução de iniciador }\end{array}$} \\
& $\mathrm{n}_{\mathrm{L}}$ & $\mathrm{r}$ & $\mathrm{n}_{\mathrm{L}}$ & $\mathrm{r}$ & $\mathrm{n}_{\mathrm{L}}$ & $\mathrm{r}$ & $\mathrm{n}_{\mathrm{L}}$ & $\mathrm{r}$ \\
\hline RC01A & 40 & 0 & 40 & 0 & - & - & - & - \\
RC01C & 50 & 0 & 40 & 0 & - & - & - & - \\
RC01D & 30 & 0 & 40 & 0 & 10 & 0 & 10 & 0 \\
RC01E & 30 & 0 & 40 & 0 & 10 & 0 & 10 & 0 \\
\hline
\end{tabular}

Apesar do aumento do número de pontos usados para computar cada valor filtrado causar uma acentuada perda de informações do sinal (Figura 7.1), neste caso esta suavização excessiva é razoável e não prejudicará a estimação de $\mathrm{Q}_{\mathrm{r}}$ por três motivos. Primeiro, as oscilações de $T_{j}$ não são totalmente repassadas para o meio reacional devido à inércia da parede que, por sua vez, não é levada em conta no balanço de energia. Segundo, devido a essa inércia, as amplitudes das 
oscilações de $T_{r}$ (Figuras 7.3a, 7.3c, 7.3e, 7.4a, 7.4c e 7.4e) são sempre muito menores do que aquelas observadas na camisa. Consequentemente, a diferença ( $T_{r}$ $-T_{j}$ ) tende a apresentar um comportamento oscilatório muito mais acentuado do que aquele que seria observado caso não houvesse o efeito da parede. Terceiro, as oscilações das alimentações instantâneas são causadas pelas oscilações das massas registradas pelas balanças semianalíticas que, por sua vez, são afetadas pela exaustão da capela e, portanto, não apresentam nenhum significado físico.

Nas Figuras 7.25 - 7.28 são apresentadas as predições das conversões (Figuras 7.25c, 7.26c, 7.27c e 7.28c) e das composições mássicas acumuladas (Figuras 7.25d, 7.26d, 7.27d e 7.28d) utilizando as predições de $Q_{r}$ obtidas pelo balanço de energia. Nessas figuras é apresentada ainda a evolução do perfil de UA para cada reação (Figuras 7.25b, 7.26b, 7.27b e 7.28b).

Comparando as predições de conversão e composição, observa-se que estes resultados apresentaram boa concordância com os resultados experimentais. Diferenças um pouco mais significativas são observadas nas estimativas das conversões instantâneas das reações semicontínuas (Figuras 7.27c e 7.28c) e na estimativa da composição mássica acumulada da reação RC01D (Figura 7.27d). Esses desvios ocorrem, pois tanto a conversão instantânea quanto a composição mássica acumulada são mais sensíveis a erros nas estimativas das concentrações residuais de monômeros, conforme citado anteriormente, e que, por sua vez, são fortemente influenciadas pela qualidade da estimativa de $Q_{r}$. Esta hipótese pode ser observada claramente na reação RC01D que apresenta um perfil predito de $Q_{r}$ ligeiramente maior do que o perfil obtido experimentalmente, além de apresentar um comportamento oscilatório mais acentuado do que as predições de $Q_{r}$ das demais reações.

Com relação ao coeficiente global de troca térmica para as reações em batelada, como conversões próximas a 100\% são obtidas logo nos 40 minutos iniciais de reação, o perfil de UA apresenta uma rápida queda durante este intervalo de tempo. Já para reações semicontínuas, como o efeito do aumento da área de troca térmica é muito maior que o descréscimo de $U$, o coeficiente UA apresenta um perfil crescente, durante o período semicontínuo, e um perfil constante após o término das alimentações dos reagentes. 

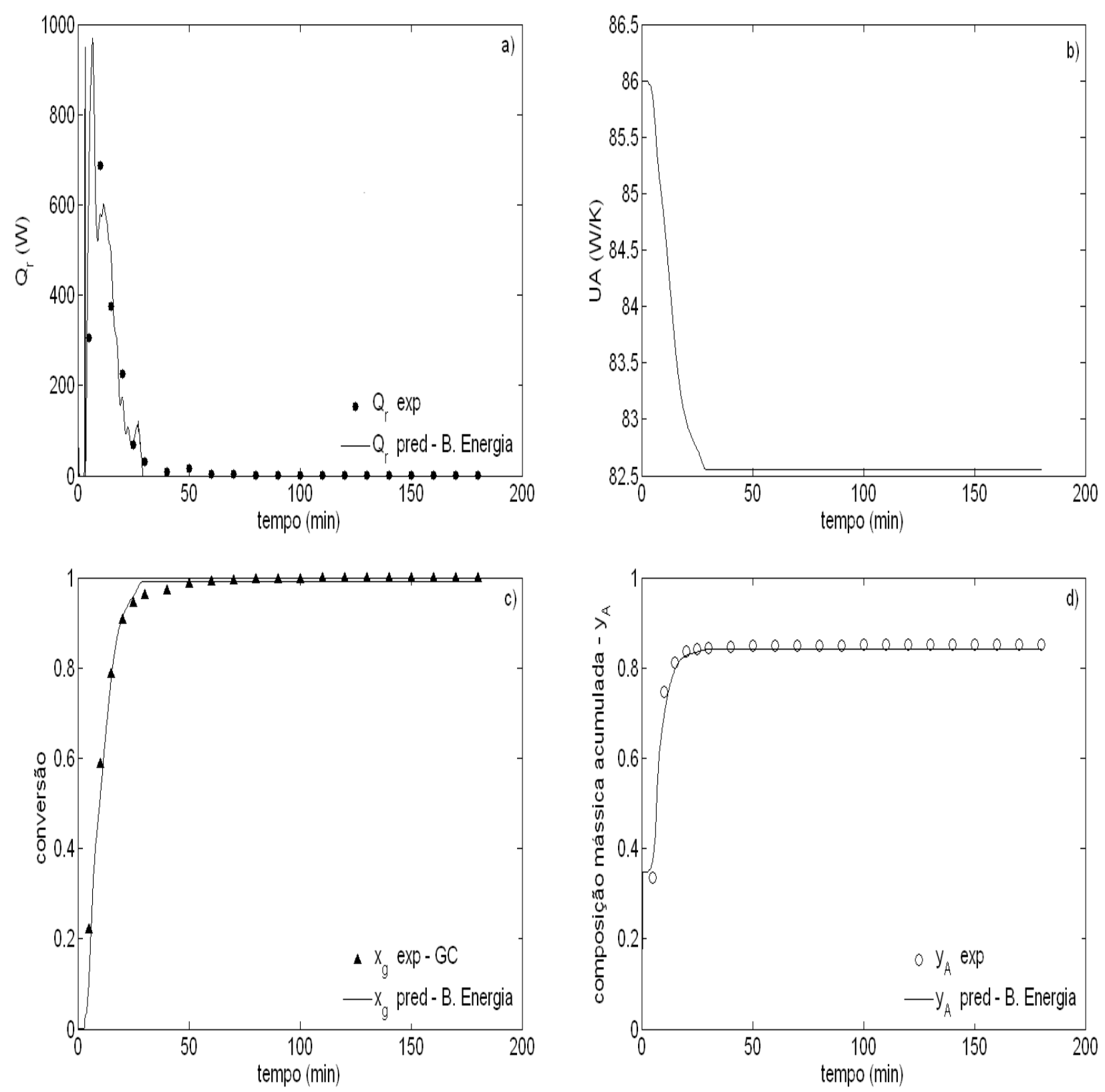

Figura 7.25 - Evolução a) do calor gerado pela reação, b) do coeficiente global de troca térmica, c) da conversão, e d) da composição ao longo da reação RC01A

Por fim, a utilização do balanço de energia para a estimação do calor gerado pela reação mostrou-se como um método bastante interessante e simples para ser implementado em linha, principalmente, pelo fato de não requerer o ajuste de nenhum parâmetro de sintônia.

Apesar das estimativas de $Q_{r}$ terem sido obtidas às custas de uma suavização de $T_{r}$ com diferentes valores de $n_{L}$ (Tabela 7.12), essa característica é menos crítica do que a necessidade de ajustes frequentes dos parâmetros de sintonia, pois o número de pontos usados no filtro pode ser mantido constante ao 
longo da reação. $\mathrm{Na}$ realidade, tanto $\mathrm{o}$ ajuste do parâmetro de sintonia dos observadores em cascata quanto 0 uso de diferentes $n_{L}$ para a suavização de $T_{r}$ aparentemente sugerem que a dinâmica da camisa não pode ser desconsiderada, ou seja, para uma estimação mais precisa de $Q_{r}$ é necessário obter um modelo mais completo no qual seja incluído a dinâmica da camisa, os efeitos da parede e os efeitos do controlador sobre as temperaturas.
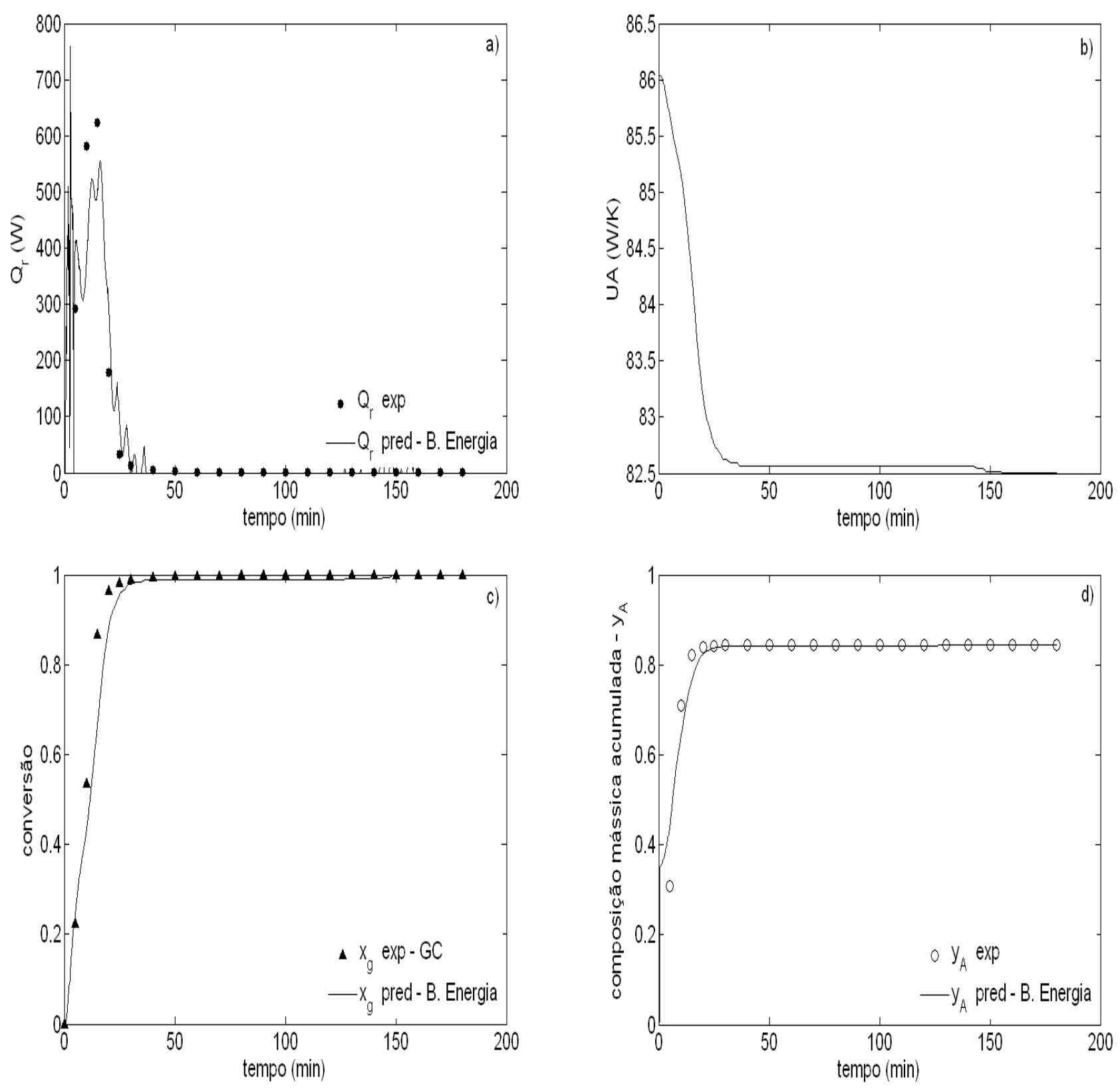

Figura 7.26 - Evolução a) do calor gerado pela reação, b) do coeficiente global de troca térmica, c) da conversão, e d) da composição ao longo da reação $\mathrm{RC01C}$ 

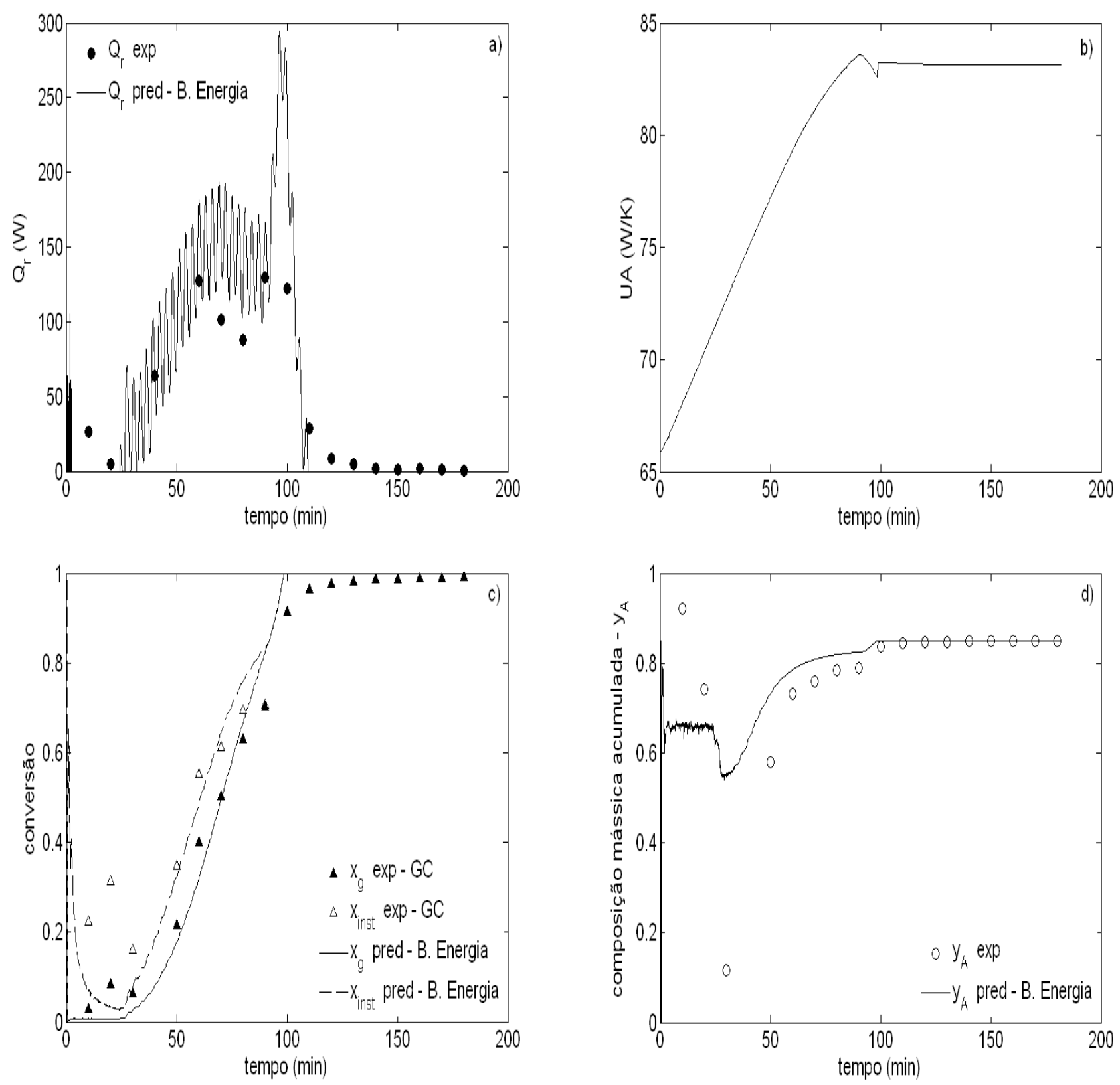

Figura 7.27 - Evolução a) do calor gerado pela reação, b) do coeficiente global de troca térmica, c) das conversões, e d) da composição ao longo da reação RC01D 



Figura 7.28 - Evolução a) do calor gerado pela reação, b) do coeficiente global de troca térmica, c) das conversões, e d) da composição ao longo da reação RC01E

\subsection{Remoção de distúrbios e predição em linha dos estados}

A remoção dos distúrbios das medidas de temperatura e os resultados preditos das variáveis desconhecidas apresentadas nas seções anteriores foram obtidos através de simulações realizadas após as reações (off line). Entretanto, a calorimetria, assim como algumas técnicas analíticas como, por exemplo, a 
espectroscopia de infravermelho, tem sua existência condicionada à possibilidade de estimação e controle em tempo real das propriedades poliméricas ou da antecipação dos fenômenos térmicos que possam comprometer a segurança do processo. Portanto, o programa utilizado durante as simulações anteriores foi adaptado para que tanto a remoção dos distúrbios quanto a predição das variáveis desconhecidas sejam obtidas em linha e levando em conta que algumas informações disponíveis durante as simulações off line somente estarão disponíveis após um dado intervalo de tempo. Adicionalmente, o programa foi implementado da forma mais genérica possível para permitir a utilização de outros valores de $n_{L}, n_{R}$ e $r$ para o filtro Savitzky-Golay, a especificação do diretório onde será salvo o arquivo contendo os resultados da simulação / monitoramento e a especificação do diretório e do arquivo onde o programa de controle do reator registra os dados coletados do processo. As principais mudanças introduzidas no programa são listadas a seguir:

i) Uso dos recursos e funções do Win32 API do Fortran, disponíveis nos módulos DFWIN, DFWINTY e DFLOGM, para a criação de programas com interface gráfica.

ii) Utilização da função GETTIM do módulo DFLIB para leitura da hora registrada pelo computador. Usando os valores retornados por essa função é possível sincronizar a leitura dos dados coletados do processo com o intervalo de tempo configurado para a aquisição destes dados. Além disso, como durante um monitoramento em tempo real o número dados registrados varia a cada instante, foi utilizado um laço indeterminado, cujo fim é controlado pela função READ do Fortran. A seguir é apresentado o trecho do código descrito nesse item: 


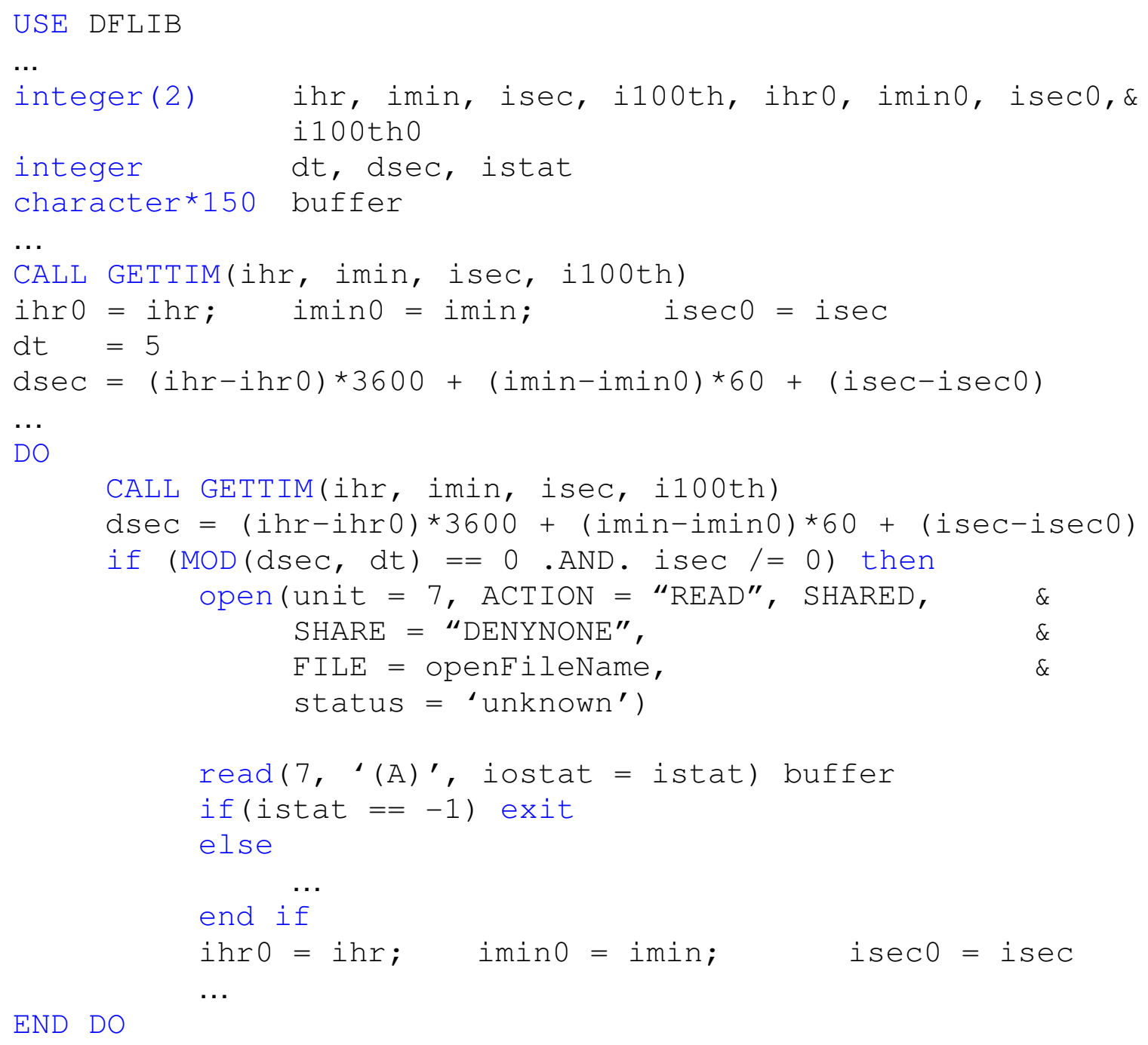

No trecho acima dt é o tempo de aquisição (em segundos) dos dados do processo pelo programa de controle do reator. A função MOD retorna o resto da divisão entre dois números, ou seja, a cada múltiplo de dt o programa irá abrir e ler o arquivo de dados experimentais. Como este arquivo é utilizado simultaneamente por dois programas, é utilizado a declaração SHARED na função OPEN para indicar a condição de compartilhamento do arquivo, e SHARE = "DENYNONE" para indicar que o compartilhamento é completo, ou seja, ambos os programas podem tanto ler quanto escrever no arquivo compartilhado. Se durante a leitura o programa atingir a última linha (fim do arquivo), o parâmetro IOSTAT é alterado de 0 para -1 encerrando o monitoramento. Esse recurso será importante caso o programa seja usado futuramente para o controle da composição do copolímero, pois nesse caso o 
tempo total da reação não é conhecido a priori, já que o tempo dependerá da massa total de monômero a ser alimentada e das vazões de alimentação que, por sua vez, são determinadas em linha pelo modelo de controle da composição.

iii) Utilização de alocação dinâmica das variáveis indexadas na subrotina responsável pela remoção dos distúrbios das medidas de temperatura. Esse recurso é utilizado, pois a quantidade de pontos experimentais é alterada a cada intervalo de tempo dt e, portanto, o vetores utilizados nessa subrotina devem ter seus índices determinados a cada chamada da subrotina. O trecho do programa descrito nesse item é apresentado a seguir:

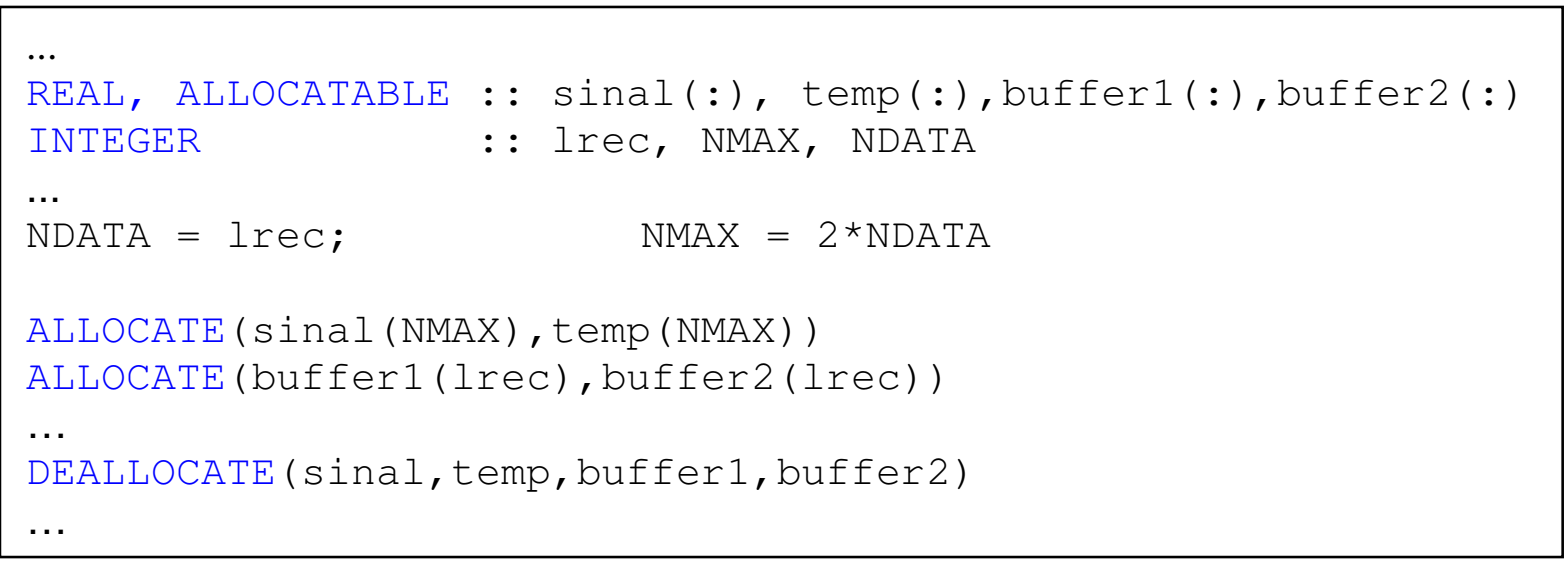

No trecho acima, o parâmetro Irec passa para a subrotina o número total de dados experimentais disponíveis no instante t. Esse valor é usado para o dimensionamento dos vetores sinal, temp, buffer1 e buffer2. Os dois últimos vetores (buffer1 e buffer2) são utilizados para o armazenamento temporário das medidas de $T_{r}$ e $T_{j}$. O vetor sinal recebe os valores de $T_{r}$ ou $T_{j}$, dependendo de qual temperatura será tratada naquele instante, e também armazena as medidas já filtradas e, por isso, é dimensionada com o dobro do tamanho de Irec.

iv) Utilização da função GetCurrentDirectory, do módulo DFWIN, e da função CHANGEDIRRQQ do módulo DFLIB. O comando GetCurrentDirectory busca o diretório onde o programa foi gravado e busca $\circ$ arquivo executável responsável por todos os cálculos e que irá rodar em paralelo ao programa principal. A função CHANGEDIRRQQ é responsável pela mudança do diretório de onde é feito a leitura dos dados experimentais para o diretório onde serão gravados os resultados preditos. 
Na Figura 7.29 é apresentada a janela do programa principal onde serão ingressadas todas as informações necessárias para o início do monitoramento em linha via calorimetria em cascata.

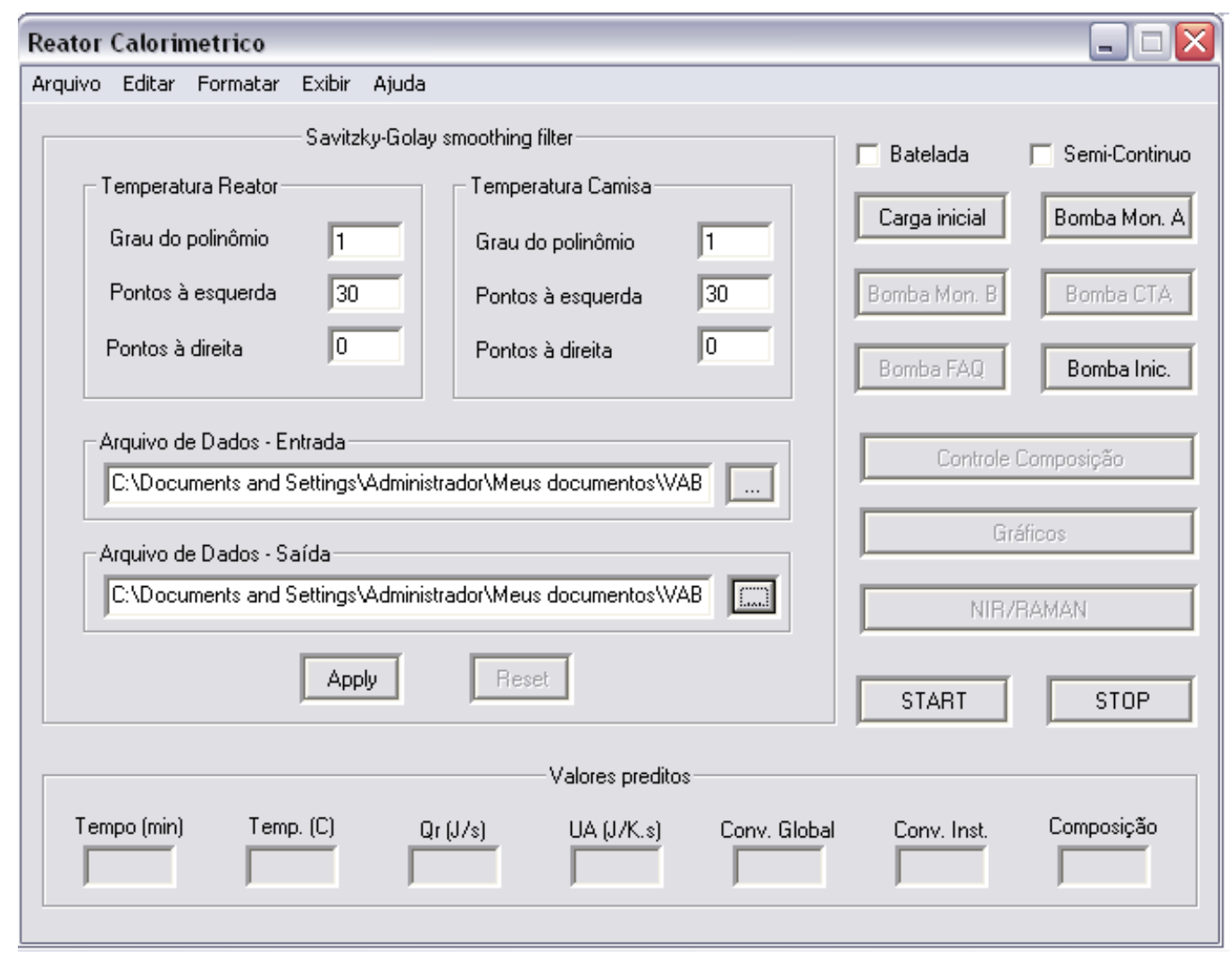

Figura 7.29 - Programa principal para monitoramento em linha

Nos campos à esquerda são definidos o grau do polinômio (r), o número de pontos à esquerda $\left(n_{L}\right)$ e o número de pontos à direita $\left(n_{R}\right)$ utilizados para a remoção dos distúrbios presentes nas medidas de temperatura. Como o programa tem por objetivo simular um monitoramento em tempo real das variáveis de estado, o parâmetro $n_{R}$ é fixado em 0 , pois o uso de pontos futuros causará um atraso nas predições e, portanto, os estados estimados em um determinado instante não corresponderão mais ao estado atual. Dessa forma, a filtragem das medidas de temperatura inicia-se apenas após o $\mathrm{n}_{\mathrm{L}}$-ésimo +1 ponto. Antes desse instante, as predições são feitas utilizando as medidas de temperatura in natura. Logo abaixo do campo onde são definidos os parâmetros do filtro Savitzky-Golay, são definidos o caminho e o nome dos arquivos onde serão gravados o resultados preditos e onde as medidas experimentais são registradas. Neste último caso, como o arquivo de 
entrada é criado pelo programa de controle do reator apenas após a etapa de préaquecimento, este campo poderá somente ser preenchido após o início da reação.

Para verificar a capacidade do programa monitorar em tempo real sem a necessidade de realizar vários ensaios experimentais, implementou-se um "simulador" usando os mesmos recursos apresentados no item ii). Neste caso, o simulador apenas lê o arquivo de dados original e gera um outro arquivo idêntico e com a mesma frequência de amostragem ( $\mathrm{dt}=5$ segundos) com que os dados do arquivo original foram obtidos. A validade do programa foi verificada utilizando os dados obtidos nos ensaios RC01A (batelada) e RC01E (semicontínuo).

$\mathrm{Na}$ Figura 7.30 as medidas de temperatura dos ensaios RC01A (Figuras7.30a e 7.30b) e RC01E (Figuras 7.30c e 7.30d) filtradas em linha são comparadas com as respostas obtidas pela simulação off line. Verifica-se nesta figura que os resultados obtidos por ambos os métodos são idênticos.
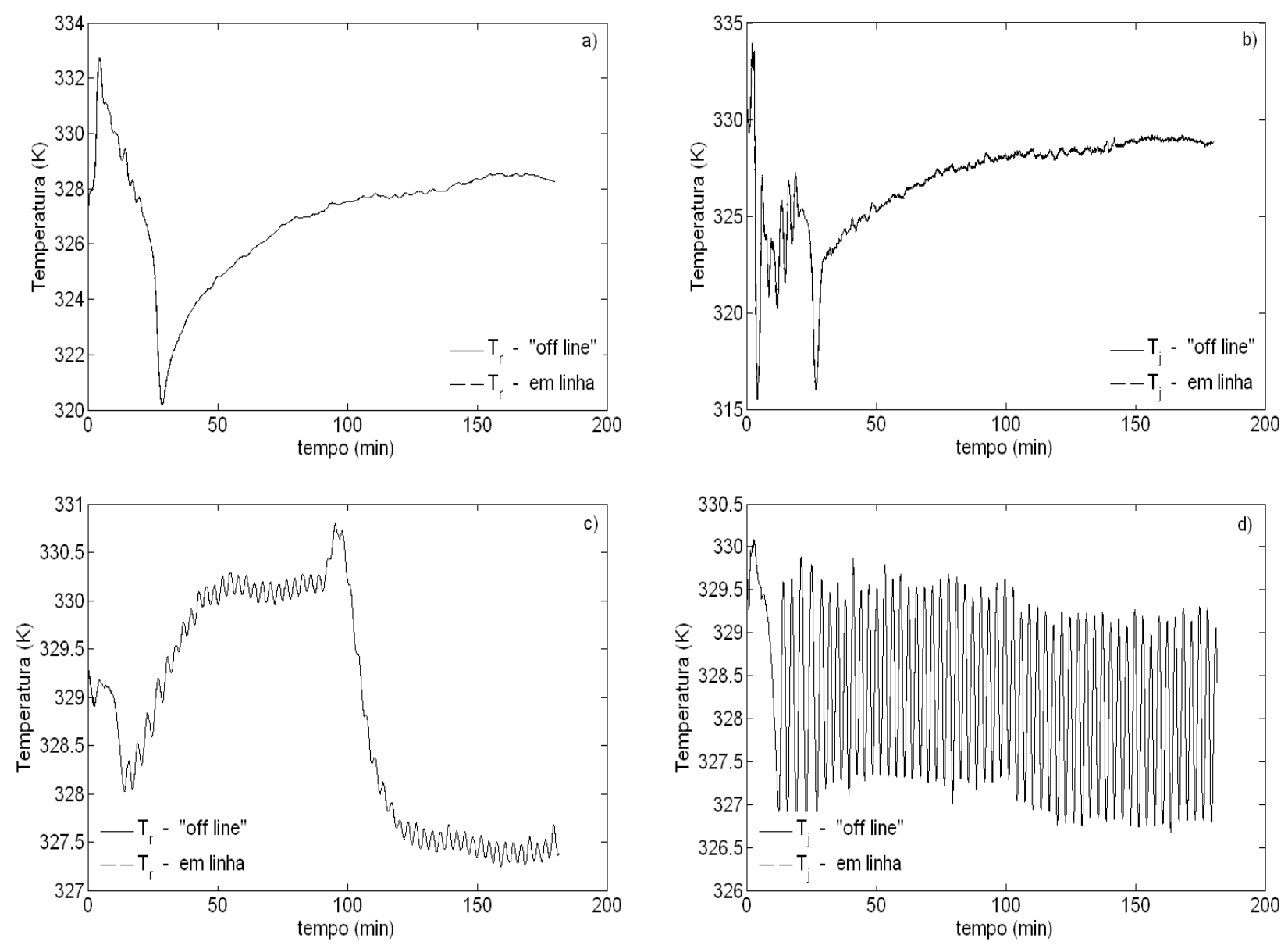

Figura 7.30 - Comparação entre as temperaturas do a) reator e b) camisa da reação $\mathrm{RC01A}$ e c) reator e d) camisa da reação RC01E filtradas em linha e e por simulações off line 
Nas Figuras 7.31 e 7.32 as predições em linha do calor de reação, do coeficiente global de troca térmica, da conversão e da composição das reações RC01A (Figura 7.31) e RC01E (Figura 7.32) são comparadas com os perfis obtidos durante as simulações off line e com os respectivos valores experimentais. Como nas reações em batelada, a conversão instantânea é idêntica à conversão global, essas medidas não serão apresentadas na Figura 7.31c.


Figura 7.31 - Reação RC01A: a) calor de reação, b) coeficiente global de troca térmica, c) conversão e d) composição experimentais e preditos em linha e através de simulações off line 

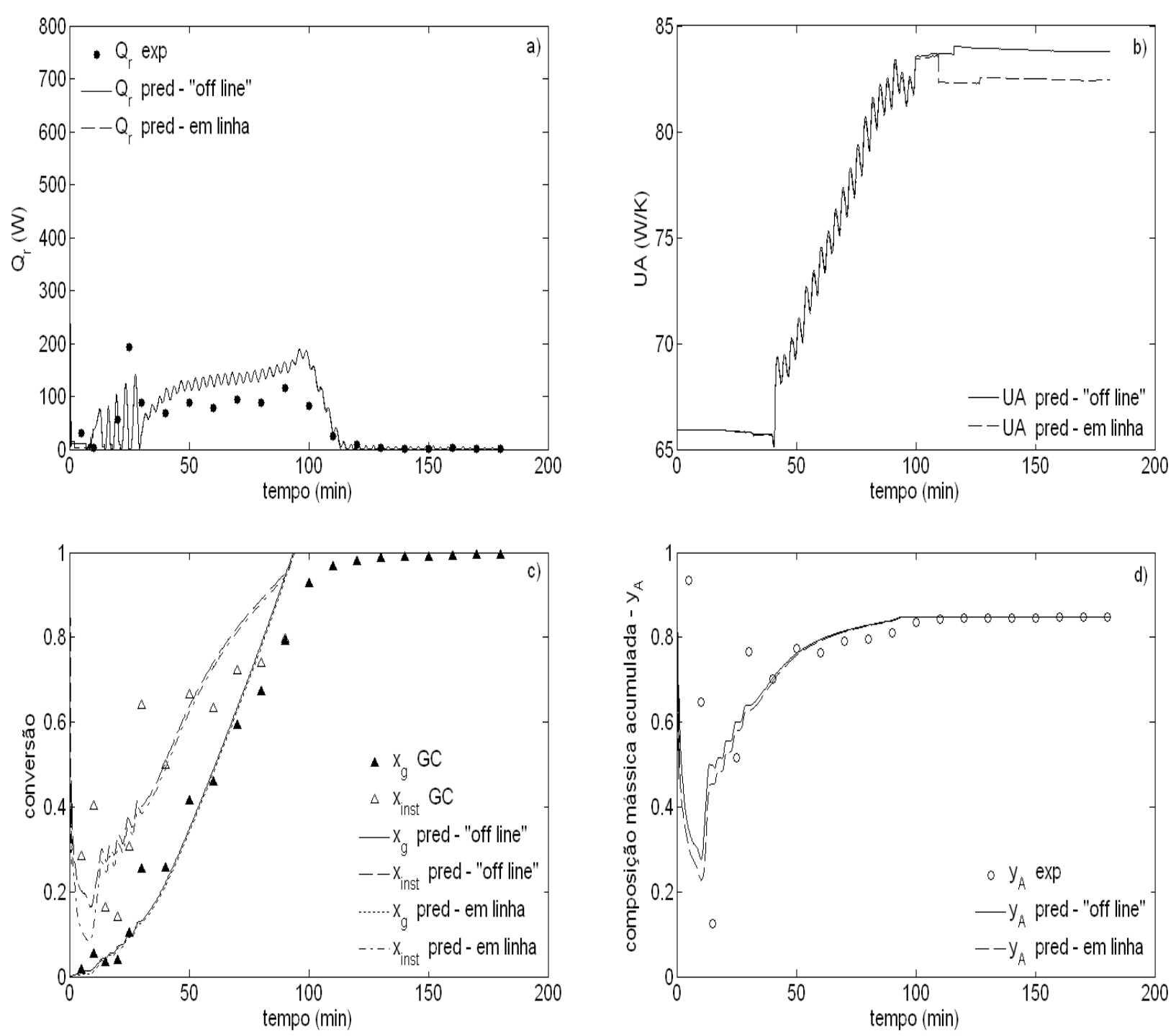

Figura 7.32 - Reação RC01E (semicontínua): a) calor de reação, b) coeficiente global de troca térmica, c) conversão e d) composição experimentais e preditos em linha e através de simulações off line

De um modo geral, as variáveis desconhecidas estimadas em linha são praticamente idênticas àquelas preditas durante as simulações off line, indicando a viabilidade da utilização do programa apresentado na Figura 7.29 para o monitoramento em tempo real de um processo de polimerização via calorimetria, desde que o problema relacionado com a sintonia dos observadores seja resolvido. Apenas um ligeiro desvio é observado nas estimativas em linha do coeficiente UA (Figuras 7.31b e 7.32b), da conversão instantânea (Figura 7.32c) e da composição (Figura 7.32d), entretanto, a diferença é muito pequena. 


\subsection{Conclusões Parciais}

Esta segunda fase do projeto teve como principal objetivo avaliar o desempenho e a capacidade preditiva de um observador não-linear de alto ganho para a estimação dos estados de reações de polimerização em emulsão conduzidos em batelada e em regime semicontínuo.

Apesar das medidas experimentais e preditas de $T_{r}, Q_{r}$ e conversão global terem apresentado boa concordância, observou-se que as estimativas fornecidas pela calorimetria em cascata são extremamente dependentes dos parâmetros de sintonia, uma vez que as variações aleatórias associadas às variáveis manipuladas ou controladas são indiretamente contabilizadas nestes parâmetros. Portanto, mesmo que as reações apresentem uma formulação base idêntica, os parâmetros de sintonia podem não ser os mesmos, inviabilizando a utilização da calorimetria em cascata para o monitoramento em linha de um processo de polimerização em emulsão. Adicionalmente, o ajuste dos parâmetros de sintonia não é uma tarefa simples, pois, como as estimativas fornecidas pela calorimetria em cascata no instante t-1 são usadas como sinais de entrada do observador no instante seguinte, uma pequena alteração no valor de $\theta$, em um determinado intervalo de tempo, irá se propagar em cascata até o final da reação.

Também se observou que este método apresenta outras duas grandes desvantagens. Primeiro, a calorimetria em cascata requer que o valor inicial de UA e de $\left(\mathrm{mC}_{\mathrm{p}}\right)_{\mathrm{r}}$ sejam estimados com boa precisão o que, na maioria das vezes, demanda um tempo demasiadamente longo. Segundo, o observador responsável pela estimação do perfil de UA é observável se, e somente se, $T_{r} \neq T_{j}$. Esta condição pode causar problemas nas estimativas do coeficiente UA após a conversão completa dos monômeros, devido ao equilíbrio térmico entre o meio reacional e o fluido de refrigeração, ou durante uma reação semicontínua, já que neste caso o calor de reação gerado é muito baixo e, portanto, a temperatura do reator permanece muito próxima da temperatura da camisa durante boa parte do tempo.

Para contornar os problemas de sintonia do observador, uma alternativa simples é a utilização direta do balanço de energia do reator. Neste caso, suavizando adequadamente as medidas das temperaturas e das vazões 
instantâneas é possível obter estimativas consistentes de $Q_{r}$, conversão e composição. A evolução do perfil do coeficiente UA pode ser rapidamente inferida em função do teor de sólidos dispondo-se apenas dos valores iniciais e finais de U. Apesar de neste enfoque ser necessária a especificação do número de pontos usados para calcular cada valor filtrado, este valor é mantido constante ao longo de toda a reação, ao contrário da calorimetria em cascata que requer que os parâmetros de sintonia sejam ajustados a cada intervalo de tempo. Isto significa que, dispondo-se dos valores iniciais e finais de $U$ e desde que as perdas térmicas para 0 ambiente sejam desprezíveis, é possível obter em linha as estimativas da conversão e composição a partir dos valores de $Q_{r}$ fornecidos pelo balanço de energia. 


\section{CONCLUSÕES E SUGESTÕES}

\subsection{Conclusões}

A implementação de estratégias para o controle das propriedades moleculares e morfológicas dos materiais poliméricos requer, inicialmente, a implementação de estratégias de monitoramento voltadas à identificação das principais variáveis de estado controladas como, por exemplo, composição, distribuição de pesos moleculares e distribuição de tamanho de partículas. Estas informações, quando obtidas em tempo real e associadas ao conhecimento das principais variáveis manipuladas, permitem ao engenheiro de processos exercer uma influência significativa sobre a qualidade final do produto, minimizando os custos operacionais decorrentes do descarte ou da necessidade de reprocessamento do material fora de especificação. Entretanto, grande parte das principais variáveis controladas não são mensuráveis em linha a partir das técnicas analíticas atualmente disponíveis. Dessa forma, várias metodologias combinadas com técnicas de observação de estados têm sido propostas na literatura.

O principal objetivo desse projeto foi verificar a viabilidade da aplicação da calorimetria combinada com observadores de estado não-linear de alto ganho para a estimação conjunta de $Q_{r}$ e UA (calorimetria em cascata), e a viabilidade de utilizar as informações do calor de reação para a estimação da conversão e da composição mássica acumulada de copolímeros de acetato de vinila/acrilato de butila produzidos durante um processo de polimerização em emulsão. Para isso, este projeto foi dividido em duas fases.

$\mathrm{Na}$ primeira fase, um observador de estado não-linear tipo Luenberger foi aplicado a uma reação de hidrólise de anidrido acético conduzida em três diferentes tipos de recipiente. As medidas de temperatura obtidas durante os ensaios foram utilizadas para a determinação dos valores experimentais do coeficiente global de troca térmica, da capacidade calorífica total e dos parâmetros da equação de Arrhenius. Estes valores, por sua vez, foram utilizados no balanço de energia e no observador para a estimação da conversão e da temperatura do sistema. 
Esta etapa do projeto evidenciou características importantes da reação de hidrólise e das metodologias de estimativa, principalmente, no que se refere a sintonia do observador. Uma primeira conclusão a ser tirada é a de que a hidrólise do anidrido acético é auto-catalisada pela acidez ou basicidade do meio reacional. Dessa forma, a presença de excesso de água diminui sensivelmente as constantes cinéticas da equação de Arrhenius e, portanto, a utilização de valores tabelados de $\mathrm{k}_{0}$ e $\mathrm{E}$ podem causar erros acentuados nas estimativas de conversão. Além disso, observou-se que os estados do processo são poucos sensíveis aos parâmetros $\mathrm{k}_{0} \mathrm{e}$ E quando comparado ao coeficiente UA. Isto significa que a inclusão das dinâmicas desses parâmetros no observador dificultariam sobremaneira a sintonia do observador, especialmente se os valores corretos de $\mathrm{k}_{0}$ e $\mathrm{E}$ não fossem conhecidos. Por outro lado, demonstrou-se que os parâmetros da equação de Arrhenius são facilmente obtidos a partir das medidas de temperatura e por um simples método de diferenciação numérica não sendo necessário, portanto, o uso de ferramentas computacionais sofisticadas.

$\mathrm{Na}$ segunda parte do projeto, um observador não-linear de alto ganho aplicado sobre o balanço de energia foi utilizado para estimar a evolução do calor de reação e do coeficiente global de troca térmica ao longo de uma reação de polimerização em emulsão de acetato de vinila/acrilato de butila. Os valores estimados de $Q_{r}$, por sua vez, foram utilizados em um simples balanço de massa para a predição das concentrações residuais dos monômeros presentes no meio reacional e, indiretamente, para a predição da conversão e da composição.

Comparando os resultados das simulações com os dados experimentais, observou-se que, devido à natureza determinística da calorimetria em cascata, as variações aleatórias associadas às variáveis manipuladas ou controladas são indiretamente contabilizadas nos parâmetros de sintonia e, portanto, mesmo que duas reações apresentem uma formulação idêntica, estes parâmetros podem não ser os mesmos, inviabilizando a aplicação dessa metodologia para o monitoramento em linha de um processo de polimerização em emulsão. Adicionalmente, o observador responsável pela estimação do perfil de UA requer que a temperatura do meio reacional seja sempre diferente da temperatura do fluido de refrigeração, caso contrário o sistema não será observável e, portanto, o observador não conseguirá estimar UA a partir das medidas de $T_{r}$. Neste trabalho, como condições isotérmicas são obtidas apenas após o consumo completo dos monômeros, o problema de 
observabilidade não apresentou maiores efeitos sobre as estimativas de $Q_{r}$ para reações em batelada. Para reações semicontínuas, como a temperatura do reator e a temperatura do fluido de refrigeração permaneceram bastante próximas durante os primeiros 50 minutos, este problema ficou mais evidente e, portanto, não foi possível obter um perfil coerente para o coeficiente UA.

Em relação ao uso do balanço de energia para a estimação do calor gerado pela reação, os resultado mostraram que a partir da suavização adequada das medidas das temperaturas e das vazões instantâneas, é possível obter estimativas de conversão e composição bastante realistas de forma simples e direta sendo, portanto, uma alternativa bastante interessante e viável para ser implementada em linha.

\subsection{Sugestões}

Os seguintes temas são sugeridos para trabalhos futuros:

i) Estimar os valores de $\mathrm{k}_{0}$ e $\mathrm{E}$ da reação de hidrólise do anidrido acético usando uma quantidade estequiométrica, ou ligeiramente maior, de água.

ii) Ainda com relação à reação de hidrólise do anidrido acético, estimar os valores de UA e $\left(\mathrm{mC}_{\mathrm{p}}\right)_{\mathrm{r}}$ através do calor dissipado por uma resistência elétrica.

iii) Instalar medidores de vazão na entrada e na saída da camisa do reator, e providenciar a adaptação da placa de aquisição e do programa de controle do reator para a coleta destas medidas. Dispondo dessas informações é possível estimar, simultaneamente, a evolução do coeficiente UA e do calor de reação através da calorimetria de balanço térmico. Entretanto, alguns cuidados devem ser tomados para evitar problemas durante a estimativa. Primeiro, o reator deve ser isolado termicamente, caso contrário o coeficiente de troca térmica entre a camisa e o ambiente bem como as perdas térmicas deverão ser estimados. Segundo, a vazão do fluido de refrigeração deve satisfazer a dois requisitos difíceis de serem 
obtidos simultaneamente: a) por um lado, o fluido de refrigeração deve ter uma vazão suficientemente alta para que seja possível o controle de $T_{r}$ em um valor constante; b) por outro lado, ela deve ser baixa para criar uma diferença de temperatura suficientemente alta ao longo da camisa para que esta possa ser medida com precisão.

iv) Para reações de polimerização em emulsão semicontínuas, ajustar a vazão de alimentação dos reagentes de modo a obter uma condição de operação próxima à condição isotérmica. Nesta condição é possível aplicar a calorimetria de temperatura oscilatória para estimar o perfil do coeficiente UA aproveitando as oscilações naturais da temperatura do fluido de arrefecimento. As estimativas do calor de reação podem ser obtidas pelo observador de alto ganho $\left(\mathrm{O}_{1}\right)$, e o período e a frequência de oscilação das temperaturas da camisa e do reator pelo gráfico de densidade de espectros de potência fornecido pelo método de máxima entropia.

v) Verificar a viabilidade da utilização da calorimetria de compensação térmica para a estimação dos estados de um processo semicontínuo de polimerização em emulsão. A principal vantagem desta técnica é que o calor de reação pode ser obtido diretamente da potência dissipada durante a compensação térmica e, portanto, não é necessário estimar a evolução do coeficiente global de troca térmica ao longo da reação. Entretanto, o calorímetro deve ser adaptado a fim de minimizar eventuais problemas relacionados com a sensibilidade de $Q_{r}$, devido à variação do coeficiente $\mathrm{h}_{\mathrm{r}}$ ou à variação da área efetiva de troca térmica, ou com a formação de hot spots.

vi) Verificar o comportamento da calorimetria em cascata quando o tempo de aquisição das medidas das temperaturas e das massas alimentadas é menor do que o tempo utilizado neste trabalho ( $t<5$ segundos) 


\section{REFERÊNCIAS BIBLIOGRÁFICAS}

\section{INTRODUÇÃO}

ASUA, J. M. Emulsion polymerization: from fundamental mechanisms to process developments. J. Polym. Sci. Part A: Polym. Chem., v. 42, n. 5, p. 1025-1041, Mar. 2004.

BENAMOR, S.; COLOMBIÉ, D.; \& McKENNA, T. Online reaction calorimetry. applications to the monitoring of emulsion polymerization without samples or models of the heat-transfer coefficient. Ind. Eng. Chem. Res., v. 41, n. 17, p. 4233-4241, 2002.

BURUAGA, S. de; AROTÇARENA, M.; ARMITAGE, P. D.; GUGLIOTTA, L. M.; LEIZA, J. R.; \& ASUA, J. M. On-line calorimetric control of emulsion polymerization reactors. Chemical Engineering Science, v. 51, n. 11, p. 2781-2786, June 1996.

CARLOFF, R.; PROSS, A.; \& REICHERT, K. H. Temperature oscillation calorimetry in stirred tank reactors with variable heat transfer. Chemical Engineering \& Technology, v. 17, n. 6, p. 406-413, Dec. 1994.

FEVOTTE, G.; BARUDIO, I.; \& GUILLOT, J. An adaptive inferential measurement strategy for on-line monitoring of conversion in polymerization process. Thermochimica Acta, v. 289, n. 2, p.223-242, Dec. 1996.

FREIRE, F. B.; McKENNA, T. F.; OTHMAN, S.; \& GIUDICI, R. A new approach to the joined estimation of the heat generated by a semicontinuous emulsion polymerization $\mathrm{Qr}$ and the overall heat exchange parameter UA. Braz. J. Chem. Eng., v. 21, n. 02, p. 293-305, Apr.-June 2004.

GUGLIOTTA, L. M.; AROTÇARENA, M.; LEIZA, J. R. \& ASUA, J. M. Estimation of conversion and copolymer composition in semicontinuous emulsion polymerization using calorimetric data. Polymer, v. 36, n. 10, p. 2019-2023, May 1995a.

GUGLIOTTA, L. M.; LEIZA, J. R.; AROTÇARENA, M.; ARMITAGE, P. D.; \& ASUA, J. $M$. Copolymer composition control in unseeded emulsion polymerization using calorimetric data. Ind. Eng. Chem. Res., v. 34, n. 11, p. 3899-3906, $1995 \mathrm{~b}$.

HUA, H. \& DUBÉ, M. A. Off-line monitoring of butyl acrylate, methyl methacrylate and vinyl acetate homo- and copolymerizations in toluene using ATR-FTIR spectroscopy. Polymer, v. 42, n. 14, p. 6009-6018, June 2001.

KOZUB, D. J. \& MACGREGOR, J. F. Feedback control of polymer quality in semibatch copolymerization reactors. Chemical Engineering Science, v. 47, n. 4, p. 929-942, Feb. 1992. 
RAY, W. H. Polymerization reactor control. IEEE, Control Systems Magazine, v. 6, n. 4, p. 3-8, Aug. 1986.

REGENASS, W. Calorimetric monitoring of industrial chemical process. Thermochimica Acta, v. 95, n. 2, p. 351-368, Sept. 1985.

SCHULER, H. \& SCHMIDT, C. U. Calorimetric-state estimators for chemical reactor diagnosis and control: review of methods and applications. Chemical Engineering Science, v. 47, n. 4, p. 899-915, Feb. 1992.

TIETZE, A.; LÜDKE, I.; \& REICHERT, K-H. Temperature oscillation calorimetry in stirred tank reactors. Chemical Engineering Science, v. 51, n. 11, p. 3131-3137, June 1996.

VICENTE, M.; BENAMOR, S.; GUGLIOTTA, L. M.; LEIZA, J. R.; \& ASUA,J.M. Control of molecular weight distribution in emulsion polymerization using on-line reaction calorimetry. Ind. Eng. Chem. Res., v. 40, n. 1, p. 218-227, 2001.

\section{REVISÃO BIBLIOGRÁFICA}

ALEXANDER, A. E.; \& NAPPER, D. H. Emulsion Polymerization. Progress in Polymer Science, v. 3, p. 145-197, 1971.

ARAUJO, O. Copolimerização e terpolimerização em emulsão: trabalho experimental e estudo de aspectos relacionados à modelagem matemática do processo. 1997. Tese (Doutorado) - Escola Politécnica, Universidade de São Paulo, São Paulo, 1997.

ARAÚJO, P. H. H. Distribuição de tamanhos de partículas em sistemas heterogêneos de polimerização. 1999. Tese (Doutorado) - Programa de Engenharia Química/COPPE, Universidade Federal do Rio de Janeiro, Rio de Janeiro, 1999.

BALDI, L. D. C.; \& ATVARS, T. D. Z. Avaliação da polaridade superficial de náilons por espectroscopia de fluorescência. Polímeros: Ciência e Tecnologia, v. 15, n. 001, p. 33-38, jan./mar. 2005.

BARUDIO, I.; FÉVOTTE, G.; \& MCKENNA, T. F. Density data for copolymer systems: butyl acrylate/vinyl acetate homo- and copolymerization in ethyl acetate. European Polymer Journal, v. 35, n. 5, p. 775-780, May 1999.

BOND, L. J.; MORRA, M.; GREENWOOD, M. S.; BAMBERGER, J. A.; \& PAPPAS, R. A. Ultrasonic technologies for advanced process monitoring, measurement and control. Instrumentation and Measurement Technology Conference, 2003. IMC 2003. Proceedings of the 20 ${ }^{\text {th }}$ IEEE, v. 2, p. 1288-1293, May 2003. 
CHALLIS, R. E.; POVEY, M. J. W.; MATHER, M. L.; \& HOLMES, A. K. Ultrasound techniques for characterizing colloidal dispersions. Reports on Progress in Physics, v. 68, n.7, p. 1541-1637, July 2005.

CHIEN, D. C.; \& PENLIDIS, A. On-line sensors for polymerization reactors. JMS Rev. Macromol. Chem. Phys., v. 30, n. 1, p. 1-42, 1990.

DIMITRATOS, J.; ELIÇABE, G.; \& GEORGAKIS, C. Control of emulsion polymerization reactors. AIChE Journal, v. 40, n. 12, p. 1993-2021, Dec. 1994.

DIMITRATOS, J.; GEORGAKIS, C.; EL-AASSER, M. \& KLEIN, A. An experimental study of adaptive Kalman filtering in emulsion copolymerization. Chemical Engineering Science, v. 46, n. 12, p. 3203-3218.

DUKHIN, A. S.; GOETZ, P. J.; WINES, T. H.; \& SOMASUNDARAN, P. Acoustic and electroacoustic spectroscopy. Colloids and Surfaces A: Physicochemical and Engineering Aspects, v. 173, n. 1-3, p. 127-158, Nov. 2000.

ELIZALDE, O; ASUA, J. M.; \& LEIZA, J. R. Monitoring of high solids content starvedsemi-batch emulsion copolymerization reactions by Fourier transform Raman spectroscopy. Applied Spectroscopy, v. 59, n. 10, p. 1270-1279, Oct. 2005a.

ELIZALDE, O.; AZPEITIA, M.; REIS, M. M.; ASUA, J. M.; \& LEIZA, J. R. Monitoring emulsion polymerization reactors: calorimetry versus Raman spectroscopy. Ind. Eng. Chem. Res., v. 44, n. 18, p. 7200-7207, 2005 b.

EMBIRUÇU, M.; LIMA, E. L.; \& PINTO, J. C. A survey of advanced control of polymerization reactors. Polymer Engineering and Science, v. 36, n. 4, p. 433447, Feb. 1996.

FÉVOTTE, G.; BARUDIO, I.; \& GUILLOT, J. An adaptive inferential measurement strategy for on-line monitoring of conversion in polymerization processes. Thermochimica Acta, v. 289, n. 2, p. 223-242, Dec. 1996.

FÉVOTTE, G.; BARUDIO, I.; \& MCKENNA, T. F. Computer-aided parameter estimation and on-line monitoring of emulsion and solution polymerization reactors. Computers \& Chemical Engineering, v. 20, n. 1, p. S581-S586.

GAO, J.; \& PENLIDIS, A. Mathematical modeling and computer simulator/database for emulsion polymerizations. Progr. Polym. Sci., v. 27, n. 3, p. 403-535, Apr. 2002.

GILBERT, R. Emulsion Polymerization: A Mechanistic Approach 1 ed. London: Academic Press, 1995. 801p.

HARKINS, W. D. A general theory of the reaction loci in emulsion polymerization. The Journal of Chemical Physics, v. 13, n. 9, p. 381-382, Sept. 1945.

HARKINS, W. D. A general theory of the mechanism of emulsion polymerization. Journal of the American Chemical Society, v. 69, n. 6, p. 1428-1444, June 1947. 
IMMANUEL, C. D.; CROWLEY, T. J.; MEADOWS, E. S.; CORDEIRO, C. F.; \& DOYLE III, F. J. Evolution of multimodal particle size distribution in vinyl acetate/butyl acrylate emulsion copolymerizations. Journal of Polymer Science: Part A - Polymer Chemistry, v. 41, n. 14, p. 2232-2249, July 2003.

KAMMONA, O.; CHATZI, E. G.; \& KIPARISSIDES, C. Recent developments in hardware sensors for the on-line monitoring of polymerization reactions. Journal of Macromolecular Science. Part C: Polymer Reviews, v. 39, n. 1, p. 57-134, Apr. 1999.

LEIZA, J. R.; de la CAL, J. C.; MONTES, M.; \& ASUA, J. M. On-line monitoring of conversion and polymer composition in emulsion polymerization systems. Process Control and Quality, v. 4, p. 197-210, 1993a.

LEIZA, J. R.; de la CAL, J. C.; MEIRA, G. R.; \& ASUA, J. M. On-line copolymer composition control in the semicontinuous emulsion copolymerization of ethyl acrylate and methyl methacrylate. Polymer Reaction Engineering, v.1, p. 461-498, 1993b.

LI, X.; XIA, S. P; ZENG, W. J.; ZHANG, W. Y.; \& DONG, S. X. Monitor of polymerization of inverse microemulsions containing methyl methacrylate and acrylic acid. Chinese Chemical Letters, vol. 17, n. 2, p. 247-250, 2006.

MIGNARD, E.; LEBLANC, T.; BERTIN, D.; GUERRET, O.; \& REED, W. F. Online monitoring of controlled radical polymerization: nitroxide-mediated gradient copolymerization. Macromolecules, vol. 37, n. 3., p. 966-975, Jan. 2004.

MIGUEL, M. da G.; BURROWS, H. D.; FORMOSINHO, S. J.; \& LINDMAN, B. Fluorescence studies of polymer-surfactante association. Journal of Molecular Structure, v. 563-564, p. 89-98, May 2001.

MIKES, F.; GONZÁLEZ-BENITO, F.; SERRANO, B.; BRAVO, J.; \& BASELGA, J. Fluorescence monitoring of polymerization reaction. a new method for treating fluorescence experimental data. Polymer, v. 43, n. 16, p. 4331-4339, July 2002.

NOËL, L. F. J.; BROUWER, E. C. P.; van HERK, A. M.; \& GERMAN, A. L. On-line gas chromatography and densimetry to obtain partial conversions of both monomers in emulsion copolymerization. Journal of Applied Polymer Science, v. 57, n. 3, p. 245-254, July 1995.

ODIAN, G. Principles of Polymerization 2 ed. New York: John Wiley and Sons, 1981.

OTHMAN, N. S. Advanced Strategies for Composition Control in SemiContinuous Emulsion Polymerization. 2000. 319p. Tese (Doutorado) - Ecole Doctorale de Chimie, Universite Claude Bernard, Lyon, França, 2000.

PARK, M. J.; HUR, S. M.; \& RHEE, H. K. Online estimation and control of polymer quality in a copolymerization reactor. AIChE Journal, v. 48, n. 5, p.1013-1021, May 2002. 
PRICE, G. J.; NORRIS, D. J.; \& WEST, P. J. Polymerization of methyl methacrylate initiated by ultrasound. Macromolecules, v. 25, n. 24, p. 6447-6454, 1992.

PRIEST, W. J. Particle growth in the aqueous polymerization of vinyl acetate. The Journal of Physical Chemistry, v. 56, p. 1077-1083, Dec. 1952.

REIS, M. M.; ARAÚJO, P. H. H.; SAYER, C.; \& GIUDICI, R. Evidences of correlation between polymer particle size and Raman scattering. Polymer, v. 44, n. 20, p. 61236128, Sept. 2003.

REIS, M. M.; ARAÚJO, P. H. H.; SAYER, C.; \& GIUDICI, R. In situ near-infrared spectroscopy for simultaneous monitoring of multiple process variables in emulsion copolymerization. Ind. Eng. Chem. Res., v. 43, n. 23, p. 7243-7250, 2004a.

REIS, M. M.; ARAÚJO, P. H. H.; SAYER, C.; \& GIUDICI, R. Development of calibration models for estimation of monomer concentration by Raman spectroscopy during emulsion polymerization: facing the medium heterogeneity. Journal of Applied Polymer Science, v. 93, n. 3, p. 1136-1150, Aug. 2004b.

REIS, M. M.; ARAÚJO, P. H. H.; SAYER, C.; \& GIUDICI, R. Spectroscopic on-line monitoring of reactions in dispersed medium: Chemometrics challenges. Analytica Chimica Acta, v. 595, n. 1-2, p. 257-265, July 2007.

RICHARDS, J. R.; \& CONGALIDIS, J. P. Measurement and control of polymerization reactors. Computers and Chemical Engineering, v. 30, n. 10-12, p. 1447-1463, Sept. 2006.

RUDSCHUNK, S.; ADAMS, J.; \& FUHRMANN, J. On-line time-resolved fluorescence spectroscopy of emulsion polymerizations to study the local dynamics in the polymerizing particles. Macromol. Chem. Phys., v. 199, n. 5, p. 771-776, May 1998.

SANTOS, A. F.; LIMA, E. L.; \& PINTO, J. C. In-line evaluation of average particle size in styrene suspension polymerizations using near-infrared spectroscopy. Journal of Applied Polymer Science, v. 70, n. 9, p. 1737-1745, Nov. 1998.

SAYER, C. Modelagem e controle de sistemas de copolimerização em emulsão. 1999. 300p. Tese (Doutorado) - Programa de Engenharia Química/COPPE, Universidade Federal do Rio de Janeiro, Rio de Janeiro, 1999.

SMITH, W. V.; \& EWART, R. H. Kinetics of emulsion polymerization. Journal of Chemical Physics, v. 16; n. 6, p. 592-599, June 1948.

URRETABIZKAIA, A.; LEIZA, J. R.; \& ASUA, J. M. On-line terpolymer composition control in semicontinuous emulsion polymerization. AIChE Journal, v. 40, n. 11, p. 1850-1864, Nov. 1994. 
VIEIRA, R. A. M.; SAYER, C.; LIMA, E. L.; \& PINTO, J. C. In-line and in-situ monitoring of semi-batch emulsion copolymerizations using near-infrared spectroscopy. Journal of Applied Polymer Science, v. 84, n. 14, p. 2670-2682, June 2002a.

VIEIRA, R. A. M.; SAYER, C.; LIMA, E. L.; \& PINTO, J. C. Closed-loop composition and molecular weight control of a copolymer latex using near-infrared spectroscopy. Ind. Eng. Chem. Res., v. 41, n. 12, p. 2915-2930, 2002b.

ZEILMANN, T.; LAVANCHY, F.; \& MEYER, T. Inline conversion monitoring in MMA high solid content polymerization process. CHIMIA International Journal for Chemistry, v. 55, n. 3, p. 249-250, Mar. 2001.

\section{OBSERVADORES DE ESTADO}

ADEBEKUN, D. K.; \& SCHORK, F. J. Continuous solution polymerization reactor control II: estimation and nonlinear reference control during methyl methacrylate polymerization. Ind. Eng. Chem. Res., v. 28, n. 12, p. 1846-1861, 1989.

ADAMS, M. E.; TRAU, M.; GILBERT, R. G.; NAPPER, D. H.; \& SANGSTER, D. F. The entry of free radicals into polystyrene latex particles. Aust. J. Chem., v. 41, n. 12, p. 1799-813, 1988.

ASTORGA, C. M.; OTHMAN, N.; OTHMAN, S.; HAMMOURI, H.; \& MCKENNA, T. F. Nonlinear continuous-discrete observers: application to emulsion polymerization reactors. Control Engineering Practice, v. 10, n. 1, p. 3-13, Jan. 2002.

BACHIR, D.; MANSOURI, A.; BOUHAMIDA, M.; \& CHENAFA, M. State estimation in free-radical polymerization reactors using a nonlinear interconnected high gain observer. Journal of Theoretical and Applied Information Technology, v. 4, n. 7, p. 647-656, July 2008a.

BACHIR, D.; MANSOURI, A.; BOUHAMIDA, M.; \& CHENAFA, M. A robust nonlinear observer for state variables estimation in multi-input multi-output chemical reactors. International Journal of Chemical Reactor Engineering, v. 6: A86, Jan. 2008b. Disponível em:

http://www.bepress.com/ijcre/vol6/A86. Acesso em: 12 mar. 2009.

BESANÇON, G.; ZHANG, Q.; \& HAMMOURI, H. High-gain observer based state and parameter estimation in nonlinear systems. $6^{\text {th }}$ IFAC Symposium on Nonlinear Control Systems (NOLCOS), Stuttgart, 2004. Disponível em:

http://www.nolcos2004.uni-stuttgart.de/downloads/204.pdf. Acesso em: 06 ago. 2008.

BESANÇON, G. An overview on observer tools for nonlinear systems. In: (Ed.). Nonlinear observers and applications. Berlin: Springer, $2007 . \overline{p .} 1-31$. (Lecture notes in control and information sciences, v. 363). 
BORNARD, G.; \& HAMMOURI, H. A high gain observer for a class of uniformly observable systems. Proceedings of the $30^{\text {th }}$ IEEE Conference on Decision and Control, v. 2, p. 1494-1496, Dec. 1991.

BRANDRUP, J.; \& IMMERGUT, E. H. Polymer Handbook. $3^{\text {rd }}$ ed. New York: Wiley, 1989.

BUSAWON, K.; FARZA, M.; \& HAMMOURI, H. Observer design for a special class of nonlinear systems. International Journal of Control, v. 71, n. 3, p. 405-418, Oct. 1998.

CASEY, B. S.; MORRISON, B. R.; \& GILBERT, R. G. The role of aqueous-phase kinetics in emulsion polymerizations. Prog. Polym. Sci., v. 18, n. 6, p. 1041-1096, 1993.

CICCARELLA, G.; DALLA MORA, M.; \& GERMANI, A. A Luenberger-like observer for nonlinear systems. International Journal of Control, v. 57, n. 3, p. 537-556, Mar. 1993.

CROWLEY, T. J.; \& CHOI, K. Y. Experimental studies on optimal molecular weight distribution control in a batch-free radical polymerization process. Chemical Engineering Science, v. 53, n. 15, p. 2769-2790, Aug. 1998.

DIMITRATOS, J.; GEORGAKIS, C.; EL-AASSER, M. S.; \& KLEIN, A. Composition control and Kalman filtering in emulsion polymerization. American Control Conf., 1988. Proceedings of the IEEE, v. 1, p. 689-694.

DIMITRATOS, J.; GEORGAKIS, C.; EL-AASSER, M. S.; \& KLEIN, A. Dynamic modeling and state estimation for an emulsion copolymerization reactor. Computers Chem. Eng., v. 13, n. 1/2, p. 21-33, Jan./Feb. 1989.

DIMITRATOS, J.; GEORGAKIS, C.; EL-AASSER, M. \& KLEIN, A. An experimental study of adaptive Kalman filtering in emulsion copolymerization. Chemical Engineering Science, v. 46, n. 12, p. 3203-3218, 1991.

DOCHAIN, D. State and parameter estimation in chemical and biochemical process: a tutorial. Journal of Process Control, v. 13, n. 8, p. 801-818, Dec. 2003.

DUBÉ, M. A.; SOARES, J. B. P.; PENLIDIS, A.; \& HAMIELEC, A. E. Mathematical modeling of multicomponent chain-growth polymerizations in batch, semibatch, and continuous reactors: a review. Ind. Eng. Chem. Res., v. 36, n. 4, p. 966-1015, 1997.

EDOUARD, D.; OTHMAN, N. S.; \& HAMMOURI, H. Observer design for particle size distribution in emulsion polymerization. AIChE Journal, v. 51, n. 12, p. 3167-3185, Dec. 2005.

ELIÇABE, G. E.; OZDEGER, E.; CORDEIRO, C.; \& GEORGAKIS, C. On-line estimation of reaction rates in semicontinuous reactors. Ind. Eng. Chem. Res., v. 34, n. 4, p. 1219-1227, 1995. 
FAN, S.; GRETTON-WATSON, S. P.; STEINKE, J. H. G.; \& ALPAY, E. Polymerization of methyl methacrylate in a pilot-scale tubular reactor: modeling and experimental studies. Chemical Engineering Science, v. 58, n. 12, p. 2479-2490, June 2003.

FARZA, M.; HAMMOURI, H.; OTHMAN, S.; \& BUSAWON, K. Nonlinear observers for parameter estimation in bioprocess. Chemical Engineering Science, v.52, n. 23, p. 4251-4267, Dec. 1997.

FARZA, M.; BUSAWON, K.; \& HAMMOURI, H. Simple nonlinear observers for online estimation of kinetic rates in bioreactors. Automatica, v. 34, n. 3, p. 301-318, Mar. 1998.

FARZA, M.; HAMMOURI, H.; JALLUT, C.; \& LIETO, J. State observation of a nonlinear system: application to (bio)chemical processes. AIChE Journal, v. 45, n. 1, p. 93-106, Jan. 1999.

FEVOTTE, G.; BARUDIO, I.; \& GUILLOT, J. An adaptive inferential measurement strategy for on-line monitoring of conversion in polymerization process. Thermochimica Acta, v. 289, n. 2, p. 223-242, Dec. 1996.

FEVOTTE, G.; MCKENNA, T. F.; OTHMAN, S.; \& HAMMOURI, H. Non-linear tracking of glass transition temperatures for free radical emulsion copolymers. Chemical Engineering Science, v. 53, n. 4, p. 773-786, Feb. 1998.

FONTOURA, J. M. R.; SANTOS, A. F.; SILVA, F. M.; LENZI, M. K.; LIMA, E. L.; \& PINTO, J. C. Monitoring and control of styrene solution polymerization using NIR spectroscopy. Journal of Applied Polymer Science, v. 90, n. 5, p. 1273-1289, Aug. 2003.

FREIRE, F. B.; \& CÔRREA, R. G. Comparison among three different Luenberger state observers for the on-line estimation of state variables in chemical process. In: XIII Congresso Brasileiro de Engenharia Química / XIX Interamerican Congress of Chemical Engineering, 2000, Águas de São Pedro.

FREIRE, F. B. Calorimetria em linha através de observadores de estado nãolineares: estimativa conjunta da taxa de geração de calor e do coeficiente global de troca de calor em reatores de polimerização. 2003. 152p Tese (Doutorado) - Escola Politécnica, Universidade de São Paulo, São Paulo, 2003.

GAO, J.; \& PENLIDIS, A. Mathematical modeling and computer simulator/database for emulsion polymerizations. Progr. Polym. Sci., v. 27, n. 3, p. 403-535, Apr. 2002.

GAUTHIER, J. P.; \& BORNARD, G. Observability for any $u(t)$ of a Class of Nonlinear Systems. IEEE Transactions on Automatic Control, v. 26, n. 4, p. 922-926, Aug. 1981.

GAUTHIER, J. P.; HAMMOURI, H.; \& OTHMAN, S. A simple observer for nonlinear systems. Applications to bioreactors. IEEE Transactions on Automatic Control, v. 37, n. 6, p. 875-880, June 1992. 
GIBON-FARGEOT, A. M.; HAMMOURI, H.; \& CELLE, F. Nonlinear observers for chemical reactors. Chemical Engineering Science, v. 49, n. 14, p. 2287-2300, July 1994.

GILBERT, R. Emulsion Polymerization: A Mechanistic Approach 1 ed. London: Academic Press, 1995. 801p.

GUO, B.; JIANG, A.; HUA, X.; \& JUTAN, A. Nonlinear adaptive control for multivariable chemical processes. Chemical Engineering Science, v. 56, n. 23, p. 6781-6791, Dec. 2001.

HAMMOURI, H.; McKENNA, T. F.; \& OTHMAN, S. Applications of nonlinear observers and control: improving productivity and control of free radical solution copolymerization. Ind. Eng. Chem. Res., v. 38, n. 12, p. 4815-4824, Dec. 1999.

HAMMOURI, H.; \& FARZA, M. Nonlinear observers for locally uniformly observable systems. ESAIM: Control, Optimization and Calculus of Variations, v. 9, p. 353370, Mar. 2003.

HAMMOURI, H. Uniform observability and observer synthesis. In: BESANÇON, G. (Ed.). Nonlinear observers and applications. Berlin: Springer, 2007. p. 35-69. (Lecture notes in control and information sciences, v. 363).

HUA, X.; ROHANI, S.; \& JUTAN, A. Cascade closed-loop optimization and control of batch reactors. Chemical Engineering Science, v. 59, n. 24, p. 5695-5708, Dec. 2004.

KABORÉ, P.; OTHMAN, S.; McKENNA, T. F.; \& HAMMOURI, H. Observer-based fault diagnosis for a class of non-linear systems - application to a free radical copolymerization reaction. International Journal of Control, v. 73, n. 9, p. 787-803, June 2000.

KAZANTZIS, N; KRAVARIS, C.; \& WRIGHT, R. A. Nonlinear observers design for process monitoring. Ind. Eng. Chem. Res., v. 39, n. 2, p. 408-419, Jan. 2000.

KIPARISSIDES, C.; SEFERLIS, P.; MOURIKAS, G.; \& MORRIS, A. J. Online optimizing control of molecular weight properties in batch free-radical polymerization reactors. Ind. Eng. Chem. Res., v. 41, n. 24, p. 6120-6131, 2002.

KOZUB, D. J.; \& MACGREGOR, J. F. State estimation for semi-batch polymerization reactors. Chemical Engineering Science, v. 47, n. 5, p. 1047-1062, Apr. $1992 a$.

KOZUB, D. J.; \& MACGREGOR, J. F. Feedback control of polymer quality in semibatch copolymerization reactors. Chemical Engineering Science, v. 47, n. 4, p. 929-942, $1992 b$.

KRÄMER, S.; GESTHUISEN, R.; ENGELL, S.; \& ASUA, J. M. Simultaneous estimation of heat transfer coefficient and reaction heat in semi-batch process. American Control Conference,2003. Proceedings of the 2003 IEEE, v. 3, p. 19801981, June 2003. 
KRÄMER, S.; \& GESTHUISEN, R. Simultaneous estimation of the heat of reaction and the heat transfer coefficient by calorimetry: estimation problems due to model simplification and high jacket flow rates-theoretical development. Chemical Engineering Science, v. 60, n. 15, p. 4233-4248, Aug. 2005.

MARTÍNEZ-GUERRA, R.; GARRIDO, R.; \& OSORIO-MIRON, A. The fault detection problem in nonlinear systems using residual generators. IMA Journal of Mathematical Control and Information, v. 22, n. 2, p. 119-136, June 2005.

MUTHA, R. K.; CLUETT, W. R.; \& PENLIDIS, A. A new multirate-measurementbased estimator: emulsion copolymerization batch reactor case study. Ind. Eng. Chem. Res., v. 36, n. 4, p.1036-1047, 1997.

OTHMAN, N. S.; \& OTHMAN, S. Control of an emulsion polymerization reactor. Ind. Eng. Chem. Res., v. 45, n. 1, p. 206-211, Jan. 2006.

RAWLINGS, J. B.; \& BAKSHI, B. Particle filtering and moving horizon estimation. Computers and Chemical Engineering, v. 30, n. 10-12, p. 1529-1541, Sept. 2006.

RUSSELL, G. T. The kinetics of free-radical polymerization: fundamental aspects.

Aust. J. Chem., v. 55, n. 7, p. 399-414, 2002.

SCHULER, H.; \&SUZHEN, Z. Real-time estimation of the chain length distribution in a polymerization reactor. Chemical Engineering Science, v. 40, n. 10, p. 18911904, 1985.

SHAHROKHI, M.; \& FANAEI, M. A. State estimation in a batch suspension polymerization reactor. Iranian Polymer Journal, v. 10, n. 3, p. 173-187, 2001.

SOROUSH, M. State and parameter estimations and their applications in process control. Computers and Chemical Engineering, v. 23, n. 2, p. 229-245, Dec. 1998.

VALLURI, S.; \& SOROUSH, M. Nonlinear state estimation in the presence of multiple steady states. Ind. Eng. Chem. Res., v. 35, n. 8, p. 2645-2659, 1996.

WILSON, D. I.; AGARWAL, M.; \& RIPPIN, D. W. T. Experiences implementing the extended Kalman filter on a industrial batch reactor. Computers and Chemical Engineering, v. 22, n. 11, p. 1653-1672, Oct. 1998.

\section{CALORIMETRIA}

AL-HAJ ALI, M.; BETLEM, B.; ROFFEL, B.; \& WEICKERT, G. Estimation of the polymerization rate of liquid propylene using adiabatic reaction calorimetry and reaction dilatometry. Macromolecular Reaction Engineering, v. 1, n. 3, p. 353-363, May 2007. 
ALHAMAD, B.; GOMES, V. G.; \& ROMAGNOLI, J. A. Calorimetry for inferential conversion monitoring in emulsion copolymerization reactors. International Journal of Chemical Reactor Engineering, v. 4: A7, 2006. Disponível em:

http://www.bepress.com/ijcre/vol4/A7. Acesso em: 18 set. 2008.

AZPEITIA, M.; LEIZA, J. R.; \& ASUA, J. M. Safety in emulsion polymerization reactors: an experimental study. Macromolecular Materials and Engineering, $v$. 290, n. 4, p. 242-249, Apr. 2005.

ASUA, J. M. Emulsion polymerization: from fundamental mechanisms to process developments. J. Polym. Sci. Part A: Polym. Chem., v. 42, n. 5, p. 1025-1041, Mar. 2004.

BENAMOR, S.; COLOMBIÉ, D.; \& McKENNA, T. Online reaction calorimetry. Applications to the monitoring of emulsion polymerization without samples or models of the heat-transfer coefficient. Ind. Eng. Chem. Res., v. 41, n. 17, p. 4233-4241, 2002.

BOU-DIAB, L.; SCHENKER, B.; MARISON, I.; AMPUERO, S.; \& von STOCKAR, U. Improvement of continuous calibration based on temperature oscillation and application to biochemical reaction calorimetry. Chemical Engineering Journal, v. 81, n. 1-3, p. 113-127, Jan. 2001.

CARLOFF, R.; PROSS, A.; REICHERT, K. H. Temperature oscillation calorimetry in stirred tank reactors with variable heat transfer. Chemical Engineering \& Technology, v. 17, n. 6, p. 406-413, Dec. 1994.

DE LA ROSA, L. V.; SUDOL, E. D.; EL-AASSER, M. S.; \& KLEIN, A. Details of the emulsion polymerization of styrene using a reaction calorimeter. Journal of Polymer Science: Part A: Polymer Chemistry, v. 34, n. 3, p. 461-473, Feb. 1996.

DE LUCA, P. G.; \& SCALI, C. Temperature oscillation calorimetry: robustness analysis of different algorithms for the evaluation of the heat transfer coefficient. Chemical Engineering Science, v. 57, n. 11, p. 2077-2087, June 2002.

ECHEVARRÍA, A.; LEIZA, J. R.; DE LA CAL, J. C.; \& ASUA, J. M. Molecular-weight distribution in emulsion polymerization. AIChE Journal, v. 44, n. 7, p. 1667-1679 July 1998.

ESPOSITO, M.; SAYER, C.; MACHADO, R. A. F.; \& ARAUJO, P. H. H. Application of calorimetry technique to estimate conversion of polymerization reactions in a standart lab-scale reactor. Macromol. Symp., v. 245-246, n. 1, p. 390-397, Dec. 2006.

ESPOSITO, M.; SAYER, C.; MACHADO, R. A. F.; \& ARAUJO, P. H. H. Effect of cooling fluid flow rate on the estimation of conversion by calorimetry in a lab-scale reactor. Macromol. Symp., v. 271, n. 1, p. 38-47, Sept. 2008. 
FAN, S.; \& ALPAY, E. Calorimetric estimation for a batch-loop emulsion polymerization reactor. Chemical Engineering Science, v. 59, n. 13, p. 2811-2815, July 2004.

FERGUSON, H. F.; FRURIP, D. J.; PASTOR, A. J.; PEEREY, L. M.; \& WHITING, L. F. A review of analytical applications of calorimetry. Thermochimica Acta, n. 363, n. 1-2, p. 1-21, Nov. 2000.

FEVOTTE, G.; BARUDIO, I.; \& MCKENNA, T. F. Computer-aided parameter estimation and on-line monitoring of emulsion and solution polymerization reactors. Computers and Chemical Engineering, v. 20, n. 1, p. S581-S586, 1996.

FEVOTTE, G.; BARUDIO, I.; \& GUILLOT, J. An adaptive inferential measurement strategy for on-line monitoring of conversion in polymerization process. Thermochimica Acta, v. 289, n. 2, p. 223-242, Dec. 1996.

FEVOTTE, G.; MCKENNA, T. F.; OTHMAN, S.; \& SANTOS, A. M. A combined hardware / software sensing approach for on-line control of emulsion polymerization process. Computers and Chemical Engineering, v. 22, n. 1, p. S443-S449, Mar. 1998a.

FEVOTTE, G.; MCKENNA, T. F.; OTHMAN, S.; \& HAMMOURI, H. Non-linear tracking of glass transition temperatures for free radical emulsion copolymers. Chemical Engineering Science, v. 53, n. 4, p. 773-786, Feb. 1998b.

FREIRE, F. B.; McKENNA, T. F.; OTHMAN, S.; GIUDICI, R. A new approach to the joined estimation of the heat generated by a semicontinuous emulsion polymerization Qr and the overall heat exchange parameter UA. Braz. J. Chem. Eng., v. 21, n. 02, p. 293-305, Apr./June 2004.

FREIRE, F. B.; \& GIUDICI, R. Temperature oscillation calorimetry by means of a Kalman-like observer: the joint estimation of $\mathrm{Qr}$ and UA in a stirred tank polymerization reactor. Macromol. Symp., v. 206, n. 1, p. 15-28, Feb. 2004.

GAULKE, A-L; PAUER, W.; \& MORITZ, H-U. Using the transfer function of an isoperibolic reaction calorimeter for thermo-kinetic analysis. Macromol. Symp., v. 236, n. 1, p. 134-144, Mar. 2006.

GESTHUISEN, R.; KRÄMER, S.; NIGGEMANN, G.; LEIZA, J. R.; \& ASUA J. M. Determining the best reaction calorimetry technique: theoretical development. Computers and Chemical Engineering, v. 29, n. 2, p. 349-365, Jan. 2005.

GIORDANI, D. S.; LONA, L. M. F.; MCKENNA, T. F.; KRÄHENBÜHL, M. A. SANTOS, A. M. Artificial neural networks associated to calorimetric measurements used as a method to predict polymer composition of high solid content emulsion copolymerizations. Macromolecular Materials and Engineering, v. 290, n. 5, p. 485-494, May 2005. 
GLOOR, P. E; \& WARNER, R. J. Developing feed policies to maximize productivity in emulsion polymerization process. Thermochimica Acta, v. 289, n. 2, p. 243-265, Dec. 1996.

GUGLIOTTA, L. M.; AROTÇARENA, M.; LEIZA, J. R.; \& ASUA, J. M. Estimation of conversion and copolymer composition in semicontinuous emulsion polymerization using calorimetric data. Polymer, v. 36, n. 10, p. 2019-2023, May 1995.

HANSEN, L. D. Toward a standart nomenclature for calorimetry. Thermochimica Acta, v.371, n. 1-2, p. 19-22, Apr. 2001.

HANSEN, L. D.; \& HART, R. M. The art of calorimetry. Thermochimica Acta, v. 417, n. 2, p. 257-273, July 2004.

JACOBSEN, J. P. Reaction calorimeter - a useful tool in chemical engineering. Thermochimica Acta, v. 160, n. 1, p. 13-23, Apr. 1990.

KAMMONA, O.; CHATZI, E. G.; \& KIPARISSIDES, C. Recent developments in hardware sensors for the on-line monitoring of polymerization reactions. Journal of Macromolecular Science. Part C: Polymer Reviews, v. 39, n. 1, p. 57-134, Apr. 1999.

KARLSEN, L. G.; \& VILLADSEN, J. Isothermal reaction calorimeters - I. A literature review. Chemical Engineering Science, v. 42, n. 5, p. 1153-1164, 1987.

KARLSEN, L. G.; \& VILLADSEN, J. Isothermal reaction calorimeters - II. Data treatment. Chemical Engineering Science, v. 42, n. 5, p. 1165-1173, 1987.

KRÄMER, S.; \& GESTHUISEN, R. Simultaneous estimation of the heat of reaction and the heat transfer coefficient by calorimetry: estimation problems due to model simplification and high jacket flow rates-theoretical development. Chemical Engineering Science, v. 60, n. 15, p. 4233-4248, Aug. 2005.

LAMB, D. J.; FELLOWS, C. M.; MORRISON, B. R.; \& GILBERT, R. G. A critical evaluation of reaction calorimetry for the study of emulsion polymerization systems: thermodynamic and kinetic aspects. Polymer, v. 46, n. 2, p. 285-294, Jan. 2005.

LANDAU, R. N. Expanding the role of reaction calorimetry. Thermochimica Acta, v. 289, n. 2, p. 101-126, Dec. 1996.

LEBEDEV, B. V. Application of precise calorimetry in study of polymers and polymerization process. Thermochimica Acta, v. 297, n. 1-2, p. 143-149, Aug. 1997.

MARTI, E. Thermal analysis, calorimetry and chemical thermodynamics - A review. Thermochimica Acta, v. 20, n. 1, p. 1-10, July 1977.

NOMEN, R.; SEMPERE, J.; \& LERENA, P. Heat flow reaction calorimetry under reflux conditions. Thermochimica Acta, v. 225, n. 2, p. 263-276, Oct. 1993. 
NOMEN, R.; SEMPERE, J.; \& CUNHA, R. L. Dynamic evaluation of heat flow reaction calorimeters under reflux conditions. Thermochimica Acta, v. 289, n. 2, p. 311-325, Dec. 1996.

OTHMAN, N. S. Advanced Strategies for Composition Control in SemiContinuous Emulsion Polymerization. 2000. 319p. Tese (Doutorado) - Ecole Doctorale de Chimie, Universite Claude Bernard, Lyon, França, 2000.

OTHMAN, N. S.; FEVOTTE, G.; \& MCKENNA, T. F. Biobjective control of emulsion polymerizations: control of the polymer composition and the concentration of monomer in the polymer particles. Chemical Engineering Journal, v. 98, n. 1-2, p. 69-79, Mar. 2004.

RANDZIO, S. L. Recent developments in calorimetry. Annu. Rep. Prog. Chem., Sect. C.: Phys. Chem., v. 94, p. 433-504, 1998.

RANDZIO, S. L. Recent developments in calorimetry. Annu. Rep. Prog. Chem., Sect. C: Phys. Chem., v. 98, p. 157-217, 2002.

REGENASS, W. Calorimetric monitoring of industrial chemical process. Thermochimica Acta, v. 95, n. 2, p. 351-368, Sept. 1985.

REGENASS, W. The development of heat flow calorimetry as a tool for process optimization and process safety. Journal of Thermal Analysis and Calorimetry, v. 49, n. 3, p. 1661-1675, Oct. 1997.

RICHNER, G.; NEUHOLD, $\quad \mathrm{Y}$ M.; PAPADOKONSTANTAKIS, S.; \& HUNGERBÜHLER, K. Temperature oscillation calorimetry for the determination of the heat capacity in a small-scale reactor. Chemical Engineering Science, v. 63, n. 14, p. 3755-3765, July 2008.

ROUQUEROL, J.; \& ZIELENKIEWICZ, W. Suggested practice for classification of calorimeters. Thermochimica Acta, v. 109, n. 1, p. 121-137, Dec. 1986.

SAENZ DE BURUAGA, I.; AROTÇARENA, M.; ARMITAGE, P. D.; GUGLIOTTA, L. M.; LEIZA, J. R.; \& ASUA, J. .M. On-line calorimetric control of emulsion polymerization reactors. Chemical Engineering Science, v. 51, n. 11, p. 27812786, June 1996.

SAENZ DE BURUAGA, I.; ARMITAGE, P. D.; LEIZA, J. R.; \& ASUA, J. M. Nonlinear control for maximum production rate of latexes of well-defined polymer composition. Ind. Eng. Chem. Res., v. 36, n. 10, p. 4243-4254, 1997.

SANTOS, A. M.; FÉVOTTE, G.; OTHMAN, N.; OTHMAN, S.; \& McKENNA, T. F. Online monitoring of methyl methacrylate-vinyl acetate emulsion copolymerization. Journal of Applied Polymer Science, v. 75, n. 13, p. 1667-1683, Mar. 2000. 
SAYER, C.; LIMA, E. L.; PINTO, J. C.; ARZAMENDI, G.; \& ASUA, J. M. Molecular weight distribution in composition controlled emulsion copolymerization. Journal of Polymer Science: Part A: Polymer Chemistry, v. 38, n. 7, p. 1100-1109, Apr. 2000.

SCHILDKNECHT, J. Reaction calorimeter for applications in chemical process industries: performance and calibration. Thermochimica Acta, v. 49, n. 1, p. 87100, Oct. 1981.

SCHULER, H.; \& SCHMIDT, C-U. Calorimetric-state estimators for chemical reactor diagnosis and control: review of methods and applications. Chemical Engineering Science, v. 47, n. 4, p. 899-915, 1992.

SEMPERE, J.; NOMEN, R.; SERRA, E.; \& SALES, J. Temperature oscillating minicalorimeter. Journal of Thermal Analysis and Calorimetry, v. 72, n. 1, p. 65-71, Apr. 2003.

STOESSEL, F. Applications of reaction calorimetry in chemical engineering. Journal of Thermal Analysis and Calorimetry, v. 49, n. 3, p. 1677-1688, Oct. 1997.

STOESSEL, F, \& UBRICH, O. Safety assessment and optimization of semi-batch reactions by calorimetry. Journal of Thermal Analysis and Calorimetry, v. 64, n. 1, p. 61-74, Apr. 2001.

TACĂ, C. D.; \& PĂUNESCU, M. Power input in closed stirred vessels. Chemical Engineering Science, v. 56, n. 14, p. 4445-4450, July 2001.

TIETZE, A.; LÜDKE, I.; \& REICHERT, K-H. Temperature oscillation calorimetry in stirred tank reactors. Chemical Engineering Science, v. 51, n. 11, p. 3131-3137, June 1996.

UBRICH, O.; SRINIVASAN, B.; LERENA, P.; BONVIN, D.; \& STOESSEL, F. The use of calorimetry for on-line optimisation of isothermal semi-batch reactors. Chemical Engineering Science, v. 56, n. 17, p. 5147-5156, Sept. 2001.

VICENTE, M.; LEIZA, J. R.; \& ASUA, J. M. Simultaneous control of copolymer composition and MWD in emulsion copolymerization. AIChE Journal, v. 47, n. 7, p. 1594-1606, July 2001.

VICENTE, M.; SAYER, C.; LEIZA, J. R.; ARZAMENDI, G.; LIMA, E. L.; PINTO, J. C.; \& ASUA, J. M. Dynamic optimization of non-linear emulsion copolymerization systems. open-loop control of composition and molecular weight distribution. Chemical Engineering Journal, v. 85, n. 2-3, p. 339-349, Jan. 2002.

VICENTE, M.; LEIZA, J. R.; \& ASUA, J. M. Maximizing production and polymer quality (MWD and composition) in emulsion polymerization reactors with limited capacity of heat removal. Chemical Engineering Science, v. 58, n. 1, p. 215-222, Jan. 2003. 
WESTERTERP, K. R.; \& MOLGA, E. J. Safety and runaway prevention in batch and semibatch reactors $-a$ review. Chemical Engineering Research and Design, $v$. 84, n. 7, p. 543-552, 2006.

ZALDIVAR, J. M.; HERNANDEZ, H.; \& BARCONS, C. Development of a mathematical model and a simulator for the analysis and optimization of batch reactors: experimental model characterization using a reaction calorimeter. Thermochimica Acta, v. 289, n. 2, p. 267-302, Dec. 1996.

ZIELENKIEWICZ, W. Towards classification of calorimeters. Journal of Thermal Analysis and Calorimetry, v. 91, n. 2, p.663-671, 2008.

ZOGG, A. A Combined Approach using Calorimetry and IR-ATR Spectroscopy for the Determination of Kinetic and Thermodynamic Reaction Parameters. 2003. 303p. Tese(Doutorado) - Swiss Federal Institute of Technology Zurich, Zurique, Suiça, 2003.

ZOGG, A.; STOESSEL, F.; FISCHER, U.; \& HUNGERBÜHLER, K. Isothermal reaction Calorimetry as a tool for kinetic analysis. Thermochimica Acta, v. 419, n. 1-2, p. 1-17, Sept 2004.

\section{MATERIAIS E MÉTODOS}

ASPREY, S. P.; WOJCIECHOWSKI, B. W.; RICE, N. M.; \& DORCAS, A. Applications of temperature scanning in kinetic investigations: the hydrolysis of acetic anhydride. Chemical Engineering Science, v. 51, n. 20, p. 4681-4692, Oct. 1996.

BENAMOR, S.; COLOMBIÉ, D.; \& McKENNA, T. Online reaction calorimetry. applications to the monitoring of emulsion polymerization without samples or models of the heat-transfer coefficient. Ind. Eng. Chem. Res., v. 41, n. 17, p. 4233-4241, 2002.

CAO, Y.; LI, S.; \& PETZOLD, L. Adjoint sensitivity analysis for differential-algebraic equations: algorithms and software. Journal of Computational and Applied Mathematics, v. 149, n. 1, p. 171-191, Dec. 2002.

CAO, Y.; LI, S.; PETZOLD, L.; \& SERBAN, R. Adjoint sensitivity analysis for differential-algebraic equations: the adjoint DAE system and its numerical solution. SIAM J. Sci. Comput., v. 24, n. 3, p. 1076-1089, 2003.

DOUGHERTY, E. P.; HWANG, J-T.; \& RABITZ, H. Further developments and applications of the Green's function method of sensitivity analysis in chemical kinetics. Journal of Chemical Physics, v. 71, n. 4, p. 1794-1808, Aug. 1979.

FREIRE, F. B. Calorimetria em linha através de observadores de estado nãolineares: estimativa conjunta da taxa de geração de calor e do coeficiente global de troca de calor em reatores de polimerização. 2003. 152p Tese (Doutorado) - Escola Politécnica, Universidade de São Paulo, São Paulo, 2003. 
FREIRE, F. B.; McKENNA, T. F.; OTHMAN, S.; GIUDICI, R. A new approach to the joined estimation of the heat generated by a semicontinuous emulsion polymerization Qr and the overall heat exchange parameter UA. Braz. J. Chem. Eng., v. 21, n. 02, p. 293-305, Apr./June 2004.

HWANG, J-T; DOUGHERTY, E. P.; RABITZ, S.; \& RABITZ, H. The Green's function method of sensitivity analysis in chemical kinetics. Journal of Chemical Physics, $v$. 69, n. 11, p. 5180-5191, Dec. 1978.

LI, S.; \& PETZOLD, L. Design of new DASPK for sensitivity analysis, Technical Report, Department of Computer Science, UCSB, 1999

LI, S.; \& PETZOLD, L. Software and algorithms for sensitivity analysis of large-scale differential algebraic systems. Journal of Computational and Applied Mathematics, v. 125, n. 1-2, p. 131-145, Dec. 2000.

LI, S.; PETZOLD, L.; \& ZHU, W. Sensitivity analysis of differential-algebraic equations: a comparison of methods on a special problem. Applied Numerical Mathematics, v. 32, n. 2, p. 161-174, Feb. 2000.

LUO, J.; YING, K.; HE, P.; \& BAI, J. Properties of Savitzky-Golay digital differentiators. Digital Signal Processing, v. 15, n. 2, p. 122-136, Mar. 2005.

LUO, J.; YING, K.; \& BAI, J. Savitzky-Golay smoothing and differentiation filter for even number data. Signal Processing, v. 85, n. 7, p. 1429-1434, July 2005.

MALY, T.; \& PETZOLD, L. R. Numerical methods and software for sensitivity analysis of differential-algebraic systems. Applied Numerical Mathematics, v. 20, n. 1-2, p. 57-79, Feb. 1996.

OMI, S.; KUSHIBIKI, K.; NEGISHI, M.; ISO, M. Generalized computer modeling of semi-batch, n-component emulsion copolymerization systems and its applications. Zairyo Gijutsu, vol.3, p.426, 1985.

PETZOLD, L.; LI, S.; CAO, Y.; \& SERBAN, R. Sensitivity analysis of differentialalgebraic equations and partial differential equations. Computers and Chemical Engineering, v. 30, n. 10-12, p. 1553-1559, Sept 2006.

PRESS, W. H.; TEUKOLSKY, S. A.; VETTERLING, W. T.; FLANNERY, B. P. Numerical Recipes in Fortran 77: The Art of Scientific Computing, $2^{\text {nd }}$ ed. Cambridge, MA: Cambridge University Press, 1992. 973p.

RABITZ, H. Chemical sensitivity analysis theory with applications to molecular dynamics and kinetics. Computers and Chemistry, v. 5, n. 4, p. 167-180, 1981.

SAVITZKY, A; \& GOLAY, M. J. E. Smoothing and differentiation of data by simplified least squares procedures. Analytical Chemistry, v. 36, n. 8, p. 1627-1639, July 1964. 
SCHLEGEL, M.; MARQUARDT, W.; EHRIG, R.; \& NOWAK, U. Sensitivity analysis of linearly-implicit differential-algebraic systems by one-step extrapolation. Applied Numerical Mathematics, v. 48, n. 1, p. 83-102, Jan. 2004.

SHATYNSKI, J. J.; \& HANESIAN, D. Adiabatic kinetic studies of the cytidine / acetic anhydride reaction by utilizing temperature versus time data. Ind. Eng. Chem. Res., v. 32, n. 4, p. 594-599, Apr. 1993.

SOARES, L. M. V. Como obter resultados confiáveis em cromatografia. Rev. Inst. Adolfo Lutz, v. 60, n.1, p. 79-84, 2001.

STAGGS, J. E. J. Savitzky-Golay smoothing and numerical differentiation of cone calorimeter mass data. Fire Safety Journal, v. 40, n. 6, p. 493-505, Sept. 2005.

VALKO, P; \& VAJDA, S. An extended ODE solver for sensitivity calculations. Computers \& Chemistry, v. 8, n. 4, p. 255-271, 1984.

VICENTE, M.; LEIZA, J. R.; \& ASUA, J. M. Simultaneous control of copolymer composition and MWD in emulsion copolymerization. AIChE Journal, v. 47, n. 7, p. 1594-1606, July 2001.

\section{RESULTADOS E DISCUSSÕES: HIDRÓLISE DO ANIDRIDO ACÉTICO}

ASPREY, S. P.; WOJCIECHOWSKI, B. W.; RICE, N. M.; \& DORCAS, A. Applications of temperature scanning in kinetic investigations: the hydrolysis of acetic anhydride. Chemical Engineering Science, v. 51, n. 20, p. 4681-4692, Oct. 1996.

LI, S.; \& PETZOLD, L. Design of new DASPK for sensitivity analysis, Technical Report, Department of Computer Science, UCSB, 1999

MORRISON, R. T.; BOYD, R. N. Organic Chemistry, $3^{\text {rd }}$ ed. Boston: Allyn and Bacon., 1973. 1258p.

SHATYNSKI, J. J.; \& HANESIAN, D. Adiabatic kinetic studies of the cytidine / acetic anhydride reaction by utilizing temperature versus time data. Ind. Eng. Chem. Res., v. 32, n. 4, p. 594-599, Apr. 1993.

\section{RESULTADOS E DISCUSSÕES: POLIMERIZAÇÃO EM EMULSÃO}

BENAMOR, S.; COLOMBIÉ, D.; \& McKENNA, T. Online reaction calorimetry. applications to the monitoring of emulsion polymerization without samples or models of the heat-transfer coefficient. Ind. Eng. Chem. Res., v. 41, n. 17, p. 4233-4241, 2002. 
FEVOTTE, G.; MCKENNA, T. F.; OTHMAN, S.; \& HAMMOURI, H. Non-linear tracking of glass transition temperatures for free radical emulsion copolymers. Chemical Engineering Science, v. 53, n. 4, p. 773-786, Feb. 1998.

FREIRE, F. B.; McKENNA, T. F.; OTHMAN, S.; GIUDICI, R. A new approach to the joined estimation of the heat generated by a semicontinuous emulsion polymerization Qr and the overall heat exchange parameter UA. Braz. J. Chem. Eng., v. 21, n. 02, p. 293-305, Apr./June 2004.

SAENZ DE BURUAGA, I.; ARMITAGE, P. D.; LEIZA, J. R.; \& ASUA, J. M. Nonlinear control for maximum production rate of latexes of well-defined polymer composition. Ind. Eng. Chem. Res., v. 36, n. 10, p. 4243-4254, 1997.

RÖBENACK, K. Computation of the observer gain for extended Luenberger observers using automatic differentiation. IMA Journal of Mathematical Control and Information, v. 21, n. 1, p. 33-47, 2004.

RÖBENACK, K.; \& LYNCH, A. F. High-gain nonlinear observer design using the observer canonical form. IET Control Theory Appl., v. 1, n. 6, p. 1574-1579, Nov. 2007.

VICENTE, M.; LEIZA, J. R.; \& ASUA, J. M. Simultaneous control of copolymer composition and MWD in emulsion copolymerization. AIChE Journal, v. 47, n. 7, p. 1594-1606, July 2001.

WENTZELL, P. D.; BROWN, C. D. Signal processing in analytical chemistry. In: MEYERS, R. A. Encyclopedia of Analytical Chemistry. Chichester: John Wiley \& Sons, 2000. p. 9764-9800. 


\section{APÊNDICE A - BANCO DE DADOS}

\section{A.1 HIDRÓLISE DO ANIDRIDO ACÉTICO}

Tabela A.1 - Propriedades físico-químicas dos reagentes e produtos

Água Anidrido acético Ácido acético Referência

\begin{tabular}{ccccc}
\hline $\mathrm{PM}(\mathrm{g} / \mathrm{mol})$ & 18,07 & 102,09 & 60,05 & \\
$\mathrm{C}_{\mathrm{p}}(\mathrm{J} / \mathrm{mol} \mathrm{K})$ & 75,53 & 124,1 & 123,1 & Yaws (1999) \\
$\rho(\mathrm{g} / \mathrm{mL})$ & 1,00 & 1,08 & & Yaws (1999) \\
\hline
\end{tabular}

Tabela A.2 - Constantes para o cálculo da capacidade calorífica específica dos reagentes e produtos $\left(C_{p}=A+B T+C T^{2}+D T^{3}, T\right.$ - Kelvin $)$

\begin{tabular}{cccccc}
\hline & $\mathrm{A}$ & $\mathrm{B}$ & $\mathrm{C}$ & $\mathrm{D}$ & Referência \\
\hline Água & 92,05 & $-3,99 \times 10^{-2}$ & $-2,21 \times 10^{-4}$ & $5,35 \times 10^{-7}$ & Yaws (1999) \\
Anidrido Acético & 71,83 & $8,89 \times 10^{-1}$ & $-2,65 \times 10^{-3}$ & $3,35 \times 10^{-6}$ & Yaws (1999) \\
Ácido acético & $-18,94$ & 1,1 & $-2,89 \times 10^{-3}$ & $2,93 \times 10^{-6}$ & Yaws (1999) \\
\hline
\end{tabular}

Tabela A.3 - Capacidade calorífica específica dos reatores e agitador

\begin{tabular}{|c|c|c|c|}
\hline & $\overline{C_{p}}$ & Unidade & Referência \\
\hline Copo poliestireno & 1,79 & $\mathrm{~J} / \mathrm{g} \cdot \mathrm{K}$ & Ullmann's (1985) \\
\hline Balão volumétrico & $0,75^{(*)}$ & $\mathrm{J} / \mathrm{g} \cdot \mathrm{K}$ & Ullmann's (1985) \\
\hline Garrafa térmica & $0,75^{(*, \ddagger)}$ & $\mathrm{J} / \mathrm{g} \cdot \mathrm{K}$ & Ullmann's (1985) \\
\hline Agitador magnético & 36,16 & $\mathrm{~J} / \mathrm{mol} . \mathrm{K}$ & Westrum (1969) \\
\hline \multicolumn{4}{|c|}{$\begin{array}{l}\text { T. Considerando o vidro com 96\% de sílica como o material predominante na fabricação } \\
\text { (f) Desconsiderando a parte plástica externa e supondo que o miolo da garrafa é vidro com } 96 \% \text { de } \\
\text { sílica e que compõe 10\% da massa total do recipiente }\end{array}$} \\
\hline \multicolumn{4}{|c|}{ Tabela A.4 - Entalpia de hidrólise do anidrido acético } \\
\hline & \multicolumn{2}{|c|}{ Valor } & Referência \\
\hline$(-\Delta \mathrm{H})(\mathrm{J} / \mathrm{mol})$ & \multicolumn{2}{|c|}{58994,4} & Conn et al. (1942) \\
\hline
\end{tabular}




\section{A.2 COPOLIMERIZAÇÃO EM EMULSÃO}

Tabela A.5 - Capacidades caloríficas (A-acetato de vinila / B-acrilato de butila / wágua)

\begin{tabular}{cccc}
\hline & Valor & Unidade & Referência \\
\hline $\mathrm{C}_{\mathrm{pA}}$ & $\left(3,621+6,676 \times 10^{-2} T_{\text {feed }}-2,103 \times 10^{-5} T_{\text {feed }}^{2}\right.$ & cal $/ \mathrm{g} . \mathrm{K}$ & Reid et al.(1987) \\
& $\left.-3,965 \times 10^{-9} T_{\text {feed }}^{3}\right) / P M_{A}$ & & \\
$\mathrm{C}_{\mathrm{pB}}{ }^{(*)}$ & $\left(3,621+6,676 \times 10^{-2} T_{\text {feed }}-2,103 \times 10^{-5} T_{\text {feed }}^{2}\right.$ & cal $/ \mathrm{g} . \mathrm{K}$ & Reid et al. (1987) \\
& $\left.-3,965 \times 10^{-9} T_{\text {feed }}^{3}\right) / P M_{B}$ & & \\
$\mathrm{C}_{\mathrm{pw}}$ & $\left(5,2634 \times 10^{4}+2,4119 \times 10^{2} T_{\text {feed }}-0,85085 T_{\text {feed }}^{2}\right.$ & cal $/ \mathrm{g} . \mathrm{K}$ & Reid et al. (1987) \\
& $\left.+10^{-3} T_{\text {feed }}^{3}\right) 0,2389 \times 10^{-3} / P M_{w}$ & & \\
\hline
\end{tabular}

(") Capacidade calorífica assumida como sendo igual ao do acetato de vinila

Tabela A.6 - Entalpias de polimerização e razões de reatividade

\begin{tabular}{cccc}
\hline Parâmetro & Valor & Unidade & Referência \\
\hline$\left(-\Delta \mathrm{H}_{\mathrm{A}}\right)$ & 21,391 & $\mathrm{kcal} / \mathrm{mol}$ & Brandrup e Immergut (1989) \\
$\left(-\Delta \mathrm{H}_{\mathrm{B}}\right)$ & 18 & $\mathrm{kcal} / \mathrm{mol}$ & Hamer et al. (1981) \\
$\mathrm{r}_{\mathrm{A}}$ & 0,037 & - & Gugliotta et al. (1995) \\
$\mathrm{r}_{\mathrm{B}}$ & 6,35 & - & Gugliotta et al. (1995) \\
\hline
\end{tabular}

Tabela A.7 - Constantes cinéticas (A-acetato de vinila/B-acrilato de butila)

\begin{tabular}{cccc}
\hline & Valor & Unidade & Referência \\
\hline $\mathrm{k}_{\mathrm{PAA}}$ & $6,14 \times 10^{10} \exp \left(-6,3 \times 10^{3} / 1,987 T\right)$ & $\mathrm{cm}^{3} / \mathrm{mol} . \mathrm{s}$ & McKenna et al. (1995) \\
$\mathrm{k}_{\mathrm{pBB}}$ & $2,73 \times 10^{10} \exp \left(-6,3 \times 10^{3} / 1,987 T\right)$ & $\mathrm{cm}^{3} / \mathrm{mol} . \mathrm{s}$ & McKenna et al. (1995) \\
\hline
\end{tabular}


Tabela A.8 - Coeficientes de partição (A-acetato de vinila/B-acrilato de butila)

\begin{tabular}{cccc}
\hline & Valor & Unidade & Referência \\
\hline$K_{d, w}^{A}$ & 34,7 & - & Gardon (1968) \\
$K_{p, w}^{A}$ & 29,5 & - & Gardon (1968) \\
$K_{d, w}^{B}$ & 705 & - & Gugliotta et al. (1995) \\
$K_{p, w}^{B}$ & 460 & - & Gugliotta et al. (1995) \\
\hline
\end{tabular}

\section{REFERÊNCIAS (APÊNDICE A)}

BRANDRUP, J.; \& IMMERGUT, E. H. Polymer Handbook. $3^{\text {rd }}$ ed. New York: Wiley, 1989.

CONN, J. B.; KISTIAKOWSKY, G. B.; ROBERTS, R. M.; \& SMITH, E. A. J. A. Chem. Soc., v. 64, p. 1747, 1942

GARDON, J. L. Journal of Polymer Science, Part A-1, v. 6, p. 643, 1968

GULIOTTA, L. M.; ARZAMENDI, G.; \& ASUA, J. M. Journal of Applied Polymer Science, v. 55, p. 1017, 1995.

HAMER, J. W.; AKRAMOV, T. A.; \& RAY, W. H. Chemical Engineering and Science, v. 36, p. 1897, 1981.

MCKENNA, T. F.; GRAILLAT, C.; \& GUILLOT, J. Polymer Bulletin, v. 34, p. 361, 1995

REID, R. C.; PRAUSNITZ, J. M.; \& POULING, B. E. The properties of gases and liquids. New York: McGraw-Hill, 1987.

ULLMANN, F. Ullmann's encyclopedia of industrial chemistry. $5^{\text {th }}$ ed. Weinheim: $\mathrm{VCH}, 1985$

WESTRUM Jr., E. F. J. Chem. Thermodynamics, v. 1, p. 543-557, 1969

YAWS, C. L. Chemical properties handbook: physical, thermodynamic, environmental, transport, safety, and health related properties for organic and inorganic chemicals. New York: McGraw-Hill, 1999 


\section{APÊNDICE B - EQUACIONAMENTO GERAL DO BALANÇO DE ENERGIA}

O equacionamento apresentado a seguir é válido para um reator tipo tanque agitado, com conteúdo perfeitamente misturado, em regime transiente, com corrente de entrada e saída (CSTR em regime transiente) e foi extraído de Giudici (2009).

O balanço macroscópico de massa (balanço molar) para um componente genérico i pode ser escrito na forma:

$$
\frac{d N_{i}}{d t}=\frac{d\left(V C_{i}\right)}{d t}=q_{e} C_{i e}-q C_{i}+V \sum_{j=1}^{m} v_{i, j} R_{j}
$$

sendo $\mathrm{N}_{\mathrm{i}}$ o número de mols do componente $\mathrm{i}, \mathrm{V}$ o volume, $\mathrm{C}_{\mathrm{i}}$ e $\mathrm{C}_{\mathrm{ie}}$ as concentrações molares do meio reacional e da corrente de alimentação, respectivamente, $\mathrm{q}_{\mathrm{e}} \mathrm{a}$ vazão molar de entrada, q a vazão molar de saída, $v_{\mathrm{i}, \mathrm{j}}$ o coeficiente estequiométrico molar do componente i na reação, e $\mathrm{R}_{\mathrm{j}}$ a velocidade da reação $\mathrm{j}$.

Para um "sistema aberto" (volume de controle) onde existe entrada e saída de material, o balanço de energia será expresso da seguinte forma:

$$
\frac{d\left(U+E_{p}+E_{c}\right)}{d t}=\dot{Q}-\dot{W}_{s}+\dot{m}_{e}\left(\underline{H}_{e}+\underline{E}_{p e}+\underline{E}_{c e}\right)-\dot{m}_{s}\left(\underline{H}_{s}+\underline{E}_{p s}+\underline{E}_{c s}\right)
$$

sendo $U$ a energia interna do sistema, $E_{p}$ a energia potencial, $E_{c}$ a energia cinética, $\dot{Q}$ a taxa de calor que entra no sistema, $\dot{W}_{s}$ o trabalho realizado pelo, ou sobre, o sistema sobre a vizinhança, $\dot{m}_{e}$ e $\dot{m}_{s}$ a vazão mássica de entrada e saída, respectivamente, no volume de controle, $\mathrm{H}$ a entalpia. As grandezas sublinhadas representam propriedades específicas.

Considerando que:

i) os termos de energia mecânica (cinética e potencial) são desprezíveis frente aos termos de energia térmica (entalpia e energia interna): $E_{p}, E_{c} \ll U, H$; 
ii) pela mesma razão, o termo de trabalho (que corresponde ao trabalho do agitador) é também usualmente desprezível frente aos demais termos do balanço e que, portanto, pode ser desconsiderado ${ }^{5}$;

iii) em um sistema líquido, $U \approx H, d U \approx d H, C_{v} \approx C_{p}, \rho=$ constante, onde $C_{v}$ é a capacidade calorífica a volume constante, $\mathrm{C}_{p}$ a capacidade calorífica a pressão constante e $\rho$ a densidade;

a eq.(B.02) pode ser re-escrita da seguinte forma:

$$
\frac{d H}{d t}=\dot{Q}+q_{e} \rho \underline{H}_{e}-q \rho \underline{H}
$$

Lembrando que $H=H\left(T, P, N_{1}, N_{2}, \ldots, N_{n}\right)$ :

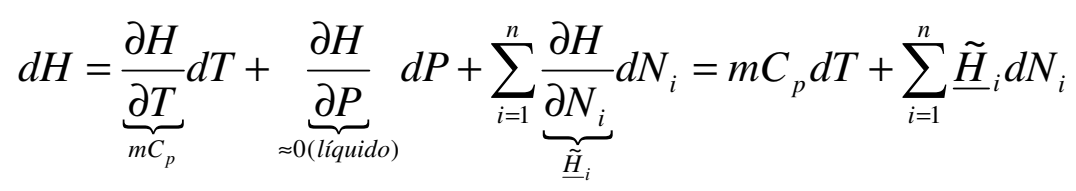

e substituindo a equação do balanço de massa (eq.B0.1):

$$
\begin{aligned}
d H & =m C_{p} \frac{d T}{d t}+\sum_{i=1}^{n} \underline{\tilde{H}}_{i} \frac{d N_{i}}{d t}=m C_{p} \frac{d T}{d t}+\sum_{i=1}^{n} \underline{\tilde{H}}_{i}\left(q_{e} C_{i e}-q C_{i}+V \sum_{j=1}^{m} \nu_{i, j} R_{j}\right)= \\
& =m C_{p} \frac{d T}{d t}+q_{e} \sum_{i=1}^{n} C_{i e} \underline{\tilde{H}}_{i}-q \sum_{i=1}^{n} C_{i} \underline{\tilde{H}}_{i}+V \sum_{j=1}^{m} R_{j} \underbrace{\sum_{i=1}^{m} v_{i, j} \tilde{\tilde{H}}_{i}}_{\Delta H_{j}}
\end{aligned}
$$

e ainda que na avaliação das entalpias específicas:

$$
\left.q \rho \underline{H}_{e}\right|_{T e}=\left.q \rho \underline{H}_{e}\right|_{T r e f}+q \rho C_{p}\left(T_{e}-T_{r e f}\right)=\left.q \sum_{i=1}^{n} C_{i e} \underline{\tilde{H}}_{i e}\right|_{T e}+q \rho C_{p}\left(T_{e}-T_{r e f}\right)
$$

\footnotetext{
${ }^{5}$ Isto só não ocorre para líquidos muito viscosos como, por exemplo, polímeros fundidos, onde o trabalho de agitação seria significativamente maior e passaria a ter importância.
} 
$\left.q \rho \underline{H}\right|_{T}=\left.q \rho \underline{H}\right|_{T r e f}+q \rho C_{p}\left(T-T_{r e f}\right)=\left.q \sum_{i=1}^{n} C_{i} \underline{\tilde{H}}_{i}\right|_{T}+q \rho C_{p}\left(T-T_{r e f}\right)$

e adotando $\mathrm{T}_{\text {ref }}=\mathrm{T}$ resulta:

$$
\begin{aligned}
& \left.q \rho \underline{H}_{e}\right|_{T e}=\left.q \sum_{i=1}^{n} C_{i e} \underline{\tilde{H}}_{i e}\right|_{T e}+q \rho C_{p}\left(T_{e}-T\right) \\
& q \rho \underline{H}_{T}=\left.q \sum_{i=1}^{n} C_{i e} \underline{\tilde{H}}_{i}\right|_{T}
\end{aligned}
$$

Substituindo as eqs.(B.05), (B.08) e (B.09) no balanço de energia (eq.B.03), resulta:

$$
\left(m C_{p}\right) \frac{d T}{d t}=q_{e} \sum_{i=1}^{n} C_{i e} \underbrace{\left(\tilde{\tilde{H}}_{i e}-\tilde{\tilde{H}}_{i}\right)}_{\text {efeitos de mistura } 00}+\rho q C_{p}\left(T_{e}-T\right)+V \sum_{j=1}^{m} R_{j}(-\Delta H)_{j}+\dot{Q}
$$

Desprezando os efeitos de mistura chega-se a:

$$
\underbrace{\left(m C_{p}\right) \frac{d T}{d t}}_{Q_{\text {acum }}}=\underbrace{\rho q C_{p}\left(T_{e}-T\right)}_{Q_{\text {feed }}}+\underbrace{V \sum_{j=1}^{m} R_{j}(-\Delta H)_{j}}_{Q_{r}}+\underbrace{\dot{Q}}_{-Q_{j},-Q_{\text {loss }}}
$$

\section{REFERÊNCIAS (APÊNDICE B)}

GIUDICI, R. Balanços de constituintes; Reatores ideais. São Paulo: EPUSP, 2009. Apostila para disciplina de pós graduação do Departamento de Engenharia Química, PQI-5820 - Fundamentos de Processos em Engenharia Química I. 